\title{
Role playing materials
}

Citation for published version (APA):

Bienia, R. P. (2016). Role playing materials. [Doctoral Thesis, Maastricht University]. Zauberfeder. https://doi.org/10.26481/dis.20160428rb

Document status and date:

Published: 01/01/2016

DOI:

10.26481/dis.20160428rb

Document Version:

Publisher's PDF, also known as Version of record

\section{Please check the document version of this publication:}

- A submitted manuscript is the version of the article upon submission and before peer-review. There can be important differences between the submitted version and the official published version of record.

People interested in the research are advised to contact the author for the final version of the publication, or visit the DOI to the publisher's website.

- The final author version and the galley proof are versions of the publication after peer review.

- The final published version features the final layout of the paper including the volume, issue and page numbers.

Link to publication

\footnotetext{
General rights rights.

- You may freely distribute the URL identifying the publication in the public portal. please follow below link for the End User Agreement:

www.umlib.nl/taverne-license

Take down policy

If you believe that this document breaches copyright please contact us at:

repository@maastrichtuniversity.nl

providing details and we will investigate your claim.
}

Copyright and moral rights for the publications made accessible in the public portal are retained by the authors and/or other copyright owners and it is a condition of accessing publications that users recognise and abide by the legal requirements associated with these

- Users may download and print one copy of any publication from the public portal for the purpose of private study or research.

- You may not further distribute the material or use it for any profit-making activity or commercial gain

If the publication is distributed under the terms of Article $25 \mathrm{fa}$ of the Dutch Copyright Act, indicated by the "Taverne" license above, 


\section{ROLE PLAYING MATERIALS}

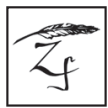

Zauberfeder Verlag, Braunschweig, Germany 
Rafael Bienia

„Role Playing Materials“

This dissertation has been randomly chosen for an originality check.

The electronic and manual plagiarism tests by the Maastricht University Library under the supervision of the Board of Deans have been negative.

Erste Auflage 2016

Copyright ${ }^{\circledR} 2016$ Zauberfeder $\mathrm{GmbH}$, Braunschweig

Autor: Rafael Bienia

Satz und Layout: Christian Schmal

Herstellung: Tara Tobias Moritzen

Druck und Bindung: Schaltungsdienst Lange, Berlin

Alle Rechte vorbehalten.

Kein Teil dieses Werkes darf ohne schriftliche Einwilligung des Verlags in irgendeiner Form (Fotokopie, Mikrofilm oder ein anderes Verfahren) reproduziert oder unter Verwendung elektronischer Systeme verarbeitet, vervielfältigt oder verbreitet werden.

Printed in Germany

ISBN: 978-3-938922-61-3

www.zauberfeder-verlag.de

Hinweis:

Das vorliegende Buch ist sorgfältig erarbeitet worden. Dennoch erfolgen alle Angaben ohne Gewähr. Autoren und Verlag bzw. dessen Beauftragte können für eventuelle Personen-, Sach- oder Vermögensschäden keine Haftung übernehmen. 


\title{
ROLE PLAYING MATERIALS
}

\author{
Dissertation
}

to obtain the degree of Doctor at Maastricht University, on the authority of the Rector Magnificus, Prof. dr. L.L.G. Soete in accordance with the decision of the Board of Deans, to be defended in public on Thursday 28. April 2016, at 14.00 hours by Rafael Peter Bienia 


\section{Promotor:}

Prof. dr. Sally Wyatt

\section{Copromotor:}

Dr. Karin Wenz

\section{Assessment Committee:}

Prof. dr. Renée van de Vall (chair)

Dr. Marinka Copier (HKU University of Arts Utrecht)

Prof. dr. Maaike Meijer

Prof. dr. Frans Mäyrä (University of Tampere) 


\section{Content}

Acknowledgements

Chapter 1: Introduction

Chapter 2: Methodology \& Theory . . . . . . . . . . . . . . . 17

2.1 Introduction, or Following Materials to Multiple Role-Playing Game Sites . . . . 17

2.2 Introduction to Actor-Network Theory, or Building a Vocabulary . . . . . . . 20

2.2 .1 Actors, or various sites of action . . . . . . . . . . . . . . . . 20

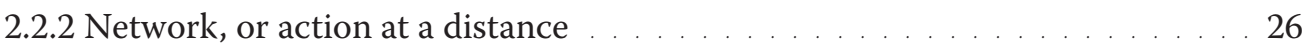

2.2.3 Agency, or making a difference . . . . . . . . . . . . . . . . . . . 28

2.2.4 Mediator and intermediary, or translating agency . . . . . . . . . . . . . . . 29

2.3 Methodology, or Selection of Qualitative Empirical Data . . . . . . . . . . . 30

2.3.1 From participant observation to field notes . . . . . . . . . . . . . 30

2.3.2 From semi-structured interviews to transcripts . . . . . . . . . . . 34

2.3.3 Ethical considerations . . . . . . . . . . . . . . . . . . . . . . . . 35

2.4 Theory, or an Actor-Network Vocabulary for Game Studies . . . . . . . . . . . 37

2.4 .1 Play . . . . . . . . . . . . . . . . . . . . . . . . . . . . . . . . . . 37

2.4 .2 Role playing. . . . . . . . . . . . . . . . . . . . . . . . . . . . . . . . . . . 39

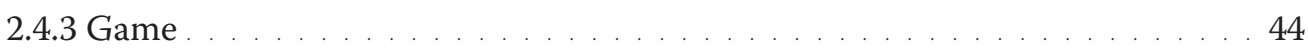

2.4 .4 Role-playing games . . . . . . . . . . . . . . . . . . . . . . . 46

2.4.5 Table 1. A vocabulary for an actor-network study of role playing . . . . . . . 52

2.4.6 Situating the study . . . . . . . . . . . . . . . . . . . . . . . . 54

2.5 Conclusion, or a Vocabulary for Writing about Role Playing Materials . . . . . . 56

Chapter 3: $\operatorname{Larp} \ldots \ldots \ldots \ldots . \ldots \ldots . . \ldots \ldots 5$

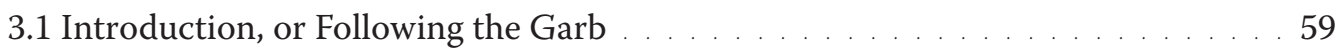

3.2 Problem, or Stories and Rules are not enough . . . . . . . . . . . . . . . 61

3.3 Results, or Material Work in German Larp . . . . . . . . . . . . . . . . 66

3.3 .1 A rhizome of actions . . . . . . . . . . . . . . . . . 66

3.3.2 A short actor-network history of German larp . . . . . . . . . . . . . . 67

3.3 .3 Role playing with garb . . . . . . . . . . . . . . . . . . . . . . . . . . . .

3.4 Conclusion, or an Actor-Network Study of German Larp in the 2010s . . . . . . 87 
4.1 Problem, or an Emerging Technology . . . . . . . . . . . . . . . . . 91

4.2 Introduction, or Reassembling Realities . . . . . . . . . . . . . . . . . 93

4.2.1 A second chance for augmented and virtual reality technology . . . . . . 93

4.2 .2 Computers everywhere . . . . . . . . . . . . . . . . . . . 96

4.3 Results, or Following Emerging Technologies with Role Playing . . . . . . . . 98

4.3.1 Obscurus 2 or Larp and Augmented Reality. . . . . . . . . . . . . 98

4.3.2 Virtual reality and role playing. . . . . . . . . . . . . . . 105

4.4 Conclusion, or Before the Blackbox of Mixed Reality Role-Playing Games . . . 122

Chapter 5: Tabletop Role-Playing Games . . . . . . . . . . . . . . 125

5.1 Introduction, or "Compare it with Improvisation Theatre" . . . . . . . . . . 125

5.2 Problem, or Experiments With a Messy Network . . . . . . . . . . . 132

5.3 Results, or Let the Materials Speak . . . . . . . . . . . . . . . . 134

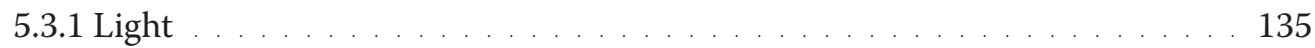

5.3 .2 Table . . . . . . . . . . . . . . . . . . . . . . 138

5.3 .3 Battle map . . . . . . . . . . . . . . . . . . . . . . . 141

5.3.4 Character sheet . . . . . . . . . . . . . . . . . . . . . 143

5.3 .5 Pencil . . . . . . . . . . . . . . . . . . . . . . . . 146

5.3 .6 Game master screen . . . . . . . . . . . . . . . . . . . . . . . . . 149

5.4 Conclusion, or Lights Out . . . . . . . . . . . . . . . . 152

Chapter 6: Conclusions . . . . . . . . . . . . . . . . . . . 157

6.1 Summary of Empirical Chapters . . . . . . . . . . . . . . . . 158

6.2 Main Findings . . . . . . . . . . . . . . . . . . . . . . 160

6.2 .1 Ontological findings . . . . . . . . . . . . . . . . . 160

6.2.2 Epistemological findings . . . . . . . . . . . . . . . . . . 161

6.3 Implications . . . . . . . . . . . . . . . . . . . . . . . . . . 162

6.3.1 Actor-network theory and game studies . . . . . . . . . . . . 162

6.3.2 Actor-network theory and methodology . . . . . . . . . . . . . . 163

6.3.3 Ephemeral role playing phenomena and material actors . . . . . . . . . 164

6.3.4 Ethical implications of game material mass production . . . . . . . . . 164

6.4 Limitations . . . . . . . . . . . . . . . . . . . . . . 166

6.5. Suggestions for Future Studies. . . . . . . . . . . . . . . . 167

6.6 Final Thoughts on Role Playing Materials . . . . . . . . . . . . . . . . . 169 
Appendix A: Participant Observation.

Appendix B: Interviews . . . . . . . . . . . . . . . . . . . . . 175

List of Tables . . . . . . . . . . . . . . . . . . . . . . . . 177

References. . . . . . . . . . . . . . . . . . . . . . . . . 179

Summary in English . . . . . . . . . . . . . . . . . . . . . . 199

Samenvatting (Summary in Dutch) . . . . . . . . . . . . . . 203

Valorization Addendum. . . . . . . . . . . . . . . . . . . . 207

About the Author . . . . . . . . . . . . . . . . . . . . . . . . . . . 214 



\section{ACKNOWLEDGEMENTS}

This dissertation is a network that includes many people who supported me during the past years. Let me take some time and say my thanks.

First of all, I want to thank my supervisors Sally Wyatt and Karin Wenz. Your support and guidance helped me to stay on track without losing my enthusiasm for the diversity of academic work. Your detailed and constructive feedback improved my academic skills immensely.

This dissertation was part of the NWO funded project "Narrative Fan Practices" led by Karin Wenz. With Karin, Nicolle Lamerichs, and Maarten Michielse, I was in the lucky position to be part of a team of excellent scholars. From our joint work, I learned the visible and invisible trades of our profession and I can only hope that my contribution was of any help to you.

To Lotte and Maarten. I enjoyed every time we shared so far. Whether it was a cappuccino with Lotte to discuss our chapters, or a chocomel with Maarten at Bandito's - it was always a pleasure to see you. I am glad that you became my paranymphs. Paranymphs are basically two angels taking care of the nervous wreck before, during, and after the defense. Whatever happens, thank you for this in advance!

To my colleagues at the Faculty of Arts and Social Sciences (FASoS) in general and the research program Arts, Media and Culture (AMC) in particular. AMC has made me feel at home, treating me as a proper colleague, giving me opportunities to teach in your courses, give lectures, and contribute to this wonderful community. Special thanks to Louis van den Hengel, Jack Post, Daniel Stinsky, and Renée van de Vall. I am grateful for the meetings of our Media \& Aesthetics group led by Ike Kamphof, who also helped me as my BKO coach to master Problem Based Learning.

To my colleagues of the research program Maastricht University - Science, Technology and Society Studies (MUSTS). I had the opportunity to benefit from your advice, feedback, and an open ear during several lectures, an introductory course, and one summer workshop. Special thanks to Wiebe Bijker, Karin Bijsterveld, Jessica Mesman, Bernike Pasveer, and Julia Quartz-Topp. 
To the reading group on Practice Theory, initiated by Jessica Mesman, it was a great opportunity to see and learn with colleagues from both programs, AMC and MUSTS. I am grateful to have been part of this fruitful collaboration within FASoS, because I experienced how interdisciplinary work really works within a faculty.

Many thanks to Geert Somsen and Alexandra Supper who led the graduate school and who were always keen on improving the diversity of topics of lectures and workshops. I had the opportunity to contribute several times with workshops and profited from many sessions on the life around a Ph.D.

My thanks towards the national Research School for Media Studies (RMeS) and the former director José van Dijk. The Winter and Summer Schools have always been an invigorating experience of discussing and learning more about the work of my fellow Ph.D. colleagues in the Netherlands. Presenting my own work was a great chance to receive constructive feedback. Thanks above all to Alex Gekker, Nils Kerssens, Lela Mosemghvdlishvili, Birte Schohaus, Rik Smit for your pleasant and stimulating company. Taking part in the research school activities showed me different universities in the Netherlands.

In the past years, my travels went beyond the Netherlands. A big thank you to my colleagues for their constructive feedback throughout the years: Benjamin Beil, J.T. Harviainen, Nathan Hook, Jonas Linderoth, Michał Mochocki, Torill Mortensen, Jan Salge, Jaakko Stenros, and Annika Waern.

Thanks to the publishers of my first articles and books: Benjamin Beil and Thomas Hensel, Benjamin Bigl and Sebastian Stoppe, Sarah Lynne Bowman, Andrea Castellani, Sebastian Deterding and José Zagal, Karsten Dombrowski, Evan Torner, and Jutta Zaremba. Also thanks to Gerke Schlickmann for co-editing the MittelPunkt books with me.

I want to thank the communities of role playing for joining me in my field work, letting me play with them, their countless conversations, help, and interest in my work. Beside my interviewees (see Appendix B), I want to thank Mercedes Buyala, Michael Hess, and Matthias Trennheuser. Above all, my thanks to all of you who have made it possible for me to go to Alcyon XVI: Frances Arndt, Maria Angelika De Barros-Alves, Bastian Heer, Kelric, Julia Kieper, Flo Krell, Lu, Nummi, Franzi Schöttner, Max Stark, and my larp brothers Martin Strzodka and Mike Tascona. 
To my office mates. Eli's calm attitude was the right antidote to my somewhat cliché nervousness of a Ph.D. candidate. You had always a moment to talk and our family meetings will be kept dear in our memories. Two years later, Assem moved in. I am grateful for your company and the many talks we had about coffee, sports, politics, and religious studies.

To Peter Waldmann who had always faith in me as a scholar. I tried to follow your example of a teacher during my time in Maastricht.

To Thomas Hensel who took care of my first steps as a Ph.D. candidate and who linked me to ANT at University of Siegen.

To my family. Thanks to my parents for your support and faith in my curiosity from early on. Thanks to my brother for your support and your special way to make this world a piece of art.

To my wife. Thank you for this better life. Without your right words at the right time, I would not have applied to what seemed and became the most spectacular job I have ever had so far. Thank you for your support during these long years.

This network does not end here and I want to thank all future readers for their interest. 



\section{Chapter 1}

\section{INTRODUCTION}

Towards the end of his commencement speech at the University of Arts in Philadelphia, author Neil Gaiman shared a trick that reminded me of role playing:

Someone asked me recently how to do something she thought was going to be difficult, in this case recording an audio book, and I suggested she pretend that she was someone who could do it. Not pretend to do it, but pretend she was someone who could. She put up a notice to this effect on the studio wall, and she said it helped. (2012)

Gaiman's trick is similar to role playing, because it involves a task and two specific stages in how to solve it. If the example was a role-playing game, the audio book would be the goal of the game. At the first stage, the player would imagine a character with the necessary production skills. At the second stage, the player would pretend to be the producer recording the audio book.

The difference between Gaiman's trick and role playing is that role playing does not necessarily aim to solve creative tasks or to make art. Role playing is a hobby for people who enjoy imagining and exploring characters who are challenged with invented tasks in fictional worlds. Imagine a person dressed up as a wizard running through thorn bushes at night. On his trail, a group of yelling cultists. They chant in an unearthly language to call upon their foul god. Iä! Iä! Iä! The wizard character tumbles, because I as the player want the situation to escalate. Quickly, he is surrounded by three men and women in gray robes - actually the color is green, but it is dark. I cannot read their faces, so I have to expect the worst. What would you do in the shoes of this wizard? Cast a spell of attack? Cast a spell of protection? Surrender? Run again? If you stop reading this book for a second and imagine the situation to decide what the wizard would do, you are roleplaying, because you pretend to be someone else and act according to this character.

This wizard example is one role-playing situation that I have experienced in the past five years of research. The fictional world was a fantasy world inhabited by wizards, cultists, and magic spells. My character's task was to escape the three robed figures. As it was a game, the game rules offered several ways in which my character could interact with his 
world. What happened then? I decided to attack one of the cultists with a spell, but at the moment when I was casting the words, the cultists beat me down. I let my character fall and lie for an hour on the spot until my fellow players found me. This happened back in 2011, but I still tell the wizard's story.

This example resonates with the definitions of role playing in the field of role-playing game studies. Heliö (2004) defines role-playing games as "games that offer implied motivation for creating narrative experiences," such as the task of recording an audio book, "and encouraging players to tell stories about them" (p. 72). Role playing is a mindset, a mental process, which players can add to any game (Heliö, 2004). Heliö's definition explains Gaiman's trick as role playing, because the elements are the same. Role playing is an activity that includes the following elements. Narrative elements, such as character and world, describe what happens. Goals and rules are ludic elements that structure how it might happen. Together, narrative and ludic elements set up the activity as a game that challenges the character in the imagined world.

Gaiman's trick hints at a third group of elements that definitions of role playing miss (Heliö, 2004; Hitchens \& Drachen, 2009; Montola, 2012a). While role playing an audio book producer, she "put up a notice to this effect on the studio wall, and she said it helped" (Gaiman, 2012). The notice and the studio wall form the third group: material elements. The group includes materials, such as the paper notice, the studio wall, or game materials that are part of a role-playing game.

By taking material elements into view, this dissertation explores an alternative understanding of how role playing works, because it is insufficient to understand role playing as a mindset or a social process between players alone (Heliö, 2004; Montola, 2012a). Role playing emerges in and by a group of heterogeneous elements. The process includes social relations between narrative, ludic, and material elements. This understanding of role playing challenges previous understandings on two levels. It is not enough to merely add a further element, in this case material, and expand the understanding on one ontological level. The understanding of role playing as a process that works in and by a group of elements demands rethinking what role playing is. I have to consider multiple ontologies, because it is insufficient to examine one ontology centered on players. If role playing emerges from the working of heterogeneous elements, how do these diverse elements collaborate? This encourages an investigation of the epistemological level, too. The epistemological question of how to know what role playing is, expands preconceived notions that define role playing as a mental process caused by players, because it requires studying collaborating elements not as post hoc 
phenomena but as they occur. Thus, it is necessary to examine materials in the process of relating to narrative and ludic elements.

By studying materials when and where role playing happens, this dissertation aims to solve the ontological and epistemological levels of the problem. The guiding question of this study is, how do materials make role playing work in role-playing games? I speak of guiding question, because "guidance" is in line with the methodological premise of actornetwork theory, "follow the actors" (Latour, 1987). As the theoretical and methodological toolset, it helped me to solve the twofold problem and answer the questions: How do materials collaborate with narrative and ludic actors in role-playing games? What changes do materials demand for their collaboration from narrative and ludic actors? How do these inter-relational processes change role-playing game networks? The results of my actor-network studies of materials in role-playing games provide the content for the next chapters.

Structure of this book. Chapter 2 explains actor-network theory in more detail. When I follow materials in different role-playing game forms, I follow one of many elements that make role playing work. I decided to follow materials, because there is a lack of understanding on how materials work in role playing in the field of game studies in general and role-playing game studies in particular. The inclusion of narrative and ludic elements aims to expand the knowledge about role playing and bridge this dissertation with previous studies. The disadvantage of this approach is that I thereby limit one of the strengths of actor-network theory, that of entering the field with a small number of concepts. The advantage is that by using these concepts in my field work, I can bridge actor-network theory and previous studies of role-playing games. More important, the study becomes feasible in the given time frame of my dissertation project.

For the next empirical chapters, I selected three forms of role-playing games where different constellations of elements constitute role playing. These three forms are live action role play or larp (Chapter 3), mixed reality role-playing games (Chapter 4), and tabletop role-playing games (Chapter 5). The results draw on empirical data collected during field work conducted primarily in Germany from 2010 to 2015.

Chapter 3 follows the costume in German larp. I participated in larps that involved hundreds of players dressing up as characters in a fantasy world. We role-played for four days at a former military camp that was rented for this event. The wizard example above was taken from one of these larps. In this chapter, I show how the costume takes part in role playing during a larp. By following the costume, I learned that it consists of a 
changing group of material elements. These changing materials have co-created German larp throughout the past 25 years and are responsible for its current shape.

Chapter 4 moves to the emerging form of mixed reality role-playing games. These games use mobile computing devices and headsets which construct augmented and virtual reality systems. For role playing with augmented reality systems, I followed the smartphone as a mobile computing device. It brought me to a larp about criminals in a darker version of the contemporary world. The players used their smartphones to access digital information in the larp world, but several things went wrong. I discuss the tensions to examine the social relations between the heterogeneous elements involved. For role playing with virtual reality systems, I followed the Oculus Rift Development Kit 2 , the prototype of a virtual reality headset. Playing a computer role-playing game with this headset, I realized that role playing reveals relations that are necessary to make the headset work in a game. Tracing these relations not only showed how they intertwine machine, player, and role-playing game, but revealed opportunities for further relations that require work with the current prototype of the virtual reality system. On the basis of these two examples, I argue that the requirements for role playing show how augmented and virtual reality systems might merge in future technological developments.

Chapter 5 is about tabletop role-playing games where people sit around a table. The core activity for players is telling each other what the character does in the shared world. Thus, the group experiences vicariously their characters' adventures. However, tabletop role-playing games involve not only people, but also the table, sheets of paper, and more material elements. To examine how these materials participate, I take a more radical step in this chapter with a methodological experiment. I explore the actions of materials in tabletop role-playing games by letting materials speak. One result is that I am able to describe what happens between materials that seem neutral during role playing. The experiment shows how future researchers can use role playing of materials as an ethnographic method. There have been forerunners in actor-network theory, but no study of role-playing games to date has investigated materials in this way.

In the concluding chapter (Chapter 6), I present an alternative understanding of how materials make role playing work not on the basis of one element, physical or material, mental or creative, but how heterogeneous elements collaborate at specific sites of role playing. 


\section{Methodology \& TheORY}

\subsection{Introduction, or Following Materials to Multiple Role-Playing Game Sites}

This book is about role-playing games, a genre of games played and enjoyed in various forms around the globe. Games are the central unit of analysis of game studies, a field which emerged at the turn of this millennium (Aarseth, 2001). Although the field focuses mainly on digital games, more and more researchers have been asking for the inclusion of analog games in recent years. These discussions take place among members of the Digital Game Research Association (DiGRA), the largest international academic association on games. As a pun, discussions about analog games bear the tag "GRA," omitting the "Di" for Digital in the association name DiGRA. Additionally, journals have emerged that focus on non-digital games, such as Analog Game Studies (since 2014). When this study includes role-playing games with digital technology (Chapter 4) as well as those without the necessary use of computers (Chapters 3 and 5), it avoids the digital/analog dichotomy with an alternative theoretical and methodological toolset: actor-network theory. As an inter-disciplinary field, game studies draws theories and methodologies mainly from the humanities and social sciences, but few studies to date have worked with actor-network theory. In Chapter 4 of this dissertation, I discuss the dichotomy between digital and non-digital games, and explain my approach that includes digital and analog role-playing games. I return to game studies later in this chapter, but I need first to explicate how this study is situated in actor-work theory, and then introduce the relevant methodological principles in more detail.

The main methodological principle of actor-network theory is to "follow the actors," so I had to go where "the structural effects actually [are] being produced" (Latour, 2005, p. 175). Since I was interested in those structural effects that produce role playing or make it work, I followed material actors to sites where they took part in three forms of roleplaying games: larp, mixed reality role-playing games, and tabletop role-playing games.

I have been familiar with role-playing games as a player since the early 1990s. The first games that I played were on an Atari computer, such as Ultima Underworld: Stygian Abyss (Looking Glass Studios and Origin Systems, 1992) and Ambermoon (Thalion Software, 
1993). In January 1995, I bought my first tabletop role-playing game Das Schwarze Auge (Schmidt Spiele / FanPro, 1992). Around this time, I read about larps that took place in the Czech Republic and were advertised in computer game magazines (PowerPlay, 1995). It was eleven years, however, before I participated in my first larp (Alcyon 10, Fantasiewelten e.V., 2006). In the meantime, my perspective on these games changed when I began to modify and design my own games. I changed from being a role-player to a designer. The first design attempt was a tabletop role-playing game in 1998. I involved myself in creating a fictional world that drew upon the works of fantasy literature and $19^{\text {th }}$ century gothic novel. I then wrote several fantasy choose-your-own-path games for DOS with the Pascal programming language, and later I created mods for the computer role-playing game The Elder Scrolls IV: Oblivion (Bethesda Softworks, 2006). Mods are software units that add content which "modifies" the core game. Moving on to designing larps, I co-organized Schwarzbernstein 1 (Utopion, Schwarzbernstein Orga, 2010) and wrote the mini larp Death Buddies about dying in contemporary Western society (2012). ${ }^{1}$ Compared to my background as a player, my activities as a designer have been limited, but they do provide me with a second perspective on the games that I studied for this book.

The field work for the three role-playing game forms provided a range of opportunities to study material actors in action. Each game session took from four hours (in the case of mixed reality role-playing games) to several days of constant play (in the case of larp). In total, I participated in hundreds of hours of different kinds of role playing from 2010 until 2014. ${ }^{2}$ During this time, I played each role-playing game form several times at different sites, because I wanted to compare how material work differs. Due to the amount and diversity of my participation, I classify this field work as multi-sited ethnography (Falzon, 2012; Marcus, 1995). Multi-sited ethnography encouraged me to visit multiple sites to uncover the spatio-temporal relationships between the three forms in order to deepen the understanding of role-playing processes and to observe how materials make them work.

I followed materials to sites before and after game sessions, because I was interested in further processes that related to sites of role playing. Some players spend hours on preparation during weekends and evenings. Following material actors to sites of discourse, where players discuss what they do to prepare game sessions or discuss past games, I

1 In 2011, I planned to organize another larp for 2012, but the larp did not happen. I and another co-organizer changed our jobs which left not enough time for this project.

2 Before, I wrote that field work took the time between 2010 until 2015. At this point I write about my participation in games that ceased in autumn 2014. My field work activities for 2015 included mainly conversations with other players. 
learned about the demands of materials and gained considerable understanding of the negotiation work that is necessary to include materials. I observed these processes in meetings of players and on online platforms where they discuss and distribute knowledge, for example how to build and modify game materials. My engagement in online forums helped me to position myself "beyond mere observing or lurking" (Michielse, 2015, p. 35 ), because I was active in discussing hands on experience and theoretical knowledge about role-playing games.

I visited player, designer, and academic meetings dedicated to these games, taking me to the cities of Haarlem (NL), Tampere (FIN), Gothenburg (S), Helsinki (FIN), Offenbach (GER), Köln (GER), and Wiesbaden (GER). At conventions, where players and designers meet, I got in touch with key figures in the contemporary culture involved in the hobby. At these meetings, I participated actively in game sessions but also contributed in reflective discussions on role playing either by sharing preliminary results of this book or by presenting about topics of general interest, such as how to take pictures without disturbing players (Solmukohta, Helsinki, 2012). Being an active part of the processes of player, designer, and academic work allowed me also to observe different types of organizations and to take their point of view on role playing. The insights from these visits helped inform my thought processes in the following chapters, as I selected data about certain phenomena instead of others.

To strengthen my relations with the communities, I became a member of DiGRA in 2013. Within the German larp association Deutscher Live-Rollenspiel Verband (D.L.R.V.), I initiated the founding of the larp research group Deutsche Larp-Forschung in the same year. I established relations between international larp communities, tying East European organizers from Poland with German, French, and American organizers. Appendix A provides a list of conventions and conferences that I participated in.

In terms of following the actors, the question remains what I concretely did to trace material work at these diverse sites of role playing and discussion. The principle "follow the actors" necessitated my going to various sites where role playing happens, including living rooms, pubs ( $\mathrm{Zu}$ den vier Winden, Bochum), former military areas (Utopion, Saarland, Germany), and youth hostels (Burg Bilstein, Sauerland, Germany). When I arrived there as a researcher, I had to participate in the game session, because role-playing games are rarely played with a non-participating audience. To trace material work in role-playing processes during game sessions, I drew upon the specifics of "follow the actors," a concept rooted in ethnography (Latour, 1987, 1999). In the following sections, I elaborate upon this principle. 
Section 2.2 introduces actor-network theory as the methodological and theoretical toolbox of this study, because I need to explain this study's alternative take on games in more detail. I elaborate that actor-network theory should not be considered as a framework, but more of an infra-language that works only with empirical data. The section presents key vocabulary that helped me to write about the selected data in the three empirical chapters.

Section 2.3 elaborates on the specifics of the chosen ethnographic tools that helped me to work with actor-network theory during my multi-sited study. The tools included field notes and semi-structured interviews as the main categories of qualitative empirical data. At the end of this section, I elaborate on ethical considerations of this study.

Section 2.4 refines the vocabulary that I use in the following chapters by bridging the vocabulary of actor-network theory with concepts from role-playing game theory, which brings me back to game studies. Table 1 summarizes the refined vocabulary for the following chapters. Finally, I situate this study of materials in the wider field of game studies.

\subsection{Introduction to Actor-Network Theory, or Building a Vocabulary}

Having addressed what I did to select data when I followed materials to the three sites, the next question is how I selected and presented the results of data analysis. This is a question of how to talk about data. I suggest actor-network theory to solve the problem, because it is also considered an infra-language that helps us to talk about data in an alternative way.

2.2.1 Actors, or various sites of action. The book that you hold in your hands or the text on a screen before you is the work of different elements that came together at certain sites. When I look around the book's place of birth, my desktop, there is the Oxford Short Dictionary, Latour's Reassembling the Social, Copier's dissertation, printed articles and book chapters on actor-network theory, books on role-playing games, but also everything I need to actually write these words: a keyboard under my ten fingertips, a mouse, an LCD display, a personal computer, a modem, pencils, and scrap paper.

For the past four years, the goal has been to make all these elements collaborate and submit the result in form of a dissertation. Some of them were easy to work with, such as pencils and scrap paper, while others disobeyed from time to time, such as my computer 
when the system crashed while I was writing, because there was an update of the operating system. The content of the articles and books on my table was more volatile. Sometimes, I had to reread a sentence, page, or the entire book to understand. Of course, understanding itself was a mental process of linking new information to what I knew. Just like the audio book producer in the Introduction, however, I pretended to be someone who could write a dissertation and experimented with materials. I assembled books and dedicated a set of writing tools only for the dissertation. Thus, I added materials to the mental processes that were part of reading about the topic and writing this book.

One example for how even words change is the "correct" spelling of role playing. The Oxford dictionary standing on my desktop tells me to hyphenate the verb "to role-play," the adjective "role-playing" in role-playing games, and also the noun "role-playing" (Brown, 1993, p. 2618). However, in 2012, the Oxford Online Dictionary changed the spelling of the gerund, omitting the hyphen (2012). Someone who is role-playing is written "role player" without a hyphen. Thus, I have retained the hyphens for the verb and adjective, but write the gerund form "role playing" and "role player" without a hyphen. ${ }^{3}$

The book next to the dictionary is Latour's (2005) Reassembling the Social. I use it as my tour guide in working with actor-network theory. Actor-network theory roots in the work of Callon (1986a), Latour $(1987,2005)$, and Law $(1987,2004)$ from the fields of science, technology, and society studies. It is in the tradition of social constructivist studies that do not primarily answer the question "What is technology?" but rather seek to trace the process of "how to make technology" (emphasis in original, Bijker, 2010, p. 63). Following these roots, this study does not aim to answer what role playing is in general or what a role-playing game is in particular, but aims to answer the guiding question how materials make role playing work. To answer this question, this study required qualitative empirical data and links its results to specific sites instead of generalizations. The focus is on role playing as a process. Actor-network theory helps to reconstruct how processes came into being, and to recognize how they changed in order to produce role playing. Role playing comes into being in and by a collective of heterogeneous actors. With the word heterogeneous I stress the point that any element can be an actor when it effects social change, be it the fictional world, game rules, or materials.

Although actor-network theory scholars emphasize the agnostic position of a researcher towards preconceived notions of processes and ask that the researcher start the study by following the actor, there is a small group of "concepts". I present the following concepts

3 See also the Tampere University nomenclature and my comment (Bienia, 2012). 
in more detail, because I want to create a bridge to readers from game studies who might not be familiar with actor-network theory. The first difficulty of actor-network theory is that it is less a theory than a methodology (follow the actors) or a language. The following concepts-actor, network, agency, mediator, and intermediary-are not definitions but words that can refer to empirical phenomena. They are empty shells without empirical evidence that the researcher has to gather in field work (Latour, 2005; Sayes, 2014; Venturini, 2010). Therefore, I put concepts into quotation marks, because they are words. These words form an infra-language or vocabulary with which the analyst can describe an empirical phenomenon, such as role playing, because "they don't designate what is being mapped, but how it is possible to map anything from such a territory" (Latour, 2005, p. 174). In this regard, actor-network theory continues the tradition of social constructivism in that it provides a vocabulary for methodology. Moreover, the legacy of post-structuralism in actor-network theory becomes apparent with the necessity to reflect language when it connects concrete reality with abstract ideas. Law (2009) suggests that "actor-network theory can also be understood as an empirical version of post-structuralism." (p. 6). Thus, the examination of concepts as words is one methodological step, because the relation between words and what is being mapped should not be taken for granted. Before I can use a word as an analytical tool, I need to establish a relation to an empirical fact and reflect instead of looking for data that fits to established concepts.

The book Reassembling the Social leans against my computer monitor that stores most of my notes, data samples, and previous versions of this book. I say "most" because in 2012 I began to draft my chapters with pencil and paper. What happened was that my writing slowed down. I am a fast writer with a typewriter or computer keyboard, but writing by hand forced the word count to drop. I gained time to think more before I wrote down the words. This new collaboration-hand, pencil, and paper-changed the way I was writing the book. In its core, this example of writing makes a point about an "actor".

An actor makes a difference to other elements. Actor is a word that refers to an element that is part of a process, for example a pencil in the process of writing. Again, actor is a word that requires empirical evidence to be of analytical value, because an actor ties to a process that the researcher observes at a specific site. A researcher can only speak of an actor when there is empirical evidence of its action. Evidence or trace of an action is observable, because "anything that does modify a state of affairs by making a difference is an actor" (Latour, 2005, p. 71). Thus, it remains uncertain what an actor is unless there is a trace of action. When there is a trace, it is not because there is an actor, but because an actor works. 
Because of this uncertainty, actor-network theory is not a theory in the sense of a stable framework that answers ontological questions, such as what an actor is, but a mode of inquiry or a tool that encourages rethinking whether the phenomenon is what it seems to be. In the example of writing with pen and paper, is it the human who is the sole actor responsible for the process of writing, or could it be otherwise?

An actor is "something that acts or to which activity is granted by others. It implies no special motivation of human individual actors, nor of humans in general" (Latour, 1996b, p. 375). The pencil is an actor, because it made me write differently. The paper itself can be an actor, too. But actor-network theory makes me aware that effects do not originate in an intrinsic essence of one element but result from the collaboration or cooperation of actors (Latour, 2011). It is the pencil, paper, and hand that change my writing compared to typing on a keyboard.

An actor has a recognizable identity only through its actions in collaboration with other actors. I can speak of the pencil as an actor in relation to hand and paper when they write together. At this point, the inter-relation between vocabulary and empirical data becomes apparent. When I sit at my desktop and remove one of these collaborators from the process, writing does not work anymore. The pencil does not write without paper or hand, the paper does not show traces of words without pencil or hand, the hand does not write without a writing device or a piece of paper. I cannot talk about a collaboration of actors anymore, because the identity-giving action of writing is missing here, and it is the identity-giving action in a collective that allows me to speak of actors, be they pencils or (later) materials in role-playing games.

This is the reason why actor-network theory does not define an actor as an element that has an intrinsic essence. An analyst refers to a pencil as a material actor, when there is a trace of action. When the graphite core that is part of the pencil collaborates with the paper and follows the movements and pressure of the hand. Non-human actors, such as pencils, "are endowed with a certain set of competencies by the network that they have lined up behind them," for example the graphite that makes the pencil, and at "the same time, they demand a certain set of competencies by the actors they line up, in turn" (Sayes, 2014, p. 138). The pencil demands from the hand the competency to write. This competency is not inherent in a hand but is the result of years of training.

Before I introduce "network", which refers here to the inter-relation of pencil and hand, in more detail, I need to explain how it is possible to say that unconscious elements like pencils demand something. 
Human, non-human, and material actors. Above, I wrote that an actor is any element that acts in relation to other elements. This understanding works to recognize actors that act, but are non-humans. So far, players, designers, and researchers have understood role playing as a human endeavor, as I will elaborate in more detail below. But if non-human actors can be part of action, this study needs not only to explore how the group of nonhuman actors cooperate with other actors in role-playing processes, but also how to talk about this process without replacing anthropocentricism with materialism.

Actor-network theory does not claim "that objects do things 'instead' of human actors" (Latour, 2005, p. 72). The point is to examine how action emerges as a process in and by heterogeneous relations. This is the reason why I wrote in Chapter 1 that it is not enough to solve the ontological problem of what role playing is in general, and how materials collaborate. The inclusion of heterogeneous actors, referring also to non-human actors, addresses the epistemological level of the problem, how to know about role playing. When I use the adjective heterogeneous, I refer to a group of actors that includes different actors, be they human or non-human. The point is not to replace human action with nonhuman action to understand role playing, but to start with the assumption that anything could be part of the process. To avoid the dichotomy that the word "non-human" evokes, I use the word material.

The group of material actors includes "things, objects" (Latour, 1993, p. 13), "microbes, scallops, rocks, and ships" (Latour, 2005, p. 11), tools and technical artifacts, material structures, transportation devices, texts, and economic goods (Sayes, 2014, p. 136). Material actors include the scale between objects and raw materials. Objects designate elements that are physically constituted, spatially defined and functionally determined. Examples in this book are paper, computers, and clothes. Some of them can be labelled as toys, but the word toy as well as object does not help, because I want to look at raw materials, too. ${ }^{4}$ Raw materials, such as rocks, water, or metal, lack a predefined functional determination.

When I refer material actors or materials, I have observed action on the physical level and noted a trace of their actions. The pencil, for example, might have a nostalgic meaning for me, because it was a present from my former employer, but when I speak of the pencil as a material actor, I refer to the physical actions of the pencil. The pencil has a certain

4 Toys evoke the image of children and in this book, I talk about adults role-playing with different toys. The word adult toy, however, evokes the image of sex toys, although the field of toy studies tries to differentiate adult interaction with contemporary toys (Heljakka, 2013). 
weight, shape, and durability, because the pencil consists of other material actors that are lined up behind it.

I do not use the word object, because I refer in this study to elements that do not have a defined function. For example, the leather that makes a costume in live action role playing is a component. Using the term material allows me to refer to players themselves as material actors, because players last and consist of matter that could be part of role playing, such as skin, hair, etc. Thus, material actors differ from symbolic, emotional, and similarly abstract actors, not because they are not able to act in these ways, but because the focus is on their physicality.

Material action does not mean that I refer only to action that the laws of causality can express, but physical action that can collaborate with mental processes. Formulating sentences and physical gravity might seem unconnected, but they need no longer be when I think about a sentence and use a pencil that leaves graphite traces on paper. The gain is an alternative understanding of writing as a process that involves material and mental action alike, where the mind/matter dichotomy dissolves because such a dichotomy is not helpful to understand how a graphite core cooperates with the rephrasing of a sentence.

The inclusion of non-humans as potentially equal actors in social processes has been a significant contribution of actor-network theory to studies of the social (Sayes, 2014). The task is to avoid reductionism that words like materials or matter might carry. "To make this possible, we have to free the matters of fact from their reduction by 'Nature', exactly as much as we should liberate objects and things from their 'explanation' by society" (Latour, 2005, p. 109). To mark that I go beyond the dichotomy between physical matters of fact and socially explicable objects or things, I use the word materials instead of physical actors or objects. Thus, I do not understand actor-network theory "as a sociology 'extended to non-humans,"' (Latour, 2005, p. 109) because I keep material actors open on a symmetric level until field work shows what clothes, rain, computer hardware, and light account for. Thinking about social processes beyond solely human actions, expands the understanding of role playing as a social process between players to a social process between actors.

The question remains, why actors act in the way they act, when they do not need or "have" an intrinsic essence or a human consciousness. An actor effects social change, but the point is that this capacity to change is not rooted always in a conscious human decision, but emerges from a relation to other actors, which can be other elements that 
do something. Therefore, I name elements as actors when they do something, when they make a difference in a network.

2.2.2 Network or action at a distance. A network is a gathering, an assemblage, a group of actors that act together. A network gains its stability when actors repeat their actions in a certain manner. When I refer to a role-playing game as a network, I refer to the collaborative work of heterogeneous actors.

Actor-network theory points out a capacity of non-human actors that highlights a spatial and temporal capacity of action. Callon (1991) ascribes the capacity of gathering actors over time and space to non-human actors, better known in the formula "acting at a distance" (Latour, 1987, p. 222). Stability in a network is gained when non-human actors, such as role-playing materials, repeat an action of a temporary gathering. For example, I want to say the word "network." I do not want to repeat the word myself, so I write the word with a pencil on a piece of paper. The paper bears the graphite marks that show the word "network." I do not have to say "network" anymore, because the paper repeats the action, saying the word network, of the temporary gathering of me, pencil, and paper.

Thus, materials can "allow an actor that is no longer present to exert a palpable influence" (Sayes, 2014, p. 140). A palpable influence is what makes a difference, although the word "influence" can be misleading when influence is not understood as a process emerging from inter-relational actions. However, the preserving of a relation over space and time is one of the actions that humans desire of non-human actors. What I aim to examine is what happens when materials transport desired actions, or to reformulate the guiding question in this context, how does role playing change over space and time when materials become part of the process?

Actor-network theory as a constructivist paradigm within science, technology, and society studies allows multiple truths instead of one, multiple truths that are constructed by and between actors. Thus, what is studied and how, is a responsibility of the actornetwork analyst. It is relevant that an actor-network refers to what is studied, in this case role playing, but it is also a tool to study role playing. 
Ontology and epistemology. Network has two meanings according to Latour (2011):

You see that I take the word network not simply to designate things in the world that have the shape of a net [...] but mainly to designate a mode of inquiry that learns to list, at the occasion of a trial, the unexpected beings necessary for any entity to exist. A network, in this second meaning of the word, is more like what you record through a Geiger counter that clicks every time a new element, invisible before, has been made visible to the inquirer. (p. 799)

The ontological meaning of network is the network as a collaboration of heterogeneous actors. Until now, I have referred to this meaning when I talked about actors. The epistemological meaning of network is the network of relational processes that become visible when the inquirer recognizes, thinks, and writes them down. The network helps to reveal material actors, because it is an epistemological tool that helps to grow a sense of what is involved in a process. In this sense, researchers like $\mathrm{Mol}$ (2010) refuse to apply actornetwork theory as a theory, and treat it more like a sensibility to approach a phenomenon while increasing one's understanding. This twofold understanding of a network is the reason why actor-network theory is apt to answer the two levels of this dissertation's problem: the ontological, what is role playing, and the epistemological, how to know about role playing.

It is not enough to re-think role playing as a phenomenon that includes narrative, ludic, and material actors. Tracing relational work between these actors, actor-network theory aims to change how a researcher learns to know and justify this knowledge about collaborating actors. Instead of referring phenomena back to concepts, I use words that have emerged from inside field work. The vocabulary at the end of this chapter is the result of my field work. It has changed in the past years when I refined it to keep my preconceived notions at bay. When I observed and analyzed what happened during game sessions, my understanding changed from role-playing games that some define as games with, for example, the mindset of role playing, to role-playing games as processes, as actor-networks that gather diverse actors and make them work together at specific sites. Using network as a mode of inquiry provides the researcher with a methodological toolbox that at the same time changes the theoretical framework. Thus, a theoretical framework is less a context than a toolbox. With the tool mode of inquiry I localized role playing in the process between actors. In this regard, the theory adds itself as an actor to the researcher's work, and as an actor, it changes its own work of constructing ontological meaning. Having explained the two meanings of network, I now return to the process, the "making a difference," because it also explains the how actors gather, or organize, other actors to form networks that last over time. 
2.2.3 Agency, or making a difference. Actors "can be made to act through the agency of a magic wand, a dwarf, a thought in the fairy's mind, or a knight killing two dozen dragons" (Latour, 2005, p. 54) . Latour does not refer here to fantasy role-playing games, but to actors that they share with fairy tales. He points out that actors act on behalf of sometimes surprising actors. Agency is the word used when referring to heterogeneous actors that act according to the same goal, such as role playing. The difference between actor and agency is that the actor does something and agency explains "the different ways to make actors do things" (Latour, 2005, p. 55).

"Making a difference" is conceptualized as agency, which is a much contested concept in social theory, but in game studies is defined as a human capacity (Wardrip-Fruin et al., 2009). While this different definition shares the understanding of agency as ability, it differs in explaining how this ability comes into action, whether it is possible to think of agency as ability, and whether the ability is an inward power, or rather a relational effect. Actor-network theory diverges from these definitions by viewing agency not as a concept that the researcher has to trace, but again as a word for a difference making process that only exists when the researcher observes an empirical trace. Agency is a source for inquiry or uncertainty about what is part of what happens. Thus, agency aims at an observable capacity to act and matter and make a difference in the world, a capacity that comes into action when actors relate with each other. Instead of an inward power in game studies' sense of agency, agency in actor-network theory refers to streamlining actions to one action. When I refer to role playing as agency, role playing is the "streamlining" action that emerges from and constitutes the interrelational actions of heterogeneous actors. These actors' actions form connections and when enough connections flow together, they create the role-playing game network and role playing works.

When "[a]ctors fill the world with agencies" (Latour, 2005, p. 52), how can a researcher understand the process of creating agency in the world? As there is no causal agency, "there might exist many metaphysical shades between full causality and sheer inexistence: things might authorize, allow, afford, encourage, permit, suggest, influence, block, render possible, forbid, and so on" (Latour, 2004, p. 226). Agency that refers to the level of a network makes a difference to the relations between all heterogeneous actors. In this study, the agency on the level of a role-playing game network, is role playing. In order to make a difference according to the agency of role playing, all actors have to change their actions. I examine this process when I ask how materials, as one group of actors, make role playing as agency work in a role-playing game network. 
When all actors have to change their actions, every actor follows its own agency before the network comes into being. Therefore the agency on the level of the network emerges when all actors abandon the agencies or "that they have lined up behind them," because every actor is a network of other actors (Sayes, 2014, p. 138). In the example above, a pencil is an actor that consists of a graphite core and wooden body.

Agency explains the multi-sited understanding of action as an effect across multiple actors. Following actors negotiating across different role-playing game sites and forms, actors can inscribe the agency of role playing to different degrees, depending on the outcome of the negotiations between actors. "They [actors] will not only enter into a controversy over which agency is taking over but also on the ways in which it is making its influence felt" (Latour, 2005, p. 57). A "felt" influence is an influence that the analyst can trace. Again, instead of influence, I refer to this process as "making a difference."

2.2.4 Mediator and intermediary, or translating agency. The word mediator refers to an actor that changes what other actors do in the network. As actor-network theory speaks of processes, this happens during the mediator's implementation to the network. At one moment, the mediator inscribes its agency to any degree into other actors' processes. "Mediators transform, translate, distort, and modify the meaning or the elements they are supposed to carry" (emphasis in original, Latour, 2005, p. 39). A mediator that transforms a game network, for example chess, is the clock. Playing against time turns the game of chess into fast chess and the clock becomes an actor that modifies how the game session works.

The word intermediary refers to an actor that spreads agency without changing it. "An intermediary, in my vocabulary, is what transports meaning or force without transformation: defining its inputs is enough to define its outputs" (emphasis in original, Latour, 2005, p. 39). An intermediary of fast chess, for example, could be a wooden chess board. The wood prevents the board from changes, thus the board repeats its action of presenting a field of 64 squares. Thus, the board spreads the agency of chess playing without changing it across the network of players, pieces, and so on.

The researcher remains uncertain whether to refer to an actor as an intermediary or mediator, because this uncertainty is the starting point of an actor-network study (Latour, 2005, p. 39). Latour suggests to "ask the actor" if the actor matters as a mediator or not. An additional question could be to think of an ex negativo case: imagine that there is no board in a game of chess or no costume in a live action role-playing game session. 
So far, I have elaborated upon actor-network theory as an infra-language that helps the researcher to question and talk about the phenomena seen during field work. The next section returns to the methodological principle of "follow the actors" to explain how I selected qualitative data about material actors, role playing agency, and role-playing game networks.

\subsection{Methodology, or Selection of Qualitative Empirical Data}

2.3.1 From participant observation to field notes. Originating in Malinowski's first reflections (1922), participant observation developed to a method in ethnography. Participant observation is "a way to collect data in naturalistic settings by ethnographers who observe and/or take part in the common and uncommon activities of the people being studied" (DeWalt \& DeWalt, 2002, p. 2). Through the extended face-to-face encounter with the actors of interest, and participating in extraordinary and mundane actions, observations gain their empirical quality, because there "is no substitute for gaining tacit and implicit knowledge of cultural behavior than living among people and sharing their lives" (DeWalt \& DeWalt, 2002, p. 291). I got insights in the wider activities of role players by participating in game sessions, and in discussions before and after them. The advantage of "being native" myself in this culture was that I had already established rapport as a role player and photographer in different communities of larp and tabletop role-playing games. The disadvantage was my familiarity with these games as player and designer. I needed to alienate myself to gain the third perspective of a researcher. I achieved this by consciously changing perspectives.

The change happened sometimes automatically during a game session, when my participant perspective moved to the perspective of researcher and to the character that I played. In this regard, becoming aware of the different perspectives of participant observation was the first step in solving the epistemological problem, how to know about role playing (see Chapter 1). Moving between participating and observing roles generated a creative tension: "Participant observation is a paradox because the ethnographers seek to understand the native's viewpoint, but NOT 'go native" (emphasis in original, DeWalt \& DeWalt, 2002, p. 263). As I moved to the position of observing researcher, I went alien to the role of participant and character that I was familiar with before.

Steering three roles: Researcher, participant in a game, character in the game. With the three options, I could write about processes from several perspectives. The problem was how to control the three roles. The challenge of studying role-playing games is 
not only to reflect about the ethnographer role-playing field-work perspectives, but at the same time reflecting how a researcher is a participant in a role-playing game and a character in the story world at the same time.

Participation in role playing requires the researcher not only to play her or his role as participant, but also to some degree that of an observer, and above all the role of the character within the game. The reason why switching roles has to be taken care of is because during role playing, the challenge for the researcher is to avoid disturbance, as this breaks the players' goal to maintain the illusion of a fictional world. Players are sensitive to elements that do not belong to the game world, which requires the researcher to take the role of the complete participant. In this case, starting from an informed position is helpful for studying role-playing games.

During my field work, participating in a role-playing game session became difficult. First, I had to role-play the character in the game. Second, I had to take different field-work perspectives. The researcher as participant role-plays the character and maintains opportunities for observation while changing field-work perspectives as necessary.

Actor-network theory integrates the researcher as an actor in a game network and encourages examining the process of changing perspectives, because it considers the third role of a participatory observant researcher. Beside changes in role-playing practices, subjectivity is one obstacle during field work which I share with other researchers on games employing participant observation (Pearce \& Artemesia, 2009; Taylor, 2006). In her study of online role playing, Copier reflects upon her researcher position by drawing on actor-network theory in general and Haraway in particular. Copier (2007) reflects herself as participant and researcher to "express situatedness in writing" (p. 30). In studying role playing, however, I found traces for three roles: researcher, participant, and character. Playing a character leaves traces for a third perspective. Observations from a character's perspective differed from those of me being a researcher and a participant. Furthermore, I distinguished the role of the participating self who was familiar with role playing from the researcher. As a researcher I had to go alien, because I needed to look at different phenomena than those I observed from the character perspective during role playing, or those that I observed from the participant or player perspective. Taking the perspective of researcher, participant in a game, and playing a role in the role-playing game, resulted in a triple role-playing practice. Changing the perspectives during a game session allowed me to select different observations. 
To remain in control of three roles, I drew upon role playing as a practice itself. In ethnography, role playing does not refer to the meaning of the word as a recreational practice, but to playing with perspectives. I draw upon the reflections of role players to inform ethnographic role playing. In their text for a Nordic larp conference book, Montola, Stenros, and Saitta (2015) describe the process of changing roles with regard to situations as steering. "Steering is the process in which a player influences the behavior of her character for non-diegetic reasons" (p. 108). Non-diegetic reasons are reasons not linked to the narrative elements that construct the story world, but relate to elements that players consider not part of the game, such as physical safety. In this case, players might not run "in the pitch-black forest even when [their] pursuers do" (Montola et al., 2015, p. 110). The decision when to steer depends on context. It might be the case that players ignore physical safety to some extent and run through a dark forest, as I did in the introductory example of the fleeing wizard. As their text informs other role players, it focuses on the "dual consciousness" of players who steer their roles as participant and character. I add here the researcher as a third "consciousness" or perspective. Thus, controlling three perspectives adds to diegetic and non-diegetic reasons of a role player those reasons important for doing research. By using role playing as an ethnographic method to control field-work perspectives, my practice and understanding of role playing changed.

I have observed that the difficulty of steering three different roles resulted in a change of my personal role-playing style. I would not have observed this change if I had not been familiar with role playing before. My personal style changed because I had to distribute play time between participating, playing a character, and doing research. When I observed this change, I alienated my style further. For example, when I began this study in 2011, I stopped making costumes for larp and relied more and more on less time-consuming practices, such as recycling previous costumes, or borrowing costumes from friends, or buying costume parts instead of making them myself. In 2012 and 2014, I ran tabletop role-playing games with less effort than I used to invest. I intensified my participation in several role-playing games and groups in the beginning of my field work in 2011 and 2012, and withdrew from 2013 until 2015 almost completely-returning only when in need of further clarification and verification of conclusions. ${ }^{5}$ Moving outside my comfort zone became a point of self-reflection. This alienation caused a tension with my personal style that was about doing costumes myself. The inner reluctance to alienate my play style

5 The issue of gender was one point of alienation that I came across during this study. I became aware that it might be possible that "men and women have access to different settings, people, and bodies of knowledge" (DeWalt \& DeWalt, 2002, p. 280). However, from my history as a player myself, I was familiar with fellow players of all genders. 
invigorated my reflections on the inter-relational demands, the seduction, and coercion of materials I had not been aware of before.

At the beginning of my study for each empirical chapter, I took an informed position to alienate what I took for granted about role playing. Taking different perspectives, oscillating between participating and observing, I produced different types of written field notes. Everything that seemed familiar or unproblematic became the source of inquiry. The question was how I came to know about an aspect and what material traces were there. Steering helped to control different roles, reflect upon changes in observation and participation, and develop sensibility for the actor that I followed for every chapter.

Participation per chapter. For Chapter 3, I followed the material actor costume to larps that took place at a former military area in Bexbach, Germany from 2010 until 2012. The former military area has been turned into a larp area and renamed Utopion. At Utopion, I focused on two larp campaigns and a fest larp that took place there. A larp campaign is a series of usually annual larp events that continue a longer narrative. The two larp campaigns were Alcyon (Fantasiewelten e.V.) and Dunkle Pfade (Nachtfalken Orga). Both larps involved around 150 participants. Fest larps are larger in scale, ranging from 1,300 participants at Epic Empires to 8,500 participants at Conquest of Mythodea. I chose Epic Empires (Epic Empires Event UG), because it took place at Utopion and involved organizers and participants of the two larp campaigns. Beside these larps, I took part in other larps. Some differed from my selection, as they drew upon a different genre than fantasy, took less time, or were played in other parts of Germany and Europe. Field notes included data samples differing in size and medium: hand-written narratives of what happened during the day, quick notes written during gameplay in a small notebook that I carried with me, and photographs of costumes, props, and locations. From the perspective of observer as participant, I wrote these notes in the evening in my tent and when the larp was over on Sunday. After the larp, I used the photographs to distance myself and describe scenes from a complete observer perspective. The photographs and the quickly written notes were from the perspective of complete participant, sometimes using the voice of my characters.

For Chapter 4, I followed two material actors, a smartphone and a virtual reality headset. With the smartphone, I explored the larp Obscurus 2 in Spaarnwoude, the Netherlands, which took place in a contemporary world (2012) ruled by criminals. The mixed reality technology involved was a banking software that players could access with their smartphones. It served as an example for augmented reality technology, because it added a digital layer of information to the location of the larp. With the virtual reality headset 
Oculus Rift DK2, I explored role playing in computer role-playing games in 2014. The virtual reality headset replaces the monitor with a $360^{\circ}$ display. Additionally, I interviewed a designer of the augmented reality role-playing game DSA Hexenwald (sprylab, 2013) and Dutch larp organizers who have used mixed reality technology before. Similar to the methods in the larp chapter, I wrote field notes during Obscurus 2 and while playing with the virtual reality headset. I participated as a player and followed how both material actors co-operate with the heterogeneous sites. Additionally, I took videos of myself roleplaying with the headset. Here too, the perspectives changed, from complete participant to complete observer.

For Chapter 5, I examined six materials that produce role playing in tabletop role-playing games taking place at different locations in Germany and at my home in Maastricht, the Netherlands from 2010 through 2014. The game system that I focused on was Dungeons E Dragons 3.5 (Cook et al., 2003), but I also participated in sessions of Vampire: The Requiem (Marmell et al., 2004), Call of Cthulhu (Petersen \& Willis, 2004), and Das Schwarze Auge (Herz et al., 2005). In this chapter, I relied less on field notes than on interviews with other players. The reason was that I changed my perspective one step further for this chapter, to that of role-playing materials. Letting materials speak allowed me to take ethnographic role playing further by role-playing non-human elements. I explain this experiment in more detail in Chapter 5.

As all of the chapters draw upon interviews, I will explain my use of interviews in more detail before I discuss the ethical questions involved in this study.

2.3.2 From semi-structured interviews to transcripts. I reflected on my observations by interviewing participants and designers after each of the game sessions. Semi-structured interviews helped me to reflect by mirroring my understanding with what players and producers said. Producers include people who produce these games for others, such as organizers in larp, designers in computer role-playing games, and game masters in tabletop role-playing games.

Semi-structured interviews engage the interviewer and interviewee in a formal interview situation. Each of the interviews took 60 minutes via online voice communication. This type of qualitative interview connects a list of open questions prepared before the interview with the opportunity to explore further certain themes that emerge during the interview (Kruse, 2011; Kvale \& Brinkmann, 2009; Silverman, 1985). As interviewer, I had prepared six questions and let the conversation follow the interviewee's answers. Thus, I could follow the topic of "role playing and materials" and let the interviewee lead. Beside 
technical difficulties that might occur when establishing an online voice communication, I had positive experiences regarding online interviews. Similarly to Michielse (2015), my interviewees preferred this form of communication, because it was natural to them, and because they could share visual information. Some send me pictures of their living room where they play tabletop role-playing games, while one interview partner showed me his game master screen while using the camera of his laptop. This procedure resulted in reliable and comparable qualitative data. After transcription, I translated the interviews from German into English. The final number of interviews was 10 for larp, three for mixed reality role-playing games, and 14 for tabletop role-playing games. In addition to formal interviews, I talked informally with role players on various occasions. In this regard, I balanced the small number of interviewees for Chapter 4. I have added the most relevant correspondence to the list of interviews. See Appendix B for the list of interviewees and correspondence.

2.3.3 Ethical considerations. Regarding research ethics, I followed the considerations laid out by the Chicago School of Writing (Booth et al., 2003; Williams \& Colomb, 2007). I share with them the "belief that [research] is a profoundly social activity that connects you both to those who will use your research and to those who might benefit-or sufferfrom that use" (Booth et al., 2003, p. 273). My field work brought me to different sites of play and discussion. In regard of time, the principle "follow the actors" connects my book with those to whom I talked during my field work in the past, with readers who hold this book in their hands now, and with colleagues who might use it in the future.

The Chicago School ties two conceptions to ethics, "the forging of bonds that create a community" and "moral choices we face when we act in that community" (Booth et al., 2003, p. 273). I forged bonds with players, designers, and scholars over the past five years as I participated in games and discussions about games at conventions and at online sites. Aside from playing, I read and wrote blog posts, forum threads, and discussions on social media sites. At these online sites, I found additional volunteers for interviews, who are included in the number of interviewees above. When working with online sites as part of the field work, it is probable that the amount of data is overwhelming. Michielse (2015) suggests to focus on "a specific part of the community" website, such as the frontpage (p. 35). In my case, I focused on discussions and online texts about crafting role-playing materials, but since there were few, I needed a further step. Throughout the time, I made my research project on materials public on my private blog (bienia. wordpress.com), on my profiles at social media sites (Facebook, Twitter, YouTube, reddit), and on my profiles in specific online communities (inlarp.de, larperning.com, forums.oculus.com). In this way, I have stimulated the necessary amount of response, 
either directly via text messages or by generating discussion on the sites. Some responses were online while some happened in person during conventions and conferences. While maintaining contact with the communities, I kept my research work transparent. I agree with Michielse (2015) about transparency as an important moral choice, and would like to add that it is also a practical choice, because it generates opportunities to attract correspondence and interview partners.

I informed my interviewees about my intention to summarize the results and make them visible within an academic study. Interviewees provided consent in advance to be recorded and quoted. Some interviewees offered their real name for use (i.e., Walter) while others chose nicknames (i.e., Section31). When the chapters were finished I sent them to all the interviewees whom I quoted, for a final check. I treated most correspondence at online forums, social media sites, and via chat anonymously. In referring to such correspondence I do not usually cite names, but the game and form of communication, for example: SVA larp, E-mail, 2011. All in all, the study followed Maastricht University's “Code of Conduct, Scientific Research” (2012).

Being in touch with the community discourse, I learned more about the three roleplaying game forms, the (in)visibility of materials, and the latest developments, such as crowdfunding and crowdsourcing, for example for Dungeons \& Dragons 5 (in 2012), Oculus Rift (in 2012), and College of Wizardry (in 2014). More importantly, with the help of online communication and online sites, I stayed in touch with fellow players and interview partners.

Staying in touch with the community made it possible to inform the community about the progress of my research and disseminate preliminary results. I wrote about preliminary results on my blog, in magazines (inlarp.de and LARPzeit), as well as in book publications of larp conventions (MittelPunkt 2011-2015, WyrdCon 2012), and presented my findings at conventions (see list in Appendix A). I also contributed as a reviewer during the set-up of the first international larp census (Vanek, 2015). Another reason was to connect national communities, and also to disseminate information beyond this study, such as the news of Disney's idea-scouting at Nordic larp communities that influenced the construction of Disney's Star Wars Land. Staying in almost daily contact with the communities helped me to examine and revise my understanding of role-playing games from different perspectives. 


\subsection{Theory, or an Actor-Network Vocabulary for Game Studies}

The preceding sections introduced the theoretical and methodological toolbox that bridges the fields of science, technology, and society and role-playing game studies. Considering the guiding question, I have explained the words in brackets: How do materials (actors) make role playing (agency) work in role-playing games (network).

What remains is to explain the role-playing game itself, by introducing definitions of play, role play, game, and finally role-playing game, and to connect them to actor-network theory. The goal is to create a vocabulary to select and analyze the data that I acquired during field work.

2.4.1 Play. Perhaps there is no need for an introduction into play, but how to define an activity that is familiar to all people, young and old? According to the Dutch historian Johann Huizinga (1955 (Original work published in 1938)), all culture originates in play. Before culture, even before language, so he argues, there was play. Imagine children playing with toy dolls and letting them have adventures. Children do not only share the ability of play with adults, but with inanimate objects, too. Play is an activity that is everywhere, at all times, and everyone understands intuitively what it is-or so it seems.

When researchers established the field of game studies in the 1990s, they drew upon the first concepts about play from two books. According to Crawford (2011, p. 9), these books became what could be considered classic texts of contemporary game studies. The first work is Huizinga's aforementioned Homo Ludens (1955) and the other is Caillois' Man, Play, and Games (2001 (Original work published in 1958)). I start with Homo Ludens, where Huizinga (1955) defines play as

a free activity standing quite consciously outside 'ordinary' life as being 'not serious' but at the same time absorbing the player intensely and utterly. It is an activity connected with no material interest, and no profit can be gained by it. It proceeds within its own proper boundaries of time and space according to fixed rules and in an orderly manner. It promotes the formation of social groupings that tend to surround themselves with secrecy and to stress the difference from the common world by disguise or other means. (p. 15) 
Play is an activity, a free activity. The definition puts freedom in opposition to activities that are found in the sphere of "ordinary' life" (Huizinga, 1955, p. 15). ${ }^{6}$ The discussion about the division between ordinary and extraordinary life turned into an invigorating debate among researchers when game designers emphasized this divide with the concept of the "magic circle." First suggested in a game design handbook, the concept of the magic circle draws from Huizinga's division between ordinary life and gameplay (Salen \& Zimmerman, 2004, p. 95). The concept was picked up by researchers, as it serves well to explain certain conceptual problems, for example how to distinguish play from other activities. ${ }^{7}$

Taking the position of actor-network theory, however, the divide has a history of its own. The cut serves analytical reasons as it allows constructing a social system of play and a social system of everyday life, but it is not helpful for every question. It limits the understanding of the complexity of ordinary life and play as determined by a conceptual divide. Moreover, the divide does not explain what action is necessary to separate and combine actors during play from what is conceptualized as different system. As the divide is the result of a construction, an actor-network analyst has to find traces for such separations despite the temptation to reaffirm the blackbox of separable systems.

Caillois replied to Huizinga's work in his publication Les jeux et les hommes (1958), separating the activities play (paidia) and game (ludus) by explaining that play is free play whereas game is structured play (Caillois, 2001). By associating Caillois' term paidia with Lalande's dictionary definition of jeu from 1928, Frasca (1999) elaborates upon this distinction: paidia is "prodigality of physical or mental activity which has no immediate useful objective, nor defined objective, and whose only reason to be is based in the pleasure experienced by the player" (emphasis in original; 1999, "Play and Game", para. 12). Ludus is a particular kind of paidia, defined as an "activity organized under a system of rules that defines a victory or a defeat, a gain or a loss" (emphasis in original; Frasca, 1999, "Play and Game", para. 13). These definitions help me to recognize actors that act regarding the structuring of play, that propose winning and losing conditions, and that construct the role-playing game as a game network. From Caillois, I take the word ludic to refer to any actor that structures play in larp, mixed reality and tabletop role-playing games.

Although alternative understandings of play exist outside the field of game studies (Goffman, 1961; Sutton-Smith, 1997) as well as inside the field (Stenros, 2015; Walther,

6 See Copier (2007, p. 126) who elaborates upon the original Dutch version of the text.

7 For an overview of the debate and a possible consolidation see Stenros (2012) and Zimmerman (2012). 
2003), the distinction between paidia and ludus remains influential. ${ }^{8}$ If play is unstructured activity, and agency is a type of activity that changes the relation between actors, then I refer to play as agency. As unstructured activity in the sense of actor-network theory, play can make actors relate beyond preconceived divisions. Thus divisions, such as between everyday life and play or between human and non-human, become sources of uncertainty.

I can now expand Latour's aforementioned list of non-human actions (2004, p. 226): "things might authorize, allow, afford, encourage, permit, suggest, influence, block, render possible, forbid" . . . and play. If things or materials act, materials participate in play beyond the engineering use of the word play referring to the scope of allowed movement in a moving part. So far, play has been discussed as a type of agency. What follows is a game-studies-based clarification of role playing as a type of play.

2.4.2 Role playing. Role playing is a type of play that becomes familiar in the context of children's play. The given example was children playing with puppets, another example would be Cops \& Robbers. Behaving like role models from movies, using improvised costumes, for children the playground becomes the scene of adventure and excitement. From the perspective of developmental psychology, these examples of role playing are forms of pretend play, or behaving as if one were someone else (Göncü \& Perone, 2005). Children learn to adapt to the social environment by role-playing parents and other adults. One aspect that role playing shares with the general category of pretend play is that both activities are found not only among children but also among adults (Göncü \& Perone, 2005). ${ }^{9}$

Adults role-play when they navigate through different social environments, such as the work place or at home, and through environments they frequent in their free time. For adult activities, when the environment changes, so (often) does the name of this activity, as pretend play is considered a premature stage in development (Erikson, 1994). Role playing is thus a common activity, although it often bears different names, but as an activity it is familiar to all, either as social role playing in everyday life or recreational role playing in one's free time. Thus, the real trick of Gaiman's advice in the Introduction is that it reveals how familiar role playing is. In this study, I refer to role playing as an adult recreational activity, an activity that is currently drawing more and more academic

8 For a criticism on Frasca's take on Caillois' concepts, compare Jensen (2013).

9 For current studies on child role playing see Fleer (2013) and Schousboe (2013); for other forms of adult role playing see Aarebrot et al. (2012), Brown (2013), Goffman (1959), Harviainen (2011), Kustritz (2008). 
interest (Deterding \& Zagal, n.d.). Before I elaborate on the field of role-playing game studies, which focuses mainly on adult role playing, I will further explore the foundations of studying role playing.

Mimicry. Caillois (1958) categorizes types of gameplay on a scale between paidia, unstructured play, and ludus, structured play. Mimicry is closer to paidia, as "mimicry exhibits all the characteristics of play: liberty, convention, suspension of reality, and delimination of space and time" (emphasis in original, Caillois, 2001, p. 22). Although mimicry is more paidia than ludus, as "the continuous submission to imperative and precise rules cannot be observed" (Caillois, 2001, p. 22), the "suspension of reality" gains a primal function. Suspension of disbelief becomes the unique "rule of the game: it consists in the actor's [in the sense of performer] fascinating the spectator, while avoiding an error that might lead the spectator to break the spell" (Caillois, 2001, p. 23). Thus, the "imperative rule" for the performer here is to maintain the "suspension of reality" for the spectator. ${ }^{10}$ The imperative rule that aims at suspension of disbelief is one shade of agency of role playing.

Suspension of disbelief is the voluntary act to take the performance seriously, despite the limitation of being flawed. Mimicry "emphasizes the active participation of the persons who inhabit the imagined form and play it out" (Henricks, 2010, p. 181). Thus, mimicry describes role playing as the playful imitation of a role with the rule not to break the imitation of the performer's and spectator's second reality. One difference between Caillois' mimicry and role playing is that performer and spectator often coincide with each other, because role-playing games include every person present as participant. ${ }^{11}$ This is also true for larp, which shares similarities with theatre performance, especially improvisation theatre. In larp, as I will show in Chapter 3, all participants are performers and spectators, and non-participant spectators are excluded. ${ }^{12}$

In the language of actor-network theory, Caillois identifies several actors that produce mimicry or role playing: performer, spectator, the role, reality, imitated second reality. The performer imitates and maintains with his role the second reality and the spectator accepts this imitation. Following the concept of mimicry as role playing, and role playing as agency,

10 Exceptions exist in drama that breaks the fourth wall, such as the distancing effects in Berthold Brecht's theory and technique of theatre.

11 Participant in the role of player or producer (organizer in larp, designer in computer and game master in tabletop role-playing games).

12 Again, with the exception of organizers who do not role-play all the time, but take the roles of event manager, game referee, and sometimes play for a short time. 
mimicry turns mediators of the reality network, such as the performer and spectator, into intermediaries of the role-playing game network. Both networks are necessary for role playing, because acting as if the imitation network is in place requires another network in relation. Without another network of "reality," there is no "second" network. The goal to maintain and not break the imitated second reality works when there is a relation between the first and the second network, otherwise the process would not be role playing, a mimicry of a second reality, but performing a social role in everyday life.

Multi-sited mimicry. The question arises, what are possible actors that construct everyday life? Goffman (1974) suggests frame analysis to understand the processes of everyday social role play. Frame analysis offers a theory to explain different groups of behaviors or qualities of certain behaviors in human society. The main concept is that of frame. Frame is a metaphor to distinguish the different social spheres to which someone relates. Frames are basic cognitive structures that guide the perception and interpretation of reality. A frame refers to the meaning making work of situations "in accordance with principles of organisation which govern events - at least social ones - and our subjective involvement in them" (Goffman, 1974, pp. 10-11). Thus, frame refines what I referred to as perspective before. Perspective as frame can be a research tool when it is consciously steered. But what about constructing and playing a frame for recreational reasons, such as a character in role playing?

Fine (1983) made frame analysis fruitful with the first well known study of a form of roleplaying games, and created a tradition of frame analysis of role playing. Fine distinguishes a primary frame of the players, a gaming frame, from a secondary fantasy frame, in order to explain the dynamics of how players relate to the different frames during play. From an actor-network theory perspective, frames are similar to networks, because they are socially constructed, but frames as a concept focus on the central activity of players.

What is interesting here is that according to frame analysis the construction of the self in everyday life employs not one but different frames, and that everyone is able to change from one frame to another (Goffman, 1959). As the participant who can be player and researcher. The point is not only that different frames are created, but that people and role players individually and collectively change awareness from one frame to the other, thus being able to relate to different networks. This multitude and simultaneity of frames explains not only the confusion of the inexperienced player, but also further actions that emerge from relating to other networks, especially those that are not in focus of discussion and instruction, such as materials. Finally, it suggests that role playing is possible with different roles at the same time or in quick succession, both individually and collectively. This shows that role playing as agency establishes a relation 
between different networks not only to create an imitation, but to organize-and thus create and maintain-a dynamic oscillation of different actors relating individually and simultaneously to different networks within the role-playing game network.

From studies of games and frames to role-playing game theory. Frame analysis focuses on people and how they make sense of their perceptions and experiences when they construct both primary and secondary frames. In this study, I expand the social towards material actors in this process of role playing as a dynamic relational process. More importantly, the division between a primary and a secondary frame does not help to explain how materials contribute to role playing, because the frames construct the divide on mental processes. What frame analysis adds, however, is an explanation of how role players are aware of different mental constructs, and of how they play with them. Mimicry acts at the level of different frames, realities, or worlds, and is thus multi-sited. This suggests the question, how do materials co-operate with the playful awareness of the multi-sited mimicry process of role playing? There are different actors that players (and researchers) interpret as constructs of reality. The question remains of how these actors co-operate with materials.

Role-playing games built on familiar forms of role playing, such as children's and social role playing, and grew to different forms in the second half of the $20^{\text {th }}$ century. After Fine's (1983) first academic study of tabletop role-playing games, it was the player community that began to discuss the hobby at conventions and in the growing online world at the turn of the $21^{\text {st }}$ century (Boss, 2008; Kim, 2008). From within these communities, researchers emerged and began to study role-playing games from an academic perspective.

In her influential text from a larp convention book in the Nordic countries, Heliö (2004) writes that usually it is the aim of role-playing games to "produce a narrative experience, or an interpretation of the game events" (p. 69). ${ }^{13}$ The aim is the construction of relations between narrative actors either during or after the game session. Players enjoy the experience of pretending to be a fictional character in a story world. Later, players share their experiences with others by retelling the events in the form of verbal accounts or written text.

Heliö (2004) distinguishes role-playing games "from other types of games in the sense that they pursue narrative experiences and storytelling" (p. 72). In the language of actor-

13 This understanding was integrated into Montola's social constructivist dissertation on role-playing games (2012a) as well as the eighth annual Tampere Game Research Lab Spring Seminar Role Playing in Games at Tampere University, April 10-11, 2012. 
network theory, Heliö constructs role playing as the relational work between narrative elements and a human player. Narrative element can include any element of fictional worlds ranging from popular novels, TV series, and movies to video games. In this understanding, role playing centers on a human actor.

Heliö (2004) elaborates the human centeredness when she defines role playing as a mindset:

... the role-playing mindset can be used when the player wants to embed narrative motives into game play, no matter what kind of a game is being played. However, this mindset does not change the game into a role-playing game, because they have, by definition, also formal traits that should be shared among the players before the game counts as a role-playing game. These traits include such things as a rule set, that is, first, used to structure the game itself, and, second, used to simulate the game world. (p. 71)

Players with a role-playing mindset can enroll narrative actors to any game network in order to produce and enjoy the "narrative experience." This in itself does not change the game into a role-playing game according to Heliö, because it is the rule set that defines. As a ludic actor, the rule set structures free play. In a role-playing game, according to Heliö, the player connects narrative motives to the structure of the game. The rule set simulates this process when it offers means for interaction with the imagined story world, for example when rules offer players the option to change what happens during a particular game sequence.

The point I want to make with this previous discussion is that role playing is a fluid word. It doesn't have just one meaning, because it has a history related to every individual game session and to every community of players or scholars. The point I want to make with this dissertation is that in order to understand role playing, it is not enough to look at people, when they combine narrative and ludic actors, but on materials, too. This brings me closer to understanding how role playing works, because it shows how difficult, time consuming, and complex the actors' work is.

When I refer to role playing, it is role playing agency in the sense of actor-network theory. Role playing emerges between any traceable actor and leads to the cooperative construction of a role-playing game network. From the discussion in this section, role playing is a type of play. Role playing is pretending a character living in a shared story world, and as agency it requires all actors at a game session to collaborate. To cooperate, the relations between actors sometimes have to change to make role playing work. This 
dissertation examines how role playing changes and is changed by the relations between narrative, ludic, and material actors in three forms of role-playing games.

2.4.3 Game. Although Heliö's text was published in a semi-academic convention book, the bridge to the field of game studies is apparent. Heliö writes that game rules define role-playing games as games. Here, she reconstructs a discourse from game studies that positions narrative and ludic elements as categories that scholars have attributed hierarchy of game definition. When the field of game studies emerged, it invigorated a debate between researchers who used games as a case study to apply methods from the established fields of literary, film, and media studies to understand the narrative potential of games. Researchers who saw the potential of studying games beyond media, defended the understanding of games as systems against games as narrative media, and proclaimed the study of (digital) games as its own field with the name ludology (Aarseth, 2001; Bogost, 2009; Frasca, 1999). Beside the meaning of ludology as the "study of games as such," ludology can be understood also as the "study of games distinct from narratives" (Perron \& Wolf, 2008, p. 363). These groups of researchers today form the subfields of narratology and ludology within the field of game studies. Their debate has constructed and deepened the understanding of two groups of actors: narrative and ludic actors. While narratology studies narrative actors (such as plot, prewritten story elements, and emerging stories, among others), ludology considers games as media-independent and focuses on actors that form the structure and mechanics of games.

During this debate, several influential definitions of game emerged out of critical enquiry with Huizinga and Caillois. Frasca asks the question, if according to Caillois play (paidia) and games (ludus) both have rules to some degree, how they can be distinguished? Following Lalande's French dictionary, Frasca answers this question: "Even though he [Lalande] does not explicitly [refer] to game and play (just one French word exist[s] for both activities), he differentiates them not because of their rules, but by their result. Games have a result: they define a winner and a loser; plays do not" (emphasis in original; Frasca, 1999, "Play and Game", para. 10). In the language of actor-network theory, a game has a result and to meet the result, the game translates any game-play action according to this aim. All actors involved in game-play actions collaborate and turn their relations into one stable and final form of the game network. According to actor-network theory, however, the final form of the game network may be the goal, but it is not safe to say whether this form becomes stable or whether ludic actors alone are responsible for its construction.

Those who design the game and set its results define how the game evolves. The game 
evolves when players interact with ludic elements that are part of the game design. This understanding of games as the work of ludic actors differs from Heliö's emphasis on narrative actors in role-playing games. What is similar is the definition of a game with one type of actor in relation to human actors, thus such game definitions replace narrative with ludic elements. One prominent game definition in game studies is part of a handbook on game design. It reaffirms a definition of games that hones the idea of the result as the major purpose of games: "A game is a system in which players engage in an artificial conflict, defined by rules, that results in a quantifiable outcome" (Salen \& Zimmerman, 2004, p. 96). The aforementioned result requires quantifiable results of a simulated conflict. Both the quantifiable result and the conflict are rooted in game rules that constitute the system. Although in this understanding, it is the player whose actions decide the shape of the outcome, it is the game system that provides certain elements and certain mechanisms which result in certain goals, all defined by the game design beforehand. What game design definitions offer is the language in which to speak about ludic actors in the chapters that follow.

An alternative definition of games that shares similar ludic elements is Juul's (2005) classic definition:

A game is a rule-based system with a variable and quantifiable outcome, where different outcomes are assigned different values, the player exerts effort in order to influence the outcome, the player feels emotionally attached to the outcome, and the consequences of the activity are optional and negotiable. (p. 36)

To speak in the language of actor-network theory, a game is a network that forms itself according to a set of agencies that include an artificial conflict and free play, and actors such as human actors, rules, and quantifiable parameters. Juul suggests this model to analyze "classic games," as he gives examples for games that do not fit into this definition. The classic game model sets categorical boundaries and, moreover, ontological boundaries as it aims to find the essence of classic games. The downside of the model is that it does not help to explain other processes that lead to this stability or instability. What about networks that emphasize both play and game, such as role-playing games?

Before I discuss role-playing games as unstable game systems that disrupt attempts at definition, a summary so far: if I follow the definitions of games above, a game network includes ludic actors, such as game rules, which structure play and role playing. Quantifiable parameters are ludic actors that connect to the outcome of play. When agency is a type of action that describes the negotiation between actors, the outcome of 
these negotiations connects primary to the group of ludic actors. I use the concepts from ludology - such as rules, result, structure-to name ludic actors when I observe them in my field work on role-playing games.

2.4.4 Role-playing games. If a role-playing game is a game, a ludic system, and it emphasizes the role-playing mindset to be concerned with narrative elements, how then to define a role-playing game as a specific game genre that oscillates between play and game? When the name uses both words in role-playing game, it bears a tension of definition. ${ }^{14}$ The underlying conceptual tension between structured and free play might be responsible for the difficulties there have been in defining role-playing games.

As the role-playing game genre has been one of the driving forces of innovation since the beginning of the video-game industry, game studies scholars have made several attempts to define role-playing games. Aarseth (1997) wrote about the significance of role-playing games for the field of video games and about the connection between game studies and role-playing games: "The Dungeons \& Dragons genre might be regarded as an oral cybertext, the oral predecessor to computerized, written, adventure games" (p. 98). Aarseth defines "cybertext" as "a perspective on all forms of textuality" (p. 18). "Perspective" means that the medium is part of the meaning-making process on the formal level. It relies, for instance, on effort on the part of the reader, beyond merely flipping the pages of a book, due to the possibility of choosing different paths in the storyline. The history of tabletop and computer role-playing games has been intertwined since the early 1970s, when students adapted the tabletop role-playing game Dungeons E Dragons (1974) for computers, such as $d n d$ (1975). ${ }^{15}$ Today the computer role-playing game genre is among the most popular video games (King et al., 2014).

Despite the importance of the genre, game studies scholars face problems when they define role-playing games from the perspective of ludology. The most apparent case is Juul's aforementioned definition of classic games. He concludes from his definition that tabletop role-playing games are a borderline game genre. They are not classic games, because game rules have to be fixed and tabletop role-playing games do not fulfill clear boundaries: the player who takes the role of referee can change game rules spontaneously during the game (Juul, 2005, p. 43). Scholars contest the role of referee, the so-called game master, and suggest that rule discussion can take place among the participants

14 Although all games are played, such as football, it is the genre of role-playing games that uses both words.

15 More about the history of tabletop and computer role-playing games, see (Caves, 2000; Hillenbrand \& Lischka, 2014; Mason, 2004). 
(Manzo, 2011). If rules are a point of constant negotiation in role-playing games, rules as ludic elements do not help when ludologists try to define role-playing games.

The case of a role-playing game challenges attempts at definition, perhaps not because role-playing games cannot be defined as a game, but because a change in perspective is required, to focus on processes rather than on elements. Actor-network theory does not necessarily challenge the understanding of a game as a system of rules, but perhaps it is not the existence of rules but the fact that some rules change more successfully in a concrete game session that enables them to co-construct a stable role-playing game network. Stability of networks does not necessarily rely on fixed rules per se, but addresses how far agency - in this study role playing-can be spread among all actors that are present and part of the process, be they narrative, ludic, or material. For this reason, I look for how ludic actors assemble a role-playing game network in relation to other actors.

Studying three forms of role-playing games. Scholars of role-playing games distinguish between forms of such games, with the most discussed being tabletop or pen'n'paper roleplaying games, single-player role-playing games, massive multiplayer online role-playing games (MMORPG), and larp (Deterding \& Zagal, n.d.; Hitchens \& Drachen, 2009). This dissertation examines three forms: larp, mixed reality, and tabletop role-playing games. In this section, I introduce them in the reverse order to show how scholars usually relate the history of role-playing games, before I move away from this history in the empirical chapters.

Tabletop role-playing games emerged in the 1970s with Dungeons E Dragons when Gygax and Anderson transported the idea of war games from historical settings, such as the Napoleonic wars, to the medieval fantasy genre inspired by the works of J.R.R. Tolkien. War games originated in tactical games for Prussian officers, such as Kriegsspiel created by Georg Leopold von Reiswitz in 1812. They were adapted as children's games by designers including authors like H.G. Wells (Little Wars, 1913). The relation to war games explains the emphasis in Dungeons $\mathcal{E}$ Dragons on tactical combat, and the detail of game rules that govern action in fantastic worlds. More importantly, only later editions of Dungeons $\mathcal{E}$ Dragons introduced storytelling and character progression while keeping several elements such as multi-sided dice and complicated tables for a chance-dominated game. With the Red Box edition in 1983, Dungeons \& Dragons introduced the name role-playing game with, for the first time, role playing as an emphasis on character play and storytelling (Gygax \& Arneson, 1983). Narrative actors became important and other role-playing game publications emphasized them while minimizing ludic actors, such as 
tables for combat outcomes and further tables for modifiers, for example Call of Cthulhu (Petersen, 1981). It is here that the dichotomy emerged between instrumental play and role playing, the opposition of playing to win the game versus playing a character (Copier, 2007). As this dissertation focuses on role playing, I position the study on this play style. I return to this point in Chapter 4 when I discuss the difference between roll-playing and role-playing a virtual reality role-playing game.

Mackay (2011) defines the tabletop role-playing game as "an episodic and participatory story-creation system that includes a set of quantified rules that assist a group of players and a game master in determining how their fictional characters' spontaneous interactions are resolved" (pp. 4-5). At the center of a tabletop role-playing game, there is a group of "characters," the protagonists, who are anchored in the narrative setting of a game world. Need for action within the game world is given by the game master. A game master, sometimes game master or referee, is a player who is in control of the game world and the game rules, but who is the obstacle for a definition such as the one given by Juul above. Are game rules flexible here, because the game master is unreliable as an intermediary? One reason for open game rules and the flexibility of a game master is the open outcome of role-playing games (Hitchens \& Drachen, 2009, p. 18). The outcome must be open, because role-playing games draw significantly on narrative actors. In line with the open game rules, players interact with each other through their characters, which results in the creation of a shared story. In order to create this participatory story, the game world is mediated between the participants with different means in different forms of role-playing games. If role-playing game networks oscillate between game and play, because they consist of ludic (and thus structural) actors and narrative actors, it is play or paidia that organizes these actors. As Montola (2012a) writes, "role-playing especially has a strong element of paidia or free play, which takes place within ludic structures" (p. 80). Thus, stable role-playing game networks rely not on ludic or narrative actors, but on the agency of role play that organizes the relations between these and other actors. From Mackay's definitions, several words become apparent that help me to talk about role-playing actors: "system," "story," "quantified rules," "group of players," "game master," and "fictional character." What is interesting here is that actors differ, as they include human actors ("group of players" and "game master") as well as non-human actors such as narrative elements ("story" and "fictional character") and ludic elements ("system" and "quantified rules"). However, players not only interact with each other through their characters, but what Fine examined as ordinary world frames. More important, this dissertation investigates the possibility that it is not only the player who interacts with players. Previous definitions that center on human actors miss material actors that I examine along with ludic and narrative actors in tabletop role-playing games and in the other two forms. 
Single and multiplayer computer role-playing games followed the publication of Dungeons $\mathcal{E}$ Dragons. The first single-player computer role-playing games adapted Dungeons $\mathcal{E}$ Dragons, for example $d n d$ by Whisenhunt and Wood (1975). Among the motivations were experimenting with computer programs, letting the computer calculate the many combats, and making it possible to play role-playing games alone. At the same time, the first multiplayer games emerged in the form of Multi User Dungeons (MUDs) (Aarseth, 1997; Mortensen, 2002). MUDs transferred role playing into solely text writing in online chats. Combat calculations were usually less important than textual descriptions of what happened, with automatic random generators to simulate chance results. ${ }^{16}$ With the emergence of enhanced visual graphics and mass access to the Internet at the end of the 1990s in Europe and North America, role playing in digital environments shifted from MUDs to MMORPGs. Today, the most successful MMORPG World of Warcraft (WoW, Blizzard Entertainment, since 2004) counts 5,6 million players, the largest number of monthly subscribers. ${ }^{17}$ Although role playing is one game style in MMORPGs, gathering a small percentage of its subscribers, WoW has separate servers, forums, and separate house rules for role playing. ${ }^{18}$

In this context of single and multiplayer computer role-playing games, I follow a currently emerging form of what I refer to as mixed reality role-playing games. Mixed reality roleplaying games include augmented and virtual reality role-playing games. Augmented reality technology uses mobile computing devices, such as smartphones, to add digital actors to a location. For example, a player accesses further interaction with the game world via a smartphone. Virtual reality technology uses additional hardware such as headsets to visualize a 3D digital environment. I elaborate on this emerging role-playing game form in Chapter 4 . The study of computer role-playing games in the field of game studies provides several words to address ludic and narrative elements in these games. What is missing is the study of material actors in role-playing games, although scholars in game studies have recently addressed material elements in games (Bogost, 2012; Sotamaa, 2014; Stenros, 2015), such as boxes (Toivonen \& Sotamaa, 2011), feelies (Karhulahti, 2012), and dice (Carter, 2014). In Chapter 4, I relate to previous vocabulary of digital game studies when I map out the emerging field of mixed reality role-playing games.

The third form is live action role play or larp. I focus on larp in Germany where some players refer to larp as live action role-playing games or simply live. Larp is a recreational

16 Players continue this practice today when they program random generators to simulate dice rolls and add them as mods to modern multiplayer role-playing games, such as World of Warcraft.

17 At its peak, WoW had 12,5 million subscribers in 2011.

18 See Copier's (2007) study for more game styles in MMORPGs. 
activity in which players and the environment turn into a physical representation of a chosen story world. Participants enact individual fictional characters in a series of events that is staged by a team of organizers. To support the illusion of performing actions and the appearance of their fictional characters, live role players (larpers) make (or buy) their own individual costumes. On the side of producers, the organization team builds stage props to decorate the playground. The space used for larp ranges from a local forest, to a rented youth hostel, to a former military ground, and even a castle. Larpers, in Germany and other countries, have a strong do-it-yourself attitude, despite a growing commercialization from national providers. Play time during a larp event ranges from several hours to several days, often taking the whole weekend. Participant numbers range from a dozen to several thousands, with the biggest events counting about nine thousand participants at the annual fantasy larp Conquest of Mythodea. Fantasy has dominated larp as a genre from the beginning on a global scale, but various settings have developed: all subgenres of the fantastic (Fantasy, Science Fiction, Horror) and alternative history (Mind's Eye Theatre from White Wolf, since 1993), to name a few. Recently, new forms have emerged employing larp for educational purposes (edu-larp), artistic forms, and larps to address political topics. This current of progressive larp forms first emerged in the Nordic larp community (Koljonen, 2010; Stenros, 2013; Stenros \& Montola, 2010).

Harviainen (2012) defines larp in Systemic Perspectives on Information in Physically Performed Role-Play as a "type of pretence play in which body language and other non-verbal cues correspond to those of the characters during play" (p. 11). Pretence play, a practice of adopting an alternate persona for recreational purposes, includes all age groups, from children playing Cops and Robbers to adults participating in costume parties. The focus of his definition is on gestures and facial expressions, but the definition can also include the "modification" of these performative elements with costumes, make-up, haircut, and other materials. What distinguishes larp from common forms of role playing is the relation to a fictional character. The player enacts this character in front of other participants during play. Anything a player does during playtime is interpreted as information that relates to the game world. According to Harviainen three criteria constitute larp as an information environment. First, a character is not simply a social role, but a convincing fictional character. In the section on methodology, I have spoken about this distinction when I differentiate the social role of participant as player and researcher from the (fictional) character. Second, the "activity has to take place in a fictional reality shared with others, and breaking that fictional reality is seen as a breach in the play itself" (Harviainen, 2012, p. 3). Third, the physical presence of "at least some of the players as their characters is necessary" (Harviainen, 2012, p. 3). People have to physically participate in a larp otherwise the 
required bodily information cues are not communicated. More important, the character is not there when the player is not present.

Harviainen (2012) takes a systemic perspective and a hermeneutical approach to answer how information influences the behavior of players in the system of a live-action roleplaying environment. Although larp is done physically, Harviainen does not analyze game materials, but concentrates on "the intentional evocation of artificial experiences, through the use of fictional characters as masks, identities or personas" (pp. 3-4). His approach of "ritualistic play" is extended in the physical presence of bodies, but as the focus of his publication is on how information systems influence the "the fictional reality," an in-depth study of game materials as physical actors is missing.

In On the Edge of the Magic Circle: Understanding Role-playing and Pervasive Games, Montola (2012a) discusses larp by combining social constructionism with ludology. He distinguishes the three role-playing game forms "based on the physical form of the simulation" (p. 11). The physical serves as a distinction only, when Montola focuses on similarities and differences between "role playing in games" and pervasive games. He establishes a basic conceptual framework for discussing pervasive and role-playing in games, approaches the significance of pervasive games and the meaning of role playing in games, and discusses how to understand and study ephemeral games in general. Ephemerality is central for understanding role playing as a practice, but at the same time it makes role playing difficult to conserve:

While play is always an ephemeral process, in some of these cases, even the very games can be considered ephemeral, as they emerge from changing contexts and are shaped by the spontaneous play, being impossible to reproduce as such. (Montola, 2012a, p. 10)

Play as a process passes and cannot be repeated in the very same way. While Montola (2012a, pp.74-78) addresses the ephemerality of role playing, this study offers one way to grasp ephemeral processes by the study of game materials and their changes. Participants of a larp, for example, create game materials specifically for a game session. They aim to represent the narrative dimension, in the sense that "ephemeral and irreversible play inspires narrativization of experience" (Montola, 2012b, p. 11). Traces of play on game materials allow for later analysis of role playing practices-as, for example, costumes that bear traces of play are not ephemeral and tell something about the narrative practices in a certain larp. Moreover, the narrativization of play experiences that larpers often tell each other, creates further sources to grasp ephemerality. Looking at Montola's concept 
from this perspective, it is possible to deepen the knowledge about a material beyond, for example, the emotional attachment of players.

Despite different definitions of role-playing game forms, I do not suggest to start with a definition, but a way to talk about role playing.

2.4.5 Table 1. A vocabulary for an actor-network study of role playing. On the next page, Table 1 summarizes the vocabulary that I use in the following chapters. It draws upon actor-network theory and role-playing game studies. As well as redefining actornetwork vocabulary with concepts from role-playing game studies, I deconstructed these concepts with actor-network theory and turned them into a refined vocabulary. In Table 1, I list the vocabulary (first column) and give a short explanation of it (second column). I then give an example (third column) and a data sample that I selected with the ethnographic tools (fourth column).

So far, I have answered the questions of how I followed and studied material actors with ethnographic tools, and how I wrote about the selected data with a refined vocabulary that bridges actor-network theory and role-playing game studies. The next section embeds this dissertation in the wider field of game studies. 


\section{Table 1. Actor-Network Vocabulary for the Study of Role Playing}

\begin{tabular}{|c|c|c|c|}
\hline Vocabulary & Explanation & Example & Trace / empirical data \\
\hline Actor & $\begin{array}{l}\text { An element that makes } \\
\text { a difference to other } \\
\text { elements. }\end{array}$ & See example below. & \\
\hline $\begin{array}{l}\text { Narrative } \\
\text { actor }\end{array}$ & $\begin{array}{l}\text { An actor that describes a } \\
\text { series of chronological and } \\
\text { causally related events. }\end{array}$ & $\begin{array}{l}\text { Alira is a female wizard who was } \\
\text { born in the fantasy world of Faerûn }\end{array}$ & $\begin{array}{l}\text { Alira's character background that I } \\
\text { wrote on my computer and printed } \\
\text { out (pdf file, 25.03.2008). }\end{array}$ \\
\hline Ludic actor & $\begin{array}{l}\text { An element that } \\
\text { structures play. }\end{array}$ & $\begin{array}{l}\text { Characters of the wizard class can } \\
\text { cast spells }\end{array}$ & $\begin{array}{l}\text { In } 2010 \text {, I played Alira at a tabletop } \\
\text { role-playing game session. She was } \\
\text { a wizard and defeated a group of } \\
\text { undead with a magnified lightning } \\
\text { bolt. For the spell, see D\&D Player's } \\
\text { Handbook. }\end{array}$ \\
\hline $\begin{array}{l}\text { Material } \\
\text { actor }\end{array}$ & $\begin{array}{l}\text { Object, thing, toy, game } \\
\text { material, item ... }\end{array}$ & Character sheet & $\begin{array}{l}\text { My character sheet for a Dungeons } \\
\text { \& Dragons tabletop role-playing } \\
\text { game session. }\end{array}$ \\
\hline Network & $\begin{array}{l}\text { A collaboration of actors } \\
\text { working together, or a } \\
\text { mode of inquiry. }\end{array}$ & See example below. & \\
\hline $\begin{array}{l}\text { Larp network } \\
\text { as an example } \\
\text { for game } \\
\text { network. }\end{array}$ & $\begin{array}{l}\text { A collaboration of } \\
\text { actors that construct a } \\
\text { larp, or the researcher's } \\
\text { report that connects } \\
\text { observations of social } \\
\text { actions between actors } \\
\text { to questions on whether } \\
\text { there are unexpected } \\
\text { actors and their actions } \\
\text { that are necessary for role } \\
\text { playing to work. }\end{array}$ & $\begin{array}{l}\text { The Alcyon } 15 \text { larp network } \\
\text { was stable, because all actors } \\
\text { collaborated. } \\
\text { Actors included: } 100 \text { players, about } \\
50 \text { non-players, about } 10 \text { organizers. } \\
\text { The narrative background of } \\
\text { Luxburg, the fictional world where } \\
\text { the characters went for adventures. } \\
\text { The ludic actors of game rules that } \\
\text { were a combination of DragonSys } \\
\text { rulebook and house rules as written } \\
\text { on the website fantasiewelten.de and } \\
\text { explained at the beginning of the larp. }\end{array}$ & $\begin{array}{l}\text { Data includes the invitation } \\
\text { pdf to Alcyon 15, the website } \\
\text { Fantasiewelten.de, the forum of } \\
\text { the website with threads about } \\
\text { previous Alcyon larps, field notes } \\
\text { in form of text and photographs } \\
\text { during the larp, and correspondence } \\
\text { and interviews with players and } \\
\text { organizers after the larp. } \\
\text { As a mode of inquiry, the selection of } \\
\text { data raises the question of whether it } \\
\text { could be otherwise, or if unexpected } \\
\text { actors were necessary. }\end{array}$ \\
\hline Agency & $\begin{array}{l}\text { Agency refers to the } \\
\text { "inertia" of the process, } \\
\text { which makes all actors } \\
\text { collaborate to make one } \\
\text { specific difference to the } \\
\text { network and the relations } \\
\text { between actors. }\end{array}$ & See example below. & \\
\hline $\begin{array}{l}\text { Role-playing } \\
\text { agency }\end{array}$ & $\begin{array}{l}\text { Role playing is pretending } \\
\text { a character living in a } \\
\text { shared story world, and } \\
\text { as agency it requires all } \\
\text { actors at a game session to } \\
\text { collaborate. To cooperate, } \\
\text { the relations between } \\
\text { actors sometimes have } \\
\text { to change to make role } \\
\text { playing work. }\end{array}$ & $\begin{array}{l}\text { To role-play the character Allanor } \\
\text { during a larp, I had to wear a } \\
\text { costume (material actor), behave } \\
\text { as if I were in the fantasy world of } \\
\text { Luxburg (narrative actor), and make } \\
\text { decisions according to the game } \\
\text { rules (ludic actor). At the same time, } \\
\text { the costume, fantasy world, and } \\
\text { the game rules had to change their } \\
\text { actions to cooperate. }\end{array}$ & $\begin{array}{l}\text { A trace could be the change of game } \\
\text { rules with house rules as announced } \\
\text { on the website of the larp, because } \\
\text { this change marks a ludic actor's } \\
\text { action to cooperate and make role } \\
\text { playing at the next larp work. }\end{array}$ \\
\hline Mediator & $\begin{array}{l}\text { An actor that cooperates } \\
\text { in role playing, but makes } \\
\text { a difference to the process } \\
\text { of role playing. }\end{array}$ & $\begin{array}{l}\text { In relation to a virtual reality } \\
\text { headset, the keyboard and mouse } \\
\text { make it difficult to operate the game, } \\
\text { because I do not see them since the } \\
\text { headset covers my eyes completely. }\end{array}$ & $\begin{array}{l}\text { A note after gameplay about the } \\
\text { disturbance, for example that the } \\
\text { keys are too small. }\end{array}$ \\
\hline Intermediary & $\begin{array}{l}\text { An actor that cooperates } \\
\text { in role playing and does } \\
\text { not change it. }\end{array}$ & $\begin{array}{l}\text { In relation to the virtual reality } \\
\text { headset, the room where I play the } \\
\text { computer game does not matter. }\end{array}$ & $\begin{array}{l}\text { Intermediaries sometimes reveal } \\
\text { themselves when looking again at } \\
\text { a game session. During the second } \\
\text { session, I ask if there are "invisible" } \\
\text { actions at work. }\end{array}$ \\
\hline
\end{tabular}


2.4.6 Situating the study. The principle to follow actors with disregard to what is out there might lead to the problem that some territory has been mapped out before. This was the case when I read Copier's (2007) dissertation on role-playing styles in online role-playing game communities. Her study draws upon Castells's (1996) network theory, and on some elements of actor-network theory. One element is Latour's inclusion of non-human elements, such as the computer code that represents characters on the screen in Copier's study. Another element is what Haraway problematized as a researcher's situated knowledge. With this framework, Copier (2007) examines the "contested relationship between instrumental play and role-play" (p. 46) in the online role-playing game World of Warcraft (Blizzard Entertainment, since 2004). With her study in mind, I moved to uncharted territory of other forms of role-playing games. Thus, my study complements Copier's work in three ways.

First, I chose three different role-playing games for an actor-network study. Copier (2007) embedded her study in the wider context of role-playing game culture. She informs about larp, tabletop role-playing games, and the (international) culture "to gain more insight in the contested relationship between instrumental play and role-play in WoW [World of Warcraft, an MMORPG]" (p. 46). MMORPGs (massive multiplayer online role-playing games) are video games in which often millions of players share one game world. My dissertation focuses on role-playing game forms other than MMORPGs and follows material actors to local sites different from hers (see Section 2.4.4).

Second, this dissertation follows materials, as the primary actors that I follow to three sites of role playing. While Copier includes non-human actors such as avatars, I follow materials as non-human actors, such as objects, things, and raw materials, to understand how role playing works (see Section 2.3.1). In this regard, the guiding question differs, because it is not concerned with understanding role-playing game communities as network communities but role-playing games as actor-networks of players, materials, and other actors.

Third, my study differs in that it draws upon actor-network theory as the primary theoretical and methodological toolbox. I engaged with literature on actor-network theory in depth, because studying materials required a rethinking process. Being familiar with role-playing games and the literature on role-playing games myself, I had preconceived notions about the role of materials as passive elements. As the guiding question of this dissertation aims to examine role playing as a process that involves heterogeneous elements, I needed to observe and write about materials as elements that change during a game from active to passive, which depends not on their essential properties, but on what collaborate with, and when. To observe and express these processes in writing, I did not rely on situated knowledge, but created a new vocabulary with actor-network theory. 
This is also the reason why I had to introduce some key terms of actor-network theory in advance, because they offer a language alternative to the one in use in the field of game studies (see Section 2.2).

During my field work between 2010 and 2015, the interest in game materials grew among game scholars, a moment which Apperley and Jayemane (2012) interpret as game studies' material turn. ${ }^{19}$ These studies differ from this dissertation as they rest on a hierarchical understanding of materials that respond to human agency, either because boxes exist to sustain a cultural meaning structure or because dice serve the player's experience and enjoyment of the game. Similarly, the community discourse among players and designers of larp rests upon a dichotomy between active humans and reactive, neutral, or passive physical aspects, most prominently approached in the thematic Knutepunkt book on physicality in larp, Crossing Physical Borders (Meland \& Svela, 2013). Scholars and role players have thus become aware of physicality, but what is left to explore lies beyond an asymmetric agency that considers the player as the means and end of any socio-material network. In the forthcoming Handbook of Role-Playing Game Studies, Deterding and Zagal (n.d.) summarize the common discourse when they state that it is the human who creates socio-material entities, because "social entities are groups of phenomena created by humans within and enmeshed in a human world." ${ }^{20}$ It is here that I situate my actornetwork study and suggest an alternative onto-epistemological way to understand role playing (see Chapter 1). As a result of introducing actor-network vocabulary, role playing is a social process that does not depend solely on human agency, but can include agencies that emerge from relations to/of/among non-human actors in general and materials in particular. The task is to trace inter-subjective as well as inter-objective processes. As every action leaves a trace even if it is "a thin trace" that appears "immaterial," the success of such an alternative study depends on revealing traces that show how role-playing games become in and by human and non-human actors (Latour, 2005, p. 208).

This approach is new to role-playing games but not to the wider field of game studies. Most importantly, Bogost (2006) bridged game studies with ideas related to actornetwork theory in his approach towards video-game criticism. Following object-oriented philosophy (Harman, 2002), Bogost (2012) discusses symmetric or flat ontology for the study of video games. In regard to network as a concept, Bogost argues against using the word network because it carries just another preconceived notion: "network" is

19 See Chapter 2.4.4 for studies of materials in (digital) games.

20 The quote is from the preliminary text version 1.0 (Summer 2015). Permission to quote was given by the authors. 
also anthropocentric. He introduces another term and continues the primal idea of actor-network theory that aims to deconstruct preconceptualizations and wonder if it could be otherwise. The idea of the network is per se not the problem, because network in the meaning of mode of inquiry transports a potential deconstructive agency. The reason why network does not work for Bogost and others might be historical. In the beginning, the network idea was helpful to deconstruct centricism, and it worked. Repeating the deconstructive idea of the network made it more and more into an institution itself: it became blackboxed. The deconstructive agency of the network idea became institutionalized itself. The way out is therefore not to repeat the word network, but to either introduce new concepts, such as Bogost's "tiny ontologies" (2012), or to introduce the word network and reflect upon this process. I opted for the second of these options, because it avoids adding new words. New words do not help, because any words reconstruct the problem of anthropocentricism despite their intention to avoid it, because any word is related to human agency, as it is the product of language. Language is anthropocentric, and the way out is to reflect upon this and provide an environment to let the deconstructive agency work. Thus, when agency emerges in relational processes, the deconstructive agency of "network" emerges when put in the environment. In this sense, the resulting study shows what happened to my understanding of role playing when I brought with me the deconstructive agency of network as a mode of inquiry to larp, mixed reality and tabletop role-playing games. I observed and was able to talk about previously invisible actors: materials.

\subsection{Conclusion, or a Vocabulary for Writing about Role Playing Materials}

The principle "follow the actors" is the primary methodological task of a researcher who wants to work with actor-network theory. When the researcher relies on this principle alone, it is probable that the study will map out familiar territory. This is not a hindrance, because any qualitative study relies on unique first-hand data and contributes to knowledge, but I decided to map other territory than previous studies, such as that of Copier (2007). I set up a question that guided me to uncharted sites of role-playing game networks. In order to contribute to the understanding of role-playing games, I decided to follow material actors and study their work in larp, mixed reality, and tabletop role-playing game networks.

At this point, I needed specific tools to select data. I drew upon the ethnographic tools of participant observation and semi-structured interviews to produce field notes and interview transcripts. Thus, I was able to provide traces that answered the guiding question, but I was not yet able to speak about the data. The words that role players and other 
researchers used were anthropocentric. The consequence was that previous concepts framed role playing as a process relying on human agency, such as the understanding of role playing as a mindset. On the one hand, these concepts helped me to learn more about narrative and ludic actors, but on the other hand these concepts blackboxed materials as passive or neutral actors. At this point, I needed to introduce the vocabulary of actornetwork theory to deconstruct concepts from role-playing game theory in order to build a set of "empty shells," a vocabulary that allowed me to write about what I observed during field work at the sites of larp, mixed reality, and tabletop role-playing games from 2010 until 2015. It is this field work that I present in the following chapters. 



\section{LARP}

It is 1997 and after school, I visit the local game shop, Fantasy World, in Aschaffenburg, Bavaria. The shop is full of books, board games, and what looks like clothes for a fantasy movie. Woolen capes, brocade robes, metal chainmail.

"What are these clothes for?" another customer asks the shop owner.

"These are garb for larp," the shop owner says.

"What is larp?"

"Larp is like reading a book, but you bring the book to life and you are in charge of how the story develops. You need garb to play the role of a character."

"Role playing is pretending to be a character?"

"Yes, and even more. Role playing is immersing into a shared story. You begin to feel like the character in a story. You are in charge, too. Instead of reading a script, you and others develop the story as you like. You have even real fights with safety weapons. Of course, there are rules, too."

"If role playing is immersing in a shared story and taking control of it according to rules, why should I care about garb?"

\subsection{Introduction, or Following the Garb}

This chapter examines how the costume as a material actor makes role playing work in larp. ${ }^{21}$ Most German larpers use the word "Gewandung" instead of "Kostüm" (German for costume). ${ }^{22}$ The word Gewandung marks a difference to the word costume, which is usually used in larp communities outside of Germany. As well as referring to this cultural specificity as drawing on the shared etymological root of the German Gewandung and English word, I use the English translation "garb" in this chapter. ${ }^{23}$

21 Some of the empirical results of this chapter have also been discussed in (Bienia, 2015).

22 Gewandung or Gewand derives from the Middle High German verb "gewanden," to put on clothes. Gewandung is still in use with festive, clerical, and medieval clothing, especially in the field of art history.

23 For a discussion of translating Gewandung, see the forum of leo.org dictionary (N., 2014). In her introductory book to larp as a hobby, Dahm writes more about the cultural specificity of the word Gewandung (2013). Larpers in the UK use "kit" as an inclusive term for clothes, make up, weapons, and personal materials. 
Role playing in German larp is about physically playing an individual character, either of one's own making or made by the organizers for the event. Instead of following a script, a larp provides a situation for players as a starting point. This situation is embedded in a shared story world and involves problems that players can solve in character. The story unfolds when players decide on the basis of their character whether to solve those problems or not. For years, German players role-play their characters at different larps which often continue a story of events. A continuing larp bears the name "campaign," such as the annual Alcyon campaign that began in 1996 and will run its 20th event in 2016.

Previous research has studied larp from different perspectives, such as game studies, sociology, or psychology (Deterding \& Zagal, n.d.). The studies have focused on different elements, such as narrative (story, character) and ludic (rules, mechanics) elements. It seems that materials do not matter when role playing is regarded as a process involving players pretending to be characters embedded in a fictional world and a set of rules for interaction. Although research acknowledges material elements and includes them to define larp as a form of role-playing game that is "based on the physical form of the simulation" (Montola, 2012a, p. 11), there are few studies that raise a relation between immersion and costume (Hook, 2012), and no studies dedicated to the physical or material side of larp. By excluding materials, research has reaffirmed the impression that materials are passive or neutral in the process of role playing. Role playing works because of narrative and ludic elements, or so it seems. If the definition of larp builds on materiality as an element of distinction, the question remains still unanswered, because the answer has to include narrative, ludic, and material elements. The problem is twofold. The ontological problem asks for understanding what actors become parts of role playing. The ontological aim of this chapter is then to examine how materials collaborate with narrative and ludic elements in making role playing work in larp. The epistemological problem asks for rethinking role playing in larp. The epistemological question is how to know what role playing is, an understanding that should include narrative, ludic, and material elements as active parts of role playing.

To solve both levels of the problem, the following section introduces the actor garb in German fantasy larp (Section 3.2). The guiding question is how garbs make role playing work in a German larp network. The central section reports the results of the study (Section 3.3). Finally, the summarizing section concludes the actor-network study of garbs in German larp (Section 3.4). 


\subsection{The Problem, or Stories and Rules are not enough}

The subsequent text sets up the situation for Alcyon, a fantasy larp (Invitation to Alcyon 15, Fantasiewelten e.V., 2011):

Alcyon is a typical Fantasy adventure larp with horror elements. We set a high emphasis on plot and action, i.e. this is no larp for those who are looking for a relaxed ambient larp! As usual there will be many battles during the night. The players are part of an expedition to uncharted territory in the Ostmark, more precisely in the Southern Drakensbergen. There are rumors that the cultists have an interest in this region, because of hidden artifacts.

The Alcyon invitation introduces narrative actors that set up the situation. In the fictional world of the Alcyon larp, characters join an expedition to the Ostmark. As this is part 15 of the series, the characters expect to face several groups who will be in conflict with their goals as expedition members. One of these groups consists of cultists who conquer in the name of a dreaming god from the star Alcyon. The invitation text promises interaction with focus on story development (plot) and action. During the four days of playtime, organizers push story development in certain directions by staging a chain of events. For example, on Saturday evening, a group of cultists try to kidnap characters. The organizers prepared this "plot element" with the help of non-players who enact nonplayer characters. A non-player character is "a character that-while roleplaying to keep up the illusion for other players-is not participating in the larp for his or her own larp experience but rather to fill some [crucial] role in the game" (Utbult, 2015). Organizers create and control the actions of non-player characters, such as opposing forces (cultists, bandits, etc.) and inhabitants of the world (kings, villagers, etc.). Following instructions instead of role playing freely, non-players pay less to participate. A couple days before the larp begins, organizers and non-players arrive at the location to prepare the place, distribute roles, and discuss the planned events.

The invitation above distinguishes Alcyon as a fantasy adventure larp with horror elements from other larp forms, such as ambient larp where players play the social life of their characters in a calm environment with few dangerous plot elements, such as cultist attacks. Still, ambience is an important part of any larp. The invitation to Alcyon $15 \mathrm{informs}$ about frequent battles during the night, which emphasizes the type of interaction during Alcyon: characters should expect danger around the clock as members of the expedition to the Ostmark. The link between night and threat of attack by cultists establishes the horror ambience for this fantasy larp. 
The invitation reveals several elements that increase the complexity of larp in general, most prominently narrative and ludic elements. The narrative elements include the fictional background of an expedition, a chain of events staged by organizers and nonplayers. The ludic elements include game mechanics that encourage role playing around the clock. ${ }^{24}$ The different elements make role playing in larp an interesting topic for research in different fields (Deterding \& Zagal, n.d.). Montola (2009, 2012a) analyzes further narrative and ludic elements and explains how they inter-relate as a structured social process. Role playing is in line with rules that govern the social interactions between participants, characters, and the story world. Following Heliö (2004), Montola explains that the structured social process works as a mindset. It allows a player to optionally use role playing as a method of game playing for any game. Thus, role playing is a mental process in line with a social structure that rests on different rules. ${ }^{25}$ Three rules define the foundations of role playing in games as a social process:

1) Role-playing is an interactive process of defining and re-defining the state, properties and contents of an imaginary game world.

2) The power to define the game world is allocated to participants of the game. The participants recognize the existence of this power hierarchy.

3) Player-participants define the game world through personified character constructs, conforming to the state, properties and contents of the game world.

(Montola, 2012a, p. 117)

These three rules (interaction with game world, power to participants, character agency) are one example for previous studies revealing narrative and ludic elements. The narrative elements include an imaginary game world and character constructs. Above, I have referred to these elements in terms of imagined story world and character. The ludic elements include the three rules as such and explain how both narrative and ludic elements construct role playing in a larp. In the example of Alcyon, players interact with

24 In Poland in the 2000s, it was common to stop a larp for the night.

25 Montola adds four further optional rules that differentiate different role-playing practices: character decisions are given to the player, decisive power beyond characters is given to game masters, process is governed by quantitative game ruleset, and there is a hierarchy of game world information. These four rules focus on ludic actors in more detail, but as they are "not necessary, but typical," I do not include them in this analysis on the same level as the first three rules (Montola, 2012a, p. 118). Furthermore, Montola introduces three additional rules to distinguish three different role-playing game forms. I have introduced Montola's distinction in Chapter 2.1. 
other players and non-players when they go on an expedition to the Ostmark. According to Rule 1, they define and re-define the state, properties, and contents of what happens in the story world. Players' interaction develops the story or the so-called plot. Rule 2 reveals how participants recognize a hierarchy between players, non-players, and organizers. Organizers set up the situation, non-players help organizers to enliven the larp, and players role-play within these boundaries. Rule 3 explains how players define what happens during the expedition in the Ostmark through their characters. Players roleplay a fictional character in line with the ludic actors that assemble the state, properties, and contents of the shared imagined world of Alcyon.

In 2011, I accepted the invitation, registered as a player and went to the Alcyon 15 larp. Together with a group of friends, I drove 300 kilometers to the location in Bexbach, Saarland. Four days of constant role playing awaited us. The following scene shows the narrative and ludic actors as I experienced them.

After the expedition headed off to the Southern Drakensbergen-after the men and women had endured a long march, after they had survived ambushes, after two sleepless nights full of cultist attacks-Allanor and his fellows search for their missing friend Gwynn. They have left the expedition camp half an hour ago. It is getting dark. A scream cuts across the sky. The four players go down into a crouch. The screaming stops. In the silence, ci-ci-ci-ci-ci, sounds a cicada. I am glad that I am wearing leather pants, because they are waterproof and the grass is wet. I smell earth, wet grass, and flowers. The moon appears between clouds. My friend Keldrahir waves. In front of us, on a hill, an altar surrounded by hooded figures. We have found Gwynn and his kidnappers. Several figures light torches. They chant.

Narrative and ludic actors help to explain how role playing as a mindset works in this scene. The narrative actors include the character Allanor, his friends, the kidnappers, and the fantasy world of Alcyon. Our actions to rescue a friend were in line with the ludic actors. The ludic actors included hierarchies between players and non-players, game rules to govern fighting, and structures for interaction to develop the plot, such as opposing parties. But being present at a larp during nightfall, I became aware of other actors that were part of the scene above: silence, screams, cicadas, moon, clouds, coldness, grass, wetness, earth, flowers, torches, and pants. These actors are not part of any definition of role playing as a mindset, because they are not mental in the sense of a cognitive function; they are not narrative or ludic actors, but material. The definition of role playing as a structured social process does not help me to answer the question of how materials co-construct this scene. The questions thus become: what material actors are part of larp, and how do materials relate to narrative and ludic elements? 
As Chapter 2 shows, previous research acknowledges the physicality or materiality of larp (Harviainen, 2012; Hitchens \& Drachen, 2009; Montola, 2012a; Montola \& Stenros, 2009). However, besides the function of materials for definition, materials do not play a further role in these studies. It seems that materials are neutral, or passive. Framing materials as neutral or passive helps studies aiming for a general answer or focusing on phenomena related to mental processes of players' experiences. But what happens when a researcher does an ethnographic study, goes to a larp and follows materials?

The cultists are gone. On the hill, on the altar, we find our unconscious friend Gwynn. Blood covers his face and bowels. Uru howls. Keldrahir heals. Elaine prays. "There is no time, we have to go," Nikolaj says, "and take any Alcyon artifact you might see." We carry Gwynn down the hill, over a meadow with unsteady ground, to our camp. Although Uru is strong and Gwynn is a light person, we have to change often. The distance, about one kilometer, seems longer. At least, it is after nightfall, the sun is gone. It has been a hot day. ${ }^{26}$

Narrative and ludic actors help to understand what happens. The kidnapping story continues in the overall plot of menacing cultists that roam the Southern Drakensbergen. Gwynn role-plays his character's suffering from wounds. Besides groaning, Gwynn is covered in theatre blood. The rest of us role-play the rescue mission by stopping his bleeding, such as Keldrahir with magic and Elaine with cleric spells. Then, we actually carry our friend over the terrain.

When I acknowledge the material side of this scene, I realize that there are different materials involved. When his friends carry Gwynn, the weight of a player turns from intermediary to a mediator that makes a difference. It is physical effort to role-play this rescue mission (narrative element) that is in line with the standard to role-play any situation (ludic actor). ${ }^{27}$ The location becomes part of role playing, because players have to take into account the hillside and uneven terrain. Replacing the location with an even asphalt street would make the scene less demanding to role-play. The location in relation to the weight of Gwynn being carried down "makes a difference" in the sense of actornetwork theory. The location is an actor. Moreover, an asphalt street would weaken the relation between the material and narrative elements, because we were role-playing in a fantasy world. This shows that without acknowledging materials as active actors, research misses understanding the complexity of larp on an ontological level.

26 As an aside, the use of kilometer is a trace for the perspective of participant, the player, who lives in a world of metric measurements.

27 One motto among players is "Spiel's aus, du Sau!" (Play it, dog!). 
It is not helpful to exclude non-mental elements from a study when short scenes like the ones above reveal material actors. But it is not enough to answer the ontological question about the role of materials in larp. The epistemological level of the problem is important, because it reveals an anthropocentric perspective on knowledge that previous studies of larp share and use to justify what larp is. Even if material actors are part of a definition of larp, it is easy to slip back and interpret materials as neutral or passive elements. When Montola (2012a) defines larp as a form of role-playing game that is "based on the physical form of the simulation" (p. 11)", he shows the benefit of integrating material elements to examine larp, but material elements do not play a further role in his work. For his study, simulation as the combination of narrative and ludic elements is interesting. Also Harviainen (2012) acknowledges the relation between the player's body as a material element and narrative elements, when he defines larp as a "type of pretence play in which body language and other non-verbal cues correspond to those of the characters during play" (p. 11). Similar to Montola, Harviainen is aware of material elements, the body that communicates non-verbal cues, but he does not examine materials as active actors in his study, because he focuses on players' information behavior. What about actions related to the body beyond language, such as the weight of a player being carried across difficult terrain? Again, it is not enough to treat materials as part of larp, when materials seem only to react to what people do. This leads to the epistemological question of how to know what role playing in larp is.

Thus, the problem of a lack of material studies has two levels. One level is ontological, because there is little knowledge about materials, and one is epistemological, because anthropocentricism requires me to reflect on how to know role playing in larp..$^{28}$ To solve this problem, I need a toolset that is wider than previous studies of larp provide. As one possible solution that tackles both levels, I suggest an actor-network study of German fantasy larp. Actor-network theory encourages analyzing both the epistemological and ontological dimensions of social processes (Callon, 1986a; Latour, 2005; Law, 1999). As I have explained in Chapter 2, an actor-network study requires empirical research that asks for observation, recording, and reporting action. In the next section, I solve this twofold problem by moving to specific larp scenes from different larps that I have participated in, such as Alcyon 15.

28 In the following sections, I will repeat ontology, epistemology, and the guiding question How does garb make role playing work in larp? I use these repetitions as a stylistic element to signal a link of new information to the main argument. 


\subsection{Results, or Material Work in German Larp}

3.3.1 A rhizome of actions. Allanor was part of an expedition to uncharted territory in the Ostmark during Alcyon 15. Besides other actors, role playing included the character Allanor living in a shared story world of the Alcyon larp (narrative actor), rules (ludic actor), and garb (material actor). But how do these actors act and become actors in the first place? The primary principle of actor-network theory is to "follow the actors", in this case a specific garb.

In the context of larp that involves physical performances, the word actor does not refer to the meaning of a theatre actor. An actor acts in and by its relations to other actors. Thus, I am interested in moments when the garb makes a difference to a larp (Latour, 1987). If making a difference is social, the garb acts in relation to other actors, such as the story world of Alcyon, game rules, or the location. The task of the researcher is to go to the field and record traces of actors interacting with other actors (Latour, 2005). For this study, I have recorded traces, such as observations, photographs, and interviews, from situations when an actor made a difference to other actors. The field work concentrated on five larps between 2010 and 2012. ${ }^{29}$

When is the garb an actor that makes a difference to role playing in a larp? I have spoken briefly about Allanor's garb above, when I wrote:

I am glad that I wear leather pants, because they are waterproof and the grass is wet.

The leather pants are an actor helping to role-play Allanor, because they allow me to crouch despite wet grass and cold ground. Allanor was a wizard; therefore I wore light fabric clothes, because in most fantasy worlds, wizards wear robes and other light clothing. I needed to adapt the light garb. If I had chosen fabric pants, I would not have crouched in the scene, because I would have been afraid of catching a cold. The rescue mission would have developed differently with different garb. This trace reveals how garb (material actor) and rescue mission (narrative actor) collaborated during Alcyon 15. Compared to other costumes, such as for cosplay, garb in larp has to represent a fictional character and has to function. While larpers usually wear garb for days, cosplayers wear costumes for few hours and often indoors in convention halls (Lamerichs, 2013, 2014). This difference allows different raw materials for costume making in cosplay. Cosplayers can use less sturdy raw materials, such as the thermoplastic Worbla. Bedder (2014)

29 See Chapter 1.2 for more details. 
recommends in her blog that larpers use Worbla for small parts and not for full armor, because armor made of thermoplastics is not sturdy enough for larp. For example, fighting in larp involves being actually hit with a safety weapon to make points, a difference to performing fights on a stage in cosplay. Despite the similarities, Worbla is one example how the materiality of garb differs from a cosplay costume. The functionality of garb goes beyond fighting or wearing it for a long time. When a player wears garb for several days and nights, garb has not only endure constant play, but also keep the player warm and dry during bad weather and in the cold of night. The garb as an actor demands functional raw materials that turn it into a stronger ally of the network. In relation to wet grass, the leather pants were a better material ally than fabric pants.

Garb acts before a larp starts, when it demands preparation. The invitation promised battles during the night. Although the larp took place in the first week of the warm June of 2011, I expected cold nights. I had to adapt the garb for waiting, running, and fighting during the night. Allanor's wizard garb was not suited for such situations, because I had chosen only light fabrics when I had made it back in 2006. One solution was to take garb parts of Mikal, my second character, which were the leather pants. Although leather does not fit the look of a wizard, the leather would protect me from wet grass and the cold. And it did. Knowing that I wore waterproof clothes encouraged me to crouch, walk through thorny bushes, and wait during night and rain.

At this point, let me follow Allanor's garb to places where larp is made, including other participants' garb. I deliver the analysis in a rhizome of situations, one situation per subsection. Presenting data in a less structured way, I pay homage to the rhizome, an image of thought by Deleuze and Guattari. Actor-network theory has drawn upon rhizome as a multi-centered network that exists and that is a mode of inquiry. At one point, Latour (1999) called actor-network theory actant-rhizome ontology. Presenting data in this style allows me two things. First, I represent data that follow the garb and focus on its actions. Second, a rhizomatic representation shows that there are multiple centers of a larp network. The next sections begin with the garb as an actor in the history of German larp, which began in the 1990s. I then follow the garb to different situations at different larps that I visited between 2010 and 2012. The situations end with me leaving the larp location in late summer 2012.

3.3.2 A short actor-network history of German larp. Allanor's garb provides an entry point into the network of German larp, because it has a history of its own. I had bought the leather pants for a different character: Mikal. Mikal was not a wizard but a hunter who specialized in monsters that inhabited the Ostmark. Mikal's garb consisted of the leather 
pants, metal greaves, linen shirt, a washed out gambeson, a necklace, and chainmail. ${ }^{30}$ If larpers enjoy role playing as pretend play-role playing is in its core to pretend to be someone who lives in a fictional world and who faces invented problems-why do larpers use metal greaves and chainmail made of metal rings? Is the use of authentic armor not counter to the experience of role playing as a mindset? The answer requires me to leave the leather pants and follow authentic garb, such as chainmail. Authentic chainmail faithfully resembles one form of historical chainmail. Thousands of metal rings form a shirt that is flexible and protects the wearer from damage. The chainmail leads me to the beginnings of larp in Germany.

The beginnings of larp in Germany relate to a commercial advance, despite historical forerunners (Harviainen, 2012; Montola, 2012a; Morton, 2007). In the early 1990s, the Drachenschmiede hobby shop in Cologne aimed to expand its business from tabletop role-playing games to larp. ${ }^{31}$ Fred Schwohl, one of the shop's owners, reflects in the German LARPWiki that the idea to organize a larp drew upon British and U.S. larp models. Drachenschmiede developed surveys among its customers to systematically test and introduce larp to the wider public as a new form of role-playing game in Germany (Schwohl, 2003). In August 1992, their first larp Draccon1 took place at Castle Starkenburg in Heppenheim an der Bergstraße. Although other role-playing groups experimented with larp-like forms of role playing in the early 1990s, 1992 can be considered as the beginning of German larp, because Draccon1 was the first commercial and officially announced German larp. Furthermore, Draccon1 significantly helped to promote larp with Drachenschmiede advertisements in computer game magazines (PowerPlay 07/1997), and a video made of this larp. ${ }^{32}$ It is tempting to see commercial interests as the historical cause for German larp, but Drachenschmiede (and later other hobby shops) was one actor in relation to a wider network that required at least two further actors to stabilize the larp network in Germany: independent role-playing game groups and the political situation of Germany.

30 A gambeson is a padded protective jacket. The gambeson also distributed the weight of Mikal's chainmail across my shoulders.

31 Tabletop role-playing games are similar to board games. Players sit together and role-play verbally, telling each other what the character does in line with an often sophisticated set of game rules. The roll of dice decides whether a character succeeds in the scene that a player describes. The first tabletop role-playing game Dungeons \& Dragons (Gygax \& Arneson, 1974) has shaped today's role-playing games and made the name 'role-playing game' popular. However, there are larp-like games that predate Dungeons E Dragons, such as Planet Atzor in 1941 (N., 1941). I analyze tabletop role-playing games in the third empirical chapter, Chapter 5.

32 The website of the film-making crew Midnight Entertainment, responsible for the first full-length larp documentary in Germany, provides further images and information: around 180 people participated in Draccon1, which took place on 7-12 August 1992 at Castle Starkenburg, in Heppenheim an der Bergstraße. The fee was 245 Deutsche Mark, which is about $€ 125$ (N., 2011). 
Role-playing game groups and the political situation of Germany. Those independent player groups were often playing tabletop role-playing games which they translated into live action formats. One of the members of such a group, Patrick Walter, explained that his Midgard group has organized "lives" twice a year since 1991 (Walter, Interview, October 13, 2012). Patrick's group experimented with the first German tabletop roleplaying game Midgard (Franke, 1981), and decided to perform the adventures of their characters for real. According to Patrick the idea originated in rumors about British larps after group members went to the UK and visited hobby shops. ${ }^{33}$ Similarly, other groups independently developed larp from the fast-growing subculture of tabletop role-playing games. These groups are still active and sometimes still separate from the visible larp community (Walter, Interview, October 13, 2012; Habakuk, E-Mail, March 6, 2013). ${ }^{34}$ When shops like Drachenschmiede began extending invitations to larps, separate groups had already shown interest and had some experience with this sort of role playing.

Some of these player groups had heard about role-playing games from Allied soldiers. After the Second World War, Allied Forces stayed in Germany, dividing most of the country into the Bundesrepublik Deutschland in the West and the Deutsche Demokratische Republik in the East. U.S. and British soldiers who were based in West Germany imported tabletop role-playing games and larp in the 1980s and 1990s. Some of these soldiers were members of the Society for Creative Anachronism (Habakuk, E-Mail, March 6, 2013). Founded in Berkeley in the 1960s, the Society blended fantasy with historical re-enactment, and is one of the origins of today's larp (Copier, 2007, pp. 58-59). Allied soldiers in the West played with Germans and role-playing games spread across the country. Re-enactment as a larp cousin was common in the U.S. where re-enactors focused on battles in the Civil War, but it was also part of leisure culture in countries of the Eastern bloc, among them East Germany, Poland, and Czechoslovakia. During their existence as satellite states of the Soviet Union, the communist governments restricted certain leisure time

33 Listed here are three possible sources for the rumors. First, popular larp events. For example, Treasure Trap was a live action role-playing game at Peckforton Castle in Cheshire, running from April 1982, and covered by the BBC show Blue Peter in 1982. See Hook on the history of British larp and Treasure Trap (Hook, 2008). Second, magazines such as GamesMaster, published on early larps in the UK; see September 1988 issue. Third, people from the UK and US moving to German speaking countries. Habakuk writes in an e-mail about early Dungeons \& Dragons tabletop groups in Zürich, Switzerland: "I was allowed to join a huge AD\&D group in Zürich from spring 1986 on: the initiator and engine: Ari (raised in California, USA) had all core books and miniatures from the US and was in contact with the larpers in Boulder, Colorado (there are still strictly structured four to six hours quest and a funny rule book, according to the game master accompanies the heroes in a black suit and a note book.)" (Habakuk, E-Mail, March 6, 2013).

34 One marker for different traditions is the different terminology. Patrick calls the activity simply "live" and told me in a conversation that he cannot get used to the word "larp." 
activities, but allowed the re-enactment of historical times (Roselt \& Otto, 2014). When East and West Germany reunified in 1989, re-enactment traditions from East and West merged with role-playing games. In the 1990s, one trace of this process became visible in the boom of medieval markets and the rise of Medieval Rock bands from former East Germany (i.e., Corvus Corax)..$^{35}$

Anglo-American role-playing games and re-enactment are actors that shaped German larp today. It would be a simplification to speak of one origin and of one coherent larp culture in Germany. The history of larp is a web of parallel inventions, re-inventions, and inspiration by earlier activities. Different traditions overlapped and interacted, such as re-enactment.

The merging of re-enactment and larp culturesin Germany explains the use of chainmail and other authentic garb components in larp. Re-enactment as staging a past event always relies on the making of authentic objects, clothes, and environments. Moreover, craftsmen and artists that provided medieval markets in East Europe joined the spread of medieval markets after the reunification of Germany. ${ }^{36}$ Suddenly, there was a supply of garb, weapons, and other objects. These products were of higher quality, because they fulfilled the authenticity standards of re-enactment. There was an infrastructure of shops for re-enactment that could supply people interested in medieval-esque fantasy larp.

In this budding network of German larp, garb became a busy actor. It was now an ally for players who were familiar with verbal role playing in tabletop role-playing games like Midgard or Dungeons \& Dragons. The garb as an actor represented the character's clothing, which had previously existed only in the imagination of tabletop players. The garb combined the narrative actor (imagined clothes) with the material actor. It became a node for role-players and re-enactors. Those interested in fantasy games gained access to the garb and do-it-yourself practices of re-enactment traditions in the West and East parts of Germany and Europe. Those interested in re-enactment gained access to fantasy role-playing games that fulfilled their standards of aesthetics, when garb followed the craftsmanship standards of re-enactment. When tabletop players experimented with larp in the late 1980s, some groups did not necessarily rely on sophisticated garb. There were different ways, for example, used to represent a chainmail. Someone could wear

35 Historical markets have existed in West Germany, too, for example the "Kunsthandwerkermarkt" (market of arts and crafts). Kunsthandwerkermärkte emphasized old craftsmanship with artists restaging historical processes of crafting. One example is the Kunsthandwerkermarkt \& Carillonfest in Aschaffenburg. Since 1987, it has taken place "in the historical ambience" of Schloss Johannisburg (http://www.kunstundcarillon.de/ Last access: 20.07.2015).

36 The Deutsche LARP-FAQ from 2002 suggests acquiring armor parts for a reasonable price from East European merchants (Wagner, 2002). 
a grey woolen pullover and stick a piece of paper with the word "chainmail" on it. ${ }^{37}$ As re-enactment relies on high quality garb, larp was not attractive in the beginning and required change. With the merging of both cultures, however, the larp garb improved when re-enactment invigorated the quality of larp garb and made larp interesting for re-enactors. Thus, the garb became a node, because it combined both groups in their interest for pretend play.

But it was not enough to know about the high standards of re-enactment to turn authentic garb into an actor in the German larp network. The garb itself needed a stronger ally.

“Only real armor counts." In this network of independent tabletop role-playing game groups and German history where East German re-enactment met role-playing games, an implicit expectation that players would use authentic armor ultimately seemed insufficient. Draccon1 helped spread the idea to use only real armor for larp, as the organizers and some players had already made authentic armor for themselves, such as plate mail or leather armor, thus combining larp with authentic garb. When the organizers distributed the first edition of the rule book DragonSys among participants of Draccon 1, the book did not contain any clarification about the use of authentic armor (Meister Habakuk, E-Mail, March 6, 2013). ${ }^{38},{ }^{39}$

The German larp rule book DragonSys is a combination of a point-based system with a widely defined rule set that players term "your character is able to do what you are able to do", a variant of "What You See Is What You Get" (German: Du kannst was du darstellen kannst, or DKWDDK). In line with DKWDDK the idea of wearing authentic armor made sense to participants of Draccon1, and in the first edition of DragonSys, there was no need to formulate the idea as a game rule (Weis \& Putzo, 1991). Although one of the Drachenschmiede owners wrote later that the idea to use real armor was intended to increase the sales and rental fees of "chainmail and other armor parts" (Schwohl, 2003), the idea predated early garb practices by the group of DragonSys authors (Putzo, Correspondence, 2015). At this point, it is an advantage to trace inter-relational processes instead of pinpointing one origin for the use

37 My wife told me one anecdote about a player who remembered the early years of German larp. Back then, his group used wooden sticks to bend their ears. The reason was to mimic elf ears, as elves have pointed ears in fantasy stories. The sticks helped to shape the ears. Today, players buy silicone elf ears from larp shops. They glue the ears on with Mastix, a special glue for skin. This change of allies to mimic elf ears permits longer role playing today.

38 "I send you scans of a first version of the DragonSys that I received during Draccon1" (Habakuk, E-Mail, 6 March 2013).

39 Draccon1 was the first official larp, although there had been earlier larps in Germany, for example the test run for the DragonSys rulebook at the ClifCon (Weis \& Putzo, 1991). 
of authentic garb, such as commercial or aesthetic interests. In order to support garb as an actor of larp, the German larp network had to include both earlier player practices, Draccon1 where these players wore authentic armor, as well as the economic idea of Drachenschmiede to support authentic garb. Nevertheless, this relation appears to have seemed insufficient in relying on earlier practices alone, because the next edition of DragonSys had to add a ludic actor as an ally to support authentic garb.

The following edition of DragonSys included the "only real armor counts" rule as part of the rule book (Weis, 2001, p. 54). "Only real armor counts" as a ludic actor combined the practice to use authentic garb with game rules and materials which strengthened the network, as it tied all actors together into stable larp network. The "only real armor counts" rule relates to fighting when a player is hit, for example with a safety sword. The DragonSys rule book quantifies damage into a point system and provides a corresponding point system for garb. According to the rule book, a successful sword hit deals one damage point. If someone wears armor, the player can ignore the successful hit according to the number of armor points as defined by the rule book. When the player is not wearing any armor, a hit with the safety weapon wounds the character. The player has to role-play the pain and according to the game rules, the player cannot move the wounded body part. Some players use fake blood to represent wounds, as in the sacrifice scene in Alcyon 15 above. DragonSys declares how many hits a player can ignore with what kind of armor. According to the DragonSys rules, fabric clothing has zero points, gambeson one, chainmail two, and so forth. When my character Mikal wore a gambeson and chainmail, his chest was protected by three points, one for the gambeson and two for the chainmail (Weis, 2001, p. 67). Thus, wearing these garb parts, I can ignore three hits during a fight, before Mikal is hurt.

This is a combination of ludic (points), narrative (wounded character), and material actors (sword, armor). This network distinguishes garb most clearly from other costumes. In cosplay, for example, costumes have at least two different functions. The costume represents a character, just as a costume in carnival, but a cosplay uses it for performing a character that can involve role playing, for example when being on a stage or posing for pictures. The difference to larp is the combination of actors. A cosplay costumes can use less sturdy materials, such as Worbla, but more important, cosplay costumes lack the relation to ludic actors, such as armor points in larp. It is this combination or network of actors that distinguishes garb. ${ }^{40}$

40 Lamerich's (2014) innovative work on cosplay uses the perspective of fan studies, while this study works with actor-network theory. Both studies are complementary and the results encourage further comparative research to examine the similarities and differences between the cultures and material practices of cosplay and larp. 
By making the ludic actor "only real armor counts" part of the game rules, the DragonSys rule book enrolled authentic garb in the German larp network. Since 1992, DragonSys has been the most commonly used rule book and has laid the foundation for following editions and other larp rule books. They all share the "only real armor counts" rule (Dombrowski, 2009; Hemmerich \& Hemmerich, 2007; Weis, 2001). Thus, DragonSys made authentic garb necessary in German larp with the game rule "only real armor counts."

If the intention to use the "only real armor counts" rule was to increase sales of "chainmail and other armor parts" for Drachenschmiede, as Schwohl (2003) claims, then the alliance between ludic and economic actors did not prove strong enough. The owners dissolved Drachenschmiede in the late 1990s. The Drachenschmiede shop became Hammerkunst at the end of the 1990s, and is now part of Mytholon Sales and Trade Company Ltd. Currently, semi-professional and professional larp material manufacturers share the market that combines larp and re-enactment. ${ }^{41}$ These shops are complemented by specialty item shops for other materials, such as masks (Ungebil.de, Maskworld.de), ambient conform tents (i.e., Sahara), and raw materials (i.e., latex and leather). The commercial interest of larp shops is influential, but that position is challenged by a maker culture with the tradition of do-it-yourself practices that are strong in Germany and other national communities, for example Nordic (Stenros, 2013) and U.S. (Simkins, 2015). One reason for making garb oneself is the tactile pleasure of working with materials. Self-made garb may increase social capital among the community, too. ${ }^{42}$ Thus, do-it-yourself practices lead to tensions with mass-produced materials, which is one reason for the economically instable market of larp materials. Another reason is the size of the hobby culture in Germany.

While the decentralist demography of larp complicates estimation of the size of German larp culture, the umbrella larp association D.L.R.V. estimates between 30,000 and 40,000 active larpers in Germany (Deutscher Liverollenspiel Verband e.V., 2010). According to the website "LARP Kalender," between 660 and 780 larps were officially announced in Germany every year between 2006 and 2011 (Wagner, 2011). ${ }^{43}$ Since the mid-2010s, websites that announce larps, such as LARP Kalender, have given way to social media

41 Other European manufacturers, such as Palnatoke (Denmark), work also on an international level and influence the German market through design, durability, and price of the sold materials.

42 Social capital is one of three capital forms distinguished by Bourdieu (1986) as "the aggregate of the actual or potential resources which are linked to possession of a durable network of more or less institutionalized relationships of mutual acquaintance and recognition - or in other words, to membership in a group" (p. 88). To evoke social capital, garb has to integrate raw materials that relate to the elements that players deem important, such as real metal.

43 The number of officially announced larps in Germany can be calculated from the LARP Kalender: in the year 2006: 663 larps; 2007: 722; 2008: 731; 2009: 784; 2010: 754; 2011: 706. 
sites, such as Facebook. This shift makes it even harder to estimate the size of the German larp community and to acquire quantitative data. One initiative to count larp on a global level is the Larp Census (Vanek, 2015). The authors are currently analyzing the census, but from preliminary data, the number of German larpers who took part in the census follows the number of larpers in the US, Russia, and the UK. Nevertheless, compared to a sold-out FC Bayern München match in the Allianz Arena with a capacity of 71,000, larp is quantitatively small. Thirty thousand larpers do not create the necessary economic potential to sustain a stable larp industry, as the bankruptcy of local shops, among them Drachenschmiede and Fantasy World, has shown in the past years.

In the pastyears, German larp created a special format: festlarp. Fighting in battle simulations has been popular among players, as seen in small scale adventure larps that hold battles both day and night, and more prominently at the so-called fest larps, such as Drachenfest since 2001, Conquest of Mythodea since 2005, and Epic Empires since 2009. Fest is an abbreviation for Schlachtenfest (battle festival), which emphasizes the amount of fighting and battle simulation during the larp, but also the size and length of this larp format. At Drachenfest 2015, 4,500 participants engaged in one week of constant role playing (Wyvern e.K., Diemelstadt, July 28-August 2, 2015). In the following week, about 7,500 players and non-players participated in Conquest of Mythodea 2015 (Live Adventure Event GmbH, Rittergut Brokeloh, August 5-9, 2015). At Epic Empires 2015, 1,300 larpers engaged in role playing at the larp location Utopion (Epic Empires Event UG, Utopion, August 12-16, 2015). The three successive fest larps allow role-playing for three weeks with thousands of other larpers every summer in Germany. The fest larp form has served as a way to promote battles on a massive scale and ambience play, both promoting the sale of real armor and further materials. The need for other materials than armor becomes evident. Fest larps not only promote battles, but also ambient role playing when they create a living larp town at each of the three fest larps. This requires further materials, such as tents, cooking and camping materials in line with the ambience of a fantasy world, and more. The relation between fest larp and larp shops continues from the relation between Drachenschmiede and the first officially announced larp Draccon1, as Conquest of Mythodea is organized by Forgotten-Dreams-Studio which also owns DeinLarpShop, one of the currently successful larp shops in Germany. As a result, garb prices have fallen due to the demand fostered by fest larps and shorter and smaller larps since the 1990s. ${ }^{44}$

44. A set of chainmail cost about $€ 100$ in 2006. Five years later, chainmail was available for $€ 50$ at Mytholon. Not all players were satisfied with the flood of qualitatively poor mass ware and showed this by coining the pejorative neologism "Mülltholon," a compound of the German word "Müll" for "trash" and "Mytholon." The shops responded to criticism from players, and quality improved while the price remained low. 
So far, I have followed garb as an actor that stabilizes the German fantasy larp network. "Only real armor counts" combined the garb with game rules, and this ludic-material relation worked well. Players have accepted the rule beyond the DragonSys rule book, because it was in line with the DKWDDK approach towards role playing in larp, and because it opened doors to new ways to role-play. Garb does not decrease the joy of role playing as a mental process. Role playing in larp combines the mental processes of role playing with tangible processes, because it combines actors such as narrative (shared imagined fantasy world), ludic (only real armor counts), and material (garb).

In the beginning of this chapter, I followed garb as a network of material actors, such as leather pants, chainmail, and others. This helped me to answer the ontological question of what a larp is. In this section, I have mapped the history of German larp by following garb as an actor. This helped me to answer how garb works with other actors to stabilize the larp network. What remains is the epistemological question, how to know about garb as part of role playing in a larp? For an answer, I need to follow garb as a network made of different actors, and trace its work in specific larp scenes. Besides participating in Alcyon 15 and 16, I went to the fest larp Epic Empires 2012. I observed the work of materials and spoke with players, non-players, and organizers about their opinions of garb as actor in larp.

\subsubsection{Role playing with garb}

Arriving at the location. The time between spring and summer smells of warm sun on leaves, leaves that glitter in the piercing light. I turn my car slowly to the right, leaving the main road of Bexbach, to the larp location. Some objects move on the back seat. The car is full, for just one person for one extended weekend. A tent, camp bed, blankets, canned food, bottles-and garb. Robes, shirts, pants, boots, safety weapons. The warm air in my car mixes with the smell of trees outside. It is a particular smell of leather, metal, foam, latex, leaves, grass, dust. I drive through the gate of the former military area. To the left, there are sanitary wagons. Looming over them on a hill, there are tents for non-players. People partly in garb.

The larps I have chosen for this chapter-Alcyon 15, Alcyon 16, and Epic Empires-took place at the larp location Utopion. Utopion is a former military training ground in Bexbach, Saarland. The German army left three buildings which have been renovated in recent years, mostly by voluntary helpers. They include a tower and two houses. The area around the two houses is chosen as the core for most larp events, as the organizers occupy the bigger Üb-Haus I, players camp in front of the building, and sanitary installations are 
in reach. The location spreads over about $107 \mathrm{ha}$, including forests, meadows, three stone pits, ruins of houses and of a mill. The owner Matthias Trennheuser emphasizes that under German law, exclusive domestic authority over a huge nature territory must be seen as an exception. In general, the authority of the forest official trumps the domestic authority. Trennheuser's motivation to negotiate these rights with the ministry was to assure the privacy of larps. Larps on his area would be less likely disturbed by outsiders (Trennheuser, Interview, 6.03.2013). In fantasy larp the presence of non-participants entering the playground tends to destroy the illusion of the shared imagined world. The negotiations between owner, law, and political parties responsible for Bexbach support role playing, because there is usually no non-participating audience in larp.

Utopion is intended as a "playground for larpers," as Trennheuser stresses (Bodenstein, 2012). Investments in sewerage, electricity, and further buildings permit events for 10,000 people. The biggest regular larp event, Epic Empires (2009-), was visited by more than 1,300 participants in 2015. Similar locations dedicated solely to larp exist in Canada (RAVEN LARP, Ontario) and Poland (Wioska Fantasy, Kunkowce; Kraina Pradziada, Opole).

The location Utopion is a material actor and becomes part of a larp network. The location provides a huge area with a great variety of terrain. It is outside the village of Bexbach, so there will be little disturbance from non-participants. The location itself is out of sight of train tracks, motorways, and other modern buildings. This helps players to immerse in fictional characters living in the medieval world of Alcyon and other fantasy larps. Utopion as location works together with the players' garb, but when players arrive at Utopion, they add further material actors to the location.

"The garb does not end with clothes." I park my car next to the ÜB-Haus I. There are dozens of other players walking around, unloading their cars and driving them away out of sight. My group has already arrived and I build my tent next to them. I will share the huge beige Sahara tent with two of them in the next days of Alcyon 15. The tent is for six people, but we all bring so many things that the space is barely enough for us. The garb occupies three of my four bags. In my travel bag are two robes, a shirt, a woolen cape, and two extra pairs of waterproof socks. In a plastic crate are chainmail, rusty greaves, gaiters to cover my modern but protective and waterproof military boots, and my brown leather pants that lack pockets and other signs of modern tailoring. A large blue bag carries the remaining parts of my garb: belts, leather satchels, a bottle of fake blood and two swords wrapped in cloth. The fourth bag contains the remaining canned food, empty coffee cans, some dry sausages, a can of ravioli, and bread. On top rests my two meter long staff. I will play Allanor. 
The description above shows that there are additional material actors to be considered. To role-play a character, players take care of details beyond the garb as a piece of clothing alone. The materials that become allies of the larp network include camping equipment for temporary accommodations, food, and the tent. Rouven Porger, player at Alcyon and organizer of Dunkle Pfade, explained that these materials are part of the garb network, too:

The garb is basically everything. From your hat to the tent and to the place where the tent stands. In my opinion, the garb does not end with the clothes. Every little detail that you consider, everything that you add, and everything you cannot leave like it is, adds a little more realism to the whole ... then every small detail makes it a little bit perfect, makes it simply more beautiful, makes it complete. (Porger, Interview, 6.08.2014)

The tent, the place around the tent on the location Utopion, they all are collaborators in role playing. It is not enough to wear garb when a larp runs for several days and nights. Players have to take care of their bodies, and activities as sleeping and eating become part of the larp network.

I have observed different ways how to integrate these activities to role playing. Most players cover modern camping equipment to support the illusion of an existing fantasy world. Some do not use plastic bottles and food containers outside the tent. They use "ambient dinnerware," meaning that it fits the medieval world. Instead of plastic or china, some players use rough pottery cups and plates. These are just a few examples of adjusting the tent and its surroundings. The aim is to increase ambience by decreasing signs of modern life, including accommodations and the need to sleep and eat. ${ }^{45}$ Thus, the material actors that make role playing work include the garb as a network of clothes, accommodations, and the location.

"Individual garb is the Alpha and Omega." The garb used has to fulfill the demands of narrative actors to represent an individual character. If players follow the alliance with

45 The sanitary wagons next to the entry to Utopion are further actors. Hygiene becomes an ally of the larp network, because the owner of Utopion, Trennheuser, decided on sanitary wagons with the largest available space. Players wearing chainmail, capes, and other garb need more space to move inside a toilet (Trennheuser, Interview, 7.03.2013). The sanitary wagons that are at the major camp site have been covered with panels of wood. This wooden screen helps to preserve the illusion. Sanitary wagons outside the major camping area stand on the main road leading through the area. They are at a point where the street goes between hills. Thus, the wagons are out of sight. The way to the toilets is usually out of the game. Players cross their arms to signal they are heading in this direction. The illusion ends inside the wagons, which is considered as a time-out area. 
the "only real armor counts" rule and buy armor at larp shops, another tension arises. This is the tension between mass-produced and self-made garb, and the reason is a material requirement for the garb to work.

When the garb as a whole relies too much on mass-produced parts, it loses the ability to represent an individual fictional character. Player characters in larp are individual. ${ }^{46}$ It is possible to use narrative elements from different sources, but a player should not role-play a known character, for example Gandalf from The Lord of the Rings novel. The reason is the same as for the garb. When garb and characters are not individual, it is possible that the same character can appear at a larp wearing the same garb. As one aim of larp is to create a shared imagined story world, two identical characters would break the illusion. ${ }^{47}$ To make role playing work in a larp, it is necessary that players have individual garb that represents an individual character. Two organizers of Epic Empires and Alcyon emphasized this point in an e-mail: "In our opinion, individual garb is the alpha and omega of good role playing" (Hess \& Blomann, E-Mail, 14 June 2011). Thus, the individuality of a garb is the most important element.

If larpers value individual garb as important, it explains the tensions between those who scorn mass ware and those who buy armor because of its affordable price. A compromise can be seen in sharing do-it-yourself practices. Users of social networking sites for larpers, such as larper.ning.com, give advice, for example in "making-of" photo series.

Garb in German larp has improved over the years, because it has combined developments in mass production with do-it-yourself techniques. Identical sets of garb provided by one supplier contradict the idea of the representation of a story world, because when all garb looks the same, the players do not succeed in representing individual characters. The aim is again to be as close as possible to the imagined story world. This connects to the idea of "Ambiente" (German for "ambience"). Players who aim at "Ambiente-Spiel" (ambient play) are interested in role-playing their character's social life in an atmospheric surrounding. They emphasize the details of materials, as Rouven said: "every small detail makes it a little bit perfect, makes it simply more beautiful, makes it complete" (Porger, Interview,

46 This is another distinction to Cosplay. In Cosplay, people imitate an existing character from pop culture that Lamerichs examines as an intermedial practice (Lamerichs, 2014). In German larp, in general, characters should be individual, even when players use some elements from existing characters. There are exceptions, especially when organizers use non-player characters in larps that happen in an existing story world, such as the Song of Ice and Fire or Harry Potter. A comparative study is needed to examine further similarities and differences between such non-player characters in larp and cosplay.

47 Unless it is a part of a doppelgänger plot, for example in a dream scene. 
6.08.2014). The garb is one actor among accommodations, food, and other materials that represent a character's daily life. To reach a high level of ambience, every material has to look as if it was part of the chosen story world, in this case a medieval fantasy world. This work creates a stable material-narrative relation. Moreover, those materials have to allow interaction. It should not only appear to be an object from the fantasy world, it has to function. Anything that players see and interact at with at a location is part of the larp. The preparation of the location decides whether interactions support the representation of the story world. A dummy works less well in this regard.

Parts of the Nordic larp community upheld ambience as a larp design ideal (Koljonen, 2007; Waern, Montola, \& Stenros, 2009). The goal of the " $360^{\circ}$ illusion" is to "to fill the mental space left by receding imagination" with material actors that minimize players' mental work of pretending (Koljonen, 2007, p. 180). In this regard, the location takes part in role playing, but demands preparation work from organizers. As an aesthetic ideal, the $360^{\circ}$ illusion should be frictionless. Frictions, however, are necessary to establish any perfect illusion. The Utopion area is huge and it is difficult to recognize what is intended to be part of the game. How do materials help to distinguish what is a ludic actor that relates to the goal of a plot? The goal could be a hidden artifact that gives the cultists their power and the expedition might need to find it, before the cultists do during the larp. How to find such an object within an area of over 100 ha? Organizers prepare the location by spreading hints, and these hints might look like something that is part of a medieval fantasy world, for example a roll of parchment with a hand drawn map. It cannot be trash left by a person from Bexbach nor can it be something the military left. Players recognize the parchment as part of the game, a ludic actor, because it fulfills the aesthetics of a medieval world so well and fits the ambience. Players accept locations and garb more easily when they see that there has been work done. Therefore, role playing is not solely about immersing, but also about carefully constructing or weaving materials and making traces of this work visible. Garb fulfills the demands of ambience to the level of a $360^{\circ}$ illusion, because it demands work and shows this work. When this demand is fulfilled, garb also becomes individual. One way to achieve individual garb in line with a recognizably constructed ambience is modification.

Modification. During the Role-Play Convention 2012 in Cologne, I met Frances, whom I had known as a non-player from Alcyon and Epic Empires larps since 2010. Excitedly, Frances showed me a metal helmet she had bought cheaply from one of the larp shops. Frances was less excited about the affordable price than about her ideas to modify the helmet in order to fit her non-player character. Three months later, I played at her side during Epic Empires 2012. She wore her new helmet, which had been painted green. She had also stamped her leather quiver with a green comet, a symbol of the invaders from the star Alcyon. 
Modification is a creative, do-it-yourself practice, also known in other game cultures (Sihvonen, 2011; Sotamaa, 2010). Modification in larp is interesting for several reasons. First, mass-produced materials are not considered conducive to "good role play" by some larpers. I have elaborated upon this point in the section on garb as the alpha and omega of role playing. Mass-produced garb does not represent everyone's individual imagination of how certain garb should look, because mass ware is standardized in order to sell high numbers of the item. Second, Frances translated her creativity into the new helmet by modifying it according to the campaign's given aesthetics. Green is the color for the Alcyon cultists and the comet is one of their signs that non-players wear on garb. These aesthetics are part of the story world that Fantasiewelten has developed and the Epic Empires organizers use. ${ }^{48}$ Modification allows individualizing items that resemble the character better, with less effort than making garb that requires extensive work. For example knitting chainmail is comparably easier to do than forging a hauberk which requires further skills in metal working and the right equipment. ${ }^{49}$ Third, because of the modification, the item is bound to a specific character. In Frances' example, the helmet is bound to a specific narrative and to a non-player character. It is exceptional to create game materials for a generic non-player character of one specific campaign only, as larps are usually played annually and the actual playtime is relatively small for such an effort.

Garb collaborates with dirty actors. A new tunic from a larp shop is a weak ally, because it bears traces of industrial textile manufacturing. Lars, the player of Gwynn, made me aware of why new materials were a problem. "The clothes of a character, who is travelling for weeks, do not look like they are new" (Lars, Correspondence, 19.4.2010). The problem is the relation between the new garb as a material actor and the narrative actor that tells the story of a travelling character in a fantasy world without textile manufacturing, washing machines, and clean travel by car or train. The solution was to "make them used, tear some parts apart, and apply Larp Dreck" (Lars, Correspondence, 19.4.2010). "Larp Dreck" (German for larp dirt) is a term that describes a practice of making new materials look used.

There are different ways how to achieve this, depending on the effect and the material. Before going to a larp, a player can distress leather parts by using sandpaper and emerizing parts of the garb that stick out, such as the elbows, knees, or edges of cloaks. At the

48 The reason for this connection is that Fantasiewelten e.V. and Epic Empires Event GmbH share a part of the organizational team.

49 Many larpers knitted chainmail in the early years of larp in Germany. When I visited the Fantasy World shop in Aschaffenburg in the late 90s, one of the owners told me about a friend who knitted chainmail during lectures at university. 
location, the player can take some earth and smear it on shoes, pants, and cloak. After a larp, the player can decide not to clean and polish metal armor. Soon a light rust film will cover the metal. Larpers share do-it-yourself tutorials that explain how to achieve a used look without ruining the impression by overdoing the process or applying Larp Dreck on wrong parts of the garb..$^{50}$ In this process, Larp Dreck combines garb with the time that passes between larp events in the story world. As Lars said, a character travels in the story world for weeks before reaching the fictional place that a larp location represents. With Larp Dreck, garb represents this narrative.

Larp Dreck serves the ambience or $360^{\circ}$ illusion ideal, because the garb appears more realistic in terms of showing a character's life span. Visible traces of use fit the narrative background of a battle-worn character. Not everyone uses this technique, as the garb gets used with play time anyway. Fights leave scratches on armor, chainmail rings are torn away, and equipment breaks. Both actions change the material-material relations of a garb. Traces of wear become part of the garb, whether they are artificial like Larp Dreck or are acquired through wearing the garb. The changed materials let the garb tell of the character's past. Scratches, for example, might tell of a wild monster that the character has survived. These traces are a relation of material and narrative actors. As they are visible, traces of wear evoke the impression of a world where time shows itself-sometimes with help of Larp Dreck. To create traces of wear, there is a third option that involves previous owners of materials that become part of the garb.

Recycling. Players do not create garb and leave it as it is for all future larps. The garb demands changes when a player wants to express the character's progress during a life of adventures. For years, players role-play their characters at different larps which often continue a story of events, the so-called campaigns.

Before and after a larp, players change the garb to express the growth of a character or simply because some garb parts get broken. When players play larps for a long time, there is a curious change in thinking about everyday things. Players begin to think twice about throwing away objects, because these materials could help them to improve the garb.

Players chose to recycle materials, because recycled materials are more apt as garb parts. Recycling includes everyday objects, such as dinnerware, and clothes. It also includes

50 The LARPWiki entry on Larp Dreck suggests several techniques to achieve this goal (Online: http://www.larpwiki.de/LarpDreck. Last access July 29, 2015). 
secondhand objects. Beside flea markets, there is another source for such things in Germany: Sperrmüll. Sperrmüll is bulky waste, but in Germany it has a further meaning. To get rid of old bulky objects, such as leather couches, people can drive to a recycling center or call the city to pick up their Sperrmüll. Sometimes, the city announces a day for Sperrmüll, meaning that numbers of households put their bulky waste on the street. Before city workers pick up the items, people may take what they need. For larp, Sperrmüll is a great source for used objects that they can recycle.

I sit in the home of Uli in 2010. He explains to me how he made his armor for his orc character Gransh. "You see these leather parts between the metal? I got them from an old couch lying on the street for Sperrmüll. I took my pocket knife and cut off some parts. It was raining, but it was worth it. These parts are great, because they are free and they are not new. I didn't have to make them looking old to fit the rest of the garb, because a generation of people used the couch and made the leather soft and supple."

Whether Sperrmüll, secondhand shops, flea markets, or old objects destined to be thrown away, players who are part of the larp network think carefully about materials. Players may recycle just about anything to create their garb, as in Uli's case with the leather couch, or to modify parts of the garb.

"Clothes have nothing to do with role playing. ..." "Clothes have nothing to do with role playing. Clothes are about money, the personal standard, and skills. This has nothing to do with role playing" (Tobi, Interview, 30 August 2012). Tobi, one organizer of Epic Empires, explains that good clothes depend on money that players spend on the garb, a player's standard towards the quality of the garb, and the skill to make, modify, or arrange different garb parts to create individual garb. However, Tobi adds: "We try to find a combination. We have always tried to find a good role player to whom we can give good clothes." Tobi and his team of organizers look for a combination of good garb and good role players when they prepare a non-player character.

These statements seem paradoxical, but only if one looks at garb as the sole center of role playing. Then, garb is either the alpha and omega of role playing or has nothing to do with role playing. But the point is, as Tobi elaborates, that garb is not responsible for role playing alone, because it is the "combination" between garb and players that makes role playing work as a collaboration or inter-relational process.

The collaboration demands good garb and a good role player. In order to be a good role player, the player needs training. As the history of German larp and the previous sections 
have shown, larp in Germany is heterogeneous and there are few standards that players share. Usually, players learn through experience from their fellow players. Good role playing is subjective to each player and differs from group to group. Organizers like Tobi have a subjective understanding, too. "According to my understanding, we try to play a role in larp, as the name already says. But we also try to create a fantasy or a second reality during playtime. There are different approaches to achieve this" (Tobi, Interview, 30 August 2012). The network as a mode of inquiry provides here an alternative understanding to the idea that garb is either everything or nothing to role playing. "Good" garb makes role playing work when it collaborates with narrative (character), ludic (game rules), and other material actors.

The actors garb and player change in this relation to become "good." The garb develops with the growing standards of the larp community on garb, as the previous sections have shown with the development of garb production, mass production, and modification. ${ }^{51}$ Larp does not work because of one actor or one approach or one way to role-play. The garb demands for its collaboration that players improve role playing as a process that includes different actors. To understand how role playing works, and how the "different approaches" become part of a specific larp, it is important to keep in mind a multi-centered network that shows larp as a collaborative work process between actors with different approaches, standards, or ideas. The understanding of larp as a network is similar to what Tobi referred to with "different approaches to achieve" good role playing. Tobi said that role playing in larp is a combination. By following garb, it is possible to examine the relations that combine the garb and a player's idea of how important garb is. And while most players learn through experience, the work of garb explains how "good garb" streamlines experimental role playing. Allied to the "only real armor counts" rule, garb demands certain ways that players should role-play in a larp. This demand emerges from the relation between the ludic actor ("only real armor counts") and the material actor (garb). The ludic-material relation exercises a process that gathers certain actors and governs how these actors work together. Understanding this as the mode of inquiry, it is possible to examine how the garb operates on an ontological and epistemological level. The garb works only when it is not central (clothes have nothing to do with role playing) despite its important status (alpha and omega). The garb is neither an actor nor a network, because it oscillates between actor and network the entire time as it makes role playing in larp work. ${ }^{52}$

51 In the context of decentralizing garb as actor in larp, there is a comparison to be made with a larp tradition that seems to abolish garb. The so-called freeform and certain Nordic larps avoid the effort of costuming (Stenros \& Montola, 2010; “The Games of Vi åker jeep / We go by Jeep," n.d.). Or they reduce the effort to a minimum following the Dogma99 manifesto (Fatland \& Wingåd, 2003).

52 See Chapter 2. An actor gathers further actors "behind" it and it is the researcher's agential cut to name the element an actor or network. 
The players play their roles or characters, the organizers create an imagined story world, the garb collaborates when it develops, and the larp network develops with all of them. Thus, decentralizing the actor garb for role playing is in line with both player statements that emphasize a combination of garb and role players along with the network. Garb has nothing to do with role playing-alone.

Weight. The relation between body and clothes works not only on the side of the material used, but also on the imagination of the player. With different clothes, a person thinks differently as the body adapts to the materiality of, for example, a corset or high heels (Entwistle \& Wilson, 2001). As well as clothes, garb works on the material and the imaginative side. When I wear my chainmail, my movements change, because it weighs nine kilograms. It is like carrying nine full water bottles attached to the upper part of my body. Wearing the heavy chainmail, I move like a different person. It is easier to imagine being someone else with this changed bodily experience of wearing chainmail.

The additional weight makes me think twice about what I will do during role playing. As a larp is constant role playing for several days, this means wearing nine or more kilograms of garb the whole time. Chainmail demands a price and I can only pay it according to my constitution. Will I walk again to the shrine two kilometers away? Will I run after a fleeing cultist? These are examples of the decisions that players make during a larp because of the garb. Additionally, these decisions are two traces of a material-material relation between body and garb, a relation that influences what players do during a larp. Consequently, the weight influences role playing and how the narrative develops. Wearing chainmail weighing nine kilograms evokes different role-playing actions than wearing a robe, but role playing emerges always in relation to a bodily experience that includes the garb. The garb reshapes the relation between the material actor body and the narrative actor character when it adds weight, thus the garb works materially and mentally.

Garb collaborates with death. Garb collaborates with the "only armor counts" rule and with Montola's (2012a) three rules of interaction with the game world, power to participants, and character agency. Montola shows how the three rules explain the narrative-ludic processes, but materials are not part of them. There are traces, however, of how the garb as a material actor makes a difference to this narrative-ludic process, because this ludic actor governs when a character dies. These traces of this narrativeludic process show how a ludic actor has changed within the network of German larp.

Game masters in most fantasy larps do not wipe out characters despite the intensity of battles and the size of non-player armies. In the battle-intense fest larp Epic Empires, 
for example, a killed character resurrects at a safe place where its wounds heal. The reason why characters do not usually die in the common and frequent battles at most larps is that players invest much effort to create individual garb and the character's background history. In our interview, Patrick explained that the materiality of garb might be responsible for bending game rules about character death and the scope of possible narrative outcomes of role playing (Walter, Interview, 13 October 2012). The network of narrative and ludic actors has changed with better garb-better in sense of detail, individuality, and functionality-, because better garb requires more effort.

The effort to create and change one's garb during years of play can be enormous in regard of time and money. This effort changes the rules about character death, because it shifts the control over life or death from game masters to players. To achieve this, a new rule has been formed. Instead of following the DragonSys rules that demand players to count seconds until their wounded character bleeds to death, more and more larp organizers use the rule "Opferregel" (translated here as "rule of the victim"). The "rule of the victim" is a rule in which the player decides upon the character's "perma-death" (Drachenroester, 2012). Perma-death is the permanent death of a character within the story world. Permanent character death is particularly important to the design of video games, as it differentiates the levels of time penalty and influences the scope of interactions and game play experiences (Wenz, 2014). In larp, the decision regarding perma-death marks a shift of ludic control towards the player and away from other participants, such as nonplayers, other players, and above all the game master, who serves partly in the function of referee. This aligns with the fact that players usually regard characters as property. For example, common larp jargon uses "my character" instead of "the character." The feeling of property is illusory, because it rests upon a relation between the player who takes care of the garb, game rules that favor the "rule of the victim," and the garb that demands further investments that became more and more demanding over time. Perma-death of larp characters in German fantasy larp is rare and this material-narrative-ludic relation is one mediator that influences plot design and what might happen during role playing.

The spread of "the rule of the victim" influences a further narrative actor and the possibilities to experience narratives in German larp. Fantasy as the genre of choice has become an obligatory passage point of larp in Germany. An obligatory passage point prewrites the negotiation between actors, because it requires being part of work in the network in general, and being part of role playing in larp. Twenty five years of German larp has provided a wide range of sophisticated game materials, modified rules, and a community in favor of fantasy narratives that have all been changed step by step to cater to the specific requirements of the narrative actor fantasy genre that has become an 
obligatory passage point for larp in Germany. It is easier to participate in a larp when it is a fantasy larp than a larp that uses a different fantastic genre, because fantasy larp requires less effort in time and money for new and old players alike to role-play and establish a stable network which sets up a shared imagined fantasy world. Garb becomes cheaper, players can create individual garb more easily due to a culture of do-it-yourself tutorials, and players can often borrow garb parts from fellow players, because such parts are in abundance. This development explains why most officially announced larps follow the fantasy genre today, as can be seen in the disproportion of about eighty percent fantasy larps to twenty percent that cover science fiction, horror, Western, and post-apocalyptic settings (Wagner, 2011). ${ }^{53}$

The rule of the victim shows how the garb as a material actor makes a difference in the narrative-ludic process of a specific larp event and of German larp in general. First, "the rule of the victim" shows how material actors relate to narrative and ludic actors and how they shape collaborative processes. Second, the better the garb becomes, the more it limits role playing as mental work according to Heliö's mindset and Montola's three rules. Players have to integrate material work when they want to define and re-define "the state, properties and contents of an imaginary game world" according to the first rule (Montola, 2012a, p. 117). But in order to follow this rule, players have to take into consideration their garb. When Frances wants to role play an Alcyon cultist, she has to interact with the imagined story world of an Alcyon larp according to the background narrative, the game rules, and this requires that she wears a garb in line with the aesthetics of the Alcyon cultist clothes. Moreover, the materiality of garb relates to economic reasons and the practice of distinguishing individual characters with individual costuming that requires custom-made pieces or modification of the original material. The economic development had a homogenizing effect on German larp culture in past decades, while the do-it-yourself attitude challenged and pushed this development further. The point is that the more larpers invest in garb in time and money, the less players are willing to let their character die, because they lose the character's social connections within the story world to other characters, the character's experience, and the individual character is at the same time the individual garb. Garb expands and limits role playing when garb as a material actor constructs or deconstructs relations to narrative and ludic actors, for example perma-death. Thus, garb is part of the processes that make and shape role playing work in German larp. Contrary to the understanding of role playing as a separate mindset in games, an understanding of role playing as a human agency, and a

53 When I asked participants of the larp convention MittelPunkt in 2013, several senior members of the DLRV larp association reaffirmed this proportion. 
preconceived notion about either narrative or ludic elements, these processes have to be seen both mental and physical, human and non-human, narrative, ludic, and material.

\subsection{Conclusion, or an Actor-Network Study of German Larp in the 2010s}

After Epic Empires 2012, I carry my four bags back to my car. While driving slowly between the hills at the entrance, I shout good-byes with a raspy voice. I have been screaming spells and commands as well as shouts of pain to inform my opponents about their successful hit. The rest of my body aches, too. When I leave Utopion and turn my car to the left, I am back to the main road of Bexbach. The air in my car will smell for the next three hours like larp. Camp fire, earth, sweat, and warm latex.

The task of the study was to examine how garb makes role playing work in German larp. The study shows that the common goal of actors is to make role playing during a larp happen. Role playing is an inter-relational process that involves heterogeneous actors, which explains why players, organizers, and researchers define role playing in larp differently. Tobi, organizer of Epic Empires, mentioned different approaches and named the creation of a second reality, which has been analyzed in role-playing game studies with concepts such as immersion (Balzer, 2011; Harviainen, 2003; Hopeametsä, 2008), information system (Harviainen, 2012), or frame analysis (Stenros, Waern, \& Montola, 2011).

Though previous research can explain how role playing works in larp with different elements that seem important to players, organizers, and researchers, studying materials with actor-network theory is important, because it reveals that previous explanations share a twofold problem. The ontological level of the problem was little knowledge about material actors. Although players, organizers, and researchers acknowledge that materials are part of larp, the question remains how materials relate to narrative and ludic actors which were the focus of previous research. On the epistemological level, the problem was an anthropocentric view on larp in previous studies. Studying garb with actor-network theory invites us to rethink role playing in larp in order to reflect what is known and how it is known. This study suggests understanding role playing in larp as a process that involves human and non-human actors alike such as narrative, ludic, and material actors. When these actors collaborate, the larp network becomes stable.

In general, the results of this study indicate a shift from role playing as a process that human actors cause to a process that involves human as well as non-human actors. This distribution of work makes a dichotomy between human and non-human irrelevant as 
a precondition to know larp. A larp unfolds as a network of players, organizers, and producers of game materials, as well as actors such as leather pants, chainmail, wet grass, cold earth, and more.

The results of an actor-network study are difficult to generalize, because such a study draws from an empirical case of a local phenomenon. This study allows a general perspective on some results, but it has to be kept in mind that these results tell about three German larps at the location Utopion in Bexbach between 2010 until 2012. As the aim of this chapter was to solve a twofold problem, the ontological and epistemological results are the following.

Ontological results. The first aim of this study was to examine how garb as a material actor collaborates in a larp network, and what garb demands for its collaboration.

Larp works when the garb contributes to role playing. The garb does not contribute if it does not relate to the shared story world (narrative actor) and the game rules (ludic actors).

The garb contributes when it changes the relational work of material actors that connect the garb as part of the overall larp network. To fulfill the demands of the network, the making of garb develops. Material work reveals itself in the different ways in which the materials make other actors act in a specific way, as was traced in the examples of mass production, modification, and do-it-yourself practices.

For its contribution, garb demands changes from narrative and ludic actors as well, and the result of these negotiations is the development of a larp network. The network stabilizes as it seems to mold itself around the garb demands rather than demanding, for example, that players follow a rule book for the exact formulation of armor points. Another example was the stabilization of the garb-genre relation that led to fantasy as an obligatory passage point in German larp.

The observations of the three larp networks resulted in this study, which reports how the development of German larp is interrelated with garb. Traces of this inter-relational work were, for example, the material-material relations that aim towards more ambience or $360^{\circ}$ illusion with modification of materials; material-ludic relations that aim away from a point-based systems to a "what you see is what you get" game mechanics that relies more on garb than on armor points; and material-narrative relations that raise the popularity of one favored narrative genre: fantasy. 
Epistemological results. The second aim was to contribute to how to understand role playing with an alternative understanding of garb as collaborator in a larp network. The results of this study indicate that materials are moving and acting according to the relations they make with other actors. These relations work beyond preconceived dichotomies of human/non-human or material/non-material. By following the garb and analyzing qualitative data, this study has shown how garb collaborates in relations beyond such dichotomies. Looking at garb beyond preconceived notions that consider non-human actors as passive or neutral, this chapter aims to expand the understanding of game materials in larp in general. Taking this alternative understanding as a starting point for a study, the understanding of how role playing works in the field of game studies grows. An actor-network study expands the understanding, because it looks at larp as relational processes and invites local examinations. Thus, an actor-network study of larp provides an alternative approach to the currently perceived material turn in game studies (Apperley \& Jayemane, 2012). Instead of replacing previously studied elements with material elements, and keeping a single centered perspective on games that the name "material turn" proclaims, an actor-network study offers a multi-centered perspective. This study offers therefore one example of how future researchers can work with actornetwork theory with previous research as a mapped out territory. An actor-network study of garb collaborates with previous study results of narrative and ludic elements and works them into a net with new insights about the often hidden, overlooked, or invisible but lively actor: the collaborating and demanding garb in larp. If future research starts to reflect on the epistemological premises of studying larp, it will expand larp beyond preconceived notions of what elements make larp work and how to know this process. One example for such a future research project is to integrate further actors, such as political, ecological, or ethical. I discuss the ethical implications of mass-produced larp garb in Chapter 6. 



\section{Mixed Reality Role- Playing GaMes}

My eyes follow text, images, and videos on the display of my smartphone. I sit in my living room. The smartphone lies in my left hand, connected with a receiver to my Wi-Fi router. My right index finger lies on the smooth surface. The liquid-crystal display (LCD) feels like glass that has been lying in a warm room. Swipe down. Tap. Swipe down. Double Tap. A display presents text, images, and videos on a rectangle shape. The shape is static. I touch the shape, but it does not change.

My eyes scan the room. I wonder what this room will look like when I am able to "augment" it with digital objects, for example adding a digital calendar to my wall, a calendar synchronized with my electronic calendar at work and with my mobile computing devices.

My eyes stop following what happens on the smartphone display. I place the smartphone on the table and walk to my personal computer. I put on a virtual reality headset. Before, I was moving within the shape of a rectangle display. Now, I seem to walk through the display. Turning my head around, I see a virtual environment.

I wonder how role playing might work in a combination of game and augmented or virtual reality?

\subsection{The Problem, or an Emerging Technology}

This chapter moves from role playing in larp to role playing in games with mixed reality technology. I introduce mixed reality as an umbrella term for technologies that range on a scale between augmented and virtual technology (see Section 4.2). One problem lies in the stage of development of these technologies; it is still too early to find fully developed role-playing games that incorporate such technology, games that I call mixed reality roleplaying games. Mixed reality technology is currently emerging for the mass market; thus, another problem could be that "mixed reality role-playing game" is not yet a solidified genre, but a loose group of prototypes that combine larps or computer role-playing games with augmented or virtual reality technology. However, actor-network theory makes a study of emerging technology possible, because an actor-network study of mixed 
reality role-playing games does not rely on predefined concepts or understandings, but analyzes the network from within while this genre is developing. Nevertheless, an actornetwork study requires a question to help me to navigate an emerging or "fluid" network (Venturini, 2010). As the focus of this book is role playing, the guiding question is: how do material actors collaborate with narrative and ludic actors to make role playing work in mixed reality role-playing game networks?

I elaborate upon the guiding question before I introduce mixed reality technology (Section 4.2) and present the results (Section 4.3).

Narrative and ludic actors have been a focus of previous studies on games in general. Games that integrate mixed reality technology, ranging from augmented reality to virtual reality, are labeled pervasive, hybrid, mobile, or located-based games (Magerkurth et al., 2005; Mäyrä, 2015; Montola et al., 2009; Silva, 2006; Sutko \& Silva, 2011; Tyni et al., 2013). Previous research in game studies has examined narrative and ludic actors, but little has been said about material actors. Understanding the work of material actors contributes to answering the guiding question of how narrative, ludic, and material actors collaborate.

Mixed reality technology is currently emerging and there are few role-playing games on the market, and fewer standardized hardware devices. The hardware is a "fluid" network itself, and it will take time and further experiments until the "fluid" hardware "solidifies" and becomes a blackbox (Venturini, 2010). ${ }^{54}$ Studying the material side of an emerging technology provides not only an understanding of how this role-playing game form works, but also volatile insights before this network solidifies in the near future and becomes a blackboxed consumer product. Thus, studying materials of emerging technologies contributes to the understanding of their current development.

To learn how role playing works in mixed reality networks, I study the collaboration between material, narrative, and ludic actors. As in the previous chapter, I follow here the work of materials and what materials do to ally with narrative and ludic actors. The aim is to understand what relations role playing needs to make a mixed reality role-playing game network stable. These relations will answer the question of how role playing works in such a network. More importantly, understanding how role playing works will provide an insight of how further relational processes between people and technology help this role-playing game form to solidify as a genre of games.

54 On the procedural understanding of a network, see the discussion of theory in Chapter 2. 
As in the previous empirical chapter, I start the analysis with a role-playing situation, but this time, I approach mixed reality in two role-playing games that use differing examples for this technology. In Section 4.3.1, I move to a larp where players use smartphones and the organizers provide a digital layer of information. I examine augmented reality actors by studying larp as an example for an augmented reality role-playing game network. In Section 4.3.2, I engage in a computer role-playing game and study how virtual reality systems change the network. Here, I examine virtual reality actors by role playing a video game with the Oculus Rift DK2 system. In Section 4.4, I discuss the results and argue that mixed reality role-playing game networks work not because of the functioning of actors that constitute the network as either augmented or virtual reality, but because augmented and virtual reality networks have to construct relations that are able to translate role playing. Understanding what these similar relations are helps to understand how material work contributes to a stable mixed reality role-playing game network.

\subsection{Introduction, or Reassembling Realities}

\subsubsection{A second chance for augmented and virtual reality technology. Mixed} reality technology is not new. The history of mixed reality technology reaches further into the past, back to the early $1960 s .{ }^{55}$ Found at university labs for human computer interaction, these mixed reality prototypes were expensive, required technical skills and programming, and were not accessible to the mass market. Since the 1960s, pioneers have experimented with mixed reality or artificial reality installations, for example Myron Krueger's VIDEOPLACE at the University of Connecticut. ${ }^{56}$

The understanding of what mixed reality technology is dates back to the first peak of virtual reality interfaces for a wider public in the 1990s. After their introduction, most devices died out, either because they were too expensive or because the technology was not convincing for the mass market. ${ }^{57}$ However, the definition of mixed reality has remained successful to the current day. In the early 1990s, Milgram and Kishino defined mixed reality on a continuum from the real environment, through augmented reality, augmented virtuality, and virtual environment (Milgram \& Kishino, 1994). The real

55 The time line reaches further, if one includes Futurist art installations after WWI, and panorama installations in the Victorian era.

56 Other examples include Morton Helig's Sensorama dating from 1957 and Ivan Sutherland's headmounted display from 1966. What led to the rise of virtual reality, a term coined by Jaron Lanier, was military and university research in the U.S. during the Cold War. For a history of mixed reality, see R. Azuma et al. (2001) and R. T. Azuma (1997).

57 Compare the $\$ 15,000$ cost of a virtual reality device in the 1990 s with the cost of the Oculus Rift Development Kit 2, about $\$ 650$ in 2014. The cost of the computer station plunged, as well. 
environment and the virtual environment are considered extremes on the continuum. The real environment would be the room around oneself. The virtual environment would be a situation where one sees only a room made of digital data, accessible via a virtual headset for example. The real environment is the "pure" reality without enhancements, while the virtual environment is a total simulation of an environment with digital means. In between these extremes, the authors classify augmented reality and augmented virtuality as mixed realities. Mixed realities include "real world and virtual world objects [that] are presented together within a single display" (Milgram \& Kishino, 1994, p. 3). In another paper, the authors explain that augmented reality enhances "natural feedback to the operator with simulated cues" (Milgram, et al., 1995, p. 283). For example, a person looks at a smartphone display which reproduces a table with the help of its camera, and adds a digital object in form of a book with its augmented reality software. Augmented virtuality adds real objects to the virtual world. One example would be the successful game series Skylanders (Activision, 2011-present). ${ }^{58}$ In a Skylanders game, people play the game on their console, and additionally, they play with small plastic toys. The company sells miniature figures with an RFID chip..$^{59}$ Putting the figurine beneath a small scanner that the game provides ("Portal of Power"), the player adds a digital representation of the figurine to the game on the display. The virtual game world on the display is augmented with a "real" toy. ${ }^{60}$

In this chapter, I examine examples for augmented reality and virtual reality as defined by Milgram and Kishino, but I consider virtual reality as an extreme form of augmented virtuality. Thus, I speak of virtual reality as an extreme form of mixed reality. Virtual reality works with digital information that constructs an audio-visual environment accessible via a headset and a computer. In the following chapter I show that the headset is always part of the virtual reality. Augmented reality works with digital information "added" to the "real environment," for example software accessible to players via smartphones during a larp.

58 "Since its introduction back in 2011, the Skylanders video game and toy series has generated upwards of $\$ 2$ billion in lifetime sales. It is one of the top 20 game franchises of all time, with 175 million toy sales" (http://www.polygon.com/2014/4/16/5614716/skylanders-story-toys-for-bobskylanders-swap-force).

59 An RFID or radio-frequency identification chip uses electromagnetic fields to transfer data, usually to identify and track tags that are attached to objects. One example is the tags in library books that help to identify information for inventory management. Unless they include a barcode, RFID tags do not need to be visible.

60 Selling "real" toys has the economic advantage that these toys cannot be copied on a filesharing site, as is the fate of all digitized media (music, film, video games). Even the advent of 3D printers will hardly affect this strategy, as the toy requires an RFID chip that responds to the algorithms of the game software. 
Since the 1990s, Milgram and Kishino's definition of mixed realities has remained influential (R. Azuma et al., 2001; Johnson, 2002; Lifton \& Paradiso, 2010). What research in this line of work shares is a discussion of mixed reality from a technical design point of view. The practical problem of these studies is either how to solve technical issues with existing technologies or how to build new devices and software. Another idea that originates in Milgram and Kishino's paper is to conceptualize mixed reality on the basis of a dichotomy. Although mixed reality is about mixing the "real" and the "virtual" on a scale, the continuum builds upon a preconceived notion that reaffirms the idea that the virtual is ontologically separate from the real. The separation itself resonates in the word "mix," because only separate elements can be mixed. Thinking a dichotomy between the real and the virtual serves the purpose of designing technology, because it facilitates thinking about building augmented technology on a real environment. However, if the task is to understand how computers connect with other actors in role playing, a technical understanding limits the view on the inter-relational process.

Moving from the technical field to the study of games, the dichotomy returns in concepts that address mixed reality technology from a humanities perspective in game studies, including concepts such as augmented reality (Bergström \& Björk, 2014; Nilsen et al., 2004), pervasive game and play (Magerkurth et al., 2005; McGonigal, 2003; Montola et al., 2009; Schneider \& Kortuem, 2001; Walther, 2007), mobile and urban games (Mäyrä, 2015; Mäyrä \& Lankoski, 2009), or hybrid play (Silva, 2006; Tyni et al., 2013). These concepts reconstruct a dichotomy between digital and real elements, because the dichotomy is the starting point to mix, pervade, or hybridize these elements in the process of gaming. What becomes the central inquiry of research is then how to define stages on the continuum, and to ask to what extent mixed reality technology changes gaming and playing.

These questions are important, but in this chapter I aim to contribute an alternative understanding. The difference between previous studies of mixed reality and games and the current chapter is that I do not start with a dichotomous definition of mixed reality. I show that the concept "mixed reality" not only has a historical dimension but is also still being developed. Otherwise the virtual or digital refers always to "the other." One consequence might be that research returns to questions centering on the dichotomy. I think that going away from a preconceptualized dichotomy reveals further actors, ones that do not fit the categories of essentially separated virtual and real actors, and that this offers an alternative perspective for the researcher of games.

When I use the terms mixed reality role-playing game, augmented reality, and virtual reality role-playing game, I refer to a network of heterogeneous actors with this study's 
focus on narrative, ludic, and material actors. When I use the words mixed, augmented, and virtual reality, I relate to previous research on games in these networks, but I do not take previous definitions for granted. I relate to previous definitions by building upon them in two ways. On an ontological level, I extend the view of role playing with mixed reality technology beyond the focus on narrative and/or ludic actors by following material actors. On an epistemological level, I take the virtual/real dichotomy as a starting point to move to a network perspective of what I refer to as mixed reality role-playing games. From this perspective, the similarity to previous definitions is, that mixed reality networks are assembled by actors, and the difference is that at the same time the network assembles the actors. Both, network and actor come into being when there is a trace for inter-relational work between them. In this chapter I refer to mixed reality role-playing game networks as relational processes between narrative, ludic, and material actors that are always rooted in a local situation that I have encountered in my field work.

So far, I have said that mixed reality technology had its origins in the 1960s and experienced its first peak in the 1990s. Since then, the understanding of mixed reality as a continuum has been helpful for research that was concerned about technical aspects, but also for questions regarding playing in the field of game studies. From the view of actornetwork theory, I have reconstructed the understanding of mixed reality technology as a local network of heterogeneous actors. In the next section, I elaborate upon the problem that mixed reality technology is currently at an experimental stage including globally distributed prototypes. By referring to current developments of computers, I explore the network of computers for role playing.

4.2.2 Computers everywhere. So far, mixed reality technology has not reached the mass market, but the recent developments of product prototypes allow the prediction of a change in data presentation and interfaces. Changes are to be expected, despite limitations inherent in predicting the success of technological innovations (Borup et al., 2006; van Lente, 1993). In addition to the technological development of smaller and faster mobile computing devices, the cultural acceptance of computers has changed. While it was an exception in the 1990s to use a computer for everyday tasks, thanks to the success of personal computers at home and at work, as well as mobile computing devices such as smartphones, computers now appear everywhere and anytime.${ }^{61}$ Computers are present in everyday culture, and current developments of computing devices lead to mixed reality applications with changes in data presentation and interfaces.

61 In the field of software engineering and computer science, the concept "ubiquitous computing" combines the idea to make computing appear everywhere and anytime. 
Mixed reality technology promises to mix digital data and the "real world." ${ }^{62}$ For example, a digital object on my smartphone might move beyond the display, and hover above my table. The task of interfaces is to help people interact with digital data that pervades and connects more and more of people's environments, currently discussed as "the internet of things" (Greengard, 2015). The task of mixed reality displays is to show digital data in combination with the environment. Mixed reality technology achieves this combination on a scale between augmented reality and virtual reality. Augmented reality technology shows digital data on the environment; for example, when looking at a magazine through a smartphone screen, the logo of a company rises as a digital image from the paper. Virtual reality technology simulates an environment with digital data, for example by using a headset that puts displays before the eyes. Currently, prototypes are ready for both categories, ready for mass media and the mass market. Exemplary prototypes for augmented reality are products such as Microsoft Hololens and smart glasses by other companies such as META, Sony, Epson, and Vuzix. Examples of virtual reality devices include Oculus Rift and other virtual reality headsets, such as Samsung Gear VR, Valve VR Room, Technical Illusions CastAR, Microsoft RoomAlive, or Google Cardboard. These examples provide alternative ways to display data and to interact with data. Current patents and prototypes try new displays that are bendable, transparent, or responsive. ${ }^{63}$ These devices connect digital information with the environment. Full visual and audio virtual reality devices create environments to interact with data not in front of oneself, but around oneself.

The downside of studying technologies in development is that obstacles come up that require an adjustment of the research plan. Games might not work, because of the relation between software and hardware, as I refer to in the case of virtual reality technology. Examples might be difficult to find, as might be people who have experienced role playing with prototypes. Nevertheless, the current chapter presents one case of a larp and augmented reality technology, and one case of a computer role-playing game with virtual reality technology. The experimental state of both cases offered the opportunity to study role playing in the making with mixed reality technology as a fluid network.

The current prototypes on the market cover the whole continuum of mixed reality technology. Smartphones offer augmented reality interfaces, headsets offer virtual reality displays. Currently, companies back their products with massive economic, technological,

62 In general, "real world" is any visual or acoustic element not simulated by a computer.

63 One way to track current developments is to follow patents. The patent for the bendable display example was filed in August 2014 by Apple. The document is available at: http://appft.uspto.gov 
and advertisement networks. ${ }^{64}$ While mixed reality systems were expensive in the 1990s, today, smartphones are accessible. More important, smartphones are able to process the data faster, companies invest strategically into the development of hard- and software, ${ }^{65}$ and prototypes are affordable, such as Oculus Rift. On the basis of this existing and growing network of technological, cultural, and economic actors, it is safe to expect that ubiquitous computing devices will expand beyond the group of devices that use an LED display. Future devices will have to change and expand the display interface, in order to sense and control more of the "real" world by providing innovative mixed reality interfaces everywhere and anytime.

Although the success of mixed reality technology in society is not sure, it is likely, because mixed reality gathers allies beyond the hardware. Allies include the cultural acceptance of mobile computers, daily interaction with computers for work and entertainment. Economic actors become part of the mixed reality technology network, when companies invest substantially in startups that build prototypes that foster the developments regarding the display of digital data and interfaces. Computers are changing everywhere and mixed reality creates new possibilities for work, home, and entertainment, such as games. Following displays, I am particularly interested in how material actors work within mixed reality role-playing game networks as electronic entertainment technology.

\subsection{Results, or Following Emerging Technologies with Role Playing}

In the following sections, I present the results for the question of how material actors collaborate with narrative and ludic actors to make role playing work in two mixed reality role-playing game networks: augmented reality (Section 4.3.1) and virtual reality (Section 4.3.2).

4.3.1 Obscurus 2 or Larp and Augmented Reality. This section examines how a network combines larp with augmented reality technology. To achieve a combined network, actors create new relations. This creates tensions that threaten the stability of

64 Job postings about a VR/AR specialist by Apple, $\$ 542$ million investment for Magic Leap, and other moves by Apple, Samsung, Microsoft, and Google in 2014 fueled the hype, but such investments are substantial and carry the development of new mobile computing devices by the current global players. A recent example is the acquisition of Oculus Rift by Facebook for 2 billion dollars in 2014.

65 See footnote above. Furthermore, there are developments in hardware-for example, the depthsensing camera. Depth-sensing cameras allow marker-less augmented reality and 3D photography, thus making it possible to create and combine 3D objects. 
the larp and augmented reality, because the stability of the combined network depends on how successfully the actors collaborate. Collaboration means a change of work that combines the work necessary to maintain a larp with the new work needed to include actors necessary to maintain augmented reality.

To illustrate this process and show traces of combination, I introduce the example of the larp Obscurus 2. First, I elaborate upon location and costume of the larp actors, and the smartphone and banking software of the augmented reality actors. Second, I discuss tensions between these actors. Third, I formulate an answer to the question on the basis of the actor-network analysis.

Introduction to Obscurus 2. In Chapter 3, I showed how a larp network becomes stable when narrative, ludic, and material actors collaborate. I followed the actor garb. In Section 3.4, I showed how garb creates relations with the story world of a fantasy larp and with the game rules. Garb relates to other material actors to spread role playing. In this section, I move from German fantasy larp to a larp that takes place in a contemporary setting in the Netherlands. With this movement between game communities, I hesitate to use the word "garb", because it relates to the larp networks in Germany. There, larpers use the German word for garb ("Gewandung") instead of costume ("Kostüm"). At the Dutch larp Obscurus 2, organizers and players used the word costume, for example in the rulebook. Thus, I use "costume" in this chapter when I refer to what a player wears to represent a character's clothing.

On the morning of Saturday, September 1, 2012, Max still believed he would get away with his life. He had just one moment to transfer the money and the threatening figures would leave him in peace. For the transaction, Max depended on my smartphone, because Max was the character I played during the Dutch larp Obscurus 2 (2.09.2012). The smartphone joined Obscurus 2 as a part of Max's costume. Other parts, or actors, included pilot glasses, a leather jacket, three Nerf toy guns, and the contents of the player kit that the organizers provided. The kit included bank account details, a deposit of $€ 10,000$, cash game money, small phials with peppermint and other candies that represented drugs, and information about contacts and enemies. In Max's case, all his enemies were gathered around him now.

In the larp Obscurus 2, narrative actors created a story world in an alternate version of our contemporary world. The setting was a more threatening version of the present day, with "quite a bit more chaos and lawlessness in [the world of] Obscurus" (Rulebook Obscurus v.2, p. 3). To represent the fictional Nightclub ZILLO, the organizers rented a 
former bunker between Haarlem and Amsterdam as location. My character Max was a German pilot who earned a living as a drug courier. With costumes, players represented criminals from Italy, Columbia, the Netherlands and Germany. Narrative actors included the characters of criminals and the lawless world of Obscurus; ludic actors included the Rulebook Obscurus v.2, and material actors included the location bunker and the costumes that represented characters' clothing.

A special element of this larp was the online banking software. Mark Otting programmed this ludic actor solely for Obscurus 2. Players transfer or receive game money by logging in their account at the website http://nsbank.obscurus.nl. The banking software added gameplay to the story world. Players could play gangsters who move large sums of money. In relation to the Nightclub, the banking software added an additional element to the gambling, poker, and roulette games. In order to engage with the software, players needed a smartphone with connection to the Internet to access the website of the fictional bank. In addition to the Obscurus 2 larp actors above, the network added the augmented reality actors banking software, smartphone, and the Internet.

The use of augmented reality technology in a larp made Obscurus 2 a special case to study how role playing works, because it was extraordinary to program banking software for one larp with a total running time of one evening, and it was unusual to use one's private smartphone as part of costume. Although the banking software and smartphone were a small part of the larp network, I follow them here because they revealed tensions that threatened the stability of the network.

Tensions between smartphone and location. During the evening, four Italian Mafiosi intimidated Max. The players played stereotypical roles of gangsters from 1980s mafia movies and their performance was supported by well-composed costumes that included Italian shoes, shirts, and sun glasses. The money transaction would bribe the gangster in exchange for Max's life. Unfortunately, inside the bunker, there was no Internet connection and we had to go outside. The scene shifted from play to solving technical problems. Outside, the connection was restored and we could role-play the money transfer.

The scene above shows a range of actors: the game world of Obscurus 2, the bunker location near Haarlem, game rules according to the Rulebook Obscurus v.2, the characters Max and the Mafiosi, players, costumes including clothes, and tools like the smartphone. The tension happened between the transmitter unit of the smartphone and the bunker walls of Nightclub ZILLO. The players could not access the banking website, because the smartphone receiver unit had no connection to the Internet. The location blocked the 
transmission from a nearby antenna or Wi-Fi router. Consequently, players had to integrate the technical problem into role playing. They decided to leave the Nightclub. Although the material-material relation required little change, for example moving outside, it is a trace of how material actors work with narrative actors. The scene changed, because the smartphone did not access the Internet, and Max could not transfer fictional money on the banking software. Although the relational work between material and narrative actors might seem small, it is not trivial or neutral to how role playing continues, because of the tension between the material location of the bunker and the smartphone as part of the costume.

Through the solution of walking outside and regaining Internet access, the tension did not interrupt role playing, but the scene was not over. Max still had to transfer money to prevent the Italians from killing him.

Tensions between smartphone and costume. In the following scene, I move from the work between location and smartphone to the work between smartphone and the costume. The task of a costume in larp is to act as a representation of the character's clothes. The smartphone becomes part of the costume, because the banking software requires a smartphone to work. However, in Obscurus 2 players used their personal smartphones as part of their costumes and this led to more tensions in the network.

Max and the Mafiosi stood outside. Connecting to the Internet took time, because my smartphone was not fast. We decided to solve the technical problem by using the smartphone of one of the Mafiosi, who owned a newer device. The banking website opened and he held me the phone to insert the login details.

Surrounded by four threatening figures, I was not sure if I remembered the login details correctly. Because I had prepared for such a case, I had taken a photo of Max's bank account details before the larp.

While the Italian waited, I switched on my smartphone and opened the photo gallery with a tap. I swiped to the left, because the current image showed a game scene that I had photographed earlier. Swipe left. Another picture of a game scene. I imagined that Max felt the rising impatience of the Mafiosi. Would he fail and would they kill him? Swipe left. Another picture of a game scene. Despite or maybe because of imagining the situation, my body began to react. Sweat on my skin. I as a player became impatient myself. Swipe left. Swipe left. I had moved one photo too far in the gallery. A different photo popped up on my display. My eyes fell on a photo of my last holiday trip. Within an instant, the illusion 
of me being and feeling the role-playing character Max was gone. My only concern was to hide the photo from the other players to prevent them from breaking their illusion. At that moment, role playing broke down.

The situation turned from role playing to hiding the private photo on the smartphone from the other players, so that they were not irritated. Max's smartphone broke the relation to the world of Obscurus, because the smartphone showed a private photo. The smartphone as part of Max's costume connected with the private life of Rafael, the player. Role playing came to a halt because the work stopped between the actors smartphone, Max, and the Obscurus story world. Similar to the scene with the bunker walls, the collaboration between actors came to a halt, because the smartphone as a material actor did not work according to the agency role playing that required action to support the narrative actor story world. A private photo broke the relation to the story world of Obscurus 2. As in the scene above, the moment was short and seemingly trivial, but it is a trace for how materials work with narrative actors. I elaborate upon this point of breakdown in more detail, before I suggest what a combined augmented reality role-playing game network needs to remain stable.

Breakdown and the need for customizable mobile devices. What I experienced as a player was a breakdown of the relational work between the narrative and material actors. In this scene, the work was maintained when the smartphone related to the fictional character Max, a narrative actor. The work stopped and the illusion broke down when the photo on the smartphone made a relation to my private life. When the smartphone was part of the costume and represented Max as a narrative actor, it worked as intermediary. When it related to me as a player, the intermediary became a mediator again. As mediator, the smartphone required further work to keep role playing going.

In such situations players need to invest further work to rebuild the relations and continue role playing. The further work, however, is not one-directional, because it does not originate in what players think is right, but emerges from inter-relational processes between players, fictional characters, and smartphones. These processes create the augmented reality role-playing game network "not as something imposed from the outside on an inert matter, not as a hierarchical command from above, but as something that may come from within the materials, a form that we tease out of those materials as we allow them to have their say in the structures we create" (DeLanda, 1995, para. 22). Materials having a say in the structures or networks is the key to understanding how role playing works. A scene such as the one above might be brief and seemingly trivial, but it reveals how the network emerges from the inter-relational work of players, characters, 
and the smartphone. When I was agitated by the menacing scene and I swiped the display too fast, the smartphone showed a photo that broke the network not by malfunctioning, as in the scene involving banking software, but because it made one connection too many. Because the smartphone would have a say in the network, I should have deleted all photos on my private smartphone before the larp. To maintain stability in a larp network that integrates augmented reality technology, it is necessary to understand what material actors such as smartphones need, in order to prevent tensions from arising.

The interruption of work between the material actor smartphone as part of the costume and the fictional character Max is one example of tensions typical for augmented reality actors: the intrusion of additional actors that relate to further networks. It is the purpose of augmented reality technology to create connections between other networks. The current everyday practice with personal mobile computers, such as the smartphone, is to use the device as a node for all online activities, including email, short messaging, social media, and storing personal memories. Using the smartphone as part of a character's costume requires further preparation. Players have to disconnect relations between the device and the player's personal life, or use an additional smartphone solely for one character. Further modifications, such as a character-related case, replace the relations between the player and the device with a relation between the character and the device.

In the scene above, the private photo created a connection to my private life, thus intruding on the story world of the fictional character Max. As a player, I had to regain control of the boundary. The purpose of boundary control is to support consistently "the illusory reality, whether a fictional one or an altered version of the real world" (Harviainen, 2012, p. 94). Harviainen defined boundary control as the task of every larp player, but a material actor can control boundaries, too. In the scene above, it did not work, because I did not let the smartphone have a say in boundary control. In order to take over, the smartphone demands action. In advance, the smartphone demands preparation, such as deleting private photos (and deactivating message popups). During play, the smartphone controls boundaries when it is seen as part of the costume and not as a property of a player.

Cost and modification. At this point, another problem arises from the use of smartphone as augmented reality actors: when first introduced, it was an expensive part of the costume. Both scenes have shown tensions between larp and augmented reality actors, between the location and the smartphone, and the smartphone and the costume. Tensions dissolve when the smartphone becomes more of a costume than a personal device. As part of the costume, the smartphone increases the relations to other actors and makes the combined network more stable. But first the smartphone has to change. 
Smartphones as part of the costume need to be cheap, because then possibilities for role playing increase. When the Mafiosi intimidated Max, it was unlikely that one player would take my smartphone and throw it against the wall to intimidate Max. Within the story world the smartphone would be an ideal device to threaten another character in this way. But the smartphone in use could not be a toy phone, because we had to use a real smartphone to access the banking system, and therefore a cost limitation was imposed on potential role-playing options. When the price of a smartphone falls from a couple of hundred euros to ten euros, the smartphone as a material actor makes new relations to translate role playing. For example, a player might take the smartphone and throw it against the wall to intimidate another player. Such an action was not imaginable in Obscurus 2, because the smartphone as a material object was expensive in the year 2012.

Smartphones work better as part of the costume when they become more modifiable. Modification is an efficient way to strengthen relations between material and narrative actors in larp, as shown in Chapter 3. As part of the costume, a smartphone has to represent a character, not its owner. However, today's smartphones have increasingly become blackboxes in terms of hardware and software. One extreme is Apple iPhones that are built as closed units. When a player wants to change the interface of the Apple operating system to make it a better match with the alternate reality of a dark world, it was practically impossible to replace the candy-colored buttons ${ }^{66}$ Neither is it possible to open the device and modify the hardware, because iPhones have built-in mechanisms to prevent tinkering. An alternative is smartphones made by other parties, such Android phones, or modular smartphones such as Project ARA. But as long as mobile computing devices keep a unified design, the means to express unique characters remains difficult. One likely solution for individual and modifiable interfaces may come when smartphones, that spend most of the time in a pocket, give way to smart devices that are worn visibly on the body, such as watches or other smart parts of clothing.

Demands of augmented reality technology for role playing. In this section, I examined how augmented reality role-playing games work as a network of heterogeneous actors that spread role playing. In two exemplary scenes from the larp Obscurus 2, I have shown that role playing spreads, firstly, when technical problems relate to narrative or ludic actors and become part of the network, and secondly, when the smartphone becomes part of the costume, thus representing the character in relation to the game rules.

66 With the operating system version 8 in 2014, Apple introduced a grayscale option for the interface. 
But narrative, ludic, and material actors do not collaborate and do not translate role playing across the network when, in the first instance, the smartphone as a material actor automatically connects to further networks, such as private photo galleries, and secondly, when the smartphone creates relations to other actors that do not collaborate with either narrative or ludic actors.

A breakdown of these relations is less probable when smartphones collaborate with location and costume. To collaborate with location, the smartphone's receiver unit needs a stable connection to a transmitter. To collaborate with costume, smartphones need to become cheaper and more modifiable or replaced by other mobile computing devices. Then the smartphone creates a stable augmented reality role-playing game network.

In this section, I have traced relations mainly between material and narrative actors. The next section examines also relations to ludic actors. It moves from larp and augmented reality technology, to virtual reality technology and computer roleplaying games.

4.3.2 Virtual reality and role playing. The following sections examine how a network combines a computer role-playing game with virtual reality technology for role playing. To form a combined network, actors create new relations, but as was the case in the previous sections, this work can create tensions that threaten the stability of the actors' collaboration. Collaboration means a change of work that combines the work necessary to maintain the computer role-playing game, with new work needed to include actors necessary to maintain virtual reality.

To illustrate how actors collaborate and to examine traces of tensions during this process, I introduce the example of the computer role-playing game The Elder Scrolls V: Skyrim (Bethesda Softworks, 2011). Skyrim allows modification of the core game software. A range of modifications extend the game especially for role playing. I elaborate upon the actors that maintain the computer role-playing game. These modifications create new relations between ludic and narrative actors, but with virtual reality headsets modification of Skyrim changes material actors. To study how role playing works with virtual reality systems, I introduce Oculus Rift Developer Kit 2 (Oculus, 2014). I then discuss tensions between actors that make Skyrim and the Rift. On the basis of these observations, I formulate an answer to the question of how narrative, ludic, and material actors collaborate and translate role playing across virtual reality role-playing game networks. 
Introduction to computer role-playing games. On the LCD display before me, I see the character. He wears metal armor, sword ready in his right hand, a fireball hovering over the open palm of his left hand. I move the mouse and the character moves. Around the figure, there are mountains with snowy peaks, blackforests, and an approaching storm. The sound of thunder mingles with the sound of a river in front of the character. Water gushes from the right to the left-a strong current. It must be icy, because snow lies around.

One reason to study virtual reality technology networks with role playing is that so far, the relation between role-playing games and computing technology has led to innovations in gaming and the technology behind displaying the game world. For example, the singleplayer computer role-playing game Ultima Underworld (Blue Sky Productions, 1992) introduced first-person action in a 3D game world that was non-linear and led to emergent gameplay. First-person action in a 3D game world became the standard for other video games, above all the first-person shooting genre, that have built on this development since Doom (id Software, 1993). Current approaches towards combining role-playing games with virtual realities seem to build on the previously made relation. One of the more attractive examples when showing virtual reality and games is the single-player computer role-playing game The Elder Scrolls V: Skyrim (Bethesda Softworks, 2011). Skyrim is considered a descendant of Ultima Underworld in regard to the elements mentioned above. It is attractive, because despite its age, constant modifications update Skyrim in terms of content, visuals, sounds, and gameplay elements. As with larp, modification can serve role playing. ${ }^{67}$ Modifying the core game makes the Skyrim interesting to study how ludic actors translate role playing on the level of game software. Even if the core game software does not provide rules, content, or effects that support role playing, Skyrim is open to change.

While the example for larp and augmented reality technology included several players, Skyrim involves just one player. I decided to study a single-player game because multiplayer online role-playing games did not cooperate well with virtual reality headsets during field work in 2014. One obstacle was that the game software of multiplayer online role-playing games identified the Oculus Rift as additional hardware and automatically categorized the hardware as cheating hardware. In the case of the popular World of Warcraft, the consequence was the ban of one's account. The relation between game software as a ludic actor and the Rift as a material actor was missing during field work, due to the current fluid state of virtual reality technology, as I wrote in Section 4.2.

67 See chapter 3.3 
Playing Skyrim with the Oculus Rift, however, required additional software. As Skyrim was one of the popular showcases for the first two versions of the Oculus Rift, third parties made driver software for this particular game. Without an additional driver, the game did not start with the Rift. I acquired the driver software VorpX to combine the game and virtual reality headset, because it supported Skyrim as one of the first dozen video games. ${ }^{68}$

Another obstacle was the interface of multiplayer online role-playing games. To play this genre of games, the player needs to operate several lines of icons. Experienced players can operate the most common commands by using keyboard shortcuts. A keyboard shortcut is a combination of two or more keys to activate a command. Although some players use keyboard shortcuts and own special mice with additional buttons, the range is limited. Moreover, the buttons on the keyboard are small and while playing with a headset, it is likely that a finger will hit the wrong button.

Playing Skyrim does require gameplay skills. Another reason I chose this game was my familiarity with it. I began studying the Rift with more than 280 hours of gameplay experience in playing Skyrim with an LCD monitor. Thus, I was familiar with the background story, game mechanics, and game design of the series. I knew how the game worked and could focus on the changes when I replaced the LCD monitor with a virtual reality system.

These obstacles - the lack of implementation of virtual reality headsets on the side of game software, as well as interface-made it impossible to play a multiplayer role-playing game with the Oculus Rift in 2014. Moving to the single-player game Skyrim solved both problems. The Skyrim game software does not detect cheating hardware and the game requires fewer commands. The interface has been designed to navigate with either keyboard and mouse or gamepad. The downside of studying Skyrim in relation to the example of Obscurus 2 was that I could only observe single play. To solve this, I matched examples from the (multiplayer) Obscurus 2 that do not rely directly on other players. In Obscurus 2, The disruption of Internet connectivity happened because of the location, and the interruption of role playing due to private photos on the smartphone had an effect on the smartphone owner as well as anyone else looking at the screen, but other players were not imperative to explain how the relations changed.

68 The list for VorpX-supported games has grown since August 2014. The list can be found at https://www.vorpx.com/supported-games/ 
So far, I have introduced the computer role-playing game genre and my chosen example The Elder Scrolls V: Skyrim (Bethesda Softworks, 2011). In the next section, I elaborate how modifications change the core game software of Skyrim for role playing.

\section{How actors translate role playing in a single-player role-playing game network.}

Despite the name of the genre, computer role-playing games focus on a limited range of role-playing actions. Todd Howard, executive producer and director of the Elder Scrolls Series, says that "at its heart, it's run through dungeons and kill creatures and take their stuff and buy bigger weapons and kill bigger creatures" (Hoff, 2006). Thus, the game design focuses on a range of actions: character creation; development of character statistics in relation to quantified skills (i.e., health, strength, etc.); and game world interaction in the form of fighting, dialogue with non-player characters, and object interaction, such as gathering equipment that supports combat (i.e., health potions, armor, weapons). ${ }^{69}$

What makes The Elder Scrolls series interesting is the additional element. Characters run through dungeons, but these dungeons are part of an open world. Open world games or sandbox games allow characters to explore a virtual world without necessarily following a story line. This explains the design focus on ludic actors instead of narrative actors. Howard adds that the player can explore what is in the world by providing further interaction with its content: "Wow, look at these flowers. Can I pick that?" However, action and exploration are "almost like two things sitting on top of each other. Here's the game and then here's the virtual world" (Hoff, 2006). Interaction with an open world requires further relations to connect them to one network, either for a small or for a wider range of role-playing actions.

Despite the freedom to move around the virtual environment, the set of actions limits role playing to fighting, collecting riches in the form of in-game money and special items, developing the character to fight stronger enemies, and finishing a story line that is more or less open. In this sense, role playing focuses on "instrumental play" and beating the game, but not on role playing in the sense of pretend play..$^{70}$ Despite the relative small size of role player communities in single and multiplayer role-playing games, role playing is possible with computer games, but players have to explore ways to expand role playing beyond playing a character that has been designed to defeat enemies.

69 Hitchens and Drachen define interaction in computer role-playing games as focused on combat, dialogue, and object interaction (2009, pp. 14-15).

70 See Chapter 2.4.4 
I hear a roar, but see no threat before the character in the water. Something must be behind the character. I click the mouse and he turns. There is a mountain lion. The animal launches itself at the character. Sword pierces, fireballs explode-but the opponent is too strong. The health points drop fast, showing that the character is dying from the wounds. The character has to flee. Should he jump into the river before him?

From a strategic point of view, jumping into the river is currently the best decision to survive the fight. From previous game experience, I know that wild animals do not follow the character into water. There is a program algorithm working to run the animal's behavior. But there is no program that calculates the effect on the character's health when he jumps into an icy river. The name for a more strategic style of playing is "instrumental play" (Copier, 2007) or roll playing. One reason for giving this name was the focus of tabletop role-playing games on rolling dice and strategic play. Another reason is the pun on role playing.

Roll playing focuses on action, combat, and beating the game; it is in line with Howard's design idea for Skyrim. Roll playing is the most common play style and ludic actors support many ways to defeat opponents, either by close combat, magic spells, or stealth attacks. But the ludic actors support relatively few non-combative solutions to conflict. Beyond conflict, the diversity of interaction with the game world is limited to exploring the world, solving riddles, and owning a house for the character with the option to buy furniture.

In order to explore the actor virtual reality headset, studying the role-playing style is more fruitful, because the promise of virtual reality correlates with the motivation for role playing: stepping into the game world and making decisions from the point of view of the character. The difference between roll playing and role playing in game play is then the difference between playing to win versus playing to take over a character and make decisions from the point of view of the character. As the ludic actors that make the Skyrim game software support combat-related actions, the scene above requires further work when it should support role playing.

Role-playing, I realize that from a character's point of view, jumping into a river is a bad decision, because it is dangerous for a character living in the province of Skyrim, a country in the northern hemisphere of the fictional world Tamriel. Moreover, the character wears metal armor, there is snow, and the river is ice cold. From a roll-playing point of view, my decision not to jump into the river might be considered as a bad decision. Bad, because it does not matter whether the character gets wet, because there 
is no supporting consequence to this action. In other terms, there is no relation between the cold water (narrative actor) and the code (ludic actor) in Skyrim. Regarding role playing, the decision requires more work from the player to immerse in the situation and look through the eyes of the character. Role playing a computer game requires more work than in a larp. Being physically at a larp location, there is no need for an algorithm to calculate the consequences of cold weather upon the character, because it is the player who stands in the cold. In Skyrim, when the game code does not calculate the relation between cold rain and the character, there is no consequence. As the core game software does not make these relations, characters can swim through icy water without effect. Interacting with the cold world does not connect the actor water to character play.

When there is no relation between the ludic and the narrative actor, role playing does not happen before players make an effort to think about new ways to incorporate further actions. For example, I can act as if the decision matters to the character anyway. I would then not jump into the water, making a connection to the game world by responding to it without a ludic actor. I then have to decide consciously to incorporate role playing and to make decisions that support role playing, decisions that are not based on the relation between the narrative and ludic dimensions in Skyrim. This is what Heliö and Montola describe as the role-playing mindset (Heliö, 2004; Montola, 2012a). Players as human actors translate role playing when they mentally immerse in the situation, when they add narrative elements to the game without changing the game itself. Looking from the eyes of a character, players can change their actions, even if the changes have no consequences on the character's statistics. But as I show, role playing works when narrative, ludic, and material actors collaborate. It is true that materials are not visible in this example, but they are here: mouse, keyboard, computer, and display. They are invisible, because they are intermediaries, they collaborate without making a difference. In the following, I replace one of them, the LCD monitor, with a virtual reality headset and trace the change. Before I examine the change in the inter-relational work of narrative, ludic, and material actors, however, I want to elaborate on how modifications alter the ludic-narrative relations especially for role playing. The following examples will make the changes in material actors more visible.

Supporting role playing with modifications: ludic-narrative relations. Role playing Skyrim requires further actions and players share ideas online, such as writing texts about their character. ${ }^{71}$ While the narrative actors of the core game include the world's

71 The Unofficial Elder Scrolls Pages wiki provides a list of actions in order to role play Skyrim (http://www.uesp.net/wiki/Skyrim:Roleplaying). 
backstory, quests, and ingame texts, players add further narrative actors when they write a character background, stories, diaries, or similar paratexts. ${ }^{72}$ Such narrative work increases the relations between the core game and how players imagine their characters, relations from which decisions result about the choice of equipment, appearance, and behavior. ${ }^{73}$ Players who base the decisions on the narrative side of the character make an additional effort to create narrative actors and tie them to playing the game. For example, if the player had written about the character's fear of water, and this character finds itself in the situation of choosing between jumping into the river or fighting the animal, the player would not decide to move the character into the water, for the sake of role playing.

Computer role-playing games provide game content and game mechanics for role playing within the range of playing an action protagonist in a dangerous world. When players want to role-play further aspects of a character living in a fictional world, they have to consciously alter decisions during game play. As this decision making requires further work regarding ludic actors.

Players can change the ludic actors of the game software by making and adding modifications to the code before playing. Then ludic actors take over this work. Software for modifications has been part of the Elder Scrolls Series since 2002 (Morrowind, 2002; Oblivion, 2006; Skyrim, 2011). ${ }^{74}$ With the available software, a modding community evolved, where players create and share smaller and larger modifications to the core game. ${ }^{75}$ Players can add these modifications to the core game, which changes the core game code and thus the ludic actors.

An example for a modification that supports role playing is Hypothermia. ${ }^{76}$ This modification adds cold weather gameplay elements, so cold and warm surroundings affect the character. The core game does not calculate the weather condition as an impact on the character. Additionally, Hypothermia calculates the type of clothes

72 A paratext refers to texts that surround a core text. One paratext for a novel, for example, is the back-cover text or simply the subtitle "A novel" (Genette, 1997). In this context, I consider text in a wider semiotic sense, including images of characters (fan art), sound recordings about the character (audio books), and videos (machinima).

73 Examples for Skyrim fan fiction that might be interesting for the study of transmedia storytelling include websites such as https://www.fanfiction.net/game/Elder-Scroll-series/.

74 Unofficial modifications of Elder Scrolls games predate the introduction of Bethesda's software; for example there are modifications for The Elder Scrolls II: Daggerfall (1996).

75 Modifications made and published by the developers bear the name "Downloadable Content" (DLC). They are usually paid for.

76 Frostfall - Hypothermia Camping Survival (CheskoMods, 2014). 
worn, the temperature, and also the type of surrounding. Integrated to the network, the new ludic actor (Hypothermia) supports role playing in the scene above. With Hypothermia, jumping into a cold river while wearing metal armor would result in chilling the character, with further effects. Without changing clothes in the inventory and finding a fireplace in the game world, the character would fall ill and become unplayable. A modification adds interaction with the game world, because it makes ludic actors work with narrative actors. Thus, modification adds a set of consequences for decisions that depend on the relation between narrative (cold environment) and ludic (Hypothermia) actors, thus supporting role playing a character exploring a cold world. The decisions change from instrumental play to character-based role playing. With Hypothermia as a ludic actor, more interactions become possible. The player hides from cold water in caves, looks constantly for fires, and chooses warm clothes. Adding modifications shows that role playing as a mindset includes the human actor player and narrative and ludic actors.

Constructing role playing with material actors. So far, I have focused on narrative and ludic actors and explained how they construct role playing. Role playing in Skyrim depends on additional work from the player, work that adds a new set of rules, replacing strategic decisions with decisions based on the character as a fictional person. This work creates relations between narrative and ludic actors and supports role playing. Modifications, such as Hypothermia, translate the work of role playing as a mindset to ludic actors. Role playing as agency moves from players to the work between the ludic actors (core game software and modification) with narrative actors (character, game world).

Role playing in Skyrim works when the player acts according to a character's point of view, a point of view that is constructed by the narrative actors that make the story world of Skyrim. Modifications support this work by taking over player actions, and add relations between the narrative actors that make the world of Skyrim and the ludic actors that provide the game software. Additional narrative-ludic relations stabilize the game network. At this point, I replace the LCD monitor with a virtual reality system.

I turn off the game and put the Oculus Rift in front of me. It consists of a headset, a tracking device for the position of my head, and two cables.

A virtual reality headset would present the world of Skyrim not in front, but around a player. In the next section, I introduce the virtual reality headset Oculus Rift, before I examine how the headset works with narrative and ludic actors in role playing Skyrim. 
Introduction to virtual reality. Holding the Rift headset in my hands, it reminds me of a plastic lunch box. Its weight is similar to a softcover textbook. I connect the headset with the head-tracking camera and the connector. The connector has four cables. I connect the HDMI cable with my computer's graphic card. There are two more USB cables to connect with my computer's USB hubs and one power cable for the power supply. An orange LED lamp turns on the front of the headset. I pull the rubber bands over my head, adjust them over my ears. At first, I see nothing.

Although virtual reality technology failed for the mass market in the 1990s, it was not the idea that failed but its translation into wider society at that time. Since then, computing technology has advanced in the sense of faster, cheaper, and more complex systems. The largest part of society has embraced innovations like the world wide web for general communication, mobile phones for pervasive communication, and video games as an entertainment technology. Video games spread as a major electronic entertainment form across most parts of society. Both computers as hardware infrastructure, and games as software applications, created a network that supported the emergence of virtual reality technology in the mid-2010s.

The public and corporate interest in this technology gained momentum with a successful crowdfunding campaign for the virtual reality system Oculus Rift in $2012 .{ }^{77}$ Oculus Rift emerged from a connection between computing technology and video games. After raising 2.4 million dollars on the crowdfunding website Kickstarter, Oculus raised additional funds of 16 million dollars in 2013. In 2014, Facebook Inc. bought the company for 2 billion dollars. The public and corporate interest shows that there are means for largescale funding and a potential craving for a new interface. The virtual reality technology network gained momentum when it related to public interest, corporate investment, and the creative industry.

This network provides the background for the emergence of virtual reality systems for video games. At the crowdfunding website, the virtual reality system Oculus Rift was

77 Belleflamme, Lambert, and Schwienbacher (2010) discuss previous academic publications on that topic, focusing on the mechanism of this financial model (Kappel, 2008); possibilities for charity organizations (Wojciechowski, 2009); a further range of financing alternatives (Cosh et al., 2009); and a theoretical framework of labor donation theory to investigate non-for-profit organizations, which was updated two years later (Ghatak \& Mueller, 2011). As a result of their work, they offer the following definition of crowdfunding: "Crowdfunding involves an open call, mostly through the Internet, for the provision of financial resources either in the form of donation or in exchange for the future product or some form of reward to support initiatives for specific purposes" (Belleflamme et al., 2013, p. 588). 
advertised as a "Step into the Game." With this larger socio-historical network, the virtual reality network evolves with an interest to incorporate games that demonstrate the strengths of virtual reality technology. Stepping into the game is an analogy for "immersion," a term of recognizable interest for game studies and for role-playing game studies (Torner \& White, 2012). Immersion refers to the player's experience of being there in the game world. This is in line with Oculus' revised company slogan "Oculus $\mathrm{VR}^{\mathrm{m}}$ is a technology company revolutionizing the way people experience video games."78 Speaking with actor-network vocabulary here, immersion emerges from the interrelation of actors that support role playing. The network needs relations between the narrative actors that construct a player's everyday life, work, and memories with relations between the player and the narrative actors that construct the fictional character and its story world. While in larp, narrative actors collaborated with garb, locations, and other material actors, computer role-playing game networks combine narrative actors with the display and sound system. ${ }^{79}$ Replacing an LCD display with the Oculus Rift virtual reality headset changes relations.

I see nothing, because the foam inside the headset wraps around my eyebrows and temples, rests on my cheekbones, and fits closely around my nose. As I live in the Netherlands, where windows have often no roller blinds, the morning light pours into my room. Out of the corner of my eye, towards the top, I slowly see some light as my eyes adjust. Looking down, I see my fingers, as the slit below my nose is just wide enough. Except for these small gaps where light comes in, it is dark in front of me. This dark field will be filled with the stereoscopic display when I turn on the device. The very small button is on the top right of the headset. My right index finger searches over the hard and cold plastic. I feel clumsy now, as I cannot rely on my eyesight. I push the button and a round bend display turns on before each eye. The displays are shaped like cups. They do not fill my eyesight completely, as there are black corners not filled with the round screen. The headset is a headset, not an "eyeset." Moving my eyes, I see as far as the round displays fill my sight. Moving my head, I can look around in the $360^{\circ}$ virtual environment, because of a head-tracking camera that is positioned on top of my computer screen. The camera calculates the position of my head and the displays present the image according to the calculation by the software. Oculus Rift does not mean to go beyond the LCD technology of the screen, but adds another display to it. As it is my familiar table, I find the mouse without looking at it. I move the mouse

78 I became aware of the change at their twitch channel in 2015. http://www.twitch.tv/oculus/profile

79 In this chapter, I do not discuss sound as an actor, because the focus of the prototype has been on the visual side, the $360^{\circ}$ display and the simulation of 3D objects. After my fieldwork with the Oculus Rift, the company announced a new version of the device that incorporates a $360^{\circ}$ sound system supported by the hardware and software level. 
cursor over the Windows 7 desktop and click the game file. A reassuring sound from the loudspeakers, and the game starts.

The virtual reality system reveals itself as a group of material actors that themselves are networks of material actors (in brackets): Rift (headset, cables, rubber bands, foam cushion, slit between head and foam cushion of headset, stereoscopic display of two cupshaped lenses), body (hands, head, ears, eyebrows, temples, cheekbones, eye, fingers), room (windows, morning light, power supply, desktop, chair, table), and computer (graphics card, LCD display, mouse, keyboard, loudspeakers).

At this moment, the actors create the material network, the hardware infrastructure for the game. Compared with the augmented reality network, the Oculus virtual reality network is stationary, as the user sits before a computer. Additionally, the head-tracking camera must be in front of the headset display. Both camera and headset connect via cables to the computer. While the augmented reality network relies on a seamless connection between the mobile computing device, the receiver, and a sender (either a Wi-Fi or a satellite system), the Rift cables secure a stable connection between the computing device, the receivers (head-tracking device) and the display. As the game starts, the actors turn into intermediaries and form the material network.

To sum up, I have introduced the Oculus Rift Developer Kit 2 (Oculus, 2014) to examine how a virtual reality role-playing game network emerges when I combine Skyrim with the Rift. While the company Oculus promises a step into the game, and immersion is one key concept in studying role-playing games, the question remains how actors construct a stable virtual reality role-playing game network. Following material actors such as headset, cables, and foam cushion, the study reveals more and more relations that should be part of role playing.

In the next section, I return to the example of the character standing before a cold river and the mountain lion attacking. The network grows. While narrative and ludic actors inter-relate character, the Northern world of Skyrim, core game code, and modification Hypothermia, the material actors that construct the virtual reality technology need further work to make role playing work. Oculus promises players to step into the game, a goal that role players share when they consciously base decisions on the character instead of on winning the game. In the example of Skyrim, a player with the virtual reality headset should feel like he or she is standing in front of the waterfall. It should not be necessary to remind oneself to role-play. With the Rift, it should be easier to enter unconsciously into the role-playing mindset. But how does the Rift support role playing exactly? By following the tensions that arise, I examine how the material actors that make the virtual 
reality system collaborate with the narrative actors that create the world of Skyrim and the ludic actors that run the game code.

Tensions between Oculus Rift and location. I load a different scene in the game. ${ }^{80}$ The game world unfolds around me as if through the eyes of my character. I move my head and look down. The view follows my head and it is as if my character moves his head around a tunnel. The first thing I notice is that the Rift display presents the game world in the "right" proportions. The tunnel walls are at arms' length. The ceiling is about one meter above me. This impression of the "right proportions" creates the impression that everything in the game world falls into place. Fly Amanita mushrooms are where they should be. Not before me on a display but projected on the ground, at the same distance to where my feet are below my table in the room. The mushrooms and the tunnel floor feel present and thus my feeling of immersion grows.

Every part of the game world falls into the "right place." However, the mushrooms on the tunnel floor are surprisingly big. When playing Skyrim with an LCD monitor, the mushrooms were small and I barely noticed them. They have been designed how the LCD (material actors) represents the character's body in proportion to the player sitting in front of the LCD in the room. Replacing the LCD with the virtual reality display, everything is still in proportion to the body of my character, but as the proportion between the character's body and my body changes, I do not sit before the character being displayed but I am at the spot where the character stands, the environment grows and the mushrooms designed for an LCD become larger than life.

Nevertheless, the impression of immersion works on me. The relation between the game world on the display and the human player supports role playing. The walls and the ceiling seem in proportion and the feeling of being in the character's shoes works.

My head moves up, too fast, the surrounding blurs. Instead of running, I move the character slowly around, because I have the feeling that it is I who am in a cave, because of the sense of height and width in front of me. Moving slowly, I realize how empty the tunnel is.

80 “Auto Save, Wolfskull Cave. Boolk, Nord, Level 61, 282.14.45. 10/14/2014, 12:55 PM." Explanation of the format: Auto Save: the game was saved automatically. Wolfskull Cave: the game world location where the character is. Boolk: the character's name. Nord: the character's race. A Nord is a denizen of the Northern country of the game world Tamriel, the title-giving country of Skyrim. Level 61: the character's experience level. This is a ludic actor indicating the overall ability score of the character. Characters begin with Level 1. 282.14.45.10: the amount of hours/minutes/seconds spent playing the game since its installation. 10/14/2014, 12:55 PM: the date and hour when the save file was created. 
Looking closer to the ground, I realize a lack of narrative actors on different scales, actors that create the fiction of an underground system of tunnels, inhabited by plants, animals, and other creatures. On the scale of the Fly Amanita mushroom, there are more items: phosphorescent plants, torches, but little more. On a smaller scale, I do not see anything. The representation of the game world on the display lacks detail when one replaces the LCD with the Rift. To work as a relation between material and narrative actors, the representation of the game world has to adapt when the material actor Rift replaces the previous display. What this scene shows is that the change requires an adaption of narrative actors and their representation by ludic actors. The world needs more details, for example items (i.e., pebbles), plants (i.e., smaller fauna), animals (i.e., insects), and other elements. Additionally, the narrative-ludic actors have to cooperate with the player's body as a material actor, because they have to be of different size and according to the proportion of the player.

Someone or something is walking in the dimly illuminated tunnel. There is a sound from the loudspeakers. With a push on the CTRL button, my character enters the stealth mode. With a push on the familiar W button, the character sneaks down the tunnel.

Pushing the CTRL button, I realize that the keyboard buttons are too small when I do not see them. It is easy to misplace one's finger when the eyes are covered by the headset and the hand is not constantly touching the keyboard (material-material relation). When I want to move the character in Skyrim, I use certain buttons on the keyboard. The button W moves the character forward, A moves it to the left, S moves it back, and D moves it to the right. Using the WASD buttons is a standard among video games that employ the keyboard and mouse as interface. When the player wants to make a screenshot, the hand has to leave the WASD buttons on the left side of the keyboard. The hand has to move across the keyboard to the right side of it, because the screenshot button is usually on the PRINT button. The headset prevents seeing the keyboard and here the material network can become a cause of irritation or breakdown (i.e., when pushing the nearby QUICK LOAD button instead PRINT). The consequence would be either to become more proficient with the input devices or to replace them. In my case, I was familiar with the game controls, because I have played Skyrim for hundreds of hours, but it was still difficult to operate the familiar input hardware (keyboard, mouse) when carrying the headset. ${ }^{81}$

81 Here, I observed that I was holding breath, not as a reaction of immersion in a suspense situation, but because operating the material interface generated excitement. This suggests the idea for future devices that might track not only the movement of the head, but also the breath pattern when operating the controls. 
To prevent day light coming in and to keep the display on my head, the rubber bands push the headset against my face. This pressure hurts after half an hour. I pause for now.

So far, the first steps into the game showed how a player stumbles with a virtual reality display. The network is not stable, because relations between actors, such as game world, keyboard, and rubber bands, do not work. The reason is that more material actors have to be turned into intermediaries before role playing Skyrim. One further material actor is location. Location in virtual reality consists of the virtual reality system (headset, tracking camera, cables, etc.) and the computer (keyboard, mouse, graphics card, etc.). Following the location, more material actors reveal themselves in the tensions that arise when location creates relations with narrative actors. In a larp network, the location combines narrative actors (story world) with material actors (costumes and buildings). I have described location in a virtual reality network by focusing on how location combines narrative actors (the world of Skyrim) with material actors (virtual reality headset). Tensions arise during play and reveal relations between further material actors, such as fingers and keyboard on the table, or the rubber band holding the Rift and the player's head. There are more material actors involved in making location.

I load an earlier scene. The character stands in a valley. I move the mouse to the right and push the $W$ button. The character walks away from the river, following a stone road. Grass is waving in the wind. The camera follows my head's movement. To the right-the mountains. They are really high. It feels like standing before the mountain Watzmann in Bavaria. To the left-a hill with a forest. Before the character-the road.

To construct the location as a reliable ally of the network, material actors have to involve the virtual reality display that represents narrative actors and further actors that construct the environment where the player sits, such as the keyboard, mouse, table, but also light sources such as the windows, and the room itself.

In a virtual reality network, the location is not just the virtual reality display in the headset. If the actor location is defined by its action of combining narrative actors with the material actors, it is the relation between these actors that is interesting. Following the relations, what constructs location in a virtual reality network is more than what is seen on the display. The scene above shows tensions when the display works. There are tensions between the fingers that try to hit the keyboard or move the mouse on a table that is out of sight. There are tensions between a dark tunnel in which the character walks and the morning sunlight that shines through the slits between the foam of the Rift and the nose of the player. To stabilize the relation between the tunnel as a narrative actor 
and the display as a material actor, the window as material actor has to become part of the network. Location is more than the virtual reality display, as it involves the work between the virtual reality system, computer, and the room.

So far, I have shown that by studying role playing reveals tensions in a network made of Skyrim and Oculus Rift. When the network is in the process of combining the computer role-playing game with a virtual reality system, these tensions point at further material actors that need work before they cooperate. I have followed tensions between the actors that construct the location and realized that location in a virtual reality role-playing game extends the virtual reality system. If the location includes the table, computer hardware, and the room and the location forms part of the network, there is one more material actor that needs to be integrated before role playing works: the body of the player.

Tensions between costume, character, and Oculus Rift. I load the tunnel scene again. The tunnel is dimly lit by phosphorescent plants, but it is not dark for me. Through the gap between my nose and the foam cushion, the morning sunlight is visible. I see my hands move on the keyboard. With time, I realize that increasingly I am checking where my hand is, so as not to push the wrong button, for example a QUICK LOAD button that would stop the game and load an earlier saved file. I should adjust the room next time, I think, but I have no roller blinds. So I should play when it is dark outside or move the character out of the tunnel. The character stands in the valley surrounded by mountains again.

This break between keyboard and fingers might be prevented by improving the skills of the human actor in relation to the input devices, or by replacing the input devices. One example would be a finger motion sensor device, such as Leap motion or Nimble VR. ${ }^{82}$ In June 2015, Oculus announced Oculus Touch, an input device to track gestures for further interaction. ${ }^{83}$ The example of finger tracking leads from the actor location to an actor that is closer to the relation between the body of the player and the character: costume. I followed the material actor costume in larp and augmented reality games, where the player wore the costume to represent the character. Playing a video game with the Rift, there is no need to wear a costume. However, the trace of this actor can be found in the action. If the costume represents the narrative actor character with a material actor in larp, the costume in a virtual reality system is supposed to be part of the representation of the character on the display. In a computer game, it is the avatar that serves as the visual (and acoustic) representation of the character. ${ }^{84}$

82 In December 2014, Oculus bought Nimble VR (https://www.oculus.com/blog/nimble-vr-13thlab-and-chris-bregler-join-oculus/).

83 https://www.oculus.com/en-us/blog/the-oculus-rift-oculus-touch-and-vr-games-at-e3/.

84 The avatar is a central unit of analysis for game studies. For an in-depth study of the avatar from a 
The clothes of the avatar do not relate directly to the body of the player, as the costume does in larp. The costume is the image of the avatar's clothes as narrative actor in relation to the game-relevant properties of the clothes as ludic actor. In a virtual reality network, the relation between costume and body requires a virtual reality system as intermediary. In this example, the Oculus Rift has to become a collaborator in the work of representing a character, but this process leads to tensions.

The avatar wears a set of heavy armor while he walks down the road, but I do not see the avatar, only the environment. When I draw a weapon, there is an animation of the hands and the equipped sword or fireball. In the corner of my eyes, there is nothing. I move my head and the camera moves down. There are no feet, no legs, no clothes.

I do not get a sense for my character. There are no parts of the avatar or its clothes visible. I look for further stimuli.

The avatar walks and the camera moves to the right and the left, imitating a walking person. While I play, I stand up and push my chair to the side. Now, my body posture equals the height of the avatar.

While hitting the button W, I move my legs as if I were walking, synchronizing my movements to the character's. Now, the camera moves to the right and the left, because the tracker follows my head and the camera imitates the movement. I get slightly dizzy and sit down.

The scene shows that the relation between the game as a ludic actor and the display as a material actor has not been programmed with a virtual reality display in mind. My body's movements, standing up and moving my legs, do not translate as part of the character's movements. The tension makes me wonder how it would be to include the full body while playing, using body movement as further input. At the moment, there are prototypes for tracking leg motion (running, walking, jumping), such as the omnidirectional treadmill Omnia or Cyberith Virtualizer. If the material-ludic relation is part of the game code, using such trackers will enable further interactions. One candidate is Valve Vive, the virtual reality system that includes headset, controller, and room tracker (Valve and HTC, end 2015). Interaction in role-playing games means a "wide range of configurative options for interacting with the game world through their character" (Hitchens \& Drachen, 2009, p. 16). As these scenes show, possibilities for interacting through the character with the 
game world require a relation with the material dimension. Replacing the input device keyboard and mouse with an alternative controller and adding further trackers, such as an omnidirectional treadmill or a room tracker, opens further interacting options.

Opening up a range of interactions reminds of the augmented reality example. Whatever might become possible, there are two more general observations. First, in order to have a meaningful range of actions, these options of input and output can be controlled by relating them directly to a character. By expanding the range of available characters, further actions with the game world become possible. Second, although I do not claim to predict what innovations in virtual reality displays will become part of role playing in years to come, current development shows that the virtual reality network is not stable when it relies on computer software and hardware alone. Stability improves with further relations between the game software as a ludic actor, the game content as a narrative actor, and material actors that include both the hardware system and its relation to other material actors, such as the room and the body of the player. To understand how a virtual reality role-playing game network works, it is necessary to understand additionally how materials collaborate with narrative, ludic, and other (sometimes seemingly invisible) material actors.

To sum up, the avatar's costume in a virtual reality role-playing game includes the character clothes, but the virtual reality system opens up relations between the character and the player's body. In order to role-play a fictional character with a virtual reality display, the range of interaction increases not only with the narrative-ludic relations, as the previous example of modifications has shown, but interactions increase with more relations. The relations become finer between the body and the character as a network of material (body), ludic (software), and narrative actors (character, game world). Role playing with the Oculus Rift reveals missing relations between the costume of the character and the body of the player, gaps that provide room for developing the actor costume with further input and output devices. Such devices are currently in a prototype stage.

Role playing in computer role-playing games requires more relations between narrative and ludic actors than the core game offers. For example, players have to make conscious decisions from the point of view of the character when they want to go beyond combatoriented game play. Modifications of the core game software add further actions, such as the effect of the weather on the character, and support this decision-making process.

Demands of virtual reality technology for role playing. In this section, I changed the computer role-playing game network by replacing the display with the virtual reality system Oculus Rift. The aim was to understand how a network combines the computer 
role-playing game Skyrim with the virtual reality system Oculus Rift with the aim of translating role playing. By following material actors that construct Skyrim and the Oculus Rift, I examined how tensions arise from relations between material, narrative, and ludic actors and how these tensions threaten the stability of such a collaboration.

Role playing Skyrim with the Oculus Rift is stable when the network not only incorporates the computer hardware, virtual reality system, and the game software, but expands beyond and incorporates the room and the body of the player. Thus, the location as the representation of the story world extends what is seen on the display. The location incorporates the virtual environment, the table before the player, keyboard, mouse, chair, and further actors such as the window. In order to fulfill the Oculus slogan "step into the game" and to help players to take the view of the character to make decisions and roleplay, the combined network makes an ally of the room and the body of the player.

\subsection{Conclusion, or Before the Blackbox of Mixed Reality Role- playing Games}

One year after the Obscurus 2 larp, I put my smartphone in a box of computer spare parts. The battery life of the phone had decreased to the point where I had to charge the phone twice a day. I needed a more reliable device, but I kept the old smartphone for a future alternate reality larp where I might destroy it as part of role-playing my character.

The Oculus Rift sits in its paper box beneath my table. I do not use it as often anymore, because a new actor has entered the room. My family has grown and when a toddler is crawling around the room, it is difficult to use a headset.

This chapter began with the question of how material actors collaborate with narrative and ludic actors to make role playing work in mixed reality role-playing game networks. Common definitions of mixed reality place augmented reality and virtual reality on a continuum (Milgram et al., 1995), but in this chapter, mixed reality is a network that consists not of either digital or real, nor of augmented or virtual, but of heterogeneous actors that can be spoken about when they leave traces of their collaborative work. In this chapter I have studied how augmented and virtual reality systems join larp and computer role-playing games with the aim to create a combined network. I examined this process by following the work of material actors and the tensions that arise.

In the example of Obscurus 2, I followed the material actor smartphone. As a part of the costume, the smartphone represents the character, as it connects the narrative actor 
character with the material actor body of the player. This work maintains role playing only if the relations that a smartphone is making to other actors are under control. Part of control emerges from the material work of the location. The location in Obscurus 2 acts as it connects the narrative actor game world with in the material actor bunker building near Haarlem, in the Netherlands. The location influences player actions, as they have to consider the walls of the bunker when the actor smartphone co-creates a role-playing scene. For example, inside the bunker the connection was cut between the receiver in the phone and the sender in form of satellites or radio masts. The players had to move outside in order to be able to use the information on the smartphone display.

In the example of The Elder Scrolls V: Skyrim, the Oculus Rift Development Kit 2 became the central actor to follow. The Rift replaces the display of an LCD screen with a $360^{\circ}$ headset. As a part of the location, the Rift creates relations between the game world as the narrative actor and the display as the material actor according to the ludic actors (game software, Rift drivers). Following the Rift as a location, further relations between the actors became visible or appeared as missing. For example, the material-material relation between the headset and the player shows that further relations between the body and the game are possible. Role playing Skyrim, thus acting as the character and exploring a range of actions, these relations became relevant. Underdeveloped relations became apparent, such as the material-ludic relation of the head-tracking camera, the body movement, and the imitation of avatar movement when walking. Missing relations between the body, game code, and the game world revealed possibilities for further input and output devices. Further devices that support role playing require innovations of the display beyond the visual and sonic. Prototypes exist, such as finger-tracking input devices, for example Leap Motion and Oculus Touch.

Following how material, narrative, and ludic actors translate role playing revealed existing relations and potential relations in the tensions that became observable. The current socio-historical context transforms the promises of the 1990s hype of virtual reality into everyday mixed reality products, such as development of mobile computing devices from the smartphone to watches, smart clothes, etc., or from computer LCD displays to Oculus Rift, Microsoft Hololens, etc. To understand how mixed reality devices work for role playing, it is not necessary to know exactly what devices will be available everywhere and anytime in the future. As this chapter shows, mixed reality devices work for role playing when the network expands beyond the mixed reality systems and the game. A network that combines larp with mobile computing devices requires a location that offers a stable wireless Internet connection and cheaper and modifiable devices. A network that combines a computer role-playing game with a virtual reality system 
requires further work that prepares the room where someone plays and suggests further relations between the hardware, software, and the body of the player. However, current mixed reality devices work on the premise that actors are already connectable to each other, not that they need to be separated and have to be remixed in a different network.

Future networks that combine role-playing games with mixed reality technology will have a different name than "augmented reality role-playing game" or "virtual reality roleplaying game." Nevertheless, the networks will need to work in a way that is similar to the examples given above. For the sake of stability, any mixed reality role-playing game network will rely on relational processes beyond narrative and ludic actors. These relational processes rely and will rely on self-organization that incorporates heterogeneous actors, such as diverse material (smartphones, headsets, location, costume), narrative (character, story world), and ludic (game rules, software, game code, modifications) actors.

Current developments show a direction where augmented and virtual reality will come together in future role-playing game networks. When more mobile computing devices become part of everyday fashion, more larps will work with augmented reality technology. When current virtual reality systems solidify and provide stable interfaces for video games, more computer role-playing games will use virtual reality interfaces. The examples in this chapter have shown that materials work in further relations. The results suggest that mobile computing devices and virtual reality systems might merge in games that combine augmented and virtual reality, for example the Pip-Boy for Bethesda's next computer role-playing game Fallout $4 .{ }^{85}$ The story world of the Fallout series takes place in a postapocalyptic setting, which is also a popular setting for larps. It is likely that a larp in the post-apocalyptic setting will integrate Bethesda's Pip-Boy as part of the costume. ${ }^{86}$ As roleplaying games integrate more and more mixed reality technology, these combined networks become more ubiquitous, and it becomes important to understand how material actors matter, before role-playing games with mixed reality technology become blackboxes.

85 In June 2015, during the annual video game conference Electronic Entertainment Expo, Bethesda announced details for their next single-player computer role-playing game, Fallout 4 . The collector's edition will provide a physical version of the in-game Pip-Boy, a smart device worn by the character at the wrist. Players can insert their smartphone into the physical version and interact with the game via the physical Pip-Boy in relation to their smartphone. At this point, augmented reality meets virtual reality (http://www.bethblog.com/2015/06/15/prepare-for-november-10thpre-order-the-fallout-4-pip-boy-edition-today/).

86 There is at least one larp group that uses the Fallout games as narrative background, the Brotherhood of Steel in Russia. The larp Fallout 2009: Nothing personal took place in 2009 and gained attention via social media, such as the Fallout Wiki (http://fallout.wikia.com/wiki/User_blog:Ausir/ Fallout_2009:_Nothing_Personal_LARP_in_Russia). 


\section{TABletop Role-Playing GAMES}

In my living room, I sit at my table and talk through a laptop microphone with Leon. We first met during two horror larps in Aachen. Last week, he joined me for a tabletop roleplaying games session. The software in my laptop records his answer to my first question: What is role playing?

"I understand role playing in a more literal sense. It is playing with the role which one embodies, or when you are the game master it is several roles. Playing is performing, immersing, and representing of logical decisions which the character would also make."

In a tabletop role-playing game, the level of performance is lower than in a larp. Players sit around a table and explain what their characters should do, what Leon refers to as "logical decisions" of a character. The game master then decides whether the action succeeds. Rules help with the decision, often by rolling dice. Performing is about facial expression, the modulation of the voice, and gestures when players describe or talk instead of their characters. During the game session with Leon, we immersed in the shared story world while we were developing the story collaboratively for one and a half days.

\subsection{Introduction, or "Compare It With Improvisation Theatre"}

Tabletop role-playing games have developed as a game genre since the commercial release of Dungeons $\mathcal{E}$ Dragons in $1974 .^{87}$ In the past 40 years, researchers, designers, and role players have come up with their own explanations of what a tabletop role-playing game is. ${ }^{88}$

87 For a history of tabletop role-playing games, consider Barton (2008), Hillenbrand and Lischka (2014), and Peterson (2012).

88 For an overview of the online discourse between designers and players since the beginning of the World Wide Web, see Kim's extensive website and Mason's historical overview (Kim, 2008; Mason, 2004). Torner analyzed the definitions given by game designers and their traces to academic work (Torner, 2015). 
In this chapter, I do not want to start with preconceived notions of what a tabletop roleplaying game might be ${ }^{89}$ but let the actors explain instead. In summer 2014, I did a series of interviews with tabletop role players. Leon's explanation of role playing was the most accessible answer and I continue with him (Leon, Interview, June 28, 2014):

Most likely, I would compare it with improvisation theatre. [In improvisation theatre,] several people stand on a stage. Someone invents a character and starts talking. The other one reacts to it, as if he was a different person. From this, a dialogue develops. Maybe, the people add some actions that they perform or describe. From this, playing develops. Now, a third person joins them on the stage, but the third person has a special ability. From the side, this person may tell the others, for example, that they are in a building and what it looks like. The third person is able to describe the world and is allowed to perform more than one character, while the other two are limited to one character per person. I think this is role playing.

A game master describes the fictional world of the players' characters. Players imagine this world they play in together as a shared imagined space. ${ }^{90}$ The game moves when a player describes what her or his character does in this world. Verbal descriptions keep role playing going, either by using the first person or third person: "I leave the group and go into the room" versus "My character leaves the group and goes into the room."

Even though all players sit at the table, in their imagined world some might not be present. As there are usually two to five players and one game master, playing rarely includes all players at once, either because a dialogue of six people is difficult to understand or because not all characters partake in the same action. Leon explained how interaction works among players who sit around the table, although their characters do not partake in all actions on the "metaphorical stage." With "metaphorical stage," Leon referred to the shared imagined space and expanded the comparison of role playing to improvisation theatre.

89 See Chapter 2.

90 The term shared imagined space originates in early online discussions of designers and players at the Forge forums. "The concept that has emerged as possibly the single unifying and distinguishing feature of role playing games is that of the Shared Imagined Space. In essence, any group of players is making an effort to imagine the same events occurring in the same imagined setting. Of course, there are some discrepancies between individual images of this, but overall the game is able to proceed because there is a common understanding of what is happening, a shared agreement of the events of the game" (emphasis in original, Young, 2005). 
It is the case that some characters do not talk. Player 3 who role-plays character 3 may not be on the metaphorical stage. When players 1 and 2 say that they want to enter room A, the game master says, OK, I describe room A. Those two who enter room A continue playing. Player 1 and 2 continue the dialogue with the game master. Player 3 might say, I want to enter room B. Then you have two characters in room $\mathrm{A}$ and one character in room $\mathrm{B}$. The game master moderates both rooms and the characters in them. The game master cannot moderate them in parallel. He can only continue the dialogue with characters in one room. Then the other player has to wait. This happens in role playing. It may happen that [as player 3] I do not do anything for one hour, because my character is not there and because the game master is occupied with the other players in my group. Then, at some point, he may stop and then it is my turn, while the others do nothing. During such breaks, I check my clock, check if I have appointments for the next day, and of course I listen to the others while they role-play, because it is exciting. When I have the feeling that they only discuss and do not play, then I distract myself until it is my turn without disturbing the others.

Role playing is a multi-vocal dialogue that demands concentration, because different actions are done at the same time. Listening, imagining, role playing, consulting rules, rolling dice-these actions involve sometimes one player, sometimes they involve others. When several people are involved in different actions, it is important to avoid disturbance. Players need a certain level of concentration to imagine, to maintain, to share, and to continue role playing their characters in a shared imagined space. Writing notes helps readers to keep up and maintain information.

While improvisation theatre is similar to role playing, one difference is how players represent the actions of their characters. A tabletop role-playing game session does not take place on a stage. The focus is on verbal speech rather than on performing actions. Sometimes players perform smaller actions, such as gestures, facial expressions, or a change in the tone of voice. For example, players might start shouting when they want to role-play their characters' anger. Actions like fighting or exploration require a different kind of representation, as everyone sits. Leon continued his explanation of role playing.

What I said up until now was just about dialogues. Then there is the case where someone does not talk in a dialogue but describes an action. Character 3 goes into room B and the player says now: I want to look around in the room and see what my character sees. If the game master has described the room well, 
the player can role-play how the character looks around, but then the character won't be able to really see what is there. For this reason, the game master has to tell the player what happens when the character looks around in the room. Maybe the character notices a letter on the table. This is the reason why we use systems, role-playing game systems, ${ }^{91}$ and why there are "abilities" and why we use dice.

Before the game starts, every player creates one character. While this might be solved quickly in improvisational theatre, character creation in tabletop role-playing games takes more time. One reason is that role-playing game systems demand an elaborate character that is described on a special sheet of paper, the character sheet. Game systems in the tradition of Dungeons $\mathcal{E}$ Dragons rely on quantifiable abilities that define the character. On a character sheet, which looks like a piece of paper full of differently sized boxes, the player notes numbers for the different attributes of his character. For example, a character might be physically strong, so the attribute score for "strength" is higher than for another character. The attribute score is expressed in a number that serves as the quantified representation of a character's "strength." The number relates to a scale that depends on the game system. The scale then relates to a specific die. In Dungeons $\mathcal{E}$ Dragons, the attribute strength ranges from 1 (lowest) to 20 (highest). According to this system, the player uses a die with 20 faces to check if the character succeeds or fails. Rolling a die according to the scale is called an attribute check roll or attribute check. When the game master describes a situation in which the character has to test her or his strength, the game master might demand an attribute check and the player rolls the die. Although a strength act is relatively simple, breaking a door becomes a complex process involving game rules (ludic actors), the described situation (narrative actors), die and the physical rule book (material actors). First, the game master decides the Difficulty Class of the door. The rule book is opened at page 62 to consult the Difficulty Class for doors. The Difficulty Class for doors is a number between 0 and 28 for non-magical doors according to Table 4-5: Example Door DCs (Cook et al., 2000, p. 62). At this point, the character does not know the number, but can ask how the door looks like. The game master describes a typical wooden door and decides covertly the Difficulty Class of 18. When the player decides that the character tries to kick in the door, there is need for an attribute check. The attribute check consists of a static modifier and the

91 "Game system" refers here to one particular tabletop role-playing game. The role-playing game system discussed by Leon is Dungeons $\mathcal{E}$ Dragons. I refer to the 3.5 edition of this system throughout the chapter (Cook et al., 2003). 
result of a die roll. The player adds the result of a twenty sided die roll to the strength modifier. When the character's score for strength is 18 , the game master finds the modifier of 4 in the rulebook on page 8 in the Table 1-2:Average Strength Scores (Cook et al., 2000, p. 8). The player adds 4 to the result of a die roll, for example 12. The sum of 16 has to be higher than the Difficulty Class of the door. As the Difficulty Class is 18, the character does not succeed, because the sum of modifier and die roll is lower than the Difficulty Class that the game master has decided upon. This is one example where the die roll and the number on the character sheet result in a success or failure of the character while doing an action in the story world.

While the relations between ludic and narrative actors are apparent, the materials side of tabletop role-playing games requires further study. Carter's (2014) work has provided a first step when he examined the players' pleasure of rolling physical dice in wargames. The example above shows additional material work: the practice of consulting several rule books and flipping through several hundred pages to find the necessary tables and statistics. A tabletop role-playing game network is only stable when this work does not create tensions. However, the more elaborate a game system, the more numbers define the character. Beside attributes, game systems often require points and tables for abilities, skills, health and stamina points, magic pool points, experience points, circumstantial bonuses, proficiencies, and other relevant statistics. These numbers define the character and its world in natural numbers and require differently shaped dice for the different checks on attributes, abilities, and so on. Moreover, certain actions ask for combination of, for example, attributes and skills. If the player decides to look around in the room for clues, the player has to use the character ability "Spot." A "Spot" action in the room requires a calculation of the attribute "Wisdom" and the score in the "Spot" skill. Game systems in the tradition of Dungeons \& Dragons use heavily different numbers and calculations to determine if a character is able to succeed an action or not. Any action that relies on calculations becomes exciting with the roll of a die. The chance aspect is one important determinant for success, although the game master might choose to change a Difficulty Class number after the die has fallen. In this example, the sum of die roll and modifier for strength were 16 and the game master might decide to lower the Difficulty Class for the door to 13, a simple wooden door, because the narrative needs to continue. After breaking the door in, the game master might tell the players that the door looked more solid than it actually was. Leon elaborated further why dice matter in tabletop role-playing games.

Game system, abilities, and dice provide an element of chance. Thus, one player can say: my character is extremely good at seeing things. When a character who is 
good at seeing looks around in room B, the player rolls his dice against the ability score. ${ }^{92}$ If the dice roll was successful, the character might find out more.

What the character finds out depends on the dice roll and the final interpretation of the success (or failure) by the game master. The game master has two functions: as a narrator, the game master is in control of what happens in the imagined shared space, because this function involves preparation of the background and often the creation of the story world. The difference between story world and imagined shared space is that the story world refers to the fictional background of the characters and their world while the imagined shared space emerges from role playing with this world. In the second function of referee, the game master is in control of the game rules that determine how something happens. Thus, the game master has a range of options to work with narrative and ludic actors in the game. When the player succeeds, the game master describes verbally what happens in the imagined shared space according to the game rules that decide whether the ability check was a success or a failure. As characters differ in their attributes and skills, some characters are better than others at succeeding. What makes the game exciting is the chance aspect. The roll of the die determines what becomes possible through character actions in the shared imagined space. Leon referred to the chance aspect here:

If it was player 1 who entered the room instead of player 3 , and player 1 is very bad at seeing [as represented by a lower ability score for "Spot" as noted on the character sheet], the character might not have had the option to find the passage. But as it is a die roll, there is always the chance that one character succeeds and another one does not succeed, even if this character has a higher ability score.

Character attributes and dice are usually open for interpretation, because game rules only determine what is a success or a failure of a specific character action. The game master can spontaneously decide against a rule and say that a success is a failure, because a change makes more sense in the context of a specific situation, or improves how the story evolves. Additionally, a game system does not define all possible character actions. What the character actually sees, and what happens in the shared imagined space as a consequence, depend on the game master's final decision and imagination.

92 An ability check is related to the numerical attribute score of a character. In addition to the calculation of the attribute "Wisdom" and the skill "Spot," a game system might include further calculations regarding the environment, the character's condition, and possible further influences in the scene. Someone looking for a needle in a dark room, bleeding from several wounds, and hearing enemies outside has a more difficult task. 
In the scene above, the game master decides to tell player 3 that in the room there is a bookshelf. It is possible that the bookshelf already existed in the story world before the player searched the room, because the game master had planned the room in advance. It is also possible that the game master imagined the bookshelf spontaneously during the game. After a successful ability check, the character notices that there are scratches on the bottom of the shelf. When the player decides to follow the trail, the game master might describe how the character moves the shelf aside and discovers a secret passage. For most role players, the option to decide what the character does in its world is an important part of role playing. Decision making or interaction has been studied as one integral part of role-playing games and is responsible for dynamic game-play. ${ }^{93}$ But studies focus usually on players. In the following chapter, I examine interaction between all actors present: players, game masters, characters, abilities, skills, imagined rooms, Spot actions, dice, character sheets, tables, and more.

So far, I have followed Leon's explanation of role playing in tabletop role-playing games. This was a common way to introduce this game, because Leon focused on what players do and explained role playing with narrative, such as the story world, and ludic actors, such as game rules. It answered the question "What is a tabletop role-playing game?" A couple of sentences tell what happened: there were one game master and three players who moved their characters into two separate rooms. Player 3 found a secret passage by succeeding in a dice roll. Although this role-playing scene can be briefly summarized, role playing the scene took more time. The reason is that different narrative and ludic actors have to collaborate, and this takes time. Splitting the characters and searching for a secret passage might have taken about half an hour of play time, because several actions were necessary: the game master describes the story world, two rooms. ${ }^{94}$ Players

93 This understanding of interaction is based on ludic (rules) and narrative (story) actors. For example, "In fantasy role-playing games, participants collectively create and play fantasy personas in an imaginary universe by using a vast system of rules that function as guidelines for makebelieve action and interaction" (Waskul \& Lust, 2004, p. 333). The definition focuses on narrative and ludic actors - narrative: fantasy persona, imaginary universe; ludic: system of rules, guideline for make-believe action and interaction. Interaction is one of the six elements that define a roleplaying game according to Hitchens and Drachen (2009). In this chapter I extend the understanding of interaction as a process when I add material actors in relation to narrative and ludic actors. "Interaction" is then not the cause of narrative or ludic concepts, but a trace of actors at work. Following materials, I can trace the relations to the player's body, his voice, tongue, etc. This extension of interaction towards the material can explain why and how game rules and a story world change in a game session.

94 The difference between story world and shared imagined space is that the story world turns into the shared imagined space when it is verbally shared and more importantly, when all hear what the story world is about. The necessity of being within hearing range is the reason why I will emphasize the role of the table later. 
decide their characters split up. Player 3 decides to search. Player 3 rolls an ability check for searching. Rules are consulted if the roll is successful. In agreement with rules and the game master in his function as referee, the dice roll is successful. In his function as narrator, the game master describes further details about the room. Then the players might decide to reunite their characters in the secret passage and continue together. Speaking with the actor-network vocabulary, role playing emerges in and by a network of actors that collaborate. Narrative actors help players to imagine and share the scene. Ludic actors govern character actions according to their numerical attributes and dice roll. When narrative and ludic actors collaborate, role playing produces the shared imagined space. As in the previous chapters, I want to show that it is not enough to consider narrative and ludic actors to understand role playing. Thus, I move away from the given explanation that stands for similar definitions of tabletop role-playing games within the community of designers, players, and researchers. The aim of the following sections is to answer "How does a tabletop role-playing game work?" by following a third group of actors that have played a silent role so far: table, character sheets, dice, and other material actors.

\subsection{Problem, or Experiments With a Messy Network}

From frame analysis to narratology, previous studies have defined tabletop role-playing games, analyzed narrative and ludic concepts, and examined what players do and why they do what they do during a game session (Cover, 2010; Fine, 1983; Harrigan \& Wardrip-Fruin, 2010; Hitchens \& Drachen, 2009; Jara, 2013; Mackay, 2001; Miller, 2006; Montola, 2009; Pappe, 2011; Young, 2005; Zagal \& Altizer, 2014). However, there are no studies on material actors in tabletop role-playing games, materials like the eponymous table, pencils, and many more things, objects, and items that seem neutral. This chapter provides clues to understanding how a tabletop role-playing game works. More importantly, the following actor-network study explains how narrative, ludic, and material actors collaborate and make role playing work in a tabletop role-playing game network.

As in the previous empirical chapters, I start the analysis with a role-playing situation. I sit with four other players and one game master together around a table. The game system is Dungeons \& Dragons 3.5 (Cook et al., 2003). The story world draws from typical elements of a fantasy setting, such as various humanoid races, mythical monsters, and supernatural abilities and events. After about two hours, the game is at its fullest intensity.

There are various narrative and ludic actors at work, for example rules and characters, actors that players and researchers are aware of. When I look also at material actors, 
the complexity of a tabletop role-playing game session increases to a point where it becomes messy:

A soft drink bottle stands on a pile of scrap paper. One of the five players moves a plastic bowl to the edge of the table. A radio plays background music that wraps around three different voices. One player explains what his character will do in the next round. Two other players discuss a specific rule above the open book resting between them on a pile of papers and dice. No one has used a smartphone for the last two hours. Four painted and two unpainted miniatures group on a piece of paper on which someone had sketched a ground plan. One player picks up a box with cacao. While one player describes what her character does, the game master makes notes behind the game master screen. In front of the screen there is a bag of chips, a pile of dice with four, six, and twelve sides. The game master changes his voice to role-play a non-player character whom characters meet in the story world. A pile of books rests at the edge of the table. Three ten-sided dice are scattered on them. The ceiling lamp is still on. The windows are dark and mirror the group. On a folder there are three empty transparent envelopes and a pencil. In between, more scrap paper. Beneath all the items, there is the plastic tablecloth. Erasers are much in use, because the numbers and words change often on the many sheets of paper. Someone hands the supplement rule book for mass combat rules across the table. On a coaster, someone has built a tower of eight-sided and twenty-sided dice. From a mug, the smell of coffee rises and mixes with the warm air in the room. The air is stale, similar to a small office room ten minutes before closing time. A closed blue plastic box for dice and pencils lies close to the center of the table. Next to it is a leather dice cup. More six-sided dice. No one uses the turned-off calculator despite the many calculations of dice numbers and statistics. More twenty-sided dice roll on the table. ${ }^{95}$

The list above describes a moment during a typical tabletop role-playing game session. The description may be confusing, because there are familiar and unfamiliar actors, and because they move or are moved from one side of the table to the other in no apparent order. While some materials are familiar to most readers, such as table and bottles, others may be unfamiliar (character sheet, game master screen, or the different dice), while other materials are seemingly irrelevant, such as the lamp. In a tabletop role-playing game session, heterogeneous actors are at work. Some actors are obviously relevant to the game, such as rule books, while others require knowledge to understand their game-specific relevance, such as pencils. Moreover, material actors are not static. They are in motion, as food is shared across the table, players read in rulebooks, and dice roll between piles of paper.

95 Field note: list of game materials, tabletop role-playing game session, 20.08.2010. 
Observing such a game session shows that materials act in different ways of no apparent order. It is a mess and my goal in this chapter is to explain the messy tabletop role-playing game network. I want to understand how role playing emerges in and by the messy network by answering the question how material actors collaborate with narrative and ludic actors to make role playing work. As in the previous chapters, when actors collaborate, there is an inter-relational process and role playing emerges. ${ }^{96}$ To find out how this happens and explain the messy network, I follow six material actors in the sections 5.3.1-6. As before, the sections build on an actor-network analysis of my observations as participant and interviews with players, but I report the results in an experimental way in this chapter. In section 5.4, I summarize the results, discuss the reporting style, and give one answer to the question.

\subsection{Results, or Let the Materials Speak}

The description above poses the problem of how to deal with a messy network in a methodological way without increasing the mess (Law, 1999). By taking materials into consideration, it seems the network becomes messier; it seems that adding materials is counterproductive. I think the network needs to become messier, because such a state confronts what is known about tabletop role-playing games, an understanding that originates in previous discourses among designers and players, as well as in studies. A seemingly messy network, where it is not clear how narrative, ludic, and material actors work, invites me to look for new relations.

In this chapter, I look for new relations and solve the problem of how to deal with a messy network by experimenting with the way I report the results. I use field notes and interview transcripts to produce texts about material actions, but choose the perspective of the very same materials. By lending an authorial voice to materials, I report the findings in imagined accounts that give an alternative answer to the questions of what materials do and why they do what they do in a tabletop role-playing game. Lending a voice to materials or non-human actors has origins in a few texts related to actor-network theory and postphenomenology (Ihde, 2009; Latour, 1996a), but a similar approach is missing for the study of tabletop role-playing games. The advantage of this approach is that I can use the imagined accounts as an instrument or "inscription device" that allows a reading of role playing processes, that results in writing them "as the final layer in a scientific text" (Latour, 1987, pp. 67-68). Thus, the following imagined accounts are the final step of the methodological principle "follow the [role playing] actors" (Latour, 1987).

96 By "process" I emphasize that action is the focus of my analysis. By "inter-relational" I point out that action is always in relation. Consider also Chapter 2.3.3 on agency. 
The disadvantage of this experiment is that I might irritate readers when I confront them with speaking materials. However, such an irritation exercises the meaning of the word network as a mode of inquiry, and exemplifies the goal of this dissertation: to "grow a sensibility" beyond the human center towards the messy tabletop role-playing game network as a collaboration of actors working together. ${ }^{97}$ To stress the empirical link of the imagined accounts, I add the corresponding interview quotes in footnotes in this chapter. Text in italics indicates an imagined account, which is from a first-person narrator perspective. When the text returns to the standard format, it returns to my comment as the analyst. By lending voice to the table and its allies, I invite the reader to look again at materials. The imagined accounts helped me to understand messy networks, because they added a perspective to my field notes. When I wrote from the perspective of materials, I did not reduce tabletop role-playing games to a few elements or made them messier when I included material actors, be they familiar, unfamiliar, or mundane such as the light. The additional perspective was helpful to trace material actions and speak about them.

5.3.1 Light. My eyes move away from the table to look for material actors around me. A typical location for a tabletop role-playing game session is the living room. ${ }^{98} \mathrm{I}$ look around to see where action happens, action that relates to role playing but has been overlooked before, because they seem to be intermediaries, actors that maintain the network but do not make a difference. One mundane part of the living room is the source of light.

Hi, this is light. Usually, people do not talk about me in relation to role-playing games. I do not make the rules, well, not the game rules. I do not tell fantastic stories. I am not even mentioned in the player's handbook. But imagine the living room. There has to be a lamp, otherwise the game would not work. Light comes from different sources. It could be a ceiling lamp. There might be indirect light from small lamps and windows, too. Together, we are quite a mix.

I look around to see where the light sources are in this room.

My favorite place is above the top of the table. You rarely find me farther away. On the contrary, I prefer to stay close to the table. I illuminate a circle on the table. Beyond the

97 See Chapter 2.2.2 on growing a sensibility (Mol, 2010) and the two meanings of network.

98 Other locations include cellars, hobby rooms, game shops, or a booth at a game convention. Role-playing game conventions allow players to meet other people in rented locations. There exist several associations that regularly meet in places like youth centers, red cross stations, or pubs. There are cafes and restaurants that host tabletop game sessions. For example, Zu den Vier Winden (Bochum, est. 2000) and Grotesque (Aachen, est. 2014) are dedicated to role-playing games, with rooms for tabletop role-playing games and larp. 
border of the circle, the room becomes dark. Thus, I blank out distractions. Paintings, furniture, bookshelves, computers, TV sets, and other things are not part of the game. ${ }^{99}$ When I keep the rest of the room dark, everyday things do not remind players of their everyday life. Players like this, because they can immerse in their shared imagined space. ${ }^{100}$ As role playing requires concentration, my job is to illuminate what is necessary and to shut out the rest of the world. ${ }^{101}$

During play, light illuminates material actors, such as the character sheet, the tiny number on the back of the small plastic die, the subtle movements of hands when players nonverbally express their characters. Light is important, because it keeps the game running. Without light, players would not be able to read their notes on a character sheet.

But light should not be too bright. People role-play for recreational reasons and dimmed light helps them to relax. A circle of light around the table relaxes, too, because it creates a cozy atmosphere. It is like sitting around a campfire and telling stories with the circle of light around a group of people. But this time it is role playing which requires proper lightning, because players have to read dice numbers and notes to play the game. A proper light illuminates what is necessary and shuts out what is distracting.

Do I change during role playing? Sometimes I do. When the characters descend into a dark dungeon, or when the game master has prepared a horror scene. Then, I prefer to emit less light. Players close the window, and might shut off the ceiling lamp. This happens often when we play game systems that use a horror setting, such as Vampire: The Requiem. When playing Vampire, less light is more effective, because less light intensifies the spooky

99 "Well, I have often experienced during role playing - it does not relate to this room-that almost bare rooms are almost better. Very often, I have had this experience, we have already played at many people's places. The best sessions were often those in somebody's cellar, where there was some old furniture, where there was nothing exciting to look at. On the contrary, playing outside in the gazebo was a great idea, but to be honest, I was distracted all the time.... I think that our living room is OK. You notice daylight, but it is furnished very well. A lot of fantasy pictures, tapestries, a lot of dragon posters, miniatures. This does not distract, even if it is not a bare room" (Koboldfeuer, Interview, 6.06.2014).

100 "These are things that I relate to directly, to the everyday life in my head. My everyday life is something from which I want to escape in role playing, because I do not want to go into my character but into a character that I want to embody. And everything that has the routines of my behavior in it, I think, is an object that fulfils this category, and it has to vanish" (Stephan "Zuris" Kinting, Interview, 3.06.2014).

101 "The room, the atmosphere in the room, you try to separate it a little bit from the outside, what is outside the room, by creating a special atmosphere with nice lights, for example. That helps to concentrate upon the game and not on what you have done today at work" (Jan Malspöler, Interview, 10.07.2014). 
atmosphere that fits well to the setting. Candle light is even better. Vampires $\mathcal{E}$ candles! Imagine the game master describing vampires who crouch in dark alleys and then a candle flickers. It is more atmospheric. It is more fun.

Changes of light during a game session are traces for agency that brings together actors. Players dim light sources, shut down windows, or light a candle to support a horror scene. Changing light is a trace for a changing relation between the material actor light and the narrative situation when characters enter a spooky place. This change of the network helps players to immerse in the shared imagined world. Without a change of light, the network would work, but it is more stable when the material collaborates with the narrative.

What I dislike is when there is one source of light, like a static ceiling lamp. I cannot adapt and support the atmosphere. People do not relax, because I pierce their eyes. When the game proceeds to a later hour, I might hurt their tired eyes. I like to have more options to illuminate a room.

Another change of light occurs when I see the relation to the body of the players as material actors. The eyes as part of the player's body hurt when the light is too bright. Then the network has to change and the light has to adjust to tired eyes in order to remain stable. Role playing requires here a change of relation between players' eyes and light. But light not only changes in collaboration, but demands action from other actors, too.

If I am to be part of role playing, I want something from several actors. From people, I want them to adjust my sources according to their eyes. I cannot do that on my own. I need people to switch light sources on or off. If they are smart and realize the need for a change in our relation, they adjust my work. If I am adjusted, I do my best and support the game. I work best when I emit enough light and at the same time when I am not too bright. Players realize the amount when they take into the consideration how much light their eyes need to read their notes on paper.

I want also the table to be in the center of my illumination work. If I am a fixed ceiling lamp, the host should place the table beneath me. If I am flexible, someone should put me at the right spot in order to light the table properly. Then people can see the numbers on the back of dice and role playing goes on.

To sum up, light constructs relations between other material actors in the network: between players' eyes and the materials on the table. Light deconstructs relations 
when it is too dark or too bright. The material-ludic relation breaks, because it is not possible to see dice numbers and the numbers on the character sheet, which are both ludic actors. Light reconstructs changing relations between players and their notes, for example, when players' eyes become tired. The light demands change. Then players have to act according to the possibilities of light switches, bulbs, and lamps. Adjusting the light in the room is not necessarily a conscious decision of human actors. It is more of a reciprocal action that involves the light source, switches in the room, players' eyes, their physical state of tiredness, and their bodily position towards the light source. Light might not seem relevant for role playing, but light co-constructs the game network when light collaborates and demands actions from its fellow actors. Light reconfigures the relations between itself and other actors, such as the table, and keeps their relations stable to make role playing work.

5.3.2 Table. I am a table, yes, a wooden dining-room table. My size is 1.60 meters in width and 2.40 meters in length. I provide sufficient space for six people, five players and a game master. As you have already read, there is a lot of action going on, on my top. No surprise that this game is called tabletop. Action begins even before the game starts. The host tidies me up. One reason is that nothing should distract the players, or so they say. I give you another reason: we need all the space we can get when the game starts. Remember the messiness? Players distribute their materials seemingly everywhere, but it is my size that influences their decisions, because I offer a clearly defined space for all: $1.60 \times 2.40$ meters.

The table in my example provides $3.84 \mathrm{~m}^{2}$ of space. It segments different areas for each of the five players, one game master, and common space between them. Players distribute materials according to the available size of their personal area. The personal area is in front of each player. There are personal game materials-for example the character sheet, dice, pencils-and personal materials-for example dishes and a glass. As players sit next to each other, player areas intersect. In this shared area, there is scrap paper, food, bottles, and other materials for common use. Dice, character sheets, and game materials rarely enter the shared area, because they have to be close by and the neighbor could accidentally pick up these items, which would hinder play. I elaborate upon this further down.

As the table provides the overall size, the table influences the size of personal and shared areas. When there is little space, materials lie on each other, and this might cause disruption in role playing. For example, snacks lie on a pile of scrap paper. The player needs the paper to make a quick note during play, but first the player has to move the 
snacks aside to get the scrap paper. As role playing continues while the player accesses the scrap paper, some information might be lost.

I am in the center of the game on different levels. People sit around me, distribute materials on the areas that I provide, and the light shines on me. I gather people to a common place, and make sure that together they take part in role playing. When the light is similar to a camp fire, I am the fireplace, the center of the gathering.

I position people in relation to each other. All sit at more or less the same distance to each other. My height corresponds with the height of the chairs. The effect is that all players and the game master are on the same eye level. The equal eye level supports a flat hierarchy between players.

Table and chairs position players geometrically around a common center at the same height. The geometry of furniture establishes a hierarchy that influences power relations. In this regard, table and chairs collaborate with ludic actors of hierarchies that the game system sets up when it divides participants to players and game master. The geometry establishes the equal power relations between players themselves, and between the group of players and the game master. ${ }^{102}$ Gathering players physically to a center stabilizes their relations, because the center positions each player's body at more or less the same geometric distance. All players are within sight and within earshot and every player hears and is heard during role playing, which stabilizes the network and makes it possible for the story to unfold in a shared imagined space. When a player does not hear what is narrated, the game master cannot share this particular part of the story world, with the consequence that this narrated part does not become part of the shared imagined space. The narrated part establishes a relation to the network when the table gathers all players within hearing range. Thus, the table and chairs position the bodies of players as material actors to support the work of ludic and narrative actors.

The geometry of the table provides areas for each player, shared areas between players, and a common area for all players and the game master in the center.

102 The distinction between participants creates an asymmetric social hierarchy between the players on the one side and the game master on the other side. Montola explains this hierarchy with "invisible rules" which are implicit ludic actors, for example the second "additional" rule that grants the game master the "decisive defining power" (Montola, 2009, p. 24). As role playing runs by verbal descriptions and dialogue between people, there is room for negotiation. In this study, I understand power as ludic agency that emerges from the negotiation between game masters who want to decide, players who want to force a change of rules, the rule books, and house rules. For an not static view on hierarchy between participants, see also Young (2005). 
I have heard of one table that a player made for playing tabletop role-playing games. There are some differences to a common living-room table. First, the tabletop role-playing game table is transportable. The player can unscrew the legs and remove them easily. Then the table fits into a car, because the owner moved to another city, but wants to play at his friends' house. As the table is transportable, it has to be light enough to be carried, but stable enough to serve the game. Stability of a table is important, because players who bounce into the table or kick a table leg, might rock the table and the mess becomes even messier. Think about all the drinks spilled over character sheets and books, and about the miniatures on the carefully drawn battle map! This would be a real mess. ${ }^{103}$

A table that is not stable introduces the risk that actors will break their relations in a network. When the tabletop and legs are of wood that is heavy enough and well screwed together, then the table provides the necessary stability. Otherwise, when the table is too light, people who bounce it may disorder the arrangement of lightweight materials on the table. This seems trivial, but a table is a better ally when it is stable, because it prevents disorder. Although the arrangement of materials seemed messy, the previous pages have already shown the rationale behind this specific order. The position of certain materials in specific areas results from hours of role playing. When the materials jumble, it is difficult to establish the same order again, because some materials took their place hours ago, or filled exactly the available space. For example, when players use miniatures to show the position of characters on a battle map, and the table shakes because it is unstable, carefully placed miniatures jumble. The consequence is that relations break between the miniature on the table as a material actor and the characters as a narrative actor. The shared imagination breaks and role playing disrupts, because the relational work between the material and the narrative actors stops until players reestablish the order. In this regard, the table as a material actor has to provide and maintain physical

103 "It has to be possible to dismantle it, because at that time my main group was in Stuttgart, and I already lived close to Karlsruhe. Basically, when you use it for game sessions at home, almost half of the option how to use it is gone for most of the groups. One factor is the battle map, because I play usually with battle map and miniature figures. Then I can draw the battle map raster directly on the table. I used table foil to draw on it and erase the drawings without a problem.... It is basically like the blackboard in school, but has an adhesive foil. ... I designed it for six players, a game master and five players. I looked for different sizes and went to the hardware store and found a ready-made tabletop. It had to be light enough regarding the weight, but it had to be stable enough not to bend. Therefore, a ready-made tabletop was quite good. The size was $80 \times 1.20$ meters. I bought two of them. I did not think about a definite size, but looked for something that would fit and found this one... . The height is like a kitchen table, about 75 centimeters, because I bought standard table-legs. ... I varnished it, before I put the adhesive foil on it. The table-legs are removable. Before that I had table-legs which I could turn down. These did not work well, so I bought new ones that are removable. I thought about cups, but I did not manage to make them. . . . It would have been funny" (Jan Malspöler, Interview, 10.07.2014)." 
stability that translates into the stability of narrative-ludic relations in the tabletop roleplaying game network to maintain role playing as a process.

As a final remark, for some players it is fine when the game master does not join them at a table. For example, the game master sits on a different chair while the players share a couch, and the table is between them. Nevertheless, the game master should not look up to his players.

The table demands certain actions from the network of actors, and a table's agency becomes apparent in relation to other actors. Players should not leave the table and continue playing somewhere else, but stay within sight and within earshot. There are situations when the game master asks a player to leave the room, for example, when the character receives secret information from a non-player character. This creates tension, because the equal position of players breaks and one player receives further information. The players that remain sitting at the table do not know whether the player's character will reveal the secret information, or only parts of it, or lie to them.

To sum up, the geometry of the table organizes players around a common center and places them at the same height and distance from each other, thus establishing a flat hierarchy between them. Moreover, the table distributes areas to actors and positions them to each other. The areas in front of players gather materials that relate to the character, such as character sheet and dice. The areas between players gather materials that players share, such as snacks and rule books. The area in the center of a table gathers materials that all have access to, such as the battle map.

5.3.3 Battle map. As everyone is in the same distance to the center of the table, players might use this area for something special. In groups that prefer many battles, players use battle maps and miniatures to mark the position of their characters and the enemies during a fight. Some player groups draw battle maps on scrap paper and put it in the center of the table, some player groups buy preprinted battle maps ${ }^{104}$ and some might draw permanently the grid of a battle map on the table. ${ }^{105}$

104 "A battlemap is a special material. A soft, coated plastic map that can be rolled up like a poster. When you roll it out, it stays flat when you put something light on it. Similar to whiteboard markers, you can draw on this battle map and wipe it away with a little bit of water and a paper towel" (Leon, Interview, 28.5.2014).

105 "During sessions, the table is in the center of the room. I built myself a special role-playing game table. With blackboard foil. Dismountable, so it can be transported with a car. On the blackboard foil, I have drawn a grid for the battle map, so that I have it there and it is of the size that one has enough space in the middle, to place a battle map there. On most tables, they are usually too narrow, you do not have enough space" (Jan Malspöler, Interview, 10.07.2014). 
One common material is a map that visualizes where characters are in which environment. Objects that represent characters on the map range from random objects that fit the size of the grid to carefully painted miniature figures. ${ }^{106}$ The environment is important, because forest, plains, or tunnels have an effect on how many points add up to dice rolls on attacks. These maps represent continents on a large scale and are usually part of the core rule books. Some groups use maps for battle only, because a map helps to coordinate strategic movements in battles. The grid of a battle map is segmented in squares or hexagons, depending on the game system and the precision. A battle map works best when it is in the center of a table, because then it is in reach for all players and the game master.

You have already heard about role-playing games, but do you know that the first roleplaying game, Dungeons \& Dragons, turned forty in 2014? And that this game developed from tabletop wargames where players use miniatures to simulate battles on the top of the table? The early Dungeons \& Dragons was a form of wargame that focused on single characters instead of large armies, but in the beginning it was all about simulating fights. Now it should be clear why battle maps are such an important feature and why there are so many rules for combat. Maps, miniatures, and miniature landscapes help and I arrange them.

Not all groups play with materials that root in wargames, because there are differences in game styles between groups that prefer instrumental play and groups that prefer role playing. Players refer to the first play style as roll playing, because dice roll frequently determine the outcome of a battle sequence. For roll playing, ludic actors become more important. The second style is role playing or character play, when the emphasis is on narrative actors. Players and game master concentrate on developing a shared story in all possible facets. They flesh out the story world, and players make decisions depending on what their character would do rather than what the player thinks would be strategic to solve a puzzle, defeat an enemy, and so forth. Groups that prefer one game style or mix roll playing and role playing use battle maps at some point, especially for key moments at the end of a campaign and for large battles that involve many combatants.

106 The miniature figure as a material actor connects tabletop role-playing games with its predecessor wargaming. The first edition of Dungeons \& Dragons bears the title Rules for Fantastic Medieval Wargames, Playable with Paper and Pencil and Miniature Figures. Players can buy figurines representing fantasy characters from hobby shops, such as Games Workshop. The relation of miniature figures to wargaming ties well to Carter's (2014) paper on dice in Warhammer 40,000, a product of Games Workshop. A future study on figurines would be one way how to expand this chapter's selection of material actors. If such a study examines the tangibility of miniature figures, it could bridge this dissertation with the results of Carter's study on the tangibility of dice in wargames, and with Dormans' (2006) study of dice as ludic elements. 
5.3.4 Character sheet. Call me character sheet, although I usually consist of several sheets of pre-printed white paper. I am similar to a CV, as I serve as a record of static and dynamic character traits. Players create a character by filling out the pre-printed boxes. The upper part of the character sheet starts, in this order, with the name of the character, its class and level, race, size, gender, alignment (on a scale between good and evil), religion, height, weight, looks. And this is just the upper part of it-one fifth of the first sheet.

The rule book of most role-playing game systems provides copy masters for character sheets, such as the Player's Handbook for Dungeons E Dragons 3.5. As an alternative, the publisher's website provides PDF versions to download and print. Many players create custom-made character sheets and some use electronic character sheets on laptops and tablets. Some players use electronic character sheets to set up the character, but they still print them out and use paper versions, because paper and pencil is more reliable. A paper character sheet does not need electricity, can move across the table when the game master demands it, and notes are easier to make with a pencil on paper than a mouse, keyboard, and a computer screen.

I am a kaleidoscope of boxes, lines, printed words, and even have some room for decoration!

The amount and design of character sheets depends on the game system. In Dungeons E Dragons 3.5, a character needs at least four sheets. There are character classes that require more sheets, for example for lists of spells, such as the wizard character that requires two additional sheets to contain spells. Players might add further sheets that contain character background, copies from rule books about special abilities, and images that portray the character. I played with a twelve-page character sheet at the end of my field work, because when my character grew in experience, I had to add more abilities, special items, and, spells. This is a trace of the ludic actor game system, which relies heavily on gaining abilities, experience, and additional rules for higher levels.

There are boxes, circles, and squares on the first sheet. They divide me into several areas. Usually a word or a short explanation stands close to each area. The area itself is empty. Players fill in numbers, words, or symbols. The content of boxes, circles, and squares describes the character, represents its attributes, abilities and skills, determines its clothing, equipment, and other details.

An empty character sheet looks complicated, because it has segments of different shapes. For a game system in the tradition of Dungeons E Dragons, filling in one character sheet takes at least one hour and only if the game master is familiar with all rules. 
The process of filling in the many areas is character creation. I create a character with the player's imagination of a character, the game master's requirements for a character in his game, and the rule book that provides the game rules for its creation. Seeing the work that is necessary, you can imagine why a simple piece of paper like me becomes important.

Players use one character sheet for one character, which means that by filling out a copy, the sheet of paper becomes linked to a unique character-a material-ludic relation. This relation expands to the fictional character as the narrative actor. Many times I have heard people refer to the sheet as their character. For example, the game master says, "Give me your character," and the character sheet is meant. The character works in a tabletop roleplaying game, when it creates a network of the imagined character, the physical character sheet, and the filled-in form.

As the character sheet is itself a network of narrative, material, and ludic actors, its work is important for role playing and players have to take care of it.

I have a prominent place on the table. I lie on the table in front of my player, ready to work during play. The player glances at the numbers written on me. The pencil makes notes on me and the rubber erases them again. When the character fights in the story world, one area on me decides upon life and death: the box that contains the hit points; a number that relates to the character's health. Especially in battles, the box with the hit points is in frequent use.

The character sheet has to be in reach. To solve puzzles, such as finding a secret passage, players have to look up the ability points. Then they can determine what modifiers they use for an attribute check. ${ }^{107}$ To defeat enemies, players have to look up weapon modifiers, armor points, and the health points that determine how strong the character is and how much damage it can take before it is killed. The character sheet needs to remain in front of a player. Ideally, other materials do not cover the sheet, because players need to look up information that maintains the relation between the character's situation, its ability points, and the game rules.

As the character sheet occupies the personal area, the size of the character sheet defines the size of the personal area on the table. For Dungeons E Dragons, players usually use a photocopied or printed character sheet which has the size of a standardized sheet of

107 An attribute check is a dice roll that determines if a character succeeds when using an attribute. Or see Section 5.1 for a scene when a player uses the ability "Spot" to find a secret passage. 
paper. ${ }^{108}$ This means that the personal area takes a certain amount of the table's size that the character sheet's size determines. It defines the minimum size of the personal area for each player, because other materials-such as pencil, snacks, and scrap paper-should not cover the character sheet. The character sheet does not work when players cannot look up what is written on it during role playing. Therefore, everything else-pencils, scrap paper, supplementary rule books, and the like-needs to find space around the sheet.

I demand care. As I am made of a standardized paper, I weigh eighty grams. Too much use of eraser and pencil might literally tear me apart, because the paper is not thick enough for frequent corrections. Health points change a lot during battles. Players should not use the box for health points to make changes during a battle scene, but use a piece of scrap paper for calculations of damage notes when health points drop. When the battle ends, players can write the final number in the health box on the first sheet. Some people transport me in a plastic cover, because it might rain during travel. Carefulness demands also that players bring me to the game session. Forgetting a character sheet is deemed a sign of disrespect.

The character sheet serves over a long period, because, similarly to larp, a campaign usually continues over several game sessions, sometimes over years. Taking care of a character sheet is necessary, because the materiality of the paper endures many changes and use during time.

All in all, I construct strong relations between the shared imagined space, the game rules, and the character. I serve as a representation of the character's life, its attributes, abilities, skills, equipment, et cetera. When I collaborate with a pencil, we translate changes directly to how players imagine the character.

The paper is in use for many game sessions and it is not only a record of how the character develops as a narrative actor, it also shows signs of physical usage. These material traces become part of the character sheet and tell more about the actors' work. Old character sheets might show coffee stains, pencil notes with quotes from the game, doodles, and more-paper can turn yellow over time. These material traces contribute to the character as a network, because they tell its history with the material changes of the character sheet. When the same character sheet is in use for several years, the changing character sheet expresses a certain age of a character that becomes a written account of the life and a material witness of the character beyond the narrative actors alone.

108 This standard roots in the work of Lichtenberg from 1776 and still determines the sizes of papers. 
When the character sheet is forgotten or destroyed, for example by spilled coffee, the sheet disrupts the relation between character and player, because the numbers become unreadable. Then players have to fill out a new copy which takes a considerable time in Dungeons \& Dragons with four character sheets at a minimum. Thus, players prefer to take care of the first character sheet page as long as possible. ${ }^{109}$

Regarding the mess on the table, the importance of a character sheet in relation to its materiality explains the messiness as a complex order in relation to the size and work of the character sheet. In relation to the table, the character sheet repositions other materials around a space that is defined by its size. Players should not place materials that might cover the paper, such as rule books, on the character sheet. Players should place material farther away that might damage the paper, such as coffee mugs. In relation to light, the character sheet demands a certain proportion of light, dependent on the size of the boxes and the writing. The character sheet is often considered as a ludic actor, part of the game rules and game mechanics, or as a narrative actor, part of the paratext in the sense that it frames narratives, ${ }^{110}$ but the materiality of a character sheet has to be taken into consideration. Because of its materiality, the character sheet demands a prominent place, demands good care and diligent use, and by relating to narrative and ludic actors, the character sheet constructs the character as a heterogeneous network itself. The character sheet becomes "endowed with a certain set of competencies by the network that [it has] lined up behind" itself (Sayes, 2014, p. 138). ${ }^{111}$ To keep this network going, the character sheet is not alone.

5.3.5 Pencil. I am a standardized pencil with a solid graphite core and a wooden body. My wooden part prevents the core from breaking. I have a hexagonal shape. There is an eraser at my other end, an old friend since the mid-19th century. I am a good ally of paper. I leave marks by physical abrasion, usually in grey or black. Together with the eraser, we are quite efficient to make changes on paper. But you have heard about this before.

I wrote before that spilled water can damage the character sheet. Unlike a pen, the pencil does not smudge when it is wet. Most people that I have played with prefer using a pencil, because graphite does not run. In case of water damage, the player will probably replace the character sheet, because the napped paper would tear when the player uses

109 A future study dedicated solely to material traces on character sheets would reveal the various traces and how they relate to the characters.

110 Jara (2013) points out the paratextual elements of rulebooks and asks to examine how they shape narrative processes during tabletop role-playing game sessions.

111 See Chapter 2.2.1 
a rubber to erase pencil marks. Even in this case, the character sheet is still readable, thanks to the graphite that does not run when it is wet. The pencil is a more reliable ally of the character sheet than any other writing tool.

What is else to say about me? When at the beginning of a game session, players realize that they have forgotten their character sheets, it is bad, but what people regret most is when they forget their pencils at home. It is more likely that players forget a pencil than a character sheet, because I seem to be such a harmless and mundane thing. I hope to change this ill-informed understanding.

It disturbs role playing when players ask for a pencil, not so much because it is a question that is not related to character play. Asking for the snacks out of reach is less disturbing, for example, because players consider forgetting a pencil as a sign of bad preparation and not taking the game seriously.

A well-prepared role player has an additional pencil that another player can borrow. Some game masters buy whole packages of spare pencils, because nothing is more disturbing than asking for a pencil, something that every role player has to have. Thus, I am just another material that seems not to be important, but is of utmost importance to run the game session. ${ }^{112}$

The pencil is easy to use and easy to maintain. It is small enough to find some space on any table, but its position is not random.

I want a sharpened point and a place next to the character sheet. Then I work without delay. I act quickly when I am close at hand. I am not a laptop computer that has to be pulled out of a standby mode, or a tablet that has to be switched on. I am always on and ready when you need me, so keep me close by.

Understanding what the pencil wants helps to understand the messy network, because although the pencil might lie next to the character sheet in the personal area or in the common area, it is always close by. In this regard, it has a specific order and because it takes a certain place, it arranges where other items are.

112 "Pencils are important. You notice, at least in my role-playing game session, that pencils disappear from time to time. It does not matter how many you have on the table, there is always one pencil less than the number of players. I do not consider the law as important anymore, that everyone should get someone else's pencil. When someone like me has an extra pencil, which one holds dear, then you have a tension" (Koboldfeuer, Interview, 6.06.2014). 
The pencil helps people to make notes while being engaged in role playing. In alliance with the eraser, the pencil can make quick changes on the character sheet, because the rubber can erase graphite marks easily, for example when there is a change in health points. In relation to the light, the graphite marks are grey and the contrast to white paper requires a certain amount of light on the table. While the eyes determine when light is too strong, the graphite marks of a pencil determine when light is too weak.

My design is great. I rest perfectly in the human hand. And I do not roll off the table, because I am hexagonal.

The shape of the pencil has a long history of manufacture. ${ }^{113}$ Its length fits both the right and left human hand. As a material-material relation, the pencil works together with the hand as a part of the player's body. The hexagonal shape collaborates with the flat table, because this shape prevents the writing tool from rolling off, a design decision that makes the pencil a reliable ally.

Interviewees told me that they use special boxes to store their dice, but they made the decision of which box to buy based on the size of a pencil. In their case, it was therefore not the look or price of boxes that is why they chose a certain box, but because the box has space for dice and pencils. ${ }^{114}$

The pencil makes role playing work, because it relates to various actors on the table. Often the pencil works so well that its work is not perceivable. In relation to material actors, pencils are easy to use, small enough to fit any space, and can change notes quickly. In relation to narrative actors, pencils make notes of character actions and note down how the story world changes, which are narrative actors that co-construct the shared imagined space. In relation to ludic actors, pencils transport the dynamics of game rules. Game rules are dynamic, because they create relations between quick dice rolls, volatile dice results, and calculations with many complex rules. A pencil works with ludic actors, because the pencil quickly notes and rewrites numbers, corrects mistakes on paper, and makes notes for the many calculations. These actions transport the necessary dynamics of ludic actions and keep role playing going.

113 For a history of the pencil, see Petroski (1990).

114 "I have a special box for it. I have really selected a box which can take as many dice as possible and which is long enough for pencils. That is my little box for role playing. There are not only dice, but pencils, sharpeners, erasers. And caffeine and headache pills. And a little troll from my childhood. I do not know why he should be there, but he must be there" (Koboldfeuer, Interview, 6.06.2014). 
To sum up, the pencil explains why the network is not so messy at all. The pencil has a special place. Moreover, the pencil demands certain actions. When the pencil should act during a game session, players have to think about what the pencil needs to cooperate. The pencil has a say in role playing, because it works when it is in reach, ideally next to the character sheet. Thus, it demands from players, that they have their own pencil that stays at the same place and is not shared among the group. One reason is that the pencil gets lost or is not available when the player needs to make a note. Its specific place on the table allows it to work quickly and reliably, for example when the pencil constructs relations with the character sheet. Here, pencil notes on paper relate to the ludic and or narrative dimension. Pencil notes are not static, as a pencil mark vanishes beneath an eraser. Then these actions reconstruct the material relations between pencil and paper, and translate these changes to ludic and narrative actions. From the light, it requires some extra care in adjusting the brightness of the light over the character sheet. While larger numbers and drawings on battle maps are visible in dim light, the character sheet is packed with tiny boxes and sometimes the pencil writes small notes. People's eyes need enough light to read the marks on paper, because the graphite core of the pencil is grey and the paper is white and the contrast might not be enough in certain light situations. As an actor the pencil constructs relations between the light in the room and the character sheet, and this relational work results in a specific order that I named messy network.

5.3.6 Game master screen. May I introduce myself? I am the game master screen. I am usually made of double-sided printed cardboard. My shape is a quadrichon; four equal panels connect in a line. As my name suggests, I am important, because I am an ally of the game master.

The screen can stand on its own, because the four panels are made of cardboard and make it stable. The game master screen separates the table into the player and the game master areas. As a physical barrier between players and the game master, the screen supports the psychological effect of making a hierarchical distinction between the participants. Thus, the game master screen reinforces the ludic and social hierarchy between the game master and the players. In this regard, it collaborates with the furniture when table and chairs put all players on the same eye level.

I make the game master sit at the head of a table and the players at the longer sides, because my panels are long enough to hide the game master area from curious players' eyes.

When the game master uses the official Dungeon \& Dragons 3.5 screen, she or he should sit at the head of the table, because this particular screen is too short to provide sight 
protection to all sides (Deluxe Dungeon Master's Screen, Book Supplement, Wizards of the Coast, 2004). As the screen is made of lightweight cardboard, the game master can easily reposition the screen during play when a player moves her or his chair and might be at a new angle to the game master's notes. Moving the screen or extending one of the side panels hides again what the game master does behind it. The game master screen is stable enough to hold additional paper notes, for example regarding riddle solutions, the prepared story line, and information about opponents. Thus, the screen helps to organize narrative and ludic actors on an additional, vertical area on the table.

The screen serves tactical functions, as it allows the game master to check notes and change dice results in secret without spoiling the game for players. ${ }^{115}$ Hiding actions creates suspense, because players do not see when the game master makes notes or rolls the dice, they only hear the sound of falling dice on the table. ${ }^{116}$ It is up to the game master to reveal what happens, but the screen makes it possible for the game master to hide something that might be in favor of or against the characters.

Beside its work as a visual screen, the game master screen has two sides that are printed differently.

Look how beautiful I am! If you buy a game master screen from the producers, I have a distinct design. On one side, there are tables and shortened game rules for quick reference. The tables can be helpful for a game master as they provide him with details for certain dice rolls and calculations. The game master saves time as it is not required to skim through the thick rule books.

The side towards the game master provides tables for dice rolls, common calculations, and other information. This side of the screen helps game masters to work with ludic actors. During certain situations, including difficult actions that players want to perform, it is necessary to find statistics, tables, and rules to determine the modifiers for dice rolls.

115 "You find the game master screen more in groups that focus on strategic play. Among other groups, it is possible that there is no game master screen, or that portraits of non-player characters are stuck to the screen. At stratetic groups no one cares what a non-player character looks like or what its name is. People ask if they have to kill or not, then one is willing to continue the talk. People in these groups do not have an interest about the personality of a non-player character. In groups that focus on atmosphere, people want to know what he looks like and so on" (Jan Malspöler, Interview, 10.07.2014). Jan distinguished in the interview between two game styles. The strategic and combat-intense games require ludic information. A game style that focuses on role playing creates a certain atmosphere by focusing on narrative actors.

116 Carter (2014) wrote about how physical dice contribute to player experiences in the Warhammer 40,000 tabletop wargame. 
Such information is scattered across different books. The two core books for Dungeons $\mathcal{E}$ Dragons 3.5 are the Dungeon Master's Guide and the Player's Handbook with 320 pages for each book. Moreover, supplementary books provide more information. There are books for different classes: one book for warriors, wizards, rogues, et cetera, books about special weapons, and books that contain spells. It disrupts role playing when the game master or players need to find certain rules or modifiers to dice rolls and have to flip one of the several game rule books. This game master screen side provides help, because it offers the most frequently used rules, modifiers, and further information. A lot of information is printed on the four panels of the screen together with page number references. The font size is small and the screen needs to collaborate with light. Thus, in collaboration, a game master screen saves time and provides the most important game rules at a glance, and if necessary, additional notes about riddles and the story.

The other side of the game master screen provides players with images that show scenes of the story world, such as a group of characters sneaking up on a red dragon in the case of the screen for Dungeons E Dragons 3.5.

On the other side of the screen, there are colorful images. The images are familiar, because they are in the style of the game system's artwork. Sometimes, the same artists design the images on the screen. For tabletop role-playing games in a fantasy setting, the images show fantastic locations from the story world, monsters, and a group of characters fighting them. Design differs from game system to game system and provides a distinct and recognizable look.

The side towards players shows images that represent the story world. Players look at these images during the whole game session, because they are between them and the game master. These images work as an additional node for the shared imagined space. While every player envisions individually, because story world and characters emerge from verbal descriptions, visible images synchronize a shared imagined space. ${ }^{117}$

It is possible that the screen is counterproductive and hinders role playing. When the game master role-plays several non-player characters, it can be difficult for players to

117 Jara (2013) writes that "game interaction among players must rely on shared understandings of the fictional world and general thematic concepts." (p. 10). Images serve both the understanding of the imagined space and general thematic concepts, for example the fantasy setting. Jara uses the concept "equifinality" explains how sense making may result from both chronological and causal events and of analogies and contrasts (Jara, 2015). Images on a game master screen form material-narrative relations and therefore serve what Jara describes earlier as paratexts of tabletop role-playing games (Jara, 2013). This study of the game master screen adds the material side to our understanding of paratexts. 
distinguish between the different non-player characters without further clues. Some game masters use specific voices to distinguish characters, but the repertoire of voices is limited. Some game masters add a distinct body language for non-player characters. The collaboration of specific voice and body language are material actions that co-construct the imagination of a non-player character. A screen can be a hindrance when the game master relies on body language, because the screen hides most upper part of the game master's body from sight. The screen deconstructs the relation between the game master's bodily performance and the imagined non-player character's action in the story world. For this reason, some groups do not use a game master screen at all. ${ }^{118}$

If I am to be part of role playing, I want something in return. From people, I want them to respect me. I am not just a screen, I am a boundary that symbolizes a division between the players and the game master, between the characters and the world, and between players and the referee. From the papers, notes, dice, and other items which the game master uses, I request that they stay in my boundaries. They might move to the center of the table, like food or dice when not in use, but notes about riddles and story or rolling dice should remain in the boundaries I define.

All in all, the game master screen acts as a material actor in relation to narrative actors, when it displays images, and in relation to ludic actors, when it establishes hierarchy and provides game rules. The screen gives the game master the opportunity to hide dice rolls and to determine spontaneously what to tell players, whether the dice are a success or a failure, because players do not see the results and rely on what is told. As a material actor in relation to the space that the table provides, the screen makes a border between the area of the game master and the players.

\subsection{Conclusion, or Lights Out}

The characters have solved the puzzles, defeated the enemies, and survived an epic campaign. The flame of the last candle extinguishes. The players stretch their muscles while the game master narrates the end of the campaign. It is past 3 A.M. and the game session is over.

118 "I hated game master screens. A game master screen cuts me off from my players.... Then I am not able to perform non-player characters. You get the feeling that there is a distance between the narrator and the character. To role-play a dialogue, the game master screen hindered me. No player has something like that in front of him. The character does not reach the others. Players have to feel into the situation that they talk to a character. When the screen was gone, they played with me" (Oliver Fischer, Interview, 16.07.2014). 
In this chapter on tabletop role-playing games, I observed actors during a game session, which resulted in a messy list. When I followed different material actors, I became aware of actions that helped me to understand the mess, and actions that previous studies have omitted. It is possible to understand tabletop role-playing games as, for example, a collaborative storytelling game (Mackay, 2001), and it is possible to understand these games as, for example, a structure of six ludic actors (Hitchens \& Drachen, 2009), but a tabletop role-playing game is also a network of light, table, battle map, character sheets, pencils, game master screen, and other materials. Previous studies of the ludic actor "game system" do not explain the position of character sheets on the table. Studies of narrative actors do not explain how a pencil works, because they examine the tabletop role-playing game as an "episodic and participatory story-creation system" (Mackay, 2001). A study of the materials is necessary, because it explains, for example, why most players use a pencil instead of a pen or a mobile computer. Such a study acknowledges the pencil's relative position to a character sheet and contributes to the understanding that there are further relations between material, narrative, and ludic actors. Insights like this one help to untangle the seemingly messy actions in a tabletop role-playing game network.

The key to understand the disorder is to acknowledge that materials in tabletop roleplaying games do not act in isolation. Light, table, battle map, character sheet, pencil, game master screen, and other materials act in social relation. Thus, they influence how relations between them and other actors are made. Moreover, they influence at a distance, how relations between other actors are made. For example, when the game master screen moves on the table, it reconstructs the area between game master and players. Furthermore, the repositioning of the game master screen changes how other materials move and make relations beyond their relation to the game master screen. When the character sheet has to move, because the game master screen takes more space, it is also the pencil, eraser, cup of coffee, and other material actors that have to move. This example explains the geometrical order of the messy network, because moving the game master screen creates more (or less) space on the table for the other materials. Dice are moved away from the game master area, rule books are placed at the edge of the table, a bowl of food is moved in front of the screen.

To understand the messy network by following six material actors, I have chosen to reproduce my observations in the form of imagined accounts from the perspective of these material actors. Light, table, and others described their actions and I could explain how materials collaborate in relation to narrative and ludic actors. For example, the table can only act if it relates to light. The table might have to change its position in 
the room according to the position of the central lamp. If the lamp is too bright, or its light becomes painful when players' eyes get tired, the lamp does not work. Then the table-lamp relation demands action from players, to dim the lamp. An imagined account from the perspective of a table helped me to reveal actions that might seem mundane but are necessary.

I have chosen six material actors for this chapter, but there are more to study. The character sheet, the game master screen, and the battle map are obvious choices when studying the genre of tabletop role-playing games. I have chosen the table and pencil, because most players are aware of their importance, but little is known about their active work. Some designers suggest additional materials for a game session, but the recommendations in the rule books describe materials as props that have an inert atmospheric quality (Oracz, 2010; Rein-Hagen et al., 1992). Then, exceptional props become interesting as sources of atmosphere, and do not act beyond. Groups can choose atmospheric props individually or leave them out completely. I did not examine atmospheric props, because they were not always present during my fieldwork. When I chose the six material actors that were usually present at all tabletop role-playing game sessions, however, I wanted to make the point that any material contributes to a game session. Thus, by choosing mundane actors, such as a table, I showed that any material that makes a difference can become a vital part of the network. Then it is possible to explain how even a table generates what game designers call "right atmosphere" (Oracz, 2010, p. 88).

The more important point of this chapter is that it is not sufficient to understand materials on their own and look for their essential qualities, but to trace how materials collaborate. Understanding inter-relational processes expands the understanding of the complexity of a tabletop role-playing game network. Understanding how a tabletop role-playing game works helps to explain the messy network and how this seemingly disorder keeps role playing going.

Beside the focus on six actors, another limitation of this study is the chapter itself. The chapter as a text is static, but networks change constantly. Therefore, the written-down analyses and conclusions reproduce one possible stable state of the network or one moment of solidification. ${ }^{119}$ Another limitation of such a solidified text is that I explained a selection of actions related to material, narrative, and ludic actors. Actors during a

119 Venturini describes the magmatic state of a network between change and stasis. The researcher's account provides a static moment, a solidifaction, while the researcher's observation in the field reveals the changing aspect of the network, the liquid side (Venturini, 2010, p. 269). 
tabletop role-playing game session, however, relate to more actors. Further studies could expand the understanding of how a tabletop role-playing game works when they expand the study of material actors to mobile computers, chairs, snacks, the change of oxygen in the room, sound systems, different locations, and other typical or mundane material actors. Although the analysis in this chapter is not all-encompassing, the six material actor sections have shown that tabletop role-playing games work as an open-ended network beyond the scope of previous studies.

The chapter began with the problem that little research has touched upon materials in tabletop role-playing games, and the problem that when I took materials into consideration I faced a messy network. By following material actors, I have shown how light, table, battle map, character sheet, pencil, and game master screen organize each other and narrative and ludic actors. I have shown how this self-organization solidifies a messy network and achieves the common goal of role playing. Tabletop role-playing games work when material, narrative, ludic actors collaborate, because then they translate role playing across various inter-relational processes that only seem messy at first sight. 



\section{CONCLUSIONS}

In this final chapter of Role Playing Materials, I present a summary of each of the preceding chapters and their main findings. I then discuss the implications and limitations of this dissertation, before providing suggestions for future work, and a final conclusion.

The following questions were addressed: How do materials collaborate with narrative and ludic actors in role-playing games? ${ }^{120}$ What changes do materials demand for their collaboration from narrative and ludic actors? How do these inter-relational processes change role-playing game networks? These questions helped me to understand how materials make role playing work in role-playing games.

I examined relational changes with actor-network theory as the methodological and theoretical toolbox (Callon, 1986b; Latour, 2005; Law, 1999). I observed how relations changed when material, narrative, and ludic actors negotiated. The negotiation between actors created agency that was visible in role playing. Role-playing games solidified as networks because of the changes that were necessary for the actors to be able to collaborate successfully. I analyzed negotiations and changes from within the processes, by taking part myself in different role-playing games. Between 2010 and 2015, I conducted ethnographic field work and interviewed participants. The details of this field work are described in Chapter 2 and the empirical analysis is presented in Chapters 3, 4, and 5. Each chapter focuses on one role-playing game form: larp (live action role play), mixed reality role-playing games, and tabletop role-playing games.

The results of the three chapters contribute to the understanding of role playing, because they show how material actors collaborate with narrative and ludic actors to make role playing work in three role-playing game networks. The following section summarizes the results.

120 Materials range from objects, such as costumes and smartphone, to raw materials, such as metal, leather, and plastic. Narrative elements include texts in the broadest, semiotic sense including written and spoken text, images, and filmic sequences. Ludic elements include game rules and social rules between players. 


\subsection{Summary of Empirical Chapters}

In Chapter 3, I followed the work of garb as material actor in German fantasy larp events that took place from 2010 until 2012. Garb and narrative actors collaborate successfully to represent an imagined character according to the game rules only if garb is functional. A larp runs for several days of constant play-day and night. During this time, a player's garb has to be functional during diverse activities, such as fighting and scouting through difficult terrain, and it has to be reliable during bad weather and cold. To function in larp, garb demands more durable raw materials than, for example cosplay costumes, because these usually function for only a few hours. When the raw materials that constitute garb change, the garb becomes functional during all conditions encountered during a larp. Garb is then more successful to represent an imagined character, and the collaboration between garb and narrative actors is more stable. However, this collaboration works only if narrative actors keep their relations within one distinct genre. Garb that works with fantasy does not work for another genre such as science fiction. The initial choice to make specific garb for a fantasy character has consequences when this particular garb develops with time, for example when it becomes more functional. This work makes the garb-fantasy collaboration more stable, but at the same time, it becomes more difficult to change the genre because of garb. Fantasy larp becomes more stable because of garb.

Garb collaborates with game rules as ludic actors. In German larp, game rules demand that garb be in line with a character's clothes. A piece of armor has to be made of raw materials such as metal or leather, otherwise it does not count as armor in a fight. Different quality of armor relates to points given for defense. A set of chainmail, for example, counts as three armor points. A player who wears chainmail can ignore three blows with weapons. When the player is hit again, the character is hurt and the player should role-play a wound. When garb is made in line with raw materials, it collaborates with armor points in a material-ludic relation. This material-ludic relation is the major difference between garb and costumes for cosplay or carnival. Such collaboration, however, changes the network in another way. Garb that fulfills the ludic and narrative demands also changes the ludic actor game rules. Role-playing a character during a larp, after several hours of constant play in any weather, it is difficult for players to keep rules in mind. However, it is easier for players to decide how many blows their character can bear according to the quality of garb. When armor points matter, because of the correct raw materials, this principle moves from exact points to a general principle of what-yousee-is-what-you-get. This principle turned into a widely accepted game rule under the name DKWDDK (your character is able to do what you are able to do). In the example of a fight, points matter less and the composition of garb decides about the outcome of 
a fight. The better a certain garb helps with the performative aspect of role playing, the less important are game rules for role playing. When garb is functional and is made of appropriate raw materials, it collaborates with fantasy as a narrative actor and with game rules as a ludic actor. This negotiation creates agency in a larp event that creates role playing. German larp is more stable with garb that functions, when garb is in line with the fantasy genre, and when it is made properly.

In Chapter 4, I examined role-playing games that have adopted the latest developments in electronic entertainment technology. Mixed reality technology, ranging from augmented to virtual reality technology, has spread along with new consumer products, such as smartphones and headsets. I followed two examples of material actors: the smartphone in the role of augmented reality devices, and the Oculus Rift DK2 as an example of virtual reality headsets. The study moved towards processes and developed an understanding from within the network. Role playing in mixed reality networks unveils further relations that actors of current products miss, because role playing is a different mode of interaction than instrumental play that emphasizes winning. The chapter concluded that role playing is difficult with current augmented reality devices, because the connectivity between device and radio transmitter is not sufficiently reliable. Even though virtual reality headsets are advertised as a step into the game, role playing demands further changes in hardware and software to achieve this experience beyond action scenes. When the network lacks material relations role playing does not emerge. A role-playing game network that adds virtual reality actors exposes tensions to material actors, such as the headset, body of the player, and the room. I concluded that a stable mixed reality roleplaying game network has to include more work on relations, a work that requires the study of processes between material, narrative, and ludic actors. In Chapter 4, I showed that role playing does hardly work with current mixed reality technology. Studying these technologies during role playing reveals missing or disruptive relations. The results suggest there are opportunities for further development in electronic entertainment technology.

In Chapter 5, I showed how materials collaborate in ways that are not directly accessible in a tabletop role-playing game session. The table as the center of play is a mess of different materials. I opted for an experimental approach to access what seemed to be disorder. I lent a voice to the material actors light, table, battle map, character sheet, and pencil. Letting these materials speak as part of the result section, I aimed to dissolve the dichotomy between human and non-human actors from inside the network, because the messy table was a trace for a missing process. I concluded that materials work on all levels of a tabletop role-playing game even if such work is not accessible. When a 
researcher ignores the fact that materials work, it becomes difficult to explain in what way the many materials collaborate in role playing. Lending a voice to non-human and therefore non-verbal actors unveils relational work between tables, pens, paper, and other actors. When materials collaborate in a tabletop role-playing game, materials roleplay, too. In Chapter 5, I concluded that researchers who want to understand materials as collaborators in role playing need to expand their understanding of role playing as a process that includes non-human actors. Actor-network theory provides the toolbox for a language that deconstructs role playing as a networking process between any actors that make a difference, even if these actors seem neutral, invisible, or silent.

\subsection{Main Findings}

An actor-network analysis does not encourage general results, because results are always tied to the specificity of an empirical case. In this section, I use main findings to formulate an answer to the two levels of the problem that I faced in the beginning of my study. Ontological findings draw upon the results of studying materials in role playing. Epistemological findings draw upon the results that are interesting to bridge game studies with actor-network theory further.

6.2.1 Ontological findings. Narrative, ludic, and material actors contribute to the understanding of role playing, but an empirical study shows that these actors work in relation to each other in a specific way during a local game session.

Role playing works in larp, mixed reality, and tabletop role-playing games, because it is a process that depends on materials as intermediaries and mediators. Materials as intermediaries collaborate and as mediators demand changes from narrative, ludic, and other material actors. Interesting to this study was when and where materials mediate role playing, because this work left traces to answer the question how materials make a particular game work. Research that merely acknowledges materials in role playing examines their role as intermediaries, but such research is insufficient, because it does not examine when and where materials are mediators. The example of German larp shows that garb as a material actor has to negotiate within the network. Then all actors collaborate with the result that garb represents a fantasy character (narrative) according to game rules (ludic) and functionality (material). The example of mixed reality role-playing games shows that a network is not stable when the collaboration is strong between narrative and ludic actors, but remains unreliable or missing in regard to material actors. For such a network to become a stable, it would have to incorporate relations with computer hardware, the location, and the body of the player. The example of tabletop role-playing games shows the case when 
materials seem trivial rather than non-existent, because they work as intermediaries. I examined when tables, pens, and dice (material) collaborate with the stories (narrative) and rule books (ludic) of a game session. At the same time, I showed when materials do not collaborate and change their role from intermediaries to mediators. This confirms that role playing is a process that depends on both kinds of material work.

The examples allow a comparison to distinguish role playing in the three role-playing game forms. Role playing in German larp differs from mixed reality role-playing games. Usually, garb takes part in larp only, while in an augmented reality game, a smartphone is often in everyday use. The consequence is that the smartphone participates within different networks during play. The difference between these actors is revealed before the game session: the garb is ready, while a smartphone demands additional preparation work. Role playing in mixed reality role-playing games differs from tabletop role-playing games. The virtual reality headset generates an audio-visual representation of the game world. In a tabletop role-playing game, the game world emerges when participants verbally describe what happens in the game world and when materials collaborate. The difference is in the relative flexibility of the shared world. In mixed reality role-playing games, the collaboration with materials is more fixed, because the display only shows what game world the software provides. In tabletop role-playing games, the collaboration with materials is less fixed, because the shared imagined space relies on verbal description with the aid of more flexible material actors, such as pencil drawings, and allow flexible ludic actors, such as game rules. The collaboration of these actors decides how flexible actors change from intermediaries to mediators and back when role playing requires it.

The three examples provide different answers to the ontological question, because the specificity of each empirical case provides examples for multiple ontologies. The material actors that I followed are only actors within these networks. The garb, smartphone, and table are not there by accident, but they are preferred by the intra-relational structure of the specific game network. At the same time they co-construct this very structure. Instead of defining what a typical role-playing material is, the results encourage future studies to look for materials and ask where and when they are necessary to create and maintain the particular role-playing game network, be it called a larp, mixed reality or tabletop role-playing game.

6.2.2 Epistemological findings. With actor-network theory, I analyze role playing as a process and examine which actors become parts of role playing by following their work. This mode of speaking moves the study from defining the properties of preselected actors to examining relational work of actors in a specific local network with its genuine 
ontology, for example Alcyon $X V$ at the Utopion location. Actor-network theory expands the study of role playing even further, because it expands previous studies beyond human-centered phenomena towards a multi-centered understanding of inter-relational processes. In each chapter, I deconstructed what is known about role-playing games by examining the known narrative and ludic actors with the less known material actors. Including materials became an epistemological tool, because I did not to reject narrative or ludic actors. Thus, I have shown that it is possible to re-construct previous research results on narrative and ludic elements for the study of materials without preferring one over the other as the cause of role playing, but explain role playing as an inter-relational process with multiple centers. Materials matter in role playing, because they may cooperate with narrative and ludic actors, and because their collaborative work changes how role playing emerges in a role-playing game network.

These findings become fruitful for further studies when researchers work with the ontological and epistemological level of role playing. The next section gives implications that suggest ways how to build upon this book's findings.

\subsection{Implications}

This section relates the findings to role-playing game studies in particular and to game studies in general. They relate to four implications that emerge from this study of materials in role-playing games, and each is discussed below.

6.3.1 Actor-network theory and game studies. Although game studies is familiar with actor-network theory (see Chapter 2), little work has been done with actor-network theory so far. Compared to studies that use concepts from actor-network theory with the study of role-playing games (for example Copier, 2007), this dissertation works with actor-network theory on a more inclusive level. This study does not ally with a few terms but works with actor-network theory as an ontological and epistemological toolbox. On the ontological level, this actor-network study of materials deconstructs the better known concepts narrative and ludic elements with empirical studies. Creating a vocabulary, this actor-network study deconstructs concepts and suggests multiple ontologies of what role playing might be. Instead of one central ontology this study extends the understanding towards multiple ontologies in combination with empirical work. Although the research methods used in this dissertation were not new, they were combined in a more inclusive way that had not been done previously. In this regard, this dissertation gives one example of how to work with actor-network theory when doing research on role-playing games in particular and games in general. 
6.3.2 Actor-network theory and methodology. A discussion of actor-network theory is missing in game studies publications on methodology, such as the recent book on game research methods that introduces quantitative, qualitative, and mixed methods (Lankoski \& Björk, 2015). Although Olsson hints at a network perspective in the chapter on repertory grid technique, the discussion builds on personal construct theory and interprets relational phenomena from a human center. Actor-network theory is a mixed method that adds to the repertoire of methods available to game studies, because it focuses not solely on people, but encourages attention to all of the actors of the networks that constitute games. It also requires that all actors of the network be treated equally. To achieve equality, an actor-network study does not take known elements for granted but examines empirically how these elements act, for example in a game session. The focus of the study moves from preselected concepts towards processes that depend on collaboration and negotiation. An actor-network study brings into question previously studied actors. This dissertation, for example, questions narrative and ludic actors. The result was that the role of narrative and ludic actors becomes less important to role playing than previous research suggests, because this dissertation shows how narrative and ludic actors depend on the collaboration with materials. Following garb, computers, and tables, actor-network theory suggests something more important than material agency alone. Actor-network theory does not replace human actors, privileged by previous studies as the center of games, but it suggests ways of avoiding prejudice towards human, material, or any actor. Thus, research projects that work with actor-network theory benefit from a view on actors on the same analytical level.

Researchers can study role-playing games with actor-network theory beyond existing conceptualizations of games, for example the dichotomy of human/non-human (Chapter 3) or virtual/real (Chapter 4). Actor-network theory does not take the divide between digital and non-digital games for granted, and provides an alternative model to current discourses in the field of game studies. Since the discussion about changing the name of the Digital Games Research Association (DiGRA) to GRA! (Game Research Association) in 2012, the discourse has opened towards non-digital or analog games. Researchers started journals and gave workshops on analog games. For example, the Analog Game Studies Journal had its first issue in 2014 and the Dimensions of Play-Analog Role-playing Games Workshop took place directly after the 2015 DiGRA conference (Heidelberg, 19-20 May 2015). This dissertation is one corresponding example when it goes beyond the binary distinction between digital and analog (role-playing) games.

Instead of reworking the dichotomy of digital/analog, actor-network theory offers a more convergent toolbox with which researchers can reflect how previous research has 
constructed the dichotomy, and what questions lie beyond the construct digital/analog games. Usually, a study of role-playing games focuses on one type of role-playing game, with a few exceptions (Montola, 2012a). This dissertation makes relations explicit between digital and analog role-playing games and gives an example of how such an alternative study beyond the digital/analog dichotomy works. An alternative is necessary, because mixed reality technology pushes game development towards a vanishing of a dividing line between the digital and non-digital (see Chapter 4). Actor-network theory provides one toolbox to understand these changes.

\subsubsection{Ephemeral role playing phenomena and material actors. One common} methodological problem of studying play and role playing is their ephemeral or intangible nature. Montola expands the problem of ephemerality from play to games "as they emerge from changing contexts and are shaped by the spontaneous play" (Montola, 2012a, p. 10). Role-playing games are ephemeral because they constantly change between stabilization and fluidity. With actor-network theory the oscillating dynamic of role playing becomes a trace, when the processes make differences to other actors. Actor-network theory solves the problem that role playing is ephemeral, because it provides the tools to study these very oscillating processes between the fluid and stable state of a network (Venturini, 2010).

A study of materials with actor-network theory makes ephemeral processes more tangible. Materials themselves can bear traces of the ephemeral process of role playing. In larp, for example, a scratch on a leg protector can be the trace for a rough action, such as crawling through a thorny bush at night. Traces of play on game materials invite analysis, because they become equally important data samples. If material traces, such as scratches on leg protectors, are not ephemeral, they reveal more than the stories that players remember consciously. Localizing traces on costumes, safety weapons, and other material actors may reveal more about forgotten or irreversible play processes. Interviewing players about on the basis of these traces leads to further information.

Researchers who analyze material traces may find out how materials change when materials collaborate with intangible actors. More importantly, researchers may reconstruct irreversible ephemeral processes on the basis of these relations. Studying materials offers therefore concrete solutions for the methodological problem of how to study ephemeral role-playing processes.

6.3.4 Ethical implications of game material mass production. In Chapter 3, I followed the chainmail throughout the history of German larp. It took me to sites beyond role 
playing that open further questions regarding ethics in games (Dodig-Crnkovic \& Larsson, 2005) beyond the question of violent video games (Bartholow et al., 2005; Elson et al., 2010; Ferguson et al., 2008; Sherry, 2001) or gamer culture (Apperley, 2015; Mortensen, 2015; Mortensen et al., 2015) . The variety and quality of garb parts available from shops has risen over the years while the prices have fallen. Products aimed at the growing larp community and a symbiosis with the reenactment market have emerged. But in order to sell better materials for a similar price, manufacturing costs had to be reduced to expand the market, which raises ethical questions when one follows mass manufactured chainmail to their origin.

In the last years, Pakistan and India have replaced East Europe in mass manufacturing of larp materials. The countries offer cheap workforce on the assembly line, and are also sources for raw materials such as metal. In the case of chainmail, one possible place to get cheap metal is Gadani Beach, Pakistan. Gadani Beach is known for "ship-breaking" and is located near the Hub River and Cape Monze in Gadani, Lasbela District, Balochistan (Chaudry, Memon, \& Danish, 2002). A similar place is the ship-breaking yard in Alang, India. Ship-breaking implies that shipwrecks stranded on the beach are climbed by workers and took into pieces under hazardous conditions. Following the chainmail beyond actual role playing opens room for ethical reflections about the production of game materials. "Have you smelled the oil that coats new chainmail from this shop? This is machine oil of the ships that have been recycled for metal," Trennheuser made me aware of (Interview, 7.03.2012). He explained that oil was used to prevent corrosion during the passage around stormy Cape of Good Hope. Following the chainmail as a network of material actors, such as oil, leads in this case to reused machine oil from shipwrecks. The origin of mass-produced chainmail opens questions about the working conditions in the production countries and environmental questions that are specific to metal recycling places like Gadani Beach.

Recent newspaper reports about working conditions on the assembly lines of the Playstation 4 add to the topic of making materials for games (Bland et al., 2013) as well as studies on gold-farming and outsourcing of MMORPG labor to China (Debeauvais et al., 2012; Nardi \& Kow, 2010; Xu \& Wünderlich, 2009). Taken together, the discussion of ethical and economic actors urges future research in the field of game studies to address ethical questions about the production of game materials. It is here that actor-network theory can include political actors into the study of games as entertainment technology, actors that were missing in early studies of technology (Wyatt, 2008), and in studies of games. Further actor-network studies can provide insights about the origin of consumer entertainment products and discuss the role of materials in (digital) games, because the 
actors leave traces to follow. Sometimes it is the smell of machine oil on chainmail that has been shipped to Europe.

So far, the sections have summarized the main findings and given implications. Actornetwork theory does not encourage the formulation of general results, but researchers can re-construct the results in line with the given implications in future studies. To map out close territory for future studies, I address three limitations of this dissertation.

\subsection{Limitations}

A limitation of this study is that the analysis focuses on just three actor groups, whereas a network is always an open-ended phenomenon. The decision to select narrative, ludic, and material actors was an agential cut. An agential cut is the conscious decision of a researcher in how to approach a phenomenon (Barad, 2003). With my decision, I intended to combine narrative and ludic actors as known aspects of role playing with the material actor, widely unknown to the field of role-playing game studies (see Chapter 2 ). This dissertation serves as a bridge that ties in previous research and suggests an expansion with further studies of actors. As an open-ended network, this study of roleplaying games as networks of three actors serves not as a complete model. Each roleplaying game allies further actors. Future studies may expand the triad of narrative, ludic, and material actors with a study of economic, environmental, or cultural actors. I have laid out relations to economic actors when I spoke about crowdfunding the Oculus Rift in Chapter 4. The link to environmental actors is in reach when a study focuses on the mass production of game materials, be they chainmail or the printing of rulebooks for tabletop role-playing games. Cultural actors in this study were the communities of role playing and their specific practices, such as do-it-yourself.

A second limitation of this study is the early stage of augmented and virtual reality devices. There are currently only a few larps that use augmented reality as an actor, such as Monitor Celestra (Sweden, 2013) or Planetfall (USA, since 2013). A more accessible case for study is any larp that takes place in an alternative reality setting of the contemporary world, because of the spread of mobile computers, for example World of Darkness larps (Woodworth, 2005). The virtual reality headset Oculus Rift $D K 2$ that I studied is a prototype for developers of computer role-playing games. A final consumer version was not on the market at the time of field work. My study of a prototype limits Chapter 4 to this stage. Mixed reality networks currently tie relations between device, software, place of play, and the body of the player. However, an actor-network analysis that includes material actors and studies role playing 
has practical implications, because it offers insights for current development. The chapter is not a final study of these devices, because it worked with a prototype, and can at least provide basic insights about interrelations between actors of mixed reality game networks.

A third limitation of this study is the main focus on role-playing game networks in German-speaking communities. One exception is field work for Chapter 4 that includes ethnographic research and interviews in the Netherlands. It was necessary, because I did not find current examples in Germany. The focus on German-speaking countries was a decision to keep the research project within the time frame. An actor-network study is time consuming, because it relies on the collection of firsthand qualitative data. More important, the loose definitions of concepts that are rather "empty shells" to speak with require from the researcher to grow a sensibility not only to the topic of study, but to the toolbox actor-network theory itself.

On the basis of the main findings, implications, and limitations, the next section gives suggestions for future projects that could directly build on the results of this dissertation.

\subsection{Suggestions for Future Studies}

A first suggestion for future studies aims at more inclusive studies that compare communities on a global level. Research has been done on role-playing communities in different countries and this dissertation adds a study on German-speaking communities. Actor-network theory provides the necessary toolbox to accomplish such a study on a qualitative level. Such a study is inclusive without losing the specifics of each country, because actor-network theory works with the premise of an open-ended network. Furthermore, the onto-epistemological position to treat all actors on the same analytical level supports a comparative study that requires a multi-sited and multi-centered ethnography.

To be feasible, an actor-network study of role playing on a global level could focus on one role-playing game type and one actor for comparison. I suggest the study of materials in larp. Recent publications have given specific information about the hobby around the globe, such as the international larp census (Vanek, 2015), and a world map of verifiable larp events (Fatland, 2014). Previous publications on international communities supplement them, such as larp in the Nordic countries (Stenros \& Montola, 2010), and larp in the Arab world (Anderson et al., 2015). 
The question for comparison would be whether materials act differently in relation to different communities of language in different countries. One example for difference is a larp tradition that seeks ways to abolish costumes. Some Nordic larps reduce the effort to a minimum, such as freeform, jeepform, and chamber games (Stenros \& Montola, 2010). These larp types have a minimalistic approach that the Dogma99 manifesto expresses most prominently. Dogma99 encourages designers to remove any unnecessary element from a larp (Fatland \& Wingård, 2003). A comparative study could aim to uncover how the design idea of reducing materials re-constructs other materials as collaborators, for example the body of participants, and a probable focus on gestures, facial expression, and other non-verbal cues (Harviainen, 2012). Further actor-network studies of role playing in larp and other role-playing games will contribute to the understanding of role-playing games as open-ended networks.

A second suggestion for a point of departure is the current state of mixed reality technology and its changes with new products. Several prototypes will enter the mass market in the near future. The releases include: Valve Vive with headset, controller, and room tracker (Valve and HTC, end 2015), Oculus Rift (Oculus, 2016), Microsoft Hololens (Microsoft, 2016), RoomAlive (Microsoft, no final release date), and further wearable computing devices that aim to blur the line between mobile computer and fashion (smart watches, glasses, and other clothes). The current development shows two types of devices: devices that create relations to the body and devices that create relations to the room. Oculus Rift and Microsoft Hololens are headsets for virtual and augmented reality, and Valve Vive and RoomAlive are room installations for virtual reality and augmented reality. When both types of devices merge to one network, the word "mixed reality" will not be sufficient to explain this device. A solution would be the study of these new devices as material actors and their part in future interactive entertainment technology. A study of role playing with new devices, such as Microsoft Hololens and Valve Vive, will offer insights about alternative modes of interplay that ask for a collaboration of actors different from everyday practices.

A third suggestion asks for an interdisciplinary project between game studies, heritage studies, and library studies. My suggestion replies to current concerns within the field of library studies on the topic of conservation of role-playing game materials, in this case rule books for tabletop role-playing games. As Schneider and Hutchinson (2015) have raised, "[e]xcept for a very small number of outstanding institutions, library collections of these [tabletop role-playing game] materials are small and lack intellectual diversity" (p. 193). One task would be to trace current collections of role playing materials in libraries, museums, such as the Computerspielmuseum in Berlin, and private collections. During 
the MittelPunkt 2012 convention, I visited the " 20 years of German larp exhibit". Although they were few, the exhibited pieces made it possible to follow the material development of safety weapons, from bamboo sticks to complex glass fiber-foam-latex assemblages. As role-playing games are diverse, collections may include books in libraries, currently collected boxes and feelies in museums, and garb in private collections. The task would be to catalogue existing collections. Another task would be to establish a coherent methodology to collect data about tangible and ephemeral traces of role playing for future studies. This would require an interdisciplinary project on game materials between game studies, heritage studies, and library studies.

The previous sections have shown how this dissertation contributes to the study of materials in role playing. In them I summarized the main findings, discussed their implications, and raised limitations. This section suggested future projects that extend the results of this dissertation in the field of game studies. The next section ends this dissertation and returns to its title Role-Playing Materials.

\subsection{Final Thoughts on Role Playing Materials}

Role Playing Materials examined how materials collaborate in role playing as an interrelational process. The dissertation revealed on the local level of specific role-playing game networks that role playing works when materials collaborate with narrative and ludic actors. In larp, garb collaborates with $360^{\circ}$ illusion, the fantasy genre, and DKWDDK (your character is able to do what you are able to do). In mixed reality role-playing games, the smartphone and virtual reality headset do not collaborate as digital actors that are separate but need to connect to other material actors. Smartphones and virtual reality headsets work already in relation to material actors and it is necessary to study heterogeneous cooperation to understand how augmented and virtual reality technology works. In tabletop role-playing games, material actors seem to keep no order. Lending voice to these actors increased the sensibility towards material agency and revealed how tables, pens, and dice collaborate. By studying materials in the process of negotiation, this dissertation has shown that materials are not neutral, because they demand changes from the role-playing game network that change narrative and ludic actions.

To conclude, I return to the title of this dissertation. First, Role Playing Materials draws attention to the question of how materials work in role playing. In this sense, the title reads as "A dissertation about role playing and materials." This opens the context for readers who are curious about the ontological questions how role-playing games work and what materials have to do with them. Second, Role Playing Materials draws 
attention to materials as role-playing actors themselves. In this sense, the title reads as "A dissertation about materials that are role-playing." This is an intriguing idea and it captures the epistemological level of this book and what is interesting about studying role-playing games with actor-network theory: thinking that it could be otherwise and playing with an idea as if it were so. Third, Role Playing Materials plays with the idea as if materials were role-playing further. In this sense, the title reads as "A dissertation that role-plays the perspective of materials." I experimented with lending authorial voice to materials in the final empirical chapter. Role-Playing Materials as a title summarizes the two levels of this book. It is a dissertation that examines what materials do where and when in a role-playing game, and studying these materials with actor-network theory changes the way how to know about role playing. 


\section{Participant Observation}

The primary sources for the fieldnotes were observations at the following sites. I took notes during or immediately after the event.

\section{Game Sessions}

Table 2. Participant observation larp 2010-2012

\begin{tabular}{|c|c|c|c|c|c|}
\hline Date & Name & Setting & Organizers & Place & Perspectives \\
\hline $30.7-1.8 .2010$ & $\begin{array}{l}\text { Dunkle Pfade } 1 \text { - } \\
\text { Der Kontakt }\end{array}$ & Fantasy & $\begin{array}{l}\text { Nachtfalken } \\
\text { Fantasy } \\
\text { Conventions e.V. }\end{array}$ & Utopion, Saarland & $\begin{array}{l}\text { Player, character } \\
\text { Mikal }\end{array}$ \\
\hline $\begin{array}{l}\text { 25.- } \\
29.08 .2010\end{array}$ & $\begin{array}{l}\text { Epic Empires } \\
2010\end{array}$ & Fantasy & $\begin{array}{l}\text { Epic Empires } \\
\text { Event UG }\end{array}$ & Utopion, Saarland & $\begin{array}{l}\text { Non-player, character } \\
\text { Asphon }\end{array}$ \\
\hline $\begin{array}{l}\text { 23.- } \\
26.09 .2010\end{array}$ & Schwarzbernstein & Fantasy & $\begin{array}{l}\text { Schwarzbernstein } \\
\text { Orga }\end{array}$ & Utopion, Saarland & $\begin{array}{l}\text { Co-organizer, several } \\
\text { non-player characters }\end{array}$ \\
\hline $\begin{array}{l}\text { 15.- } \\
17.07 .2011\end{array}$ & $\begin{array}{l}\text { Dunkle Pfade } \\
2 \text { - Der Pakt }\end{array}$ & Fantasy & $\begin{array}{l}\text { Nachtfalken } \\
\text { Fantasy } \\
\text { Conventions e.V. }\end{array}$ & Utopion, Saarland & $\begin{array}{l}\text { Player, character } \\
\text { Allanor }\end{array}$ \\
\hline 29.04.2011 & $\begin{array}{l}\text { BAM - From } \\
\text { Dusk til Dawn }\end{array}$ & Fantasy & $\begin{array}{l}\text { Sturmwächter } \\
\text { Orga }\end{array}$ & Marburg, Hessen & $\begin{array}{l}\text { Player, character } \\
\text { Allanor }\end{array}$ \\
\hline 2.-5.06.2011 & $\begin{array}{l}\text { Alcyon } 15 \text { - Der } \\
\text { Komet }\end{array}$ & Fantasy & $\begin{array}{l}\text { Fantasiewelten } \\
\text { e.V. }\end{array}$ & Utopion, Saarland & $\begin{array}{l}\text { Player, character } \\
\text { Allanor }\end{array}$ \\
\hline $14-16.10 .2011$ & neXus & Fantasy & Nightfall Orga & $\begin{array}{l}\text { Burg Bilstein, North } \\
\text { Rhine-Westphalia }\end{array}$ & $\begin{array}{l}\text { Player, character } \\
\text { Allanor, photographer }\end{array}$ \\
\hline 13.04.2012 & Police 1942 & Chamber larp & Sergei Lopariov & Helsinki, Finland & Player \\
\hline $\begin{array}{l}\text { 17.- } \\
\text { 20.05.2012 }\end{array}$ & $\begin{array}{l}\text { Alcyon } 16- \\
\text { Bluthochzeit }\end{array}$ & Fantasy & $\begin{array}{l}\text { Fantasiewelten } \\
\text { e.V. }\end{array}$ & Utopion, Saarland & $\begin{array}{l}\text { Non-player, several } \\
\text { characters }\end{array}$ \\
\hline 28.07.2012 & $\begin{array}{l}\text { Smokers' Lounge } \\
\text { IV }\end{array}$ & 1920 Cthulhu & $\begin{array}{l}\text { Cthulhu Aachen } \\
\text { Orga }\end{array}$ & $\begin{array}{l}\text { Aachen, North Rhine- } \\
\text { Westphalia }\end{array}$ & $\begin{array}{l}\text { Player, character } \\
\text { Tadeusz Ochorowicz }\end{array}$ \\
\hline 8.-12.08.2012 & $\begin{array}{l}\text { Epic Empires } \\
2012\end{array}$ & Fantasy & $\begin{array}{l}\text { Epic Empires } \\
\text { Event UG }\end{array}$ & Utopion, Saarland & $\begin{array}{l}\text { Non-player, character } \\
\text { Asphon }\end{array}$ \\
\hline 21.09.2012 & Kidslarp Gruga & Fantasy & $\begin{array}{l}\text { Avonturenwinkel } \\
\text { Lost \& Found }\end{array}$ & Utrecht, Netherlands & $\begin{array}{l}\text { Non-player character, } \\
\text { Crow }\end{array}$ \\
\hline 7.02 .2013 & $\begin{array}{l}\text { Prayers on a } \\
\text { Porcelain Altar }\end{array}$ & Mini-larp & $\begin{array}{l}\text { J.T. Harviainen } \\
\text { (author) }\end{array}$ & Goteborg, Sweden & Player \\
\hline 19.04.2013 & $\begin{array}{l}\text { Prayers on a } \\
\text { Porcelain Altar }\end{array}$ & Mini-larp & $\begin{array}{l}\text { J.T. Harviainen } \\
\text { (author) }\end{array}$ & $\begin{array}{l}\text { Köln, North Rhine- } \\
\text { Westphalia }\end{array}$ & Organizer \\
\hline 26.-28.04.2013 & $\begin{array}{l}\text { Dunkle Pfade } \\
3 \text { - Lokens } \\
\text { Vermächtnis }\end{array}$ & Fantasy & $\begin{array}{l}\text { Nachtfalken } \\
\text { Fantasy } \\
\text { Conventions e.V., }\end{array}$ & Utopion, Saarland & $\begin{array}{l}\text { Non-player, several } \\
\text { characters }\end{array}$ \\
\hline Summer 2013 & $\begin{array}{l}\text { Prayers on a } \\
\text { Porcelain Altar, } \\
\text { Fat Man }\end{array}$ & Mini-larp & $\begin{array}{l}\text { Maastricht mini } \\
\text { larp events }\end{array}$ & $\begin{array}{l}\text { Maastricht, the } \\
\text { Netherlands }\end{array}$ & Organizer \\
\hline 22.03.2014 & EntArtet & 1920 Cthulhu & $\begin{array}{l}\text { Cthulhu Aachen } \\
\text { Orga }\end{array}$ & $\begin{array}{l}\text { Aachen, North Rhine- } \\
\text { Westphalia }\end{array}$ & $\begin{array}{l}\text { Player, character } \\
\text { Henry Barnes }\end{array}$ \\
\hline
\end{tabular}


Table 3. Participant observation tabletop role-playing games 2010-2014 The order of fieldwork is not in line with the order of chapters, because I waited until the release of Oculus Rift DK2 in 2014 for the chapter on mixed reality role-playing games.

\begin{tabular}{|c|c|c|c|c|c|}
\hline Date & Name & Setting & Game master & Place & Perspectives \\
\hline 13.-20.8.2010 & $\begin{array}{l}\text { D20 World } \\
\text { of Warcraft, } \\
\text { Pathfinder }\end{array}$ & Fantasy & Changing & $\begin{array}{l}\text { Eifel, North Rhine- } \\
\text { Westphalia and } \\
\text { Rhineland-Palatinate }\end{array}$ & Player, character Alira \\
\hline 22.-31.07.2011 & $\begin{array}{l}\text { D20 World } \\
\text { of Warcraft, } \\
\text { Pathfinder, } \\
\text { Vampire: } \\
\text { Requiem }\end{array}$ & $\begin{array}{l}\text { Fantasy, } \\
\text { Horror }\end{array}$ & Changing & $\begin{array}{l}\text { Eifel, North Rhine- } \\
\text { Westphalia and } \\
\text { Rhineland-Palatinate }\end{array}$ & $\begin{array}{l}\text { Player, character } \\
\text { Alira, Pater }\end{array}$ \\
\hline 6.03 .2012 & $\begin{array}{l}\text { World of } \\
\text { Darkness }\end{array}$ & Horror & Rafael Bienia & $\begin{array}{l}\text { Maastricht, the } \\
\text { Netherlands }\end{array}$ & Game master \\
\hline 26.-31.12.2013 & $\begin{array}{l}\text { Pathfinder, } \\
\text { Vampire: } \\
\text { Requiem, Fiasko }\end{array}$ & $\begin{array}{l}\text { Fantasy, } \\
\text { Horror, } \\
\text { Alternative } \\
\text { Reality }\end{array}$ & Changing & $\begin{array}{l}\text { Zweibrücken, } \\
\text { Rhineland-Palatinate }\end{array}$ & $\begin{array}{l}\text { Player, character Ser } \\
\text { Ceras von Strom, } \\
\text { Pater; game master } \\
\text { Fiasko }\end{array}$ \\
\hline 21.03.2014 & $\begin{array}{l}\text { Das Schwarze } \\
\text { Auge } 4\end{array}$ & Fantasy & Daniel Stinsky & $\begin{array}{l}\text { Maastricht, the } \\
\text { Netherlands }\end{array}$ & Player, character \\
\hline
\end{tabular}

Table 4. Participant observation mixed reality role-playing games 2012-2015

\begin{tabular}{|l|l|l|l|l|l|} 
Date & Name & Setting & Designers & Place & Perspectives \\
\hline 2.09.2012 & Obscurus 2 & $\begin{array}{l}\text { Alternative } \\
\text { Reality }\end{array}$ & $\begin{array}{l}\text { Anne-Marieke } \\
\text { and Wouter } \\
\text { Apner }\end{array}$ & $\begin{array}{l}\text { Haarlem, the } \\
\text { Netherlands }\end{array}$ & $\begin{array}{l}\text { Player, character Max } \\
\text { Gruber }\end{array}$ \\
\hline Summer 2013 & DSA: Hexenwald & Fantasy & $\begin{array}{l}\text { Sprylab, } \\
\text { Chromatrix, } \\
\text { tripventure }\end{array}$ & - & Player, hunter \\
\hline Summer 2014 & $\begin{array}{l}\text { Diverse game } \\
\text { demos for Oculus } \\
\text { Rift }\end{array}$ & Diverse & Diverse & $\begin{array}{l}\text { Maastricht, the } \\
\text { Netherlands }\end{array}$ & Player \\
\hline $\begin{array}{l}386 \text { hours } \\
\text { until spring } \\
2015\end{array}$ & $\begin{array}{l}\text { The Elder Scrolls } \\
\text { V: Skyrim }\end{array}$ & Fantasy & $\begin{array}{l}\text { Bethesda } \\
\text { Softworks }\end{array}$ & $\begin{array}{l}\text { Maastricht, the } \\
\text { Netherlands }\end{array}$ & $\begin{array}{l}\text { Player, character } \\
\text { Boolk }\end{array}$ \\
\hline
\end{tabular}




\section{Role playing Conventions and Conferences}

Table 5. Participant observation conventions and conferences

\begin{tabular}{|c|c|c|c|c|c|}
\hline Date & Name & $\begin{array}{l}\text { Convention } \\
\text { / Conference }\end{array}$ & Presentation & Place & Language \\
\hline 15.01.2012 & MittelPunkt 2012 & Convention & $\begin{array}{l}\text { Actor-Network Theory in } \\
\text { Role-Playing Games }\end{array}$ & $\begin{array}{l}\text { Mainz, Rhineland- } \\
\text { Palatinate }\end{array}$ & German \\
\hline 10.04 .2012 & $\begin{array}{l}\text { Role-playing in } \\
\text { Games seminar }\end{array}$ & $\begin{array}{l}\text { Academic } \\
\text { Seminar }\end{array}$ & My dissertation project & $\begin{array}{l}\text { University of Tampere, } \\
\text { Finland }\end{array}$ & English \\
\hline 14.04 .2012 & Solmukohta & Convention & $\begin{array}{l}\text { Ninja Ethnography: How to } \\
\text { gather data during a larp }\end{array}$ & Helsinki, Finland & English \\
\hline 5.05 .2012 & $\begin{array}{l}\text { Role-Play } \\
\text { Convention }\end{array}$ & $\begin{array}{l}\text { Convention, } \\
\text { trade fair }\end{array}$ & $\begin{array}{l}\text { Nordische Rollenspiel- } \\
\text { forschung für Einsteiger }\end{array}$ & $\begin{array}{l}\text { Köln, North Rhine- } \\
\text { Westphalia }\end{array}$ & German \\
\hline 11.01 .2013 & MittelPunkt 2013 & Convention & $\begin{array}{l}\text { Larpforschung Ziele } \\
\text { 2013. Konkretes aus dem } \\
\text { Elfenbeinturm }\end{array}$ & $\begin{array}{l}\text { Limburg an der Lahn, } \\
\text { Hesse }\end{array}$ & German \\
\hline 12.01 .2013 & MittelPunkt 2013 & Convention & $\begin{array}{l}\text { LIVE! Polish-German Larp } \\
\text { Conversations }\end{array}$ & $\begin{array}{l}\text { Limburg an der Lahn, } \\
\text { Hesse }\end{array}$ & $\begin{array}{l}\text { German } \\
\text { Polish }\end{array}$ \\
\hline 24.1.2013 & Lecture & Lecture & $\begin{array}{l}\text { Materials for Computer Role- } \\
\text { Playing Games. Connecting } \\
\text { Digital and Non-Digital } \\
\text { Actors }\end{array}$ & $\begin{array}{l}\text { University of Cologne, } \\
\text { Germany }\end{array}$ & German \\
\hline 30.04 .2013 & $\begin{array}{l}\text { Physical and Digital } \\
\text { in Games seminar }\end{array}$ & $\begin{array}{l}\text { Academic } \\
\text { Seminar }\end{array}$ & $\begin{array}{l}\text { Agency of Game Materials in } \\
\text { German larp }\end{array}$ & $\begin{array}{l}\text { University of Tampere, } \\
\text { Finland }\end{array}$ & English \\
\hline 4.07 .2013 & $\begin{array}{l}\text { mash2013. Making } \\
\text { and Sharing. } \\
\text { Conference on } \\
\text { Audience Creativity }\end{array}$ & Conference & $\begin{array}{l}\text { Locations and User-Made } \\
\text { Maps in German Live Action } \\
\text { Role-Playing Games }\end{array}$ & $\begin{array}{l}\text { Maastricht, the } \\
\text { Netherlands }\end{array}$ & English \\
\hline 27.08.2013 & $\begin{array}{l}\text { DiGRA: DeFragging } \\
\text { Game Studies }\end{array}$ & Conference & $\begin{array}{l}\text { Role-Playing Game Studies. } \\
\text { A Handbook. Meeting }\end{array}$ & $\begin{array}{l}\text { Atlanta, United States } \\
\text { of America }\end{array}$ & English \\
\hline 18.10.2013 & $\begin{array}{l}\text { STAGE\#02: } \\
\text { Protokolle }\end{array}$ & Conference & $\begin{array}{l}\text { Methoden der } \\
\text { Spieleforschung. } \\
\text { Protokollieren Ephemerer } \\
\text { Spielpraktiken im } \\
\text { Liverollenspiel }\end{array}$ & $\begin{array}{l}\text { University of Cologne, } \\
\text { Germany }\end{array}$ & German \\
\hline 2.12 .2014 & $\begin{array}{l}\text { Games Couch } \\
\text { Conference }\end{array}$ & Conference & $\begin{array}{l}\text { Perspektiven des Materiellen } \\
\text { auf Digitale Spielewelten }\end{array}$ & $\begin{array}{l}\text { Technische Hochschule } \\
\text { Mittelhessen, Gießen, } \\
\text { Hesse }\end{array}$ & German \\
\hline 14.05.2015 & $\begin{array}{l}\text { RPG Summit at } \\
\text { DiGRA Conference }\end{array}$ & Conference & $\begin{array}{l}\text { A Perspective for Exploring } \\
\text { Material Agency in Role- } \\
\text { Playing }\end{array}$ & $\begin{array}{l}\text { Leuphana University, } \\
\text { Germany }\end{array}$ & English \\
\hline
\end{tabular}




\section{Online Ethnography 2010-2015}

Type of participation included writing, responding, and sharing information.

The frequency of participation was at least weekly per site.

\section{Forums}

http://larper.ning.com

http://www.inlarp.de

http://www.orkenspalter.de

http://www.teilzeithelden.de

http://www.die-dorp.de

http://www.cthulhu-live.de/

http://www.tanelorn.de

http://foren.pegasus.de

http://www.rpg.net/

https://forums.oculus.com/

\section{Groups on Facebook}

Larpforschung im deutschsprachigen Raum (founder, 2012)

Cthulhu LARP Aachen \& Umgebung

LARP Academia

LARP Social Media Vernetzung

LARP Handwerker und Hersteller

Rollenspiel Sammlerstücke und Sammlungen An und Verkauf

P\&P Rollenspiel

Rollenspielbedarf und Zubehör

Oculus Rift (VR Headset) Creative Community 


\section{INTERVIEWS}

For this book, I conducted semi-structured interviews with players, designers, and organizers of role-playing games between 2011 and 2015. The tables below give details, such as the names or pseudonyms, the background of the interviewee, the date and (in case of sufficient information) place of the interviewee's life, and further remarks, such as on the language in which the interview was conducted. Apart from these audio-recorded interviews, of which most were conducted via online speech software, the research is informed by face-to-face and mediated conversations with people involved with roleplaying game communities in different countries. In order of diversity, these informants were part of the communities in Germany, the Netherlands, Finland, Norway, Sweden, Denmark, Poland, Belarus, Austria, Switzerland, France, Bulgaria, Czech Republic, Brazil, Italy, Greece, and global online communities. These spontaneous and often informal conversations are not included in the list below, unless I directly quoted them.

\section{Chapter 3: Larp}

\section{Table 6. Interviews larp}

\begin{tabular}{l|l|l|l|} 
Name of Interviewee & $\begin{array}{l}\text { Background/Function at } \\
\text { the time of interview }\end{array}$ & Date and Place & Language/Remarks \\
\hline Chris & Organizer Epic Empires & 28.08 .2012 & German \\
\hline Keldrahir & Player & 12.07 .2012$, Marburg & German, pseudonym \\
\hline Fang & Organizer & 12.07 .2012 , Friedberg & German, pseudonym \\
\hline Steven & Player & 15.08 .2012$, Switzerland & German \\
\hline Tobi & Organizer Epic Empires & 30.08 .2012 & German \\
\hline Patrick Walter & Player & 13.10 .2012 & German \\
\hline Dr. Ulrike Horstmann & Highschool teacher & 16.10 .2012$, Aschaffenburg & German \\
\hline Section31 & Player & 18.10 .2012 & German, pseudonym \\
\hline Christoph Bielak & Nebelhorn Organizer & 26.02 .2013$, Osnabrück & German \\
\hline Dr. Dr. Matthias Trennheuser & Owner Utopion, player & 6. and 7.03 .2013$, Bexbach & German \\
\hline Rouven Porger & Organizer & 6.08 .2014 & German \\
\hline
\end{tabular}


Table 7. Correspondences larp

\begin{tabular}{|l|l|l|l|} 
Name of Correspondent & $\begin{array}{l}\text { Background/Function at } \\
\text { the time of talk }\end{array}$ & Date and Place & Language/Remarks \\
\hline $\begin{array}{l}\text { Michael Hess and Julian } \\
\text { Blomann }\end{array}$ & $\begin{array}{l}\text { Organizers Alcyon / Epic } \\
\text { Empires }\end{array}$ & 14.06 .2011$, online & German, E-Mail \\
\hline Michael Hess & $\begin{array}{l}\text { Organizer/Epic Empires } \\
\text { and Alcyon }\end{array}$ & 12.10 .2011 & English, E-mail \\
\hline Meister Habakuk & Organizer & 5. and 6.3.2013, online & German, E-Mail \\
\hline Tobi Putzo & Author & $8 .-10.7 .2015$, online & $\begin{array}{l}\text { German, Facebook } \\
\text { Private Message }\end{array}$ \\
\hline
\end{tabular}

\section{Chapter 4: Mixed Reality Role-Playing Games}

\section{Table 8. Interviews mixed reality role-playing games}

\begin{tabular}{|l|l|l|l|} 
Name of Interviewee & $\begin{array}{l}\text { Background/Function at } \\
\text { the time of interview }\end{array}$ & Date and Place & Language/Remarks \\
\hline Stefan Blanck & Game Designer & 17.09 .2013$, Bodelshausen & German \\
\hline Sander Burger & Organizer & 1.12 .2013$, Netherlands & English \\
\hline Florian Hermann & Player & 19.11 .2014$, Vienna & German \\
\hline Ork & Game Designer & 9.12 .2014$, Belgium & English, real name \\
\hline
\end{tabular}

\section{Chapter 5: Tabletop Role-Playing Games}

\section{Table 9. Interviews tabletop role-playing games}

\begin{tabular}{|c|c|c|c|}
\hline Name of Interviewee & $\begin{array}{l}\text { Background/Function at } \\
\text { the time of interview }\end{array}$ & Date and Place & Language/Remarks \\
\hline A.-G. Piel & Professional writer & 2.07.2014, Mainz & German \\
\hline Clarissa Baer & Player & 2.07.2014, Vienna & German \\
\hline Dennis Vogel & Player & 5.06.2014, Aachen & German \\
\hline Jan Enseling & Player & $\begin{array}{l}\text { 26.06.2014, Frankfurt am } \\
\text { Main }\end{array}$ & German \\
\hline Jan Pralle & Player & 10.07 .2014 & German \\
\hline Jessica Krzonkalla & Player & 3.07 .2014 & German \\
\hline Kalle Paulsen & Game programmer & 4.07 .2014 & German, pseudonym \\
\hline Feuerkobold & Player & 6.06.2014, Aachen & German, pseudonym \\
\hline Leon & Player & 28.05.2014, Aachen & German \\
\hline Nina Leberecht & Player & 26.06 .2014 & German \\
\hline Robert & $\begin{array}{l}\text { Professional writer of P\&P } \\
\text { game books }\end{array}$ & 9.07 .2014 & German, pseudonym \\
\hline Turmnagel & Player & 9.07.2014, Bochum & German, pseudonym \\
\hline Stephan Zuris Kinting & Player & 3.06.2014, Aachen & German \\
\hline Timothy Roven & Music designer & 16.07.2014, New York City & English \\
\hline
\end{tabular}




\section{LIST OF TABLES}

Name

Page

Table 1. A vocabulary for an actor-network study of role playing . . . . . . . . 53

Table 2. Participant Observation Larp 2010-2012 . . . . . . . . . . . . . . 171

Table 3. Participant Observation Tabletop Role-Playing Games 2010-2014 . . . . . 172

Table 4. Participant Observation Mixed Reality Role-Playing Games 2012-2015 . . 172

Table 5. Participant Observation Conventions and Conferences . . . . . . . . . 173

Table 6. Interviews larp . . . . . . . . . . . . . . . . . . . . . 175

Table 7. Correspondences larp . . . . . . . . . . . . . . 176

Table 8. Interviews mixed reality role-playing games . . . . . . . . . . 176

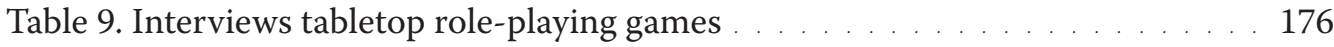





\section{REFERENCES}

Aarseth, E. (1997). Cybertext: Perspectives on ergodic literature. Johns Hopkins University Press.

Aarseth, E. (2001). Computer game studies, year one. Game Studies, 1(1).

Anderson, A. M., Kharroub, R., Levin, H., \& Rabah, M. (Eds.). (2015). Birth of larp in the arab world. A community book project. Oslo: Fantasiforbundet.

Andresen, M. E. (Ed.). (2012). Playing the learning game: A practical introduction to educational roleplaying: Based on experiences from The Larpwriter Challenge. Oslo: Fantasi Forbundet.

Apperley, T. H. (2015, November). Gaming's secret public: Nerdcore porn, \#gamergate and the in/visible body of the female gamer. Presented at the Reason Plus Enjoyment Conference 2015, Sydney. Retrieved from https://www.academia.edu/13907585/Gamings_secret_ public_Nerdcore_porn_gamergate_and_the_in_visible_body_of_the_female_gamer

Apperley, T. H., \& Jayemane, D. (2012). Game studies' material turn. Westminster Papers in Communication and Culture, 9(1), 5-25.

Azuma, R. T. (1997). A survey of augmented reality. Presence, 6(4), 355-385.

Azuma, R., Baillot, Y., Behringer, R., Feiner, S., Julier, S., \& MacIntyre, B. (2001). Recent advances in augmented reality. Computer Graphics and Applications, IEEE, 21(6), 34-47.

Balzer, M. (2011). The creation of immersion in live role-playing: Englische, überarbeitete version. In A. Castellani \& J. T. Harviainen (Eds.), Larp frescos: Volume pubblicato in occasione della seconda edizione del Larp Symposium (pp. 79-90). Firenze: Lulu Press.

Barad, K. (2003). Posthumanist performativity: Toward an understanding of how matter comes to matter. Signs, 28(3), 801-831.

Bartholow, B. D., Sestir, M. A., \& Davis, E. B. (2005). Correlates and consequences of exposure to video game violence: Hostile personality, empathy, and aggressive behavior. Personality and Social Psychology Bulletin, 31(11), 1573-1586. 
Barton, M. (2008). Dungeons and desktops: The history of computer role-playing games. Wellesley, MA: AK Peters.

Bedder, R. (2014). Worbla for LARP [Blog]. Retrieved from https://alhazredsghost. wordpress.com/larp-costume-101/larp-worbla-guide/

Beil, B. (2014). Avatarbilder: Zur Bildlichkeit des zeitgenössischen Computerspiels. Bielefeld: transcript Verlag.

Belleflamme, P., Lambert, T., \& Schwienbacher, A. (2013). Crowdfunding: Tapping the right crowd. Journal of Business Venturing, 29(5), 585-609.

Bergström, K., \& Björk, S. (2014). The case for computer-augmented games. Transactions of the Digital Games Research Association, 1(3). Retrieved from http://todigra.org/index. $\mathrm{php} /$ todigra/article/view/32

Bienia, R. (2012, February 5). Stop spelling mistakes in role-playing or is it "role playing"? [Blog]. Retrieved from https://bienia.wordpress.com/2012/01/27/role-playing-vs-roleplaying-hyphenation/

Bienia, R. (2015). Costume agency in german larp. In Proceedings of the 2015 DiGRA International Conference. Lüneburg, Germany. Retrieved from http://www.digra.org/ digital-library/publications/costume-agency-in-german-larp/

Bijker, W. E. (2010). How is technology made?-That is the question! Cambridge Journal of Economics, 34(1), 63-76.

Bland, B., Mishkin, B., \& Mishkin, S. (2013, July 10). Young Chinese shunning factory jobs, says Foxconn founder. Financial Times Online. Nusa Dua, Taipei. Retrieved from http://www.ft.com

Bodenstein, U. (2012). Die Herren der Spiele (Documentary). Maag Film GmbH.

Bogost, I. (2006). Unit operations: An approach to videogame criticism. Cambridge, MA: The MIT Press.

Bogost, I. (2009). Videogames are a mess. Presented at the DiGRA 2009, Brunel University, West London, United Kingdom. 
Bogost, I. (2012). Alien phenomenology, or, what it's like to be a thing. University of Minnesota Press.

Booth, W. C., Colomb, G. G., \& Williams, J. M. (2003). The craft of research. Chicago: University of Chicago Press.

Borup, M., Brown, N., Konrad, K., \& Van Lente, H. (2006). The sociology of expectations in science and technology. Technology Analysis E Strategic Management, 18(3-4), 285-298.

Boss, E. C. (2008). Key concepts in forge theory. In M. Montola \& J. Stenros, Playground Worlds. Creating and Evaluating Experiences of Role-Playing Games, (pp. 232-247). Helsinki: Ropecon ry.

Bourdieu, P. (1986). The forms of capital. Wiley Online Library.

Brown, A. M. L. (2013). Sex between frames: An exploration of online and tabletop erotic role play (Doctoral dissertation). The University of Manchester, Manchester, UK.

Brown, L. (1993). New shorter Oxford English dictionary on historical principles (5th ed., Vol. 2). Oxford: Clarendon Press.

Caillois, R. (2001). Man, play and games. Trans. Meyer Barash. Urbana and Chicago: University of Illinois Press. (Original work published in 1958).

Callon, M. (1986a). Éléments pour une sociologie de la traduction: La domestication des coquilles Saint-Jacques et des marins-pêcheurs dans la baie de Saint-Brieuc. L'Année Sociologique (1940/1948-), 36, 169-208.

Callon, M. (1986b). The sociology of an actor-network: The case of the electric vehicle. Mapping the Dynamics of Science and Technology, 23.

Callon, M. (1991). Techno-economic networks and ir reversibility. A Sociology of Monsters: Essays on Power, Technology and Domination, 38, 132-161.

Carter, M. (2014). The roll of the dice in Warhammer 40,000. Transactions of the Digital Games Research Association, 1(3). Retrieved from http://todigra.org/index.php/todigra/ article/view/20 
Castells, M. (1996). The rise of the network society: The information age: Economy, society, and culture (2nd ed.). Cambridge, MA: Wiley-Blackwell.

Castronova, E. (2003). Theory of the avatar (No. 863, CESifo working paper). Munich: Leibniz Institute for Economic Research at the University of Munich. Retrieved from http://www.econstor.eu/bitstream/10419/76336/1/cesifo_wp863.pdf

Caves, R. E. (2000). Creative industries: Contracts between art and commerce. Harvard Univ Pr.

Chaudry, M. A., Memon, M. Q., \& Danish, M. (2002). Heavy minerals concentration along the Baluchistan coast, Pakistan from Gadani to Phornala. Marine Georesources and Geotechnology, 20(1), 73-83.

Cook, M., Tweet, J., \& Williams, S. (2000). Dungeons \& Dragons player's handbook: Core rulebook I. Renton, WA: Wizards of the Coast. Inc.

Cook, M., Tweet, J., \& Williams, S. (2003). Dungeons \& Dragons dungeon master's guide: Core rulebook II v. 3.5. Renton, WA: Wizards of the Coast.

Copier, M. (2007). Beyond the magic circle: A network perspective on role-play in online games (Doctoral dissertation). Utrecht University, Utrecht.

Cosh, A., Cumming, D., \& Hughes, A. (2009). Outside enterpreneurial capital. The Economic Journal, 119(540), 1494-1533.

Cover, J. G. (2010). The creation of narrative in tabletop role-playing games. Jefferson NC: McFarland \& Company.

Crawford, G. (2011). Video gamers. London \& New York: Routledge.

Dahm, I. (2013). LARP: Einstieg in ein phantastisches Hobby. Braunschweig: Zauberfeder Verlag.

Debeauvais, T., Nardi, B. A., Lopes, C. V., Yee, N., \& Ducheneaut, N. (2012). 10,000 Gold for 20 Dollars: An exploratory study of World of Warcraft gold buyers. In Proceedings of the International Conference on the Foundations of Digital Games (pp. 105-112). ACM. 
DeLanda, M. (1995). Uniformity and variability: An essay in the philosophy of matter. In Doors of Perception 3: On Matter. Amsterdam. Retrieved from http://www.t0.or.at/ delanda/matterdl.htm

Deterding, S., \& Zagal, J. P. (n.d.). Role-playing game studies: Transmedia foundations. Version 1 summer 2015.

Deutscher Liverollenspiel Verband e.V. (2010). Was ist LARP. Retrieved from http:// www.dlrv.eu/index.php?id=wasistlarp

DeWalt, K. M., \& DeWalt, B. R. (2002). Participant observation: A guide for fieldworkers. AltaMira Press.

Dodig-Crnkovic, G., \& Larsson, T. (2005). Game ethics: Homo ludens as a computer game designer and consumer. International Review of Information Ethics, 4(12), 19-23.

Dombrowski, K. (2009). DragonSys: Regelwerk für Fantasy-Live-Rollenspiele. Braunschweig: Zauberfeder Verlag.

Dormans, J. (2006). On the role of the die: A brief ludologic study of pen-and-paper roleplaying games and their rules. Game Studies, 6(1).

Drachenroester, T. (2012, December 7). Regeln/OpferRegel [Wiki]. Retrieved from http://www.larpwiki.de/Regeln/OpferRegel

Elson, M., Breuer, J., \& Quandt, T. (2010). Too fast or too furious? The effects of displayed violence and game speed in first-person shooters on physiological arousal and aggressive behavior. Presented at the 4th Vienna Games Conference: Future and Reality of Gaming (FROG-2010).

Entwistle, J., \& Wilson, E. (2001). Body dressing (dress, body, culture). New York: Berg.

Erikson, E. H. (1994). Identity and the life cycle (Reissue edition, Vol. 1). New York: WW Norton \& Company.

Falzon, M. A. (2012). Multi-sited ethnography: theory, praxis and locality in contemporary research. Farnham: Ashgate Publishing, Ltd. 
Fatland, E. (2014). A history of larp: Larpwriter Summer School 2014. Presented at the Larpwriter Summer School. Retrieved from https://www.youtube.com/watch?v=Rf gej5Pxkg

Fatland, E., \& Wingård, L. (2003). The Dogma 99 Manifesto. In M. Gade, L. Thorup, \& M. Sander (Eds.), As Larp Grows up: Theory and Methods in Larp (pp. 20-31). Copenhagen: BookPartner.

Ferguson, C. J., Rueda, S. M., Cruz, A. M., Ferguson, D. E., Fritz, S., \& Smith, S. M. (2008). Violent video games and aggression causal relationship or byproduct of family violence and intrinsic violence motivation? Criminal Justice and Behavior, 35(3), 311-332.

Fine, G. A. (1983). Shared fantasy: Role-playing games as social worlds. Chicago: University of Chicago Press.

Fleer, M. (2013). Collective imagining in play. In I. Schousboe \& D. Winther-Lindqvist (Eds.), Children's Play and Development (pp. 73-87). Dordrecht: Springer.

Franke, J. E. (1981). Midgard: Fantasy-Rollenspiel. Stelzenberg: Verlag fuer F\&SF-Spiele.

Frasca, G. (1999). Ludology meets narratology: Similitude and differences between (video) games and narrative. Retrieved from http://www.ludology.org/articles/ludology. htm

Gaiman, N. (2012, May 17). Keynote address 2012. 134th Commencement, University of the Arts Philadelphia. Retrieved from http://www.uarts.edu/neil-gaiman-keynoteaddress-2012

Genette, G. (1997). Paratexts: Thresholds of interpretation (Vol. 20). Cambridge University Press.

Ghatak, M., \& Mueller, H. (2011). Thanks for nothing? Not-for-profits and motivated agents. Journal of Public Economics, 95(1), 94-105.

Goffman, E. (1959). The presentation of self in everyday life. New York: Anchor.

Goffman, E. (1961). Encounters: Two studies in the sociology of interaction. Indianapolis, NY: The Bobbs-Merrill Company. 
Goffman, E. (1974). Frame analysis. London: Harper \& Row.

Göncü, A., \& Perone, A. (2005). Pretend play as a life-span activity. Topoi, 24(2), 137-147.

Greengard, S. (2015). The Internet of Things. Cambridge, MA: The MIT Press.

Gygax, G., \& Arneson, D. (1974). Dungeons \& Dragons: Rules for fantastic medieval wargames, playable with paper and pencil and miniature figures. Tactical Studies Rules.

Gygax, G., \& Arneson, D. (1983). Dungeons E Dragons. Basic rules (3 revised). Lake Geneva: Tactical Studies Rules.

Harman, G. (2002). Tool-being: Heidegger and the metaphysics of objects. Open Court Publishing.

Harrigan, P., \& Wardrip-Fruin, N. (Eds.). (2010). Second person: Role-playing and story in games and playable media. Cambridge, MA: The MIT Press.

Harviainen, J. T. (2003). The multi-tier game immersion theory. In M. Gade, L. Thorup, \& M. Sander (Eds.), As Larp Grows Up: Theory and methods in larp (pp. 194-198). Copenhagen: BookPartner.

Harviainen, J. T. (2011). The larping that is not larp. In T. D. Henriksen, C. Bierlich, K. F. Hansen, \& V. Kolle (Eds.), Think larp. Academic Writings from Knutepunkt 2011 (pp. 175-193). Copenhagen: Rollespilsakademie.

Harviainen, J. T. (2012). Systemic Perspectives on Information in Physically Performed Role-play (Doctoral dissertation). University of Tampere, Tampere, Finland.

Heliö, S. (2004). Role-playing: A narrative experience and a mindset. In M. Montola \& J. Stenros (Eds.), Beyond role and play: tools, toys and theory for harnessing the imagination (pp. 65-74). Helsinki: Ropecon ry.

Heljakka, K. (2013). Principles of adult play(fulness) in contemporary toy cultures: from wow to flow to glow. School of Arts, Design and Architecture.

Hemmerich, E., \& Hemmerich, S. (2007). DragonSys Neues Zeitalter - Regelbuch für LARP. Zirndorf: G \& S Verlag GmbH. 
Henricks, T. (2010). Caillois's "Man, Play, and Games: An appreciation and evaluation." American Journal of Play, 3, 157-85.

Herz, B., Kramer, I., \& Römer, T. (2005). Das Schwarze Auge (4 (revised)). Erkrath: Fantasy Productions.

Hillenbrand, T., \& Lischka, K. (2014). Drachenväter. Die Geschichte des Rollenspiels und die Geburt der virtuellen Welt. Münster: Monsenstein und Vannerdat.

Hitchens, M., \& Drachen, A. (2009). The many faces of role-playing games. International Journal of Role-Playing, 1(1). Retrieved from http://www.ijrp.subcultures.nl/wp-content/ uploads/2009/01/hitchens_drachen_the_many_faces_of_rpgs.pdf

Hoff, J. (2006). Making of Oblivion [DVD]. Bonus Materials, Disc 2, thinkfilm.

Hook, N. (2008). The children of treasure trap: History and trends of British live action role-play. Playground Worlds. Creating and Evaluating Experiences of Role-Playing Games, (pp. 70-79). Helsinki: Ropecon ry..

Hook, N. (2012). A social psychology study of immersion among live action role-players. In S. Bowman \& A. Vanek (Eds.), Wyrd Con Companion 2012 (pp. 106-117). City of Orange, California: WyrdCon.

Hopeametsä, H. (2008). 24 hours in a bomb shelter: Player, character and immersion in Ground Zero. In M. Montola \& J. Stenros (Eds.), Playground Worlds. Creating and Evaluating Experiences of Role-Playing Games (pp. 187-98). Helsinki: Ropecon ry.

Huizinga, J. (1955). Homo ludens: A study of the play-element in culture. Boston: Beacon Press.

Ihde, D. (2009). Postphenomenology and technoscience: The Peking University lectures. Albany, NY: State University of New York Press.

Jara, D. (2013). A closer look at the (rule-) books: Framing and paratexts in tabletop roleplaying games. International Journal of Role-Playing, 1, 39-54.

Jara, D. (2015). Ambiguity, polysemy and poetic knowledge in tabletop role-playing games. In DiGRA 2015 RPG Summit. Lüneburg, Germany. 
Jensen, G. H. (2013). Making sense of play in video games: Ludus, paidia, and possibility spaces. Eludamos. Journal for Computer Game Culture, 7(1), 69-80.

Johnson, B. R. (2002). Virtuality and place. In Proceedings of the 2002 Annual Conference of the Association for Computer Aided Design In Architecture (pp. 77-84). At Pomona, California.

Juul, J. (2005). Half-real: Video games between real rules and fictional worlds. Cambridge, MA: The MIT Press.

Kappel, T. (2008). Ex ante crowdfunding and the recording industry: A model for the US. Loyola of Los Angeles Entertainment Law, 29(3), 375-385.

Karhulahti, V.-M. (2012). Feelies: The lost art of immersing the narrative. In Proceedings of Digital Games Research Association (DiGRA) Nordic 2012 Conference: Local and Global-Games in Culture and Society (pp. 1-9).

Kim, J. H. (2008, July 29). An Introduction to tabletop RPGs. Retrieved from http://www. darkshire.net/ jhkim/rpg/whatis/tabletop.html

King, B., Borland, J., \& Stewart, R. (2014). Dungeons and dreamers: The rise of computer game culture from geek to chic (2nd ed.). ETC Press.

Klevjer, R. (2006). What is the Avatar? Fiction and embodiment in avatar-based singleplayer computer games (Doctoral dissertation). University of Bergen, Bergen.

Klevjer, R. (2012). Enter the avatar: The phenomenology of prosthetic telepresence in computer games. In H. Fossheim, T. Mandt Larsen, \& J. R. Sageng (Eds.), The Philosophy of Computer Games (pp. 17-38). London \& New York: Springer.

Koljonen, J. (2007). Eye-witness to the illusion. An essay on the impossibility of 360 roleplaying. In J. Donnis, M. Gade, \& L. Thorup (Eds.), Lifelike (pp. 175-187). Skive: Arco Grafisk A/S.

Koljonen, J. (2010). Introduction to Nordic Larp. Presented at the Nordic Larp Talks, Stockholm. Retrieved from https://www.youtube.com/watch?v=fH_RLgR4DI4

Kruse, J. (2011, October). Einführung in die qualitative Interviewforschung. Retrieved from http://www. soziologie.uni-freiburg.de/kruse 
Kustritz, A. (2008). Painful pleasures: Sacrifice, consent, and the resignification of BDSM symbolism in "The Story of O" and "The Story of Obi." Transformative Works and Cultures, 1.

Kvale, S., \& Brinkmann, S. (2009). Interviews: Learning the craft of qualitative research interviewing. Sage.

Lamerichs, N. (2013). The cultural dynamic of doujinshi and cosplay: Local anime fandom in Japan, USA and Europe. Participations, 10(1), 154-176.

Lamerichs, N. (2014). Productive fandom: intermediality and affective reception in fan cultures.

Lankoski, P., \& Björk, S. (Eds.). (2015). Game research methods: An overview. Carnegie Mellon University: ETC Press.

Latour, B. (1987). Science in action: How to follow scientists and engineers through society. Cambridge, MA: Harvard University Press.

Latour, B. (1993). The pasteurization of France. Harvard University Press.

Latour, B. (1996a). Aramis, or The love of technology. Cambridge, MA: Harvard University Press.

Latour, B. (1996b). On actor-network theory: a few clarifications. Soziale Welt, 369-381.

Latour, B. (1999). On recalling ANT. In J. Law \& J. Hassard (Eds.), Actor network theory and after. Oxford: Blackwell.

Latour, B. (2004). Nonhumans. In S. Harrison, S. Pile, \& N. Thrift (Eds.), Patterned ground: entanglements of nature and culture (pp. 224-227). Chicago: University of Chicago Press.

Latour, B. (2005). Reassembling the social: An introduction to actor-network-theory. Oxford University Press, USA.

Latour, B. (2011). Network theory| networks, societies, spheres: Reflections of an actornetwork theorist. International Journal of Communication, 5(Special Issue), 796-810. 
Law, J. (1987). Technology and heterogeneous engineering: the case of Portuguese expansion. The Social Construction of Technological Systems: New Directions in the Sociology and History of Technology, 111-134.

Law, J. (1999). Actor network theory and after. Oxford \& Malden, MA: Wiley-Blackwell.

Law, J. (2004). After method: Mess in social science research. London \& New York: Routledge.

Law, J. (2009). Actor network theory and material semiotics. In B. S. Turner (Ed.), The new Blackwell companion to social theory (pp. 141-158). Hoboken, NJ: Blackwell Publishing.

Lifton, J., \& Paradiso, J. A. (2010). Dual reality: Merging the real and virtual. In F. LehmanGrube \& J. Sablatnig (Eds.), Facets of Virtual Environments. Lecture Notes of the Institute for Computer Sciences, Social Informatics and Telecommunications Engineering (Vol. 33, pp. 12-28). Springer.

Mackay, D. (2001). The fantasy role-playing game: A new performing art. Jefferson NC: McFarland \& Co.

Magerkurth, C., Cheok, A. D., Mandryk, R. L., \& Nilsen, T. (2005). Pervasive games: Bringing computer entertainment back to the real world. ACM Computers in Entertainment, 3(3), 4-4.

Malinowski, B. (1922). Argonauts of the western Pacific (2nd ed.). London: Routledge.

Manzo, R. (2011). There Is No Such Thing as a "Game Master." Larp Frescos: Affreschi Antichi E Moderni Sui Giochi Di Ruolo Dal Vivo, 103-122.

Marcus, G. E. (1995). Ethnography in/of the world system: the emergence of multi-sited ethnography. Annual Review of Anthropology, 24(1), 95-117.

Marmell, A., Shomshak, D., \& Suleiman, C. A. (2004). Vampire: The Requiem. Stone Mountain, GA: White Wolf Publishing.

Mason, P. (2004). A Survey of the First 25 Years of Anglo-American role-playing game theory. In M. Montola \& J. Stenros (Eds.), Beyond role and play: tools, toys and theory for harnessing the imagination. Helsinki: Ropecon ry. 
Mäyrä, F. (2015). Mobile Games. In R. Mansell, P. H. Ang, C. Steinfield, S. van der Graaf, P. Ballon, A. Kerr, D. J. Grimshaw (Eds.), The International Encyclopedia of Digital Communication and Society. Hoboken, NJ: Blackwell Publishing.

Mäyrä, F., \& Lankoski, P. (2009). Play in a mixed reality: Alternative approaches into game design. Digital Cityscapes: Merging Digital and Urban Playspaces, 129-147.

McGonigal, J. (2003). A real little game: The performance of belief in pervasive play. Proceedings of DiGRA 2003. Retrieved from http://www.digra.org/digital-library/ publications/a-real-little-game-the-pinocchio-effect-in-pervasive-play/

Meland, K. J., \& Svela, K. Ø. (Eds.). (2013). Crossing physical borders. Norway: Fantasiforbundet.

Michielse, M. (2015). Remix, cover, mash: remediating phonographic-oral practice online. Maastricht University:

Milgram, P., \& Kishino, F. (1994). A taxonomy of mixed reality visual displays. IEICE TRANSACTIONS on Information and Systems, 2351(12), 282-292.

Milgram, P., Takemura, H., Utsumi, A., \& Kishino, F. (1995). Augmented reality: A class of displays on the reality-virtuality continuum. In Photonics for Industrial Applications (pp. 282-292). International Society for Optics and Photonics.

Miller, J. (2006). Role playing games as interactive fiction. Reconstruction: Studies in Contemporary Culture, 6(1).

Mol, A. (2010). Actor-network theory: Sensitive terms and enduring tensions. Kölner Zeitschrift Für Soziologie Und Sozialpsychologie. Sonderheft, 50, 253-69.

Montola, M. (2009). The invisible rules of role-playing: The social framework of roleplaying process. International Journal of Role-Playing, 1(1), 22-36.

Montola, M. (2012a). On the edge of the magic circle: Understanding role-playing and pervasive Games (Doctoral dissertation). University of Tampere, Finland.

Montola, M. (2012b). Social constructionism and ludology. Implications for the study of games. Simulation E Gaming, 43(3), 300-320. 
Montola, M., \& Stenros, J. (2009). Pervasive game genres. In M. Montola, J. Stenros, \& A. Waern (Eds.), Pervasive games: Theory and design (pp. 31-46). Burlington, MA: Morgan Kaufmann.

Montola, M., Stenros, J., \& Saitta, E. (2015). The art of steering: Bringing the player and the character back together. In C. B. Nielsen \& C. Raasted (Eds.), The Knudepunkt 2015 Companion Book (pp. 106-117). Copenhagen: Rollespilsakademiet.

Montola, M., Stenros, J., \& Waern, A. (2009). Pervasive games: Theory and design. Burlington, MA: Morgan Kaufmann.

Mortensen, T. (2002). Playing with players: Potential methodologies for MUDs. Game Studies, 2(1). Retrieved from http://www.gamestudies.org/0102/mortensen/

Mortensen, T. E. (2015, May 20). DiGRA 2015 aftermath, the hashtag anger. Retrieved from http://torillsin.blogspot.nl/2015/05/digra-2015-aftermath-hashtag-anger.html

Mortensen, T. E., Linderoth, J., \& Brown, A. M. L. (2015). The dark side of game play: Controversial issues in playful environments. New York: Routledge.

Morton, B. (2007). Larps and their cousins through the ages. In J. Donnis, M. Gade, \& L. Thorup (Eds.), Lifelike (pp. 245-260). Skive: Arco Grafisk A/S.

Nardi, B., \& Kow, Y. M. (2010). Digital imaginaries: How we know what we (think we) know about Chinese gold farming. First Monday, 15(6).

Nilsen, T., Linton, S., \& Looser, J. (2004). Motivations for augmented reality gaming. Proceedings of FUSE, 4, 86-93.

N., N. (1941, March 3). Life visits the planet Atzor. LIFE, 102-105.

N., N. (2011, August 6). DRACCON 1: Erste Liverollenspiel Convention in Deutschland. Retrieved from http://midnightentertainment.blog.com

N., N. (2012). Definition of role playing. Oxford Online Dictionary. Retrieved from http:// oxforddictionaries.com/ 
N., N. (2014, February 12). Englisch-Deutsch Forum - leo.org - Englisch gesucht: Gewandung [Online Dictionary]. Retrieved from http://dict.leo.org/forum/ viewUnsolvedquery.php?idThread=1276596\&idForum $=1 \&$ lang $=$ de \&lp=ende

Olsson, C. M. (2015). Systematic interviews and analysis. Using the repertory grid technique. In P. Lankoski, S. Björk, \& C. M. Olsson (Eds.), Game Research Methods: An Overview (pp. 291-307). Carnegie Mellon University: ETC Press.

Oracz, M. (2010). De profundis: Letters from the abyss (2nd ed.). Oxford: Cubicle 7.

Pappe, G. (2011). PEP-Rollenspiel: Der kollektive Zugang zu utopischen Weltentwürfen und individuellen Phantasie-Konstrukten. Berlin: Logos Verlag Berlin GmbH.

Pearce, C., \& Artemesia. (2009). Communities of play: Emergent cultures in multiplayer games and virtual worlds. Cambridge, MA: The MIT Press.

Perron, B., \& Wolf, M. J. (2008). The video game theory reader 2. Routledge.

Petersen, S. (1981). Call of Cthulhu. Fantasy role-playing in the works of H.P. Lovecraft (1st ed.). Albany, CA: Chaosium.

Petersen, S., \& Willis, L. (2004). Call of Cthulhu: Horror roleplaying in the worlds of HP Lovecraft (6th ed.). Hayward, California: Chaosium.

Peterson, J. (2012). Playing at the world. Unreason Press (self published).

Petroski, H. (1990). The pencil: A history of design and circumstance. New York: Alfred A. Knopf.

Rein-Hagen, M., Davis, G., Dowd, T., Stevens, L., \& Wieck, S. (1992). Vampire: The Masquerade: A storytelling game of personal horror. Stone Mountain, GA: White Wolf.

Roselt, J., \& Otto, U. (2014). Theater als Zeitmaschine: Zur performativen Praxis des Reenactments. Theater-und kulturwissenschaftliche Perspektiven (Vol. 45). transcript Verlag.

Ryan, M.-L. (2006). Avatars of story. Minneapolis \& London: University of Minnesota Press. 
Salen, K., \& Zimmerman, E. (2004). Rules of play: Game design fundamentals. Cambridge, MA: The MIT Press.

Sayes, E. (2014). Actor-network theory and methodology: Just what does it mean to say that nonhumans have agency? Social Studies of Science, 44(1), 134-149.

Schneider, E., \& Hutchinson, B. (2015). Referencing the imaginary: An analysis of library collection of role-playing game materials. The Reference Librarian, 56(3), 174-188.

Schneider, J., \& Kortuem, G. (2001). How to host a pervasive game - Supporting face-toface interactions in live-action roleplaying. In Position paper at the Designing Ubiquitous Computing Games Workshop at UbiComp.

Schousboe, I. (2013). The structure of fantasy play and its implications for good and evil games. In I. Schousboe \& D. Winther-Lindqvist (Eds.), Children's Play and Development (pp. 13-27). Dordrecht: Springer.

Schröter, F., \& Thon, J.-N. (2014). Video game characters. Theory and analysis. DIEGESIS. Interdisziplinäres E-Journals Für Erzählforschung, 3(1), 40-77.

Schwohl, F. (2003, October 10). Geschichte Des Larp. Retrieved from http://www. larpwiki.de/Geschichte\%20Des\%20Larp

Sherry, J. L. (2001). The effects of violent video games on aggression: A meta-analysis. Human Communication Research, 27(3), 309-331.

Sihvonen, T. (2011). Players unleashed!: Modding The Sims and the culture of gaming (Vol. 5). Amsterdam University Press.

Silva, A. de S. e. (2006). From cyber to hybrid mobile technologies as interfaces of hybrid spaces. Space and Culture, 9(3), 261-278.

Silverman, D. (1985). Qualitative methodology and sociology: Describing the social world. Gower Aldershot.

Simkins, D. (2015). The arts of LARP: Design, literacy, learning and community in liveaction role play. McFarland. 
Sotamaa, O. (2010). When the game is not enough: Motivations and practices among computer game modding culture. Games and Culture.

Sotamaa, O. (2014). Artifact. In M. J. P. Wolf \& B. Perron (Eds.), The Routledge companion to video game studies (pp. 310-316). New York: Routledge.

sprylab. (2013, July 18). Das Schwarze Auge - Hexenwald. Retrieved from https://itunes. apple.com/us/app/das-schwarze-auge-hexenwald/id669474545? $\mathrm{mt}=8$

Stenros, J. (2012). In Defence of a magic circle: The social and mental boundaries of play. In Proceedings of 2012 DiGRA Nordic. Tampere.

Stenros, J. (2013, April 18). Keynote Script: What does "Nordic Larp" mean? [Blog]. Retrieved from http://jaakkostenros.wordpress.com/2013/04/18/keynote-script-whatdoes-nordic-larp-mean/

Stenros, J. (2015). Playfulness, play, and games: A constructionist ludology approach (Doctoral dissertation). University of Tampere, Tampere, Finland.

Stenros, J., \& Montola, M. (Eds.). (2010). Nordic Larp. Stockholm: Fëa Livia.

Stenros, J., Waern, A., \& Montola, M. (2011). Studying the elusive experience in pervasive games. Simulation \& Gaming, 43(3), 391-412.

Sutko, D. M., \& Silva, A. de S. e. (2011). Location-aware mobile media and urban sociability. New Media \& Society, 13(5), 807-823.

Sutton-Smith, B. (1997). The ambiguity of play. Cambridge, MA: Harvard University Press.

Taylor, T. L. (2006). Play between worlds: Exploring online game culture. Cambridge, MA: The MIT Press.

The Games of Vi åker jeep / We go by Jeep. (n.d.). Retrieved from http://jeepen.org/games/

Toivonen, S., \& Sotamaa, O. (2011). Of discs, boxes and cartridges: the material life of digital games. In Proceedings of DiGRA 2011 Conference: Think Design Play. Utrecht. Retrieved from http://www.digra.org/wp-content/uploads/digital-library/11312.23263.pdf 
Torner, E. (2015). RPG theory and game text definitions of "what is a role-playing game." Presented at the DiGRA 2015 RPG Summit, Lüneburg, Germany.

Torner, E., \& White, W. J. (Eds.). (2012). Immersive gameplay. Jefferson, North Carolina: McFarland Press.

Tyni, H., Kultima, A., \& Mäyrä, F. (2013). Dimensions of hybrid in playful products. In Proceedings of Mindtrek 2013. Tampere: ACM.

Utbult, S. (2015, January 4). Non-player character. In Nordic Larp Wiki. Retrieved from http://nordiclarp.org/wiki/Non-player_Character

Vanek, A. (2015). Behind the Larp Census: 29.751 larpers can't (all) be wrong. In C. B. Nielsen \& C. Raasted (Eds.), The Knudepunkt 2015 Companion Book (pp. 16-23). Copenhagen: Rollespilsakademiet.

van Lente, H. (1993). Promising technology: The Dynamics of expectations in technological developments (Doctoral dissertation). University of Utrecht, Utrecht.

Venturini, T. (2010). Diving in magma: How to explore controversies with actor-network theory. Public Understanding of Science, 19(3), 258-273.

VSNU. (2012). Code of conduct for scientific integrity. Vereniging van Universiteiten VSNU. Retrieved from http://www.maastrichtuniversity.nl/web/Main/AboutUM/ OurProfile/FactsFigures1/CodesOfConductRegulations.htm

Waern, A., Montola, M., \& Stenros, J. (2009). The three-sixty illusion: Designing for immersion in pervasive games. In Proceedings of the SIGCHI Conference on Human Factors in Computing Systems (pp. 1549-1558). ACM.

Wagner, T. (2002, August 22). Die deutsche Liverollenspiel FAQ. Retrieved from http:// www.larpkalender.de/larpfaq/larpfaq.php3\#KAP5.4.3

Wagner, T. (2011, July 12). Larp-Statistik 2011 Stecken wir schon mitten in der LARPRezession? - LarpeR. Retrieved from http://larper.ning.com/forum/topics/stecken-wirschon-mitten-in-der-larp-rezession 
Walther, B. K. (2003). Playing and gaming: Reflections and classifications. Game Studies $3(1), 1-20$.

Walther, B. K. (2007). Pervasive game-play: Theoretical reflections and classifications. In C. Magerkurth \& C. Röcker (Eds.), Concepts and Technologies for Pervasive Games: A Reader for Pervasive Gaming Research (Vol. 1). Aachen: Shaker Verlag.

Wardrip-Fruin, N., Mateas, M., Dow, S., \& Sali, S. (2009). Agency reconsidered. Digital Games Research Association.

Waskul, D., \& Lust, M. (2004). Role囚playing and playing roles: The person, player, and persona in fantasy role冈playing. Symbolic Interaction, 27(3), 333-356.

Weis, R. (2001). DragonSys Classic LARP. Regeln für Life-Rollenspiele (1st ed.). Zirndorf: G\&S Verlag.

Weis, R., \& Putzo, T. (1991). DragonSys - DIE REGELN - Volume 1. self published.

Wenz, K. (2014). Death. In M. J. P. Wolf \& B. Perron (Eds.), The Routledge Companion to Video Game Studies (pp. 310-316). New York: Routledge.

Williams, J. M., \& Colomb, G. G. (2007). The craft of argument. Longman Publishing Group.

Wojciechowski, A. (2009). Models of charity donations and project funding in social networks. In On the Move to Meaningful Internet Systems: OTM 2009 Workshops (pp. 454-463). Springer.

Woodworth, P. (2005). Mind's Eye Theatre Core Rulebook. White Wolf Publishing.

Wyatt, S. (2008). Technological determinism is dead; long live technological determinism. In E. J. Hackett, O. Amsterdamska, M. E. Lynch, \& J. Wajcman (Eds.), The handbook of science and technology studies (pp. 165-180). Cambridge, MA: The MIT Press.

Xu, F., \& Wünderlich, N. V. (2009). Neue Businessmodelle im Bereich Online-Gaming: Gold-farming in China. Geschäftsmodelle in Virtuellen Spielewelten: Eine Broschüre Aus Dem Forschungsprojekt Second Business. 
Young, M. J. (2005). Theory 101: The impossible thing before breakfast. Places to go, people to be, 27. Retrieved from http://ptgptb.org/0026/theory101-01.html

Zagal, J. P., \& Altizer, R. (2014). Examining "RPG elements": Systems of character progression. In T. Barnes \& I. Bogost (Eds.), Proceedings of the 9th International Conference on the Foundations of Digital Games. Fort Lauderdale, FL: Society for the Advancement of the Science of Digital Games.

Zimmerman, E. (2012, July 2). Jerked around by the magic circle: Clearing the air ten years later. Retrieved from http://www.gamasutra.com/view/feature/6696/ jerked_around_by_the_magic_circle_.php 



\section{SumMARY IN ENGLISH}

Role Playing Materials examines the work of material actors in networks of larp, mixed reality, and tabletop reality role-playing games. Materials are physical elements that include things, objects, but also raw materials, like wood or metal. Actors are any elements that make a difference within their environment. This environment of interrelated actors is a network. For example, a larp network consists of actors that provide the story, game rules, and costumes to make a larp work. Larp is a type of role playing where people pretend to be a character living in an imagined world. To play this game form, they rent a location, dress up, and remain in character for a couple of days. The study of larp is the first example of this dissertation. Mixed reality role-playing games is the second example. Here, computers, smartphones, and virtual reality headsets are actors that collaborate with computer games and other elements. People can dress up and use smartphones or sit in front of a computer with a $360^{\circ}$ headset that simulates the fantastic environment. The third example is tabletop role-playing games where people sit around a table and tell each other what their character does. Game rules help to decide whether an action is successful and a game master tells where the characters are in a shared imagined world and whom they meet.

These role-playing game forms have been a topic of study in various fields, most prominently in the field of game studies. Game studies tells us how narrative actors work, and identifies elements that create the story world and the characters. It also provides studies on ludic actors, elements that constitute the game rules and system. Thanks to previous studies, we may know about narrative and ludic elements and how they collaborate, but we do not know about material actors. With a study on material actors in three role-playing game forms, this dissertation aims to expand our understanding of role playing.

If we do not know how materials make role playing work, we lack an understanding of material processes and narrative and ludic processes that solely work with materials. The consequence is a closed path for future research on the topic of game materials which are products of one of the biggest entertainment industries including international companies and local start-ups.

To solve the lack of material studies, Role Playing Materials addresses the following questions: How do materials make role playing work? How do materials collaborate with 
narrative and ludic actors in role-playing games? What changes do materials demand for their collaboration from narrative and ludic actors?

These questions bring into focus not just what materials in role-playing games are, an ontological problem, but also the epistemological side of the issue. The epistemological question, how to know about materials that collaborate with narrative and ludic actors, stretches the understanding of materials as passive actors and examines whether these non-human elements co-create relations within their game environment.

To answer these questions, this study draws upon actor-network theory as a theoretical and methodological toolbox. According to actor-network theory's main principle "follow the actors," I followed material actors to sites of role playing to observe how relations change when material, narrative, and ludic actors negotiate. I analyzed these negotiations from within by observing game sessions as a participant. Between 2010 and 2014, I conducted ethnographic fieldwork and participated in role-playing game sessions. The results of the empirical analysis are presented in Chapters 3, 4, and 5. Each chapter focuses on one role-playing game form.

With actor-network theory, I speak about role playing as a process and examine which actors become part of it by following their work. This mode of speaking moves the study from defining the properties of preselected actors to examining relational work of actors in a specific local network. Such a movement changes how to know about role playing. Actor-network theory expands the study of role playing by looking beyond human-centered phenomena towards a multi-centered understanding of inter-relational processes. In each chapter, I have deconstructed what is known about role-playing games by examining the known narrative and ludic actors along with the less known material actors. One thing that does not follow from this study is a rejection of narrative and ludic actors as keys to understanding role playing, because it was possible to re-construct previous research results for the study of materials.

The three chapters provide answers to the ontological question, because the specificity of each empirical case provides concrete examples. The material elements that I followed are necessary actors within these networks. The costume in larp, the smartphone in mixed reality, and the table in tabletop role-playing games are not there by accident. They are preferred by the intra-relational structure of the specific game network. At the same time they co-construct this very structure and maintain role playing. In this regard, role playing extends mere pretend play of people to include further processes between material, narrative, and ludic actors. 
Instead of defining what a typical role-playing material is, the results encourage future studies to look for materials and ask where they are necessary to create and maintain the particular role-playing game network, be it called a larp, mixed reality, or tabletop role-playing game.

The results of this study contribute to the understanding of role playing, because they show how role playing as an inter-relational process includes material, narrative, and ludic actors in three forms of role-playing games. Materials matter in role playing, because they cooperate with narrative and ludic actors, and because their collaborative work changes how role playing emerges in a role-playing game network.

Role Playing Materials concludes that in order to understand the complexity of roleplaying games, future research has to acknowledge relations between narrative, ludic, and material actors, and more importantly, this inter-related process should be studied without giving one actor or the other a preferred position. 



\section{SAMENVATTING}

(Summary in Dutch)

Role Playing Materials onderzoekt het werk van materiële actoren in netwerken van larp-, mixed reality- en tabletop reality-rollenspellen. Materialen zijn fysieke elementen die dingen en objecten omvatten, maar ook ruwe materialen zoals hout of metaal. Actoren zijn alle elementen die een verschil maken binnen hun omgeving. Deze omgeving van intergerelateerde actoren is een netwerk. Zo bestaat een larp-netwerk bijvoorbeeld uit actoren die zorgen voor het verhaal, de spelregels en de kostuums om een larp te laten functioneren. Larp is een soort rollenspel waarbij mensen zich voordoen als een personage dat in een imaginaire wereld leeft. Om deze spelvorm te spelen huren ze een locatie, verkleden ze zich en blijven ze een paar dagen in hun rol. De bestudering van larp is het eerste voorbeeld van deze dissertatie. Mixed reality-rollenspellen zijn het tweede voorbeeld. Hier zijn computers, smartphones en virtual reality-headsets actoren die samenwerken met computerspellen en andere elementen. Men kan zich verkleden en smartphones gebruiken of achter een computer gaan zitten met een $360^{\circ}$ headset die de fantasieomgeving simuleert. Het derde voorbeeld zijn tabletop-rollenspellen, waarbij mensen rond een tafel zitten en elkaar vertellen wat hun personage doet. De spelregels helpen om te bepalen of een actie succesvol is en een game master vertelt waar de personages in een gedeelde imaginaire wereld zich bevinden en wie ze ontmoeten.

Deze vormen van rollenspel zijn onderwerp van studie op verschillende gebieden geweest, vooral op het gebied van game studies. Game studies vertelt ons hoe narratieve actoren werken en identificeert elementen die de verhaalwereld en de personages creëren. Daartoe behoren ook studies over ludische actoren, elementen die de spelregels en het systeem vormen. In eerdere studies hebben we misschien al kennis gemaakt met narratieve en ludische elementen en gezien hoe ze samenwerken, maar we weten nog niets over materiële actoren. Met een studie over materiële actoren in drie vormen van rollenspel beoogt deze dissertatie ons begrip van rollenspel te vergroten.

Als we niet weten hoe materialen rollenspel laten werken, ontbreekt het ons aan inzicht in materiële processen en narratieve en ludische processen die alleen met materialen werken. Het gevolg is een gesloten pad voor toekomstig onderzoek op het gebied van spelmaterialen die het product zijn van een van de grootste entertainmentindustrieën, waartoe internationale ondernemingen en lokale startups behoren. 
Om het gebrek aan materiële studies op te lossen, worden in Role Playing Materials de volgende vragen gesteld: Hoe laten materialen rollenspel werken? Hoe werken materialen samen met narratieve en ludische actoren in rollenspellen? Welke veranderingen vragen materialen voor hun samenwerking van narratieve en ludische actoren?

Deze vragen geven niet alleen zicht op wat materialen in rollenspellen zijn, een ontologisch probleem, maar ook op de epistemologische kant van het vraagstuk. De epistemologische vraag hoe kennis wordt opgedaan over materialen die samenwerken met narratieve en ludische actoren, verruimt het begrip van materialen als passieve actoren en onderzoekt of deze niet-menselijke elementen relaties binnen hun spelomgeving co-creëren.

Om deze vragen te beantwoorden is dit onderzoek gebaseerd op de actor-netwerktheorie als een theoretische en methodologische toolbox. Volgens het basisprincipe van de actor-netwerktheorie 'volg de actoren' heb ik materiële actoren gevolgd naar plaatsen waar een rollenspel wordt gespeeld om te observeren hoe relaties veranderen wanneer materiële, narratieve en ludische actoren onderhandelen. Ik heb deze onderhandelingen van binnenuit geanalyseerd door spelsessies als deelnemer te observeren. Tussen 2010 en 2014 heb ik etnografisch veldwerk uitgevoerd en aan rollenspelsessies deelgenomen. De resultaten van de empirische analyse worden gepresenteerd in hoofdstuk 3, 4 en 5. In elk hoofdstuk wordt één vorm van rollenspel behandeld.

Met de actor-netwerktheorie spreek ik over rollenspel als een proces en onderzoek ik welke actoren er deel van uitmaken door hun werk te volgen. Deze wijze van spreken verschuift de studie van het definiëren van de eigenschappen van vooraf geselecteerde actoren naar het onderzoeken van relationeel werk van actoren in een specifiek lokaal netwerk. Een dergelijke verschuiving verandert de manier waarop kennis over rollenspel wordt opgedaan. De actor-netwerktheorie verbreedt de studie van rollenspel door verder te kijken dan mensgerichte fenomenen naar een multi-gecentreerd begrip van interrelationele processen. In elk hoofdstuk heb ik gedeconstrueerd wat er over rollenspellen bekend is door de bekende narratieve en ludische actoren samen met de minder bekende materiële actoren te onderzoeken. Wat niet uit deze studie volgt is dat narratieve en ludische actoren als sleutel tot het begrijpen van rollenspel worden verworpen, omdat eerdere onderzoeksresultaten konden worden gereconstrueerd voor de studie van materialen.

De drie hoofdstukken geven antwoorden op de ontologische vraag, omdat de specificiteit van elk empirisch geval concrete voorbeelden geeft. De materiële elementen die ik heb gevolgd, zijn noodzakelijke actoren binnen deze netwerken. Het kostuum in 
larp-, de smartphone in mixed reality- en de tafel in tabletop-rollenspellen zijn er niet toevallig. Ze genieten de voorkeur door de intrarelationele structuur van het specifieke spelnetwerk. Tegelijkertijd co-construeren ze juist deze structuur en houden ze rollenspel in stand. In dit opzicht gaat rollenspel verder dan mensen die alleen maar 'doen alsof' en omvat het ook andere processen tussen materiële, narratieve en ludische actoren.

In plaats van te definiëren wat een typisch rollenspelmateriaal is, zijn de resultaten een stimulans om in toekomstige studies te kijken naar materialen en te vragen waar deze nodig zijn om het specifieke rollenspelnetwerk op te zetten en in stand te houden, of het nu een larp-, mixed reality- of tabletop-rollenspel wordt genoemd.

De resultaten van deze studie dragen bij tot een beter begrip van rollenspel, omdat ze laten zien hoe rollenspel als interrelationeel proces materiële, narratieve en ludische actoren in drie vormen van rollenspel omvat. Materialen zijn van belang in rollenspel omdat ze samenwerken met narratieve en ludische actoren en omdat hun samenwerking de verschijningsvorm van rollenspel in een rollenspelnetwerk verandert.

De conclusie van Role Playing Materials luidt dat om de complexiteit van rollenspellen te begrijpen in toekomstig onderzoek de relaties tussen narratieve, ludische en materiële actoren moeten worden erkend en, wat nog belangrijker is, dat dit intergerelateerde proces moet worden bestudeerd zonder de ene of de andere actor een voorkeurspositie te geven. 



\section{VALORIZATION ADDENDUM}

Towards the end of my dissertation project, Maastricht University came up with the idea of having Ph.D. candidates write about the social and/or economic value of their work in an additional chapter, the Valorization Addendum. I first introduce the rationale behind this addendum. Then, I explain what it means to me, and finally, I show what social and economic value readers might draw from my dissertation project.

\section{What Is the Valorization Addendum?}

The Valorization Addendum is an additional chapter that is not part of the dissertation's assessment. The addendum should demonstrate the value of the knowledge that a dissertation in the Humanities provides. Knowledge valorization refers to the "process of creating value from knowledge, by making knowledge suitable and/or available for social (and/or economic) use and by making knowledge suitable for translation into competitive products, services, processes and new commercial activities" (adapted definition based on the National Valorization Committee, 2011, p. 8, as quoted from the Regulation Valorization Addendum sent by the Graduate School on 19 June 2014).

As stated in the definition above, the task is to suggest or show examples of how one's knowledge produces commodities for sale on the market. It should offer the Ph.D. candidate an opportunity to create bridges between her or his theoretical work and its utility.

\section{What Is the Valorization Addendum to Me?}

I have studied comparative literature and English studies at the Johannes GutenbergUniversity in Mainz, Germany. Both philological disciplines are at the heart of the Humanities. English studies as a discipline creates further value in that one track of this study program produces English teachers. I did not follow this track. I studied English for the sake of the language, culture, and literature. My choice to study comparative literature followed the same interests. Interestingly, comparative literature in Mainz changed in 2009 into European Literature. The value of international comparative literature studies seemed to be not enough for my former university to translate knowledge into 
"competitive products, services, processes and new commercial activities" (National Valorization Committee, 2011, p. 8). Or am I wrong and this change was rather about narrowing of focus, a change that has nothing to do with an economical imperative translating its agency across all differentiated institutions? By differentiated institutions I refer to Niklas Luhman's theory that state, religion, and economy began to separate during the Renaissance. I wrote my masters thesis on this topic and how it shows in the work of Shakespeare. It seems that the imperative or driving force of economy is reuniting all these systems again. What I saw at my former university with the change in comparative literature and what I see in Maastricht looks like the same driving force at work. Humanities have to show how well they play the economic game, and how they produce commodities, otherwise they do not get funded and perish. One of the English studies scholars whom I admired during my more theoretical studies, Terry Eagleton, wrote about these changes more drastically in his essay "The Slow Death of the University" (2015). Here, he gives more examples of how the "deap-seated political and economic forces" work (Eagleton, para 14, 2015). One anecdote stuck in my mind, his withdrawal as a chair at the University of Oxford because he had the impression that his duties were those of a manager rather than those of a scholar. It is a drastic decision and in Eagleton's case it serves as an exemplum, but for me as a Ph.D. candidate, I need other ways to signal what I think. Despite the lukewarm resistance to the addendum by my colleagues in 2014 (only two showed up at an open information morning on this topic), I think that the Valorization Addendum is the right place to show how a Humanities Ph.D. can play. I do not think that I am a good player or gamer, but I do not simply want to withdraw.

I thought about the economic valorization of my work after I submitted my masters thesis in 2009. At the time, I worked at Deutsche Telekom AG and was familiar with an operating economic force from within the economy. I wondered how to bridge my future academic work with these new impressions I got as an intern and later as an employee of this company. In 2010, I spoke with Dr. Peter Waldmann, a former tutor at Mainz University who shaped my studies profoundly with his expertise and passion for our discipline. At an Argentine restaurant, we talked about my plans. I showed him three dissertation projects: one on Shakespeare, one on virtual realities, and one on games. The moment I explained what I wanted to do, I made my decision. He also thought that it would better fit my development as a scholar if I did not write another piece on Shakespeare, but pursued my theoretical interest in role-playing games. Role-playing games are a genre of games that is enriched with narrative elements, an ideal topic to bridge my former interest in literary studies with new disciplines closer to economy. The work of the economic imperative in my decision was: If video games make more money 
than Hollywood and the music industry together, there must be something interesting to keep me working for five years, right? Thus, my choice to write a dissertation on games has changed my pursuit of 'purely' theoretical knowledge to include the economic imperative. After a detour at the University of Siegen with GamesCoop, a group of scholars dedicated to games, I joined the project Narrative Fan Practices, part of the national project Cultural Dynamics, funded by the Netherlands Research Organization (NWO).

\section{Valorization Questions}

My dissertation is in the hands of the committee now. It is the end of 2015. I need to finish my musings about valorization that began in 2009. The "Regulation Valorization Addendum" document that I mentioned above suggests five questions that may guide the Ph.D. candidate in writing this chapter.

The first question is on relevance: "What is the social (and/or economic) relevance of your research results (i.e. in addition to the scientific relevance)?" This dissertation is the very first dissertation to examine the role of materials in role-playing games, one of the most successful genres of games. Video games alone made a revenue of $\$ 22.41$ billion in the US in 2014. Of this total, $\$ 5.08$ billion is spent on hardware (Electronic Software Association, 2015, p. 13). As such, people spend more money on video games than on DVDs, music CDs, or cinema. This dissertation proves that materials, such as hardware, have value as a research topic for game studies. The theoretical value of studying materials, as well as their economic weight, encourage further studies to improve our understanding of video games and analog games. Further research will provide vital insights for academia and for game designers. In Chapter 4, this dissertation shows game designers that in order to design more stable mixed reality games, they need to rethink their understanding of the digital/real divide. This dichotomy permeates not only academic thought, but also the video game industry. I show this ingrained belief in Chapter 4 when I discuss some of the literature on mixed reality technology and how Oculus promotes its virtual reality headset as a "step into the game." The economic relevance of Chapter 4 alone helps the designer to rethink how game software, hardware, the site of play, and the player interact.

The second question asks about target groups: "To whom, in addition to the academic community, are your research results of interest and why?" The target group of my research results includes game journalists, game designers, and hobbyists. Game journalists have rarely written on the topic of game materials. As gamers are a growing and aging subculture, there are many interesting topics that my research invigorates. For example, 
what does your gaming environment look like? What are your favorite game materials from the 1990s? Game designers include materiality in their game design documents when they plan a video game, but often this materiality does not refer to the physical aspects of playing a game, but to the materiality within the virtual world. My research informs how players experience the tangible side of games, even virtually oriented video games. Hobbyists get a voice with my research, as I address practices such as the crafting, maintaining, and modding of game materials ranging from costumes to computers.

The third question is on activities and/or products that might result from the theoretical work: "Into which concrete products, services, processes, activities or commercial activities will your results be translated and shaped?" This dissertation raises awareness on materials as active actors in role-playing games. To increase the awareness among players, designers, and scholars, I have disseminated my research and stimulated the discourse on game materials over the past four years. I have regularly contributed to the community of larpers by co-editing and editing an essay collection for the annual larp conference MittelPunkt in Germany. I have written for, edited, and co-edited the 2013, 2014, and 2015 anthologies (Bienia, 2009, 2011a, 2011c, 2012; Bienia \& Dombrowski, 2013). Especially, the MittelPunkt Aufsatzsammlung 2015 anthology ties directly into my research with its thematic focus on materials in larp with the title Larp:Zeug (English: Larp:Stuff) (Bienia \& Schlickmann, 2015). Beside this, I have written popular articles for the print magazine LARPzeit, and the online magazines Fandom Observer, inlarp. de, and teilzeithelden.de (Bienia, 2009, 2011a). I have presented my research at the German MittelPunkt and Nordic Knutepunkt conventions. I contributed to the U.S. larp convention anthology with a quantitative analysis of larp motivations (Bienia, 2012). Additionally, I initiated the founding of the first academic research group on larp in Germany in autumn 2013 during a meeting of kids' larp organizers. The research group is part of the Deutscher Live-Rollenspiel Verband e.V. and provides contacts, a library, and further help to students and graduate researchers. Thus, I have provided concrete products (MittelPunkt books), services (library at larp research group, articles), and processes (larp research group for networking).

The fourth question is on innovation: "To what degree can your results be called innovative in respect to the existing range of products, services, processes, activities and commercial activities?" There has been no academic monograph of comparable scope on game materials in general, and on role-playing game materials in particular. Above, I wrote that the concrete and theoretical results of this study can offer help in rethinking game design. The explicit focus on materials opens possibilities to approach games from an innovative perspective. Although game design always includes materials 
and their function, the innovative result of my research is that it demonstrates the value of a change of perspective. It is the symmetric perspective that puts materials on the same level as the player (and designer). Materials are active collaborators, not passive intermediaries. The key to using the theoretical results is that designers change their focus from previously defined aspects of games, such as story or rules, to materials as collaborators, such as displays, input devices, and the movement of the player's body during play. Including game materials unveils how players experience the material aspects of games. Additionally, this change of focus interrogates how designers work themselves in relation to materials when they make games. Following Latour's laboratory studies, Hensel and Beil transferred the study of laboratories as workplaces to game development studios (Beil \& Hensel, 2011). I contributed to this book at the beginning of my dissertation (Bienia, 2011b). A study of materials with actor-network theory, as I have done in this dissertation, offers insights and innovative tools for how to approach game design, work practices, and the workplace.

The fifth question is on the schedule and implementation of the products resulting from the dissertation: "How will this/these plan(s) for valorization be shaped? What is the schedule, are there risks involved, what market opportunities are there and what are the costs involved?" As concrete products, I have published the MittelPunkt books at the Zauberfeder Verlag in Braunschweig (Bienia, 2014; Bienia \& Dombrowski, 2013; Bienia \& Schlickmann, 2015). Furthermore, this book will be published with Zauberfeder Verlag as a print and ebook version in 2016. Any profit will be donated to non-profit organizations who create opportunities for children to play role-playing games. Additionally, there will be a free pdf offered for download at the publisher's website. The free pdf will guarantee everyone the access to this book.

\section{Final Thoughts}

In the beginning, I wrote that Maastricht University came up with the idea to have Ph.D. candidates write about the social and/or economic value of their work. I believe this is a move on the part of the university to translate the economic imperative.

As Eagleton writes in his essay, what is lost is a necessary distance between the ivory tower and other systems. Distance is necessary for being critical about "the values, goals, and interests of a social order too frenetically bound up in its own short-term practical pursuits to be capable of much self-criticism" (Eagleton, para 2, 2015). It is the shortterm vision that I find most troublesome. 
I do not disagree on the idea of thinking about the social and/or economic value of a dissertation in the Humanities. As I have written above, my professional and academic path has tried to bridge both. Writing this valorization document, I could ask myself new questions about the theoretical implications of my dissertation. Thus, I could reflect on and strengthen my point on how a study of game materials may contribute to the (video) game industry. However, I want to use the opportunity to stress the need for distance when writing any official document that asks the researcher to justify her or his work. If academia trains its next generations to write like marketing professionals, it should encourage them to keep a critical distance in this task. The Valorization Addendum gains its value when it becomes a place for new ideas about how to bridge theoretical and economic forces, and where a critical reflection on this bridging is necessary. A sixth question should be included to the regulation document: How does the task of justifying the social and/or economic value of my work collaborate with my academic tasks? Omitting a self-reflective question in a Valorization Addendum betrays the core principle of academic work: to ask questions. Otherwise next-generation scholars will degrade their work into craftsmanship that works for its own sake, a decorative art that justifies short-term ideas. Instead, any such task should encourage them to ask further questions. Good questions determine the value of any academic work. 


\section{References}

Beil, B., \& Hensel, T. (2011). “Game laboratory studies." Navigationen, 11(2), Siegen: Universitätspresse Siegen.

Bienia, R. (2009, Apri212l 15). Hilfreiches zur LARP-Fotografie. Retrieved from http:// www.inlarp.de/larp-allgemein/hilfreiches-zur-larp-fotografie/

Bienia, R. (2011a). „BAM! ,From Dusk till Dawn': Gattungstypologische Betrachtung Eines Nachtlarpies." Fandom Observer, 266, 14-15.

Bienia, R. (2011b). „Literatur.“ In B. Beil \& T. Hensel (Eds.), Game Laboratory Studies (pp. 93-96). Siegen: Universitätspresse Siegen.

Bienia, R. (2011c). "Writing plot: Suggestions from narratology." In A. Castellani \& J. T. Harviainen (Eds.), Larp Frescos: Volume pubblicato in occasione della seconda edizione del Larp Symposium (pp. 91-102). Firenze: Lulu Press.

Bienia, R. (2012). "Why do they larp? Motivations for larping in Germany." In S. Bowman \& A. Vanek (Eds.), Wyrd Con Companion 2012 (pp. 99-105). City of Orange, California: WyrdCon.

Bienia, R. (2014). LARP: Kommunikation. Aufsatzsammlung zum MittelPunkt 2014. Braunschweig: Zauberfeder Verlag.

Bienia, R., \& Dombrowski, K. (Eds.) (2013). LARP: Nur ein Spiel? Aufsatzsammlung zum MittelPunkt 2013. Zauberfeder Verlag.

Bienia, R., \& Schlickmann, G. (Eds.) (2015). LARP: Zeug. Aufsatzsammlung zum MittelPunkt 2015. Braunschweig: Zauberfeder.

Eagleton, T. (2015, June 4). „The slow death of the university“. Retrieved from https:// chronicle.com/article/The-Slow-Death-of-the/228991/ 


\section{About the Author}

Rafael Bienia (Święntochłowice, Poland, 1981) obtained a Magister Artium degree in Comparative Literature and English Studies at Johannes Gutenberg-Universität in Mainz, Germany. Rafael has worked for the corporate communications department at Deutsche Telekom AG in Darmstadt (2007-2011) and as a teacher at Maastricht University (20112015). He received his basic teaching qualification (BKO) in 2014. Rafael wrote Role Playing Materials at the Literature and Arts department of the Faculty of Arts and Social Sciences at Maastricht University (2011-2015). 